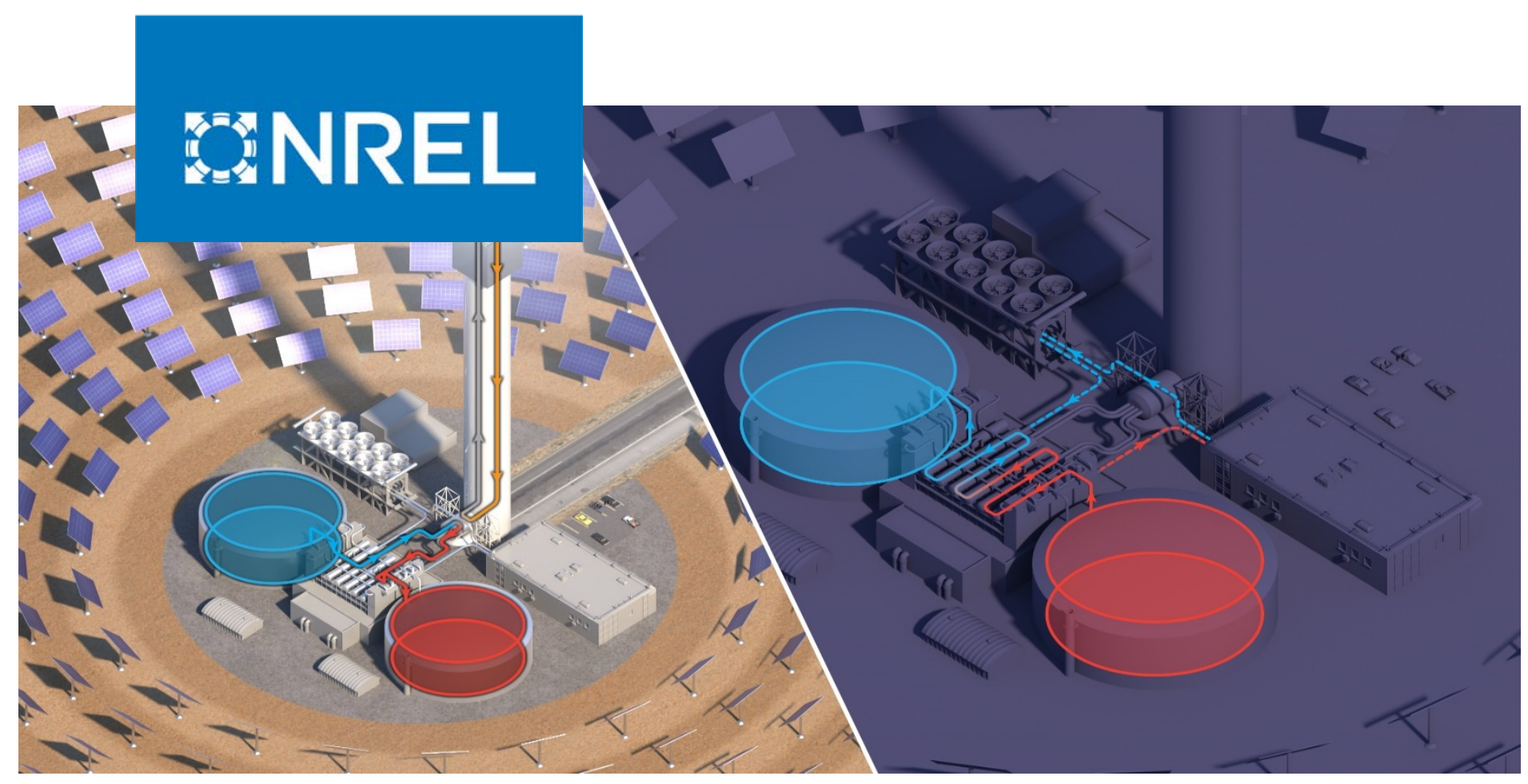

\title{
CSP Gen3: Liquid-Phase Pathway to SunShot
}

Craig Turchi, ${ }^{1}$ Samuel Gage, ${ }^{1}$ Janna Martinek, ${ }^{1}$ Sameer Jape, ${ }^{1}$ Ken Armijo, ${ }^{2}$ Joe Coventry, ${ }^{3}$ John Pye, ${ }^{3}$ Charles-Alexis Asselineau, ${ }^{3}$ Felix Venn, ${ }^{3}$ William Logie, ${ }^{3}$ Armando Fontalvo, ${ }^{3}$ Shuang Wang, ${ }^{3}$ Robbie McNaughton, ${ }^{4}$ Daniel Potter, ${ }^{4}$ Theodore Steinberg, ${ }^{5}$ and Geoffrey Will ${ }^{5}$

${ }^{1}$ National Renewable Energy Laboratory

2 Sandia National Laboratories

${ }^{3}$ Australian National University

${ }^{4}$ CSIRO

${ }^{5}$ Queensland University of Technology

NREL is a national laboratory of the U.S. Department of Energy Office of Energy Efficiency \& Renewable Energy

Operated by the Alliance for Sustainable Energy, LLC

This report is available at no cost from the National Renewable Energy Laboratory (NREL) at www.nrel.gov/publications.
Technical Report

NREL/TP-5700-79323

July 2021 


\section{ENREL}

\section{CSP Gen3:}

\section{Liquid-Phase Pathway to SunShot}

Craig Turchi, ${ }^{1}$ Samuel Gage, ${ }^{1}$ Janna Martinek, ${ }^{1}$ Sameer Jape, ${ }^{1}$ Ken Armijo, ${ }^{2}$ Joe Coventry, ${ }^{3}$ John Pye,${ }^{3}$ Charles-Alexis Asselineau, ${ }^{3}$ Felix Venn, ${ }^{3}$ William Logie, ${ }^{3}$ Armando Fontalvo, ${ }^{3}$ Shuang Wang, ${ }^{3}$ Robbie McNaughton, ${ }^{4}$ Daniel Potter, ${ }^{4}$ Theodore Steinberg, ${ }^{5}$ and Geoffrey Will ${ }^{5}$

${ }^{1}$ National Renewable Energy Laboratory

2 Sandia National Laboratories

${ }^{3}$ Australian National University

${ }^{4}$ CSIRO

${ }^{5}$ Queensland University of Technology

\section{Suggested Citation}

Turchi, Craig, Samuel Gage, Janna Martinek et al. 2021. CSP Gen3: Liquid-Phase Pathway to SunShot. Golden, CO: National Renewable Energy Laboratory. NREL/TP-5700-79323. https://www.nrel.gov/docs/fy21osti/79323.pdf.

NREL is a national laboratory of the U.S. Department of Energy Office of Energy Efficiency \& Renewable Energy Operated by the Alliance for Sustainable Energy, LLC

This report is available at no cost from the National Renewable Energy Laboratory (NREL) at www.nrel.gov/publications.
Technical Report NREL/TP-5700-79323 July 2021

National Renewable Energy Laboratory 15013 Denver West Parkway Golden, CO 80401

303-275-3000 • www.nrel.gov 


\section{NOTICE}

This work was authored in part by the National Renewable Energy Laboratory, operated by Alliance for Sustainable Energy, LLC, for the U.S. Department of Energy (DOE) under Contract No. DE-AC36-08GO28308. Funding provided by the U.S. Department of Energy Office of Energy Efficiency and Renewable Energy Solar Energy Technologies Office. The views expressed herein do not necessarily represent the views of the DOE or the U.S. Government.

This report is available at no cost from the National Renewable Energy Laboratory (NREL) at www.nrel.gov/publications.

U.S. Department of Energy (DOE) reports produced after 1991 and a growing number of pre-1991 documents are available free via www.OSTI.gov.

Cover image created by Besiki Kazaishvili, NREL.

NREL prints on paper that contains recycled content. 


\section{Acknowledgments}

The Gen3 Liquid Pathway project engaged a wide range of experts in academia, national laboratories and industry, in addition to working closely with the CSP subprogram within the U.S. Department of Energy's Solar Energy Technologies Office. The authors thank Dr. Levi Irwin, the project's technical monitor for the DOE, for his tireless support and encouragement to the team, as well as his contributing knowledge on molten salt chemistry and assistance connecting the team with complementary research happening across the country.

Additional contributors at the two lead national labs include Youyang Zhao, Deanna Payne, and Cindy Gerk at NREL and Matt Carlson at Sandia National Laboratories.

Additional contributing researchers and organizations not captured among the author list include Dr. Frank Bruno from University of South Australia, Dr. David Lewis from Flinders University, Dr. Nathaniel Hoyt from Argonne National Laboratory, Dr. Kevin Robb at Oak Ridge National Laboratory, and Dr. Brenda Garcia-Diaz and her team at Savannah River National Laboratory.

The team benefited from contributions from multiple industrial partners - first and foremost, Dwight Dorsey of Bridgers \& Paxton led the effort to integrate the disparate research components into a functional design for the liquid-phase system. Dwight's practical experience and seemingly boundless patience were essential to our ability to pull together a viable integrated design of this technology. As illustrated in Figure 2, the project benefitted from multiple contractual partners. The team leaders and companies include Dwight with B\&P, Joe Rigby with JT Thorpe \& Son, Gordon Bigham with Job Industrial Services, Dereje Shiferaw with Vacuum Process Engineering, Glen Bostick and David Wait with Nooter/Eriksen, and Nathan Tedford with Hatch. Dan Barth with High Temperature System Designs and Hank Price and Bruce Kelly with Solar Dynamics provided crucial details on pump, valve, and tank design for molten salts. Dr. Reinhard Effenberger with ICL was an early and consistent supporter of the research plan, leading the effort on industrial salt chemistry.

Outside of these contractual partners, the team benefitted greatly from pro bono guidance from Ildo Agnetti with John Cockerill, Rich VanLieshout with Creative Engineers, and Craig Wood and Kurt Drewes with Vast Solar, among others.

Lastly, the authors wish to thank the members of our Technical Advisory Committee, ably led by Cara Libby from the Electric Power Research Institute: Ryan Bowers and Clay Jones (Advisian), Bob Charles (Sargent \& Lundy), Jenifer Hedrick (Southern California Edison Co.), Tim Held (Echogen Power Systems), Hank Price (Solar Dynamics), Nick Smith (Idaho National Laboratories), Cory Stansbury (Westinghouse Electric Company), Richard VanLieshout (Creative Engineers, Inc.) and Blair Walters (Aurecon). This committee made possible the comprehensive and balanced comparison of the liquid receiver options that led to selection of the sodium receiver design. 


\section{Table of Contents}

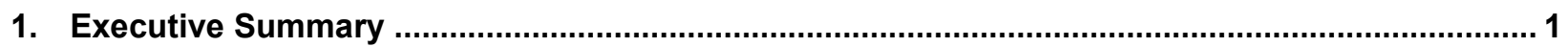

1.1. Liquid Pathway Commercial System Design and Advantages ............................................... 3

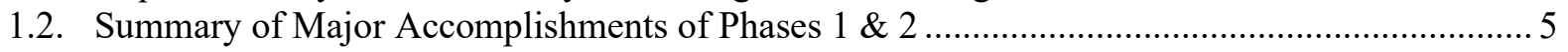

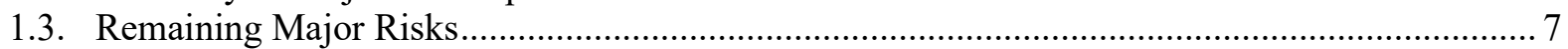

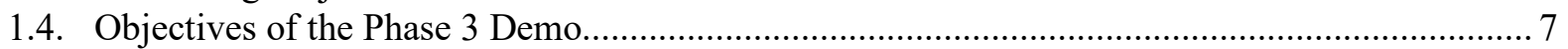

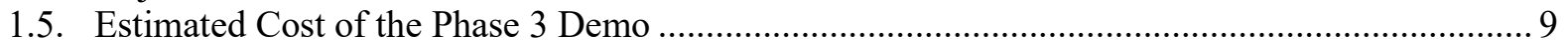

1.6. Plan B: Other Molten-Salt Stakeholders and Demonstration Options ....................................... 9

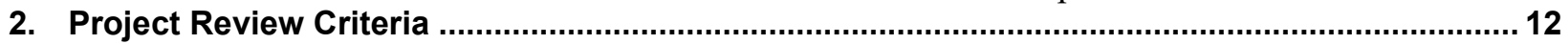

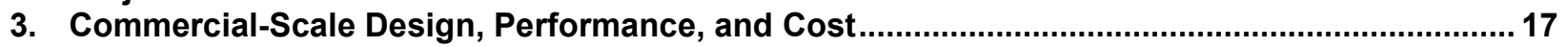

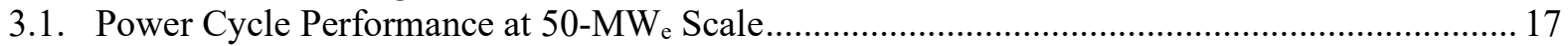

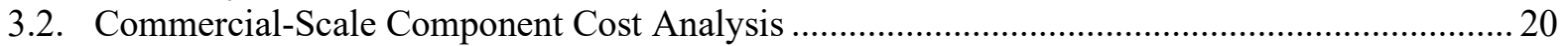

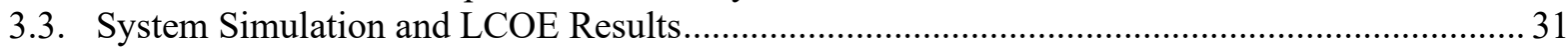

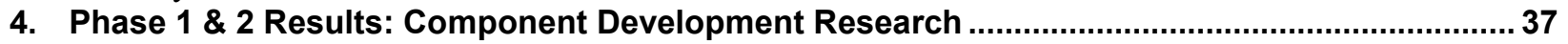

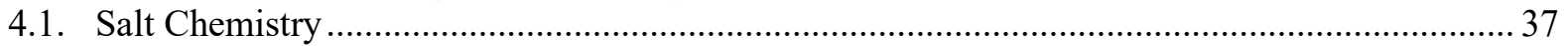

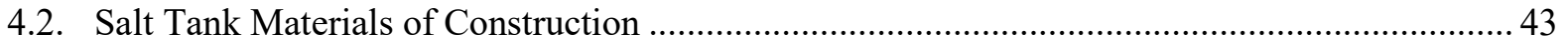

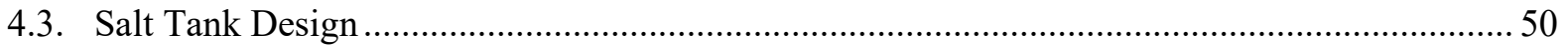

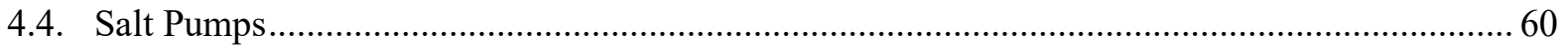

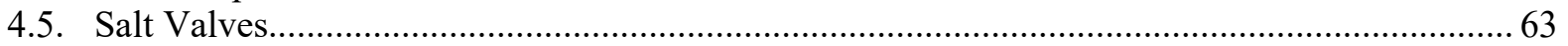

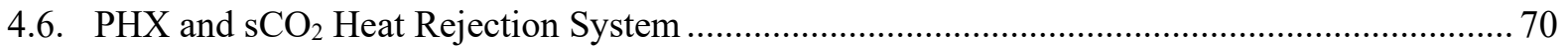

4.7. Sodium Materials Compatibility .................................................................................................. 72

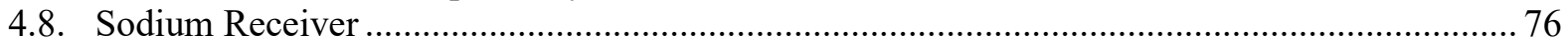

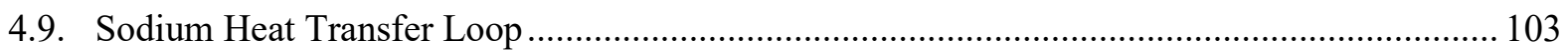

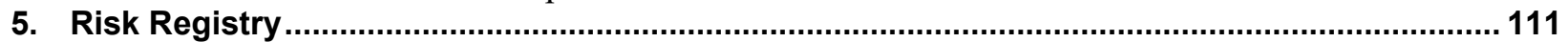

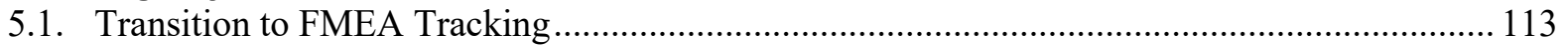

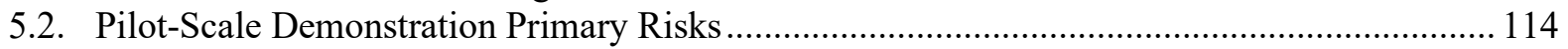

5.3. Risk Registry for Progression to Commercial Scale .............................................................. 117

6. Phase 3 System Design, Project Management, Construction, and Operations.........................121

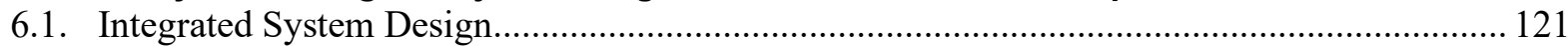

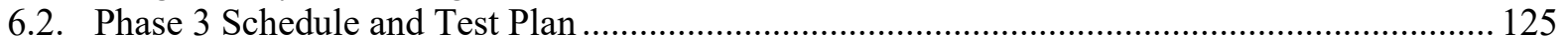

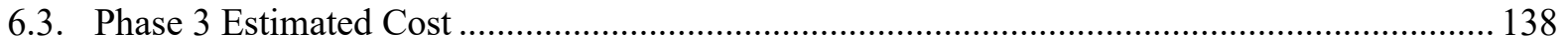

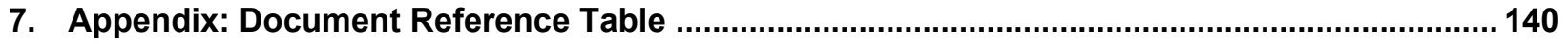

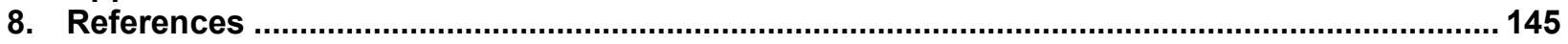

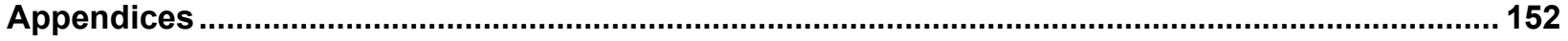




\section{List of Figures}

Figure 1. Sodium/Salt Gen3 system showing on-sun charging of the salt storage system.............................2

Figure 2. Gen3 Liquid Pathway team.................................................................................................. 3

Figure 3. Probability distribution for the LCOE of the commercial system. The FOA target value for Gen3 is

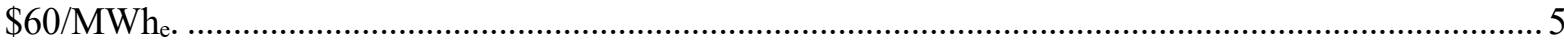

Figure 4. System layout at the base of the NSTTF tower: Melter in color at front left, $\mathrm{N}_{2}$ ullage gas supply in left rear, scrubber in right rear on the elevated deck, and $\mathrm{PHX}$ with $\mathrm{sCO}_{2}$ system in foreground at

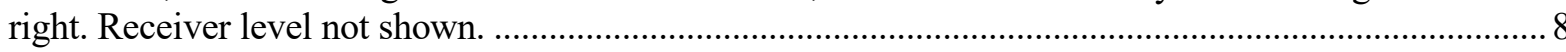

Figure 5. The proposed 50- $\mathrm{MW}_{\mathrm{e}}$ modular design would shorten project construction time while allowing for larger, multi-unit facilities if desired. Photo: Ivanpah Solar Electric Generating Station, USA (NREL

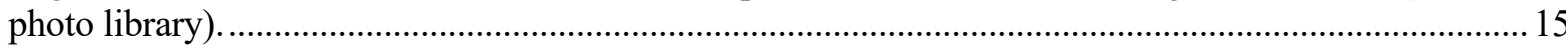

Figure 6. Liquid Pathway commercial system design showing charging of thermal storage (left) and discharging thermal storage to the $\mathrm{sCO}_{2}$ power cycle (right). $\mathrm{HEX}=$ heat exchanger ............................. 17

Figure 7. Absolute deviation of SolarTherm output from the detailed data generated from the SAM offdesign model for (left) Power cycle gross efficiency and (right) off-design heat power fraction $\left(\mathrm{Q} / \mathrm{Q}_{\text {des }}\right)$. Ambient temperature $=40^{\circ} \mathrm{C}$.

Figure 8 . Tower designs investigated by sbp: (a) concrete tube, diameter $22 \mathrm{~m}$; (b) concrete tube, diameter $15 \mathrm{~m}$; (c) lattice steel tower with socket; (d) three-leg hybrid tower with concrete columns and steel bracings; (e) cable-stayed concrete tube with two layers of cables [20].

ure 9. Sodium receiver concept adapted from John Cockerill [24]. While the referenced study placed all components at the top of the tower, the Liquid Pathway design locates the heat exchanger, pumps and sump tank adjacent to the base of the tower (as depicted in Figure 6).

Figure 10. Breakdown of costs for internally insulated, carbon-steel salt tanks. The cost is split roughly evenly between the salt, the refractory liner, and the tank shell and foundation....................................2 29

Figure 11. Breakdown of the total capital costs for the commercial-scale sodium-salt tower $2 \times 50-\mathrm{MW}_{\mathrm{e}}$ system

Figure 12. Dynamics of the commercial system in summer (left) and winter (right).................................. 35

Figure 13. Probability distribution for the LCOE of the commercial system. The mean value for the commercial system of \$58.4/MWhe meets the CSP Gen3 target value of less than $\$ 60 /$ MWhe.............. 35

Figure 14. Ranked regression analysis, showing the relative impact of cost uncertainties on LCOE ............36

Figure 15. Ternary chloride salt properties (left). The salt composition (red dot) is slightly off-eutectic, with a melting point of approximately $400^{\circ} \mathrm{C}$. Melting point is not particularly sensitive to composition as indicated by the phase diagram at right.

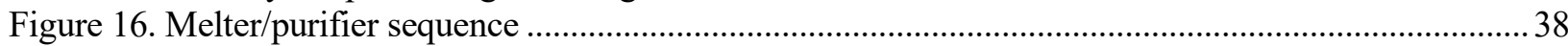

Figure 17. Pilot-scale salt melter layout showing the salt transfer line (red) to the hot tank and sparge-gas

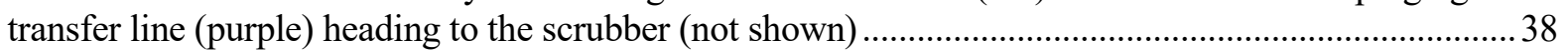

Figure 18. Candidate material allowable stress per ASME code [31] ....................................................... 41

Figure 19. Piping costs based on raw material prices (not used) and quotes from Arch City Steel per mass (blue bar) and per unit length (grey bar) for 3" Schedule 80 pipe. Lead times are also taken from the Arch City Steel quotes.

Figure 20. Compiled corrosion data for alloys under consideration

Figure 21. Sectioned cup tests after 100-hour salt exposure. Cup dimensions shown on the left. Sectioned cups of Duro Type II (a), HD 45 (b), and Patriot (c), with EDS map showing presence of chlorine where the top of the EDS image was the surface in contact with the salt.

Figure 22. Volume renderings of the surface-connected porous networks for (left) Duro Type II and (right) HD-45, where the color indicates the volume of individual connected-pore networks. Penetration from the Z-face of the cubic sample is shown...... 
Figure 23. Salt Permeation into Duro Type II as a function of time. EDS maps of $\mathrm{Cl}$ and $\mathrm{Mg}$ of cross sectioned native Duro Type II and Duro Type II immersed in molten chloride salt for 50, 100, 500, 1000 , and 3000 hours (left to right, respectively). Note that each data point is a different refractory sample. Salt permeation is measured as the depth of $\mathrm{Cl}$ into the bulk of the material. 46

Figure 24. Virgin Duro Type II (top row) and Duro Type II immersed in salt for 3000 hours (bottom row). From left to right: X-ray diffractograms ( $\mathrm{a}$ and $\mathrm{b}$ ), scanning acoustic microscopy of coupon surfaces (c and d), and EDS Mg maps (e and f). The $\uparrow$ symbols in (b) highlight peaks that belong to the forsterite secondary phase.

Figure 25. X-ray CT representation of colored porous regions in the mortar joint after compaction at $720^{\circ} \mathrm{C}$ to $10 \mathrm{MPa}$ (left) and $75 \mathrm{MPa}$ (right) suggest reduction, but not elimination of porous regions...............49

Figure 26. EDS maps of potassium $(\mathrm{K})$, magnesium $(\mathrm{Mg})$, sodium $(\mathrm{Na})$ and chlorine $(\mathrm{Cl})$ of cross-sectioned brick and mortar specimen after 50 -hour exposure to molten salt at $720^{\circ} \mathrm{C}$. ......................................... 49

Figure 27. 1-D heat transfer analysis through a refractory liner design when dry (blue circles), the same refractory liner configuration when wetted by salt (green squares), and a wetted liner design when wetted (red triangles). The markers define the regions of the three liner materials: hot face, insulating firebrick, microporous insulation. The horizontal black dashed line denotes the temperature at which the chloride salt freezes $\left(\sim 400^{\circ} \mathrm{C}\right)$.

Figure 28. ANSYS thermal profile between the wall and floor (a) and mechanical stress, including salt hydrostatic pressure, transmitted to the tank shell (b). Both metrics meet project targets.

Figure 29. Greater detail of brick mortar and expansion joints. Recommended expansion joints are corrugated metal expansion joints with flexible graphite (left) and these are positioned between bricks periodically throughout the liner in vertical and horizontal orientations (right).

Figure 30. Design of commercial-scale salt tank refractory liner. Different refractory materials are selected to balance the heat flux through the insulating liner, e.g., wall-floor (a) and wall-roof (b) intersections.54

Figure 31. Representative commercial-scale tank design....

Figure 32. Dimensional drawings for the pilot-scale hot and cold tanks. Both tanks use the same liner design. Expansion joints in the floor and walls will test the ability of these joints to seal and maintain their integrity. Higher resolution image in Folder 12-Project Reports, Salt Tanks.

Figure 33. Predicted stress on pilot unit tank shell under ideal conditions with floor and tank wall temperature difference $\leq 10^{\circ} \mathrm{C}$ (a) and under high stress conditions with floor and tank wall temperature

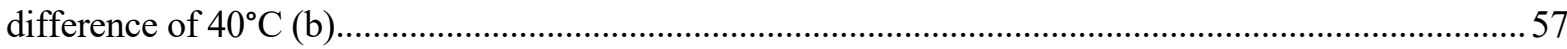

Figure 34. Sulzer hot-salt pump curves (head vs. flow). The hot pump is a two-stage design. ...................... 61

Figure 35. Sulzer cold-salt pump curves. The pilot-scale cold pump requires four stages (aka bowls) to

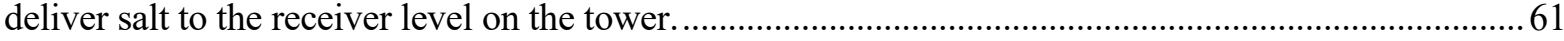

Figure 36. Static corrosion mass reduction tests in hot $\left(720^{\circ} \mathrm{C}\right)$ molten chloride salt ...................................62

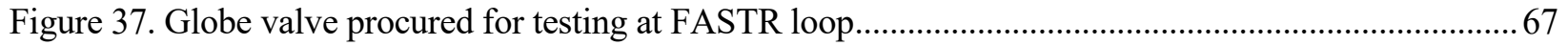

Figure 38. Globe valve design for molten-salt service featuring a bellows seal design ................................. 68

Figure 39. Globe valve design for molten-salt service featuring a quick-change packing canister ................ 69

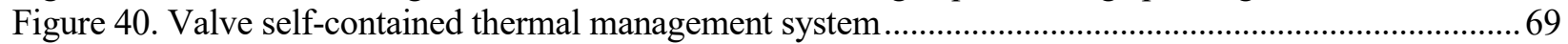

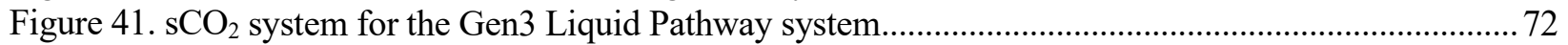

Figure 42. Left: Corrosion rate of austenitic stainless steels in liquid sodium as a function of oxygen concentration and temperature up to $650^{\circ} \mathrm{C}$ [47]. Right: Influence of nickel content on corrosion rate of 316 and six other austenitic steel alloys in sodium at $700^{\circ} \mathrm{C}$ [45] ...................................................... 73

Figure 43. Molybdenum-based coatings such as Tribaloy 700 exhibit good resistance to sodium at temperature.

Figure 44. Schematics of static-capsule (left) and dynamic-thermosiphon (right) sodium exposure

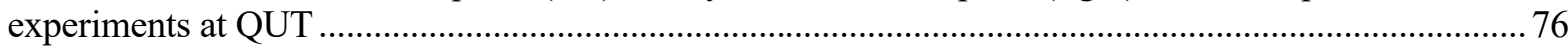

Figure 45. (a) nominal field obtained along with the receiver diameter of $14 \mathrm{~m}$ and oversized height (20m) and (b) the oversized field used for the final system with receiver dimensions of 14-m diameter and 14.5-m height.

Figure 46. Receiver flow-path arrangement. 


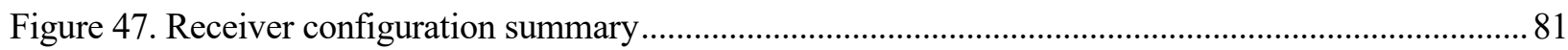

Figure 48. Design point receiver performance per flow-path...................................................................... 83

Figure 49. 3D renderings of the $1 \mathrm{MW}_{\text {th }}$ pilot sodium receiver design. See also Folder 13-Sodium

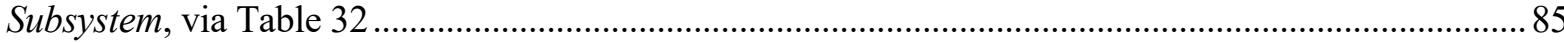

Figure 50. 3D renderings from the Heliosim software GUI of the NSTTF heliostat field and 1MWth pilot

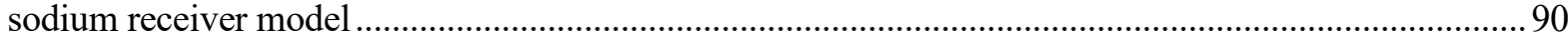

Figure 51. Block of 84 heliostats from the NSTTF estimated to be required for annual operation of the

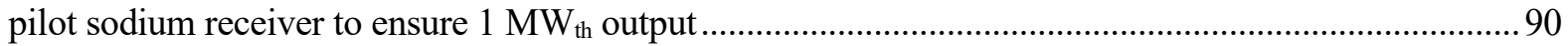

Figure 52. Comparisons of measured and simulated irradiance maps for 14:25 shot from the NSTTF solar field characterization experiment rebuilding with Heliosim...........................................................93

Figure 53. Visualizations of the simple and detailed computational meshes for the 1-MW th pilot sodium

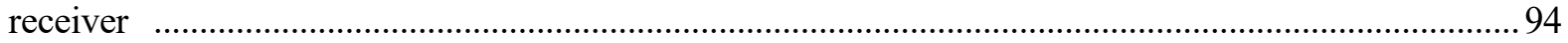

Figure 54. Incident solar irradiance on the aperture plane $(1.77 \times 1.77 \mathrm{~m})$ of the 1-MWth pilot sodium receiver using 4 distributed aim points and the simple receiver model ...................................................96

Figure 55. Flow path profiles at the spring equinox design point for the 1-MW th pilot sodium receiver using distributed aim points and the simple receiver model. Each line represents the variation along the flow axis of an individual tube. The $\mathrm{x}$ coordinate is the accumulated distance from the sodium inlet.

Figure 56. Temperature (left) and equivalent thermoelastic stress (right) of $10.5 \mathrm{~m}$ long (z coordinate scaled by 0.1 ) $60-\mathrm{mm}$ OD and $1.2-\mathrm{mm}$ wall $740 \mathrm{H}$ tube with peak flux density $1-\mathrm{MW} / \mathrm{m}^{2}$, sodium mass flow $7 \mathrm{~kg} / \mathrm{s}$ (bulk fluid velocity $3.4 \mathrm{~m} / \mathrm{s}$ ) and bulk fluid temperature of 682 to $740^{\circ} \mathrm{C}$ - plane indicates location of 2D-GPS model

Figure 57. Uniaxial $\mathrm{A} 740 \mathrm{H}$ creep at $800^{\circ} \mathrm{C}$ in (left) showing a "hot tensile" ramp of strain at a strain rate of $8.33 \mathrm{e}-5 \mathrm{~s}-1$ up to peak values and subsequent hold with relaxation over 100 hours (solid lines using logarithmic time-step, dashed lines FEA time-step, and black dotted lines time-integration of powerlaw equivalent), and a comparison of element-averaged equivalent von Mises stress from 10 cycles of a Bree cylinder (with fictive material parameters and Bree coordinates $\mathrm{X}=0.1, \mathrm{Y}=1.5$ ) in (right) with 100 second hold times.

Figure 58. Maximum allowable flux determined by ASME B\&PVC Section VIII Elastic Ratchet Analysis Method (solid lines) and ANL-20/03 Method C (dashed) for (left) the 1-MWth Sandia prototype using $25.4 \mathrm{~mm}$ OD and $1.65 \mathrm{~mm}$ wall and (right) the commercial-scale sodium receiver using $60 \mathrm{~mm}$ OD and $1.2 \mathrm{~mm}$ wall $\mathrm{A} 740 \mathrm{H}$ tubing, also comparing two different fluid velocities.

Figure 59. Sodium Loop at the 220 level of the Sandia tower. View from inside the tower: back of receiver housing is at left, also depicted in Figure 60

Figure 60. Interference of sodium receiver housing and existing crane, which will be removed during initial site construction. (Left) site photo; (Right) 3D render of proposed sodium-receiver housing overlaying with the crane.

Figure 61. Operating points for various sodium pumps, with the circle highlighting typical operating

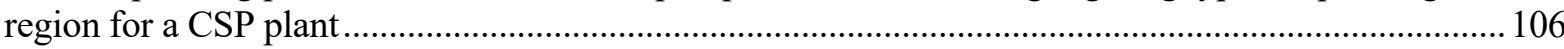

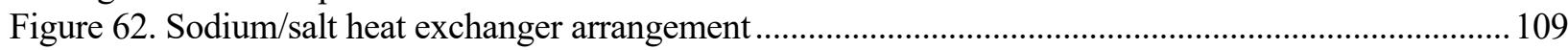

Figure 63. Considerations for technology development [91] ................................................................... 117

Figure 64. Vast Solar's 5-MW Jemalong pilot plant has derisked sodium handling in preparation for their proposed Mt. Isa project

Figure 65. Rendering of the pilot-scale system components at the base of the NSTTF tower. See Table 32 for additional System Layout Drawings.

Figure 66. Rendering of the pilot-scale system at NSTTF showing a cut-away view of the salt piping in the tower. See Table 32 for additional System Layout Drawings.

Figure 67. Plan view of the sodium loop at the 220 level in the tower. The receiver sits in the box at upper left and the sodium/salt HEX runs along the lower edge of the containment tray (dark hatched area). The entire loop will be enclosed in a steel-sheeted chamber. 
Figure 68. Detail of the salt tanks, showing piping expansion loops and heat trace. Scrubber is at upper right. See Table 32, Folder 04-Drawings, for higher resolution and additional System Layout Drawings

Figure 69. Process flow diagram for the Long Term Hold operational mode

Figure 70. Sodium Receiver Preheat operational mode diagram showing system filled with argon.

Figure 71. Sodium Receiver Fill operational mode diagram showing sodium circulation via the EM pump

Figure 72. Sodium/Salt HEX Attemperation operational mode diagram

Figure 73. Molten salt flow to the preheated sodium/salt HEX is established. Cold salt returns to the cold salt tank

Figure 74. Molten-salt storage Charging operational mode diagram

Figure 75. Molten salt PHX Attemperation operational mode diagram 135

Figure 76. Molten salt Discharging operational mode diagram 136 


\section{List of Tables}

Table 1. Summary of Liquid Pathway technology risk from original Gen3 Roadmap to present. Asterix $\left(^{*}\right)$ denotes risk element identified in the Gen3 Roadmap................................................ 12

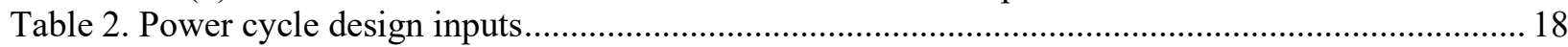

Table 3. Financial and cost inputs for commercial-scale LCOE estimate. In most cases reference values are scaled to the specific conditions of the $50-\mathrm{MW}_{\mathrm{e}}$ commercial-scale design - additional details given in following text and via Folder 02-Calculations, Cost Calculations (see Table 32)..... 21

Table 4. Estimated cost for melted salt at a representative commercial-plant scale ................................ 30

Table 5. High-level performance and cost parameters for the 50- $\mathrm{MW}_{\mathrm{e}}$ unit ......................................... 32

Table 6. Capital cost breakdown for the commercial system. All costs in USD ........................................ 33

Table 7. Candidate alloy list developed at the Salt Chemistry Workshop in Golden, CO......................... 40

Table 8. Cold crush strength (CCS) of Native Duro Type II and Duro Type II after immersion in molten chloride salt for 3,000 continuous hours. No statistical difference seen in crush strength....... 47

Table 9. Calculated effective thermal conductivity $\left(\kappa_{\mathrm{e}}\right)$ of commercially available refractories at hot tank operating temperature $\left(720^{\circ} \mathrm{C}\right)$ in air and after salt infiltration. The hot face bricks and reference brick are mullite-based materials, and the insulating firebrick is anorthite based................50

Table 10. Summary of shim fabrication results from this and other projects ....

Table 11. 1-MW th pilot-scale heat exchanger designs. A single-core design will be used for simplicity

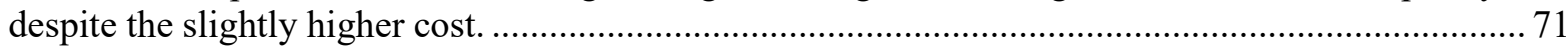

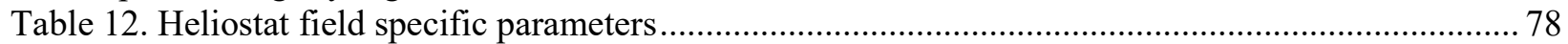

Table 13. Summary of key receiver parameters for the commercial-scale design ................................ 81

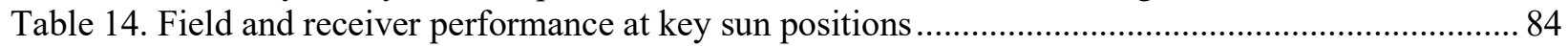

Table 15. Summary of flow path parameters for the $1-\mathrm{MW}_{\text {th }}$ pilot sodium receiver design....................... 86

Table 16. Pilot sodium receiver panel and piping materials (WT $=$ wall thickness) ................................. 87

Table 17. Key parameters for the NSTTF heliostat field model implemented in Heliosim. Parameters that are known to differ from the actual facility are shown in blue italics........................................ 91

Table 18. Summary of NSTTF heliostat field characterization experiment rebuilding with Heliosim for selected cases.....

Table 19. Summary of ray tracing and heat transfer simulation results for the 1-MW th pilot sodium receiver using four distributed aim points and the simple receiver model ...................................... 95

Table 20. Pump specifications for the commercial and pilot-scale sodium pumps ............................... 105

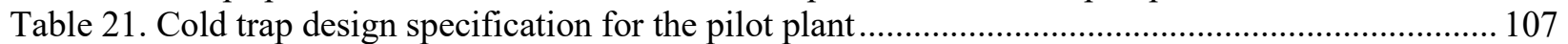

Table 22. Key parameters for the sodium-salt heat exchanger in the commercial plant ........................ 108

Table 23. Key parameters for the sodium-salt heat exchanger in the pilot plant ................................... 109

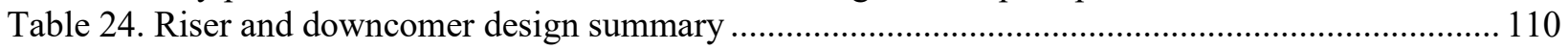

Table 25. Risk Registry component categories and responsible parties .............................................. 111

Table 26. Risk progression through the project's first six quarters that constituted budget Phase $1 \ldots \ldots . . .113$

Table 27. Primary risks in the transition from 1-MW th to commercial scale........................................ 120

Table 28. Expected timeline for Phase 3 contracting, procurement, construction, and testing ............... 125

Table 29. Commissioning team communication diagram.................................................................. 127

Table 30. Overview of receiver operational modes. See 04 - Drawings via Table 32 for more detail. ... 130

Table 31. Estimated costs for Phase 3 under the Liquid Pathway project. See also, Folder 02-

Calculations, Cost Calculations, Phase 3 Pilot System.

Table 32. Reference table for 90\% Design Package documents. 


\section{Acronyms}

$\mathrm{AC}$

AHP

ANU

ASME

ASTRI

B\&P

BOS

BPVC

CCS

CSIRO

CSP

DNI

DOE

EM

EPRI

FASTR

FCV

FMEA

FMOC

FOA

HEX

HTF

IFB

LCOE

NDT

NREL

NSTTF

ORNL

PBHT

PWHT

PCHE

PHX

QUT

ROM

$\mathrm{sCO}_{2}$

sbp

Sandia

TAC

UniSA

USD

VPE anhydrous carnellite

analytic hierarchy process

Australian National University

American Society of Mechanical Engineers

Australian Solar Thermal Research Institute

Bridgers and Paxton

balance of system

boiler and pressure vessel code

cold crush strength

Commonwealth Scientific \& Industrial Research Organization

concentrating solar power

direct normal insolation

U.S. Department of Energy

electromagnetic (sodium pump)

Electric Power Research Institute

Facility to Alleviate Salt Technology Risks

flow control valve

failure modes \& effects analysis

Facilities Management and Operations Center

funding opportunity announcement

heat exchanger

heat transfer fluid

insulating fire brick

levelized cost of energy

non-destructive testing

National Renewable Energy Laboratory

National Solar Thermal Test Facility

Oak Ridge National Laboratory

post bend heat treatment

post weld heat treatment

printed circuit heat exchanger

primary heat exchanger

Queensland University of Technology

rough order of magnitude (cost estimate)

supercritical carbon dioxide

Schlaich Bergermann Partner (German architectural and engineering company)

Sandia National Laboratories

Technical Advisory Committee

University of South Australia

United States dollars (all costs are in USD)

Vacuum Process Engineering 


\section{Executive Summary}

The U.S. Department of Energy (DOE) established the Concentrating Solar Power Generation 3 (CSP Gen3) program to promote the development of advanced CSP systems capable of producing electricity at a levelized cost of energy (LCOE) less than $\$ 60 / \mathrm{MWh}$, based on criteria published in the CSP Gen3 Roadmap [1] and a subsequent funding opportunity announcement (Gen3 FOA) [2]. This report documents the progress and potential of the "Liquid Pathway" to meet these objectives. The Liquid Pathway proposes the use of low-cost molten chloride salts for energy storage, mated with an operationally flexible solar receiver that employs liquid-metal sodium for heat capture and transfer to the storage salt. This approach leverages molten-salt technology from the current state-of-the-art CSP power towers embodied by plants such as Gemasolar, Crescent Dunes, Noor III, and the DEWA 700 CSP project. Furthermore, the design builds on the knowledge gained over decades of use of liquid-metal sodium as a hightemperature heat transfer fluid (HTF) in solar tests and nuclear-power applications.

The commercial representation of the proposed Gen3 design incorporates a high-efficiency sodium receiver operating at $\sim 740^{\circ} \mathrm{C}$, with a liquid-liquid heat exchanger feeding a two-tank, molten-chloride salt storage system, see Figure 1. Chloride salt is dispatched to a supercritical $\mathrm{CO}_{2}\left(\mathrm{sCO}_{2}\right)$ power cycle to provide electric power to the grid. The design integration is a conceptual match for the current sodium receiver $\rightarrow$ solar salt storage $\rightarrow$ steam-Rankine power cycle promoted by Vast Solar, which may facilitate commercial acceptance and development.

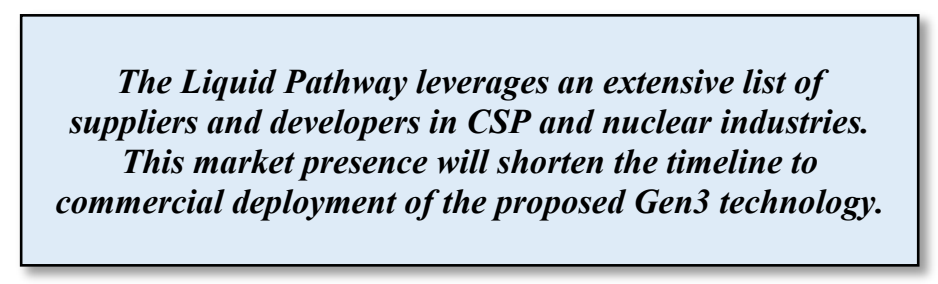

To advance this sodium/salt Gen3 system, the Liquid Pathway team proposes the design and construction of an integrated 1-MW th pilot-scale system, per the goals of the DOE Gen3 Program. The Liquid Pathway team is led by the National Renewable Energy Laboratory (NREL) and includes industry, academic, and national laboratory contributors. Sandia National Laboratories, working closely with Bridgers \& Paxton (B\&P), serves as the host site and system integrator. Industrial and academic partners provide expertise related to system components as outlined in Figure 2. Partners of the Australian Solar Thermal Research Institute (ASTRI) lead the development of the sodium receiver and sodium handling system and have provided research amounting to an approximate 34\% in-kind cost share over the span of Phases 1 and 2.

In addition to the official project team shown in Figure 2, the Liquid Pathway benefits greatly from an ecosystem of industrial suppliers and developers working with these liquid HTFs. In particular, Vast Solar has provided guidance on sodium handling and components, while receiver manufacturer John Cockerill has given the team significant, often proprietary, guidance on receiver design and construction. Molten salt component suppliers Flowserve (pumps and valves), Sulzer (pumps), Flexitallic (gaskets and seals), Guichon (valves), and Gosco (valves) have shared information and hardware with the project team. Questions regarding sodium handling and system design have been guided by experts at Creative Engineers, Inc. (USA), 
Argonne National Lab and CEA France. Materials selection and compatibility with these fluids has leveraged work in the wider DOE "Salt Collective" with specific engagement from Special Metals (alloy properties), Powdermet (protective cermet coatings), Liquid Metal Holdings (protective thermal-spray coatings), Argonne National Lab (salt chemistry sensor), Oak Ridge National Lab (corrosion and small-scale testing), and Universities of Wisconsin and Arizona (salt chemistry). This supply chain network and the similarity of design with the existing CSP fleet of power towers lends the Liquid Pathway a clear path to commercial implementation once the technology has been demonstrated.

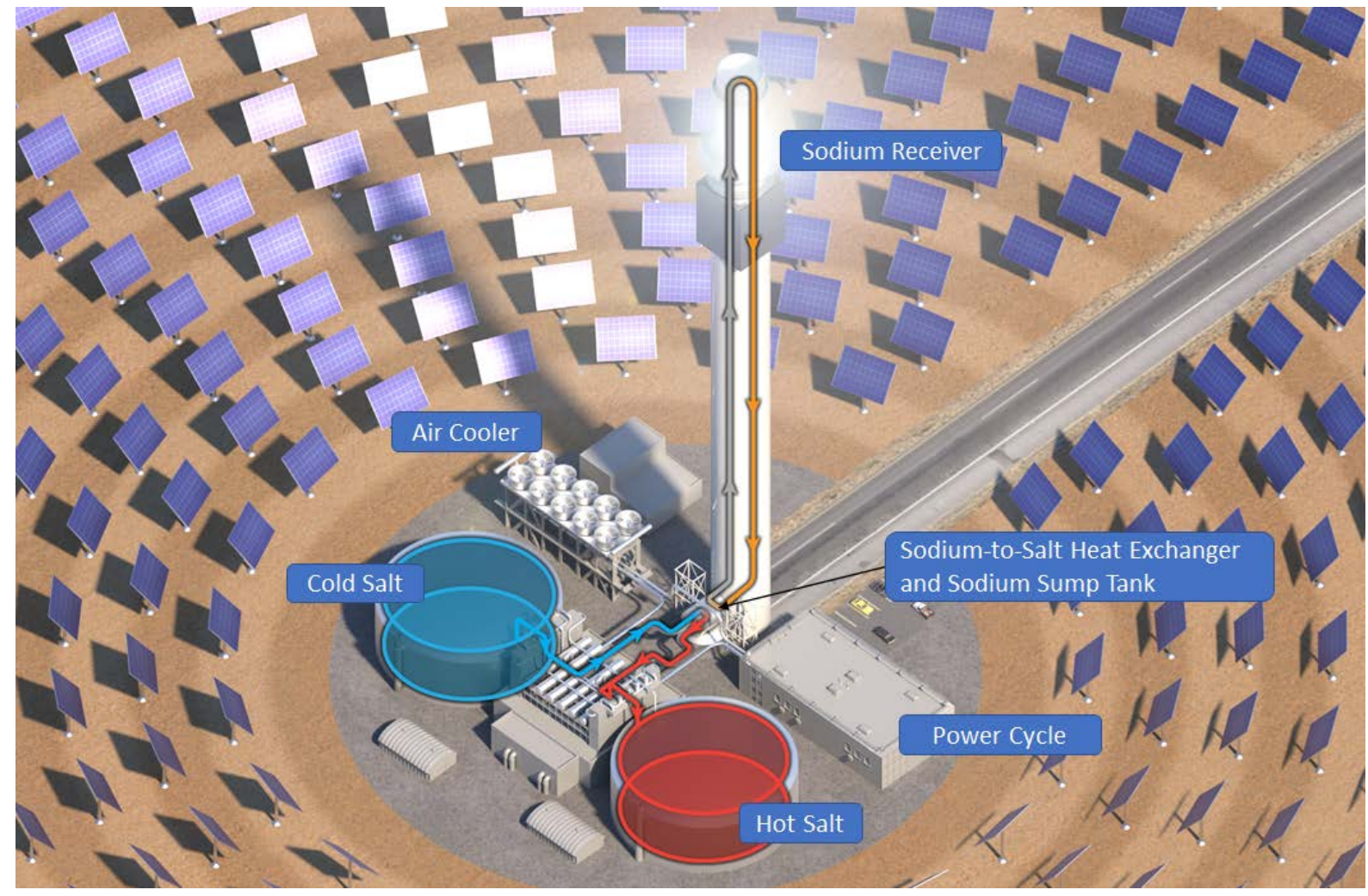

Figure 1. Sodium/Salt Gen3 system showing on-sun charging of the salt storage system

Graphic by Besiki Kazaishvili, NREL 


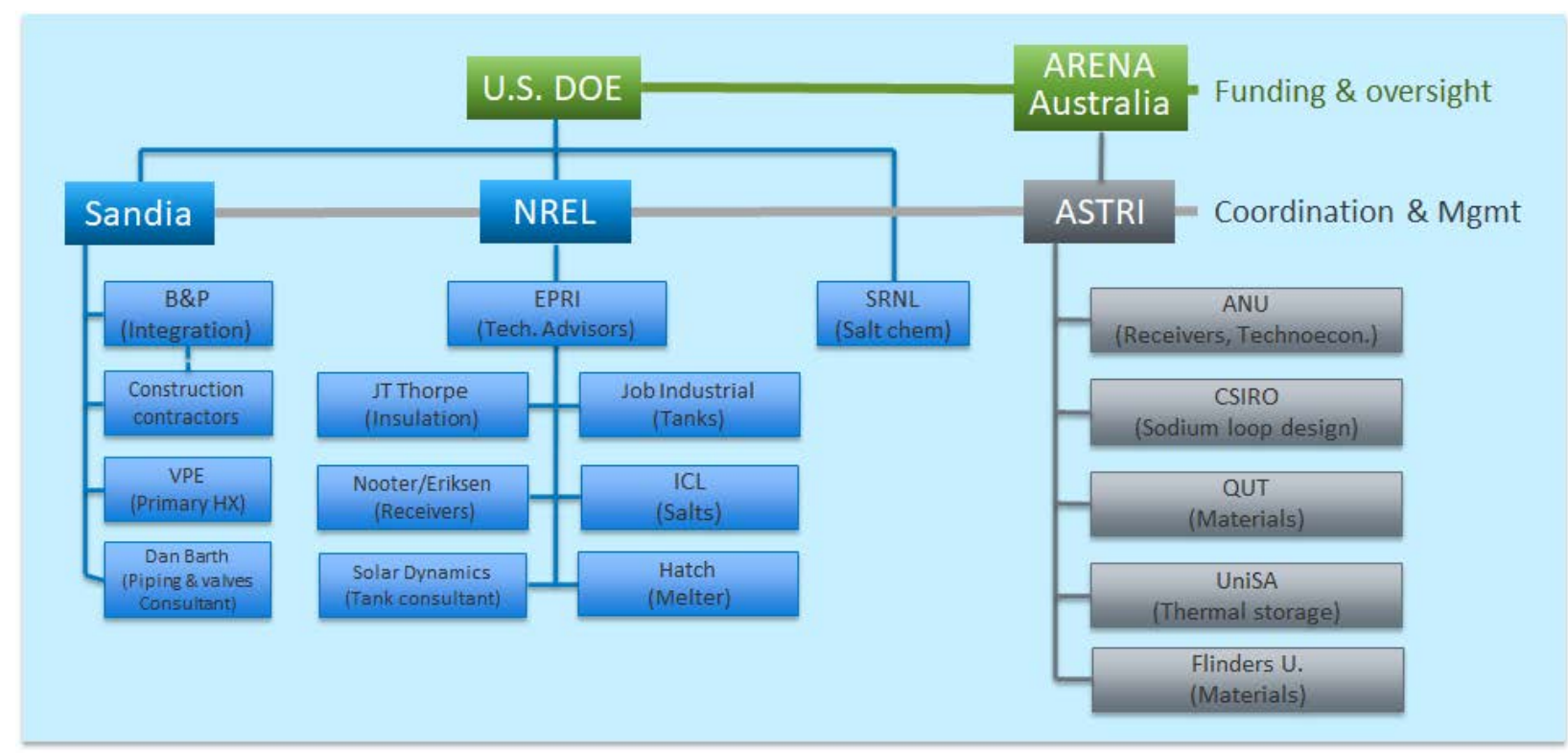

Figure 2. Gen3 Liquid Pathway team

The Liquid Pathway has been further aided by engagement with our project Technical Advisory Committee (TAC), led by Cara Libby of the Electric Power Research Institute (EPRI). The TAC has attended quarterly reviews and was essential to the receiver down selection process. New TAC members were brought onboard at the end of Phase 1 to bolster the team's knowledge of sodium systems after the sodium receiver was selected in the down selection.

\subsection{Liquid Pathway Commercial System Design and Advantages}

During Project Phase 1 the team compared the benefits and risks of salt storage mated to a salt receiver or a sodium receiver. This review was undertaken via a structured analytic hierarchy process (AHP) facilitated by EPRI [3]. The AHP participants, which included the project's leadership team and TAC, concluded that the sodium receiver had both a significantly higher benefit $(19.3 \%)$ and a lower LCOE $(11.4 \%)$, with only a slightly higher risk (3\%) than the salt alternative. Key observations included:

- While the score for criterion Minimize risk to people and the environment was the primary factor that resulted in a higher risk for sodium, it did not seem to impact the scores for Minimize the risk of obtaining bank financing and insurance for a commercial plant, which received roughly the same score for both receiver types. The group concluded that even with the added risk from sodium, it would be feasible to educate bank engineers and the public about sodium as a safe technology.

- In the benefit hierarchy, the sodium alternative scored higher than the salt alternative across all six criteria. The three biggest differentials between the salt and sodium criteria scores were (i) accommodate different plant sizes and configurations, (ii) maximize efficiency and performance, and (iii) maximize long-term reliability and availability.

The sodium receiver's operational benefits are due to sodium's superior thermophysical properties versus the chloride salt, such as lower melting point $\left(98^{\circ} \mathrm{C}\right.$ vs. $\left.400^{\circ} \mathrm{C}\right)$, lower volume change on freezing/melting ( $3 \%$ vs. $\sim 20 \%$ ), lower viscosity ( $\sim 10 \mathrm{x}$ lower), and greater thermal conductivity ( $64 \mathrm{vs} .0 .4 \mathrm{~W} / \mathrm{m}-\mathrm{K})$. These attributes led to greater operational flexibility and 
greater allowable flux on the receiver (i.e., a smaller, cheaper, and more efficient receiver), as showcased by developer Vast Solar in their SolarPACES 2019 Innovation Award acceptance presentation and at their $5-\mathrm{MW}_{\text {th }}$ Jemalong facility. The overall result is a lower projected LCOE, despite the need for a sodium/salt heat exchanger.

Importantly, the dual-fluid design allows each to operate where best suited. The unparalleled HTF properties of sodium are dedicated to the solar receiver, leading to higher receiver efficiency and lower freeze risk. Sodium inventory is kept at a minimum and confined to the receiver, tower, and close proximity to the tower base. Low-cost chloride salt serves as sensibleheat thermal storage media capable of operation at temperatures exceeding $700^{\circ} \mathrm{C}$. Both media are available in bulk quantities from existing commercial suppliers. The ternary salt blend is provided to this project by ICL as anhydrous carnellite, a feedstock used by the magnesium industry.

\subsubsection{Commercial-Scale System LCOE Estimate}

In the team's Phase 1 comparison of a salt-only and salt/sodium design, both units were modeled as $100-\mathrm{MW}_{\mathrm{e}}$ single-tower systems. As noted above, the salt/sodium design was selected. The versatility offered by a sodium receiver opens the design space to include modular or multitower systems as evidenced by the Vast Solar system design. Accordingly, in Phase 2, the team explored multitower designs, examining the tradeoff between economy-of-scale and benefit of smaller size systems, such as optical efficiency. This analysis led to the selection of a $50-\mathrm{MW}_{\mathrm{e}}$ unit design, which is duplicated to form a $100-\mathrm{MW}_{\mathrm{e}}$ power facility to meet the DOE FOA requirement for a $100-\mathrm{MW}_{\mathrm{e}}$ system. Advantages of the $50-\mathrm{MW}_{\mathrm{e}}$ unit design include significant optical efficiency benefit, ability to utilize smaller towers (with potential cost savings), smaller salt tanks (allowing for a single pair of salt tanks per tower), better capacity match to the nascent $\mathrm{sCO}_{2}$ power cycle, adaptability to fringe-of-grid and small-grid markets (noted by Arizona Public Service and important in the Australian market, which is perceived as a likely early adopter), easier financing and shorter construction times, and learning-by-doing replication. The twinned facility also offers operational redundancy where $50 \%$ generation can be maintained while maintenance is performed on the second unit. Bigger facilities can employ a "power park" design that allows for shared staff and support infrastructure [4]. These advantages overwhelmed the negative effects of the smaller plant capacity, mainly higher cost-per-kW capacity and lower efficiency of the power cycle.

ASTRI's SolarTherm model was used to generate LCOE estimates for the proposed design with a reference case of best-estimate costs and a parametric study that statistically varies each cost input. This analysis resulted in a probability distribution of LCOE as shown in Figure 3 with a mean of $\$ 58 / \mathrm{MWh}$ (USD), meeting the FOA target of $\$ 60 / \mathrm{MWh}$. More detail is found in $\$ 3$. 


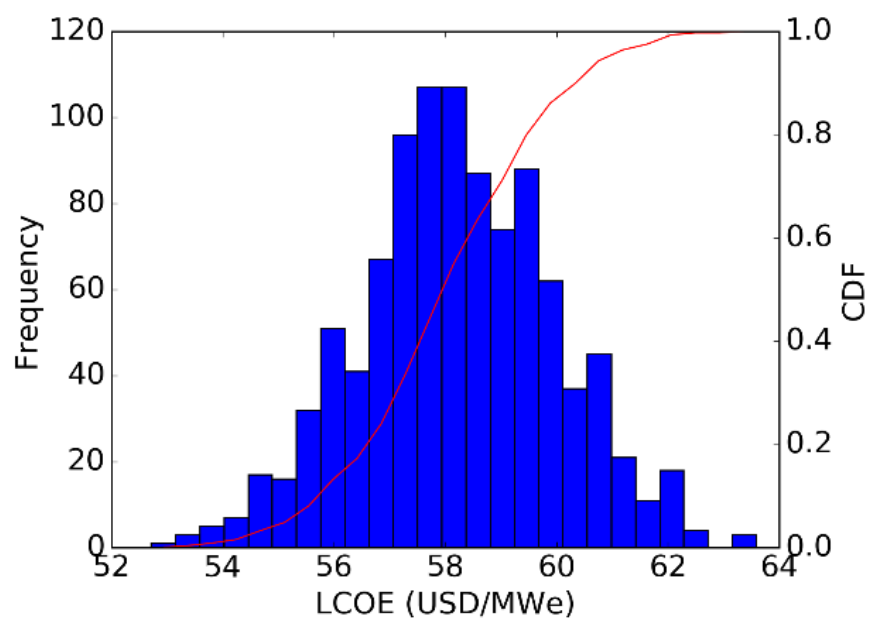

Figure 3. Probability distribution for the LCOE of the commercial system. The FOA target value for Gen3 is $\$ 60 / \mathrm{MWh}_{\mathrm{e}}$.

Source: ANU

\subsection{Summary of Major Accomplishments of Phases 1 \& 2}

During the project's Phase $1 \& 2$ research periods, significant knowledge was gained to derisk the technology. As will be described in the body of this report, the tank design and liner materials were investigated, and a refractory liner defined that withstands the temperature and corrosion challenges of the salt. This design was built on knowledge from the magnesium and refractory industries. The salt tank design employs a hot face brick liner shown to be resistant to salt attack and forms a protective forsterite phase in the presence of magnesium salt. This design insulates and protects the tank shell so that carbon steel can be used for the shell itself.

Melting and purification of the salt was demonstrated at the laboratory and bench scale. Building on research from DOE's wider research program in molten chloride salts (aka, the Salt Collective), the team developed a protocol for melting the multi-ton quantity of salt required for the pilot scale system. This protocol has been tested with the melting of a $200-\mathrm{kg}$ batch of salt at Oak Ridge National Lab.

Prior to the sodium vs. salt comparison and down selection, the project evaluated multiple salt and sodium receiver designs, which has been submitted for publication by the ASTRI and NREL teams. Two designs were selected for the head-to-head down selection mentioned in the section above, where the results concluded that a sodium receiver design could achieve a lower LCOE and had greater operational benefits versus the salt design.

The proposed pilot-scale sodium receiver design is representative of the selected commercialscale receiver. The pilot-scale receiver is estimated to have a thermal efficiency of approximately $84 \%$, not accounting for intercept losses, which is negatively influenced by the small receiver size and large heliostats at the test site. The exit sodium temperature is $740^{\circ} \mathrm{C}$. The commercialscale design is estimated to have an overall receiver efficiency of $88 \%$, accounting for all thermal and intercept losses.

Maximum allowable flux on the receiver is limited by creep-fatigue damage of receiver tubes. Detailed inelastic analysis explored the design constraints for the receiver in collaboration with 
experts at Argonne and Idaho National Labs. A protocol was developed for estimating receiver lifetime in the creep-fatigue regime that avoids the conservativism inherent in simpler (elastic) design procedures. Testing of the pilot-scale system with aggressive excursions in temperature and flux will provide confidence in estimated receiver lifetime and a means to further calibrate the protocol. The high flux allowances currently under consideration correspond to lower cost and higher efficiency in a commercial design.

The primary salt-to-s $\mathrm{CO}_{2}$ heat exchanger ( $\mathrm{PHX}$ ) will use a printed circuit heat exchanger design (PCHE). Etching and bonding tests during Phase 2 confirmed the ability to fabricate such a unit out of Inconel 617 and H230. The high-nickel alloy PCHE design allows for a compact heat exchanger that can withstand both the $\mathrm{sCO}_{2}$ pressure and differing corrosive effects of the two fluids. The commercial familiarity of PCHE technology gives a high degree of confidence to the estimated performance of these units.

\subsubsection{Relevant Accomplishments Under Topic 2 or Other R\&D}

The Liquid Pathway project has benefited from several complementary projects funded under Topic 2 of the Gen3 CSP FOA, alloy materials research funded by EPRI and the DOE nuclear program, and other research around the world. These include projects examining chloride salt chemistry, salt chemistry sensors, salt pumps, salt valves, coatings to protect against salt corrosion, and the prototype test Facility to Alleviate Salt Technology Risks (FASTR) at Oak Ridge National Lab.

Projects led by Powdermet [5] and Liquid Metal Holdings [6] have developed and tested protective coatings for use in chloride salts. Other research has examined the potential of cladding as a protective liner in pipes and tanks. The cermet coatings developed by Powdermet are applicable as a wear-protective layer in pumps, valves, and fittings and have been quoted to the team for use in the project. The thermal spray coatings developed by Liquid Metal Holdings can be applied to tanks and large-diameter piping. Both of these approaches allow for use of lower-cost substrate alloys and longer life components.

Monitoring of the salt chemistry is essential for corrosion control. Argonne National Lab has developed an electrochemical sensor shown to effectively measure salt redox potential and corrosion indicators in laboratory and bench scale testing. This technology will be deployed at the pilot system to monitor salt conditions.

Pump suppliers Sulzer, Flowserve, and Hayward Tyler engaged with the Liquid Pathway team on the design of molten-chloride salt pumps. These pumps leverage extensive knowledge of long-shaft, vertical-turbine salt pumps used in current CSP plants. Changes are made to adjust for the differing corrosion, salt property, and temperature conditions of the Gen 3 molten chlorides. Sulzer and Flowserve provided pump designs, performance specifications, and pricing for the pilot scale salt pumps, as well as budget estimates for the commercial scale.

Similarly, chloride salt valve technology borrows heavily from the knowledge of current molten salt valves. High-nickel alloys, globe-valve design, and bellows seals are recommended for dealing with chloride salts. The Liquid Pathway project consulted with valve suppliers Flowserve, Guichon, Trillium, Gosco, and Jarecki during Phases 1 and 2. Both Flowserve and 
Gosco have supplied valves for bench-scale testing, although these tests have been delayed due to pandemic related issues.

Recognizing the value in preliminary prototype component testing, DOE funded the FASTR test unit at Oak Ridge National Lab. This chloride-salt test facility provides similar piping size, temperature, and flow rates as expected in the proposed 1-MW th pilot scale system. Hampered by pandemic related delays, FASTR's anticipated start in summer 2020 was pushed back into late fall. Recently, the FASTR team successfully melted their $200-\mathrm{kg}$ batch of salt and charged the system. However, the delays mean FASTR is unlikely to inform the Gen3 down select decision, although the facility is key to derisk components prior to potential integrated-system demonstration.

\subsection{Remaining Major Risks}

Risks associated with the proposed Liquid Pathway were identified and tracked throughout the project in a formal Risk Registry. The Risk Registry is reviewed in $\S 5$ and summarized here. The risk registry captured project risks across over 17 component and subsystem categories. The registry currently tracks over 400 identified risks associated with design, operation, and performance of the pilot-scale system. Current significant risks include the integrity of the tank liner, the performance of the salt valves, the impact of salt vapor on system components, salt piping freeze recovery, pressure and chemical sensor performance, online corrosion control, $740 \mathrm{H}$ alloy compatibility with sodium, and sodium fires. Addressing these risks and demonstrating reliable operation is the goal of the pilot scale system.

\subsection{Objectives of the Phase 3 Demo}

The overall goal of the integrated system demonstration is to derisk the Liquid Pathway approach and facilitate the development of the liquid pathway technology for Gen3 CSP. The general system layout is shown in Figure 4. Specific objectives include:

\section{Operational Performance}

- Demonstrate operational modes including dynamic and steady-state conditions. Operation and control of the sodium receiver and sodium-salt heat exchanger will be demonstrated under all modes of operation expected in a commercial-scale system to derisk the ability of the system to respond to and survive expected conditions.

- Demonstrate safe operation of a sodium receiver and sodium loop. While sodium provides superior heat transfer capabilities in the receiver, the safety and reactivity concerns surrounding sodium can have significant implications on perception and acceptance of the technology.

- Demonstrate operation at the target thermal rating of $1 \mathrm{MW}_{\text {th }}$ and outlet temperature of $740^{\circ} \mathrm{C}$. Many failure modes for the receiver system arise from operation at target outlet temperatures, which are well above those encountered in current commercial CSP systems. Material incompatibilities, corrosion, and creep or creep-fatigue damage are all exacerbated by these conditions. Thus, operating the receiver and sodium-salt heat exchanger at the target conditions is critical to derisk the functionality and survivability of the technology, and will improve assessments of these damage mechanisms via posttest metallurgical evaluation. 
- Demonstrate thermal ramp rates for all three interconnected loops and quantify limits of dynamic performance. CSP receiver systems operate under inherently dynamic conditions owing to the diurnal cycle of solar radiation and DNI variability from cloud transients. Rapid temperature changes in receiver outlet temperature arising from cloud transients will expose the sodium-salt heat exchanger to similarly rapid transient events. Responsiveness, controllability, and survivability under dynamic conditions are paramount to successful system performance.

- Demonstrate response to and recovery from emergency conditions. Demonstrate safe operation and survivability of components in response to emergency conditions including power loss for heliostat control or receiver flow control, simulated critical component failures, or excursion of properties including receiver flux concentration and temperature conditions from the desired set point.

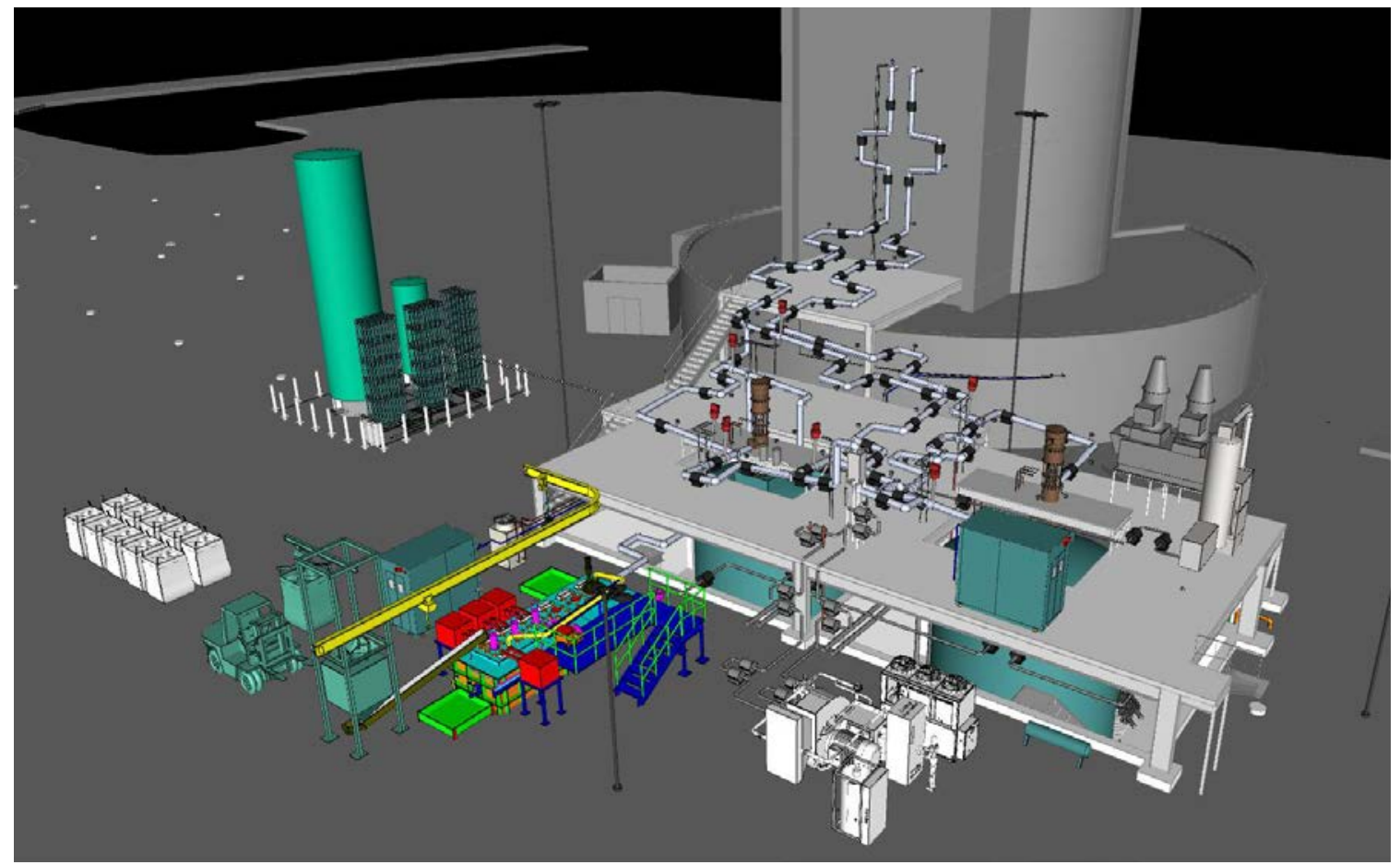

Figure 4. System layout at the base of the NSTTF tower: Melter in color at front left, $\mathbf{N}_{2}$ ullage gas supply in left rear, scrubber in right rear on the elevated deck, and $\mathrm{PHX}$ with $\mathrm{sCO}_{2}$ system in foreground at right. Receiver level not shown.

Figure courtesy of Sandia

Model Validation

- Characterize heat loss and receiver thermal performance. Validated pilot-scale performance models will provide confidence in commercial-scale performance projections.

- Characterize salt tank heat loss and thermal performance.

$\underline{\text { Salt Tank }}$

- Characterize the temperature across the foundation in the pilot-scale tanks to refine predicted temperature ranges for air cooling of the commercial-scale tank floors. Successful implementation of air-cooling low temperature tank floors may point to 
cheaper methods of implementation using cheaper and more available materials in large salt tanks.

- Demonstrate tank liner integrity. Leakage of salt into the refractory liner will degrade the liner's insulating ability and tank life.

- Post-test evaluations will identify areas of liner vulnerability and/or excessively high stresses in the pilot tank steel. These evaluations can be used to improve commercial scale tank design by identifying areas of concern for focus during the design process.

Pumps, Valves and Piping System

- Demonstrate salt and sodium pump and valve operational capabilities at Gen3 conditions.

- Demonstrate sodium and salt freeze recovery.

- Demonstrate operation and durability of heat tracing in the valve and piping network.

Materials and Corrosion

- Demonstrate receiver panel fabricability. Fabrication of the $1-\mathrm{MW}_{\text {th }}$ pilot-scale receiver system will provide a detailed assessment of the workability of the materials, ease of manufacturing for the $740 \mathrm{H}$ alloys and tube dimensions, and fabrication cost.

- Demonstrate sodium cold trap operation and salt corrosion control. Maintaining purity levels in the sodium and salt fluids is essential to their long-term performance and the durability of the system.

- Test corrosion rates and compatibility of alloys and coatings with sodium and salt at the hot-side and cold-side temperature conditions.

- Post-test metallurgical evaluation. Upon completion of the test campaign, tube samples from each straight-tube and tube-header interface sections will be subjected to metallurgical evaluation to assess alloy suitability and sustained damage. Post-test destructive testing will be used in conjunction with laboratory-scale testing to validate material degradation models and gain confidence in the ability to predict damage and degradation, and thereby to design components to a specified commercial-scale service life.

\subsection{Estimated Cost of the Phase 3 Demo}

The estimated budget for the Phase 3 project as calculated by the team's $90 \%$ Design Report is approximately $\$ 57$ million dollars (estimated range $\$ 52$ to $\$ 68$ million), with cost details provided in the body of this report $\$ 6.3$. This estimate is approximately double the $\$ 31.2$ million funding target set by the DOE program (federal share of $\$ 25$ million plus $20 \%$ minimum cost share).

\subsection{Plan B: Other Molten-Salt Stakeholders and Demonstration Options}

Should the Liquid Pathway project not be selected for construction of the full integrated 1-MW demonstration system under the Gen3 FOA, the team suggests that the DOE Solar Office consider partnering with other stakeholders for continued development of the chloride-salt thermal energy storage technology. As discussed in the sections above, the potential of low-cost chloride salts for thermal energy storage has garnered interest and spawned R\&D activity around the world, including work in the USA, Australia, Germany, and China. Furthermore, this interest is not limited to application in CSP. Stand-alone thermal energy storage, aka thermal batteries or Carnot Batteries, and Gen IV nuclear reactor systems also benefit from chloride salt storage. 
Liquid Pathway receiver down selection meetings held in February 2020 were hosted by nuclearpower developer TerraPower in Bellevue, Washington. Privately funded TerraPower is developing both a molten chloride fast reactor (MCFR) and a sodium-cooled reactor design for future power generation. Their Natrium reactor combines a sodium-cooled reactor with energy storage in nitrate salt. The design was recently selected for an $\$ 80$ million DOE demonstration award with the plan for a reactor to be operational within the next seven years (https://www.terrapower.com/doe-natrium-demonstration-award/). The MCFR design uses a binary $\mathrm{MgCl}_{2} / \mathrm{NaCl}$ salt coolant with properties very similar to the ternary salt promoted by the Liquid Pathway team. Both systems currently interface with nitrate salt for thermal energy storage to facilitate reactor stability and load-following dispatchability. Transition to a chloride salt for energy storage offers significant benefits if the technology can be demonstrated to be reliable and cost-effective. Potential advantages vs. nitrate salts include:

- Higher temperature energy storage that translates into higher power cycle thermal conversion efficiency,

- Better chemical compatibility between sodium and the storage salt in the Natrium system,

- Better chemical compatibility between the binary $\mathrm{MgCl}_{2} / \mathrm{NaCl}$ coolant and the storage salt in the MCFR system, and

- Lower cost media (although overall storage cost for the chlorides currently exceeds that for nitrates due to the estimated tank costs.)

- Applicability to a wider range of industrial applications beyond the power sector, due to the higher temperature stability of chloride vs. nitrate salts.

In particular, TerraPower indicates the desire to operate the MCFR system at temperatures up to $650^{\circ} \mathrm{C}$ or higher (assuming a suitable storage salt) and the need to develop and test molten salt components for both reactor development programs.

The Liquid Pathway team sees value in combining the knowledge gained by the DOE Solar program's salt development research with that of the DOE Nuclear Energy office and TerraPower. Such a cost-shared development and demonstration effort could derisk chloride salt energy storage for both nuclear and CSP applications. Potential program objectives could include the demonstration of chloride salt storage and handling at $\sim 1 \mathrm{MW}_{\text {th. }}$ Test objectives would include many of the same objectives listed in this report for the CSP Gen3 program, namely:

- Demonstrate robust, affordable high-temperature salt storage tanks

- Demonstrate reliable pressure and flow sensors

- Demonstrate reliable and affordable flow control, isolation, and check valves

- Demonstrate the ability to monitor and control corrosion in chloride-salt systems

- Demonstrate the durability of alloys and coated alloy samples in flowing chloride salt

- Characterize the performance of sodium-to-salt heat exchangers (relevant to the Natrium and CSP systems).

Potential cost savings vs. the Liquid Pathway project proposed here would be manifested by elimination of the riser/downcomer, sodium receiver and sodium loop, reduction in the energy storage capacity of the salt holding tanks, reduction in the maximum test temperature to $<700^{\circ} \mathrm{C}$ (initially), and (probable) relocation of the testing to a non-national laboratory site. 
Under such an eventuality, the team recommends maintaining a strong link with ASTRI's planned testing of a $700-\mathrm{kW}_{\text {th }}$ sodium receiver in Australia. Information exchange (e.g., on pumps, valves, pipe heating, materials) in sodium and salt technologies would be beneficial to both parties. In short, the development for sodium/salt power systems from the Nuclear and Solar perspectives could be accelerated by cooperation in the development and demonstration of many of the objectives in the current proposal under such a cross-program partnering agreement, albeit without proving the integration/operability aspects of the combined sodium/salt configuration proposed for Phase 3. 


\section{Project Review Criteria}

The criteria below were defined by the U.S. DOE in Gen 3 CSP Topic 1 -Phase 3 Test Facility Down-Selection Criteria, issued to the Topic 1 awardee teams on April 25, 2019.

\subsection{Criterion \#1}

Evaluate the extent to which the critical concerns for a given technology have been adequately derisked in Phase 1/2, and in previous research to advance and succeed in Phase 3.

The Gen3 Roadmap [1] identified numerous gaps and challenges associated with the molten salt receiver technology that became the focus for the Phase 1 and Phase 2 research. These, and subsequently identified risks, are outlined in Table 1.

Table 1. Summary of Liquid Pathway technology risk from original Gen3 Roadmap to present. Asterix $(*)$ denotes risk element identified in the Gen3 Roadmap.

\begin{tabular}{|c|c|}
\hline Risk Category & Current Status and Notes \\
\hline Salt Chemistry * & $\begin{array}{l}\text { Salt properties well defined. Melting methodology documented and tested at } 200-\mathrm{kg} \\
\text { scale. }\end{array}$ \\
\hline \multirow{2}{*}{$\begin{array}{l}\text { Materials } \\
\text { Selection / } \\
\text { Compatibility * }\end{array}$} & $\begin{array}{l}\text { Corrosion data obtained for chloride salts; material life adequate if salt chemistry } \\
\text { controlled. Need remains to demonstrate in an industrial setting. }\end{array}$ \\
\hline & $\begin{array}{l}\text { Sodium compatibility well-understood for cold side. Corrosion resistance of Ni alloys } \\
\text { for hot side remains a risk, although validation testing is underway. }\end{array}$ \\
\hline $\begin{array}{l}\text { Thermal Energy } \\
\text { Storage * }\end{array}$ & $\begin{array}{l}\text { Salt tank design based on industrial experience. Hot face material shows good } \\
\text { chemical compatibility. Tank performance depends on integrity of the hot face layer, } \\
\text { which remains a high-risk item requiring MW-scale demonstration. }\end{array}$ \\
\hline $\begin{array}{l}\text { Salt Solar } \\
\text { Receiver * }\end{array}$ & $\begin{array}{l}\text { Viewed as high risk due to high freezing temperature and poor heat transfer } \\
\text { properties of the salt. Removed from the pathway and replaced by a sodium } \\
\text { receiver, which is considered to have significantly lower operational risk. }\end{array}$ \\
\hline Pumps * & $\begin{array}{l}\text { Perceived as relatively low risk. Pumps quoted by two suppliers for the salt pumps } \\
\text { and commercial pumps are available for } 500^{\circ} \mathrm{C} \text { sodium systems (note that a hot- } \\
\text { side sodium pump is not required). }\end{array}$ \\
\hline Valves * & $\begin{array}{l}\text { Designs based on commercial nitrate salt valves with materials suitable for the } \\
\text { chloride salt. Performance and durability in chloride salt still to be determined. Salt } \\
\text { vapors present a previously unexpected risk. A wide range of standard valve } \\
\text { configurations are available for sodium, within an operating temperature range and } \\
\text { size range employed in nuclear programs. }\end{array}$ \\
\hline $\begin{array}{l}\text { Heat Trace and } \\
\text { Insulation * }\end{array}$ & $\begin{array}{l}\text { Ceramic fiber heaters identified as preferred approach for high-temp side }\left(720^{\circ} \mathrm{C}\right) \text {. } \\
\text { Low-temp Gen3 }\left(500^{\circ} \mathrm{C}\right) \text { less severe than current nitrate-salt conditions }\left(560^{\circ} \mathrm{C}\right) \text {. }\end{array}$ \\
\hline Salt Piping * & $\begin{array}{l}\text { Suitable materials identified. Internal coatings available for enhanced corrosion } \\
\text { control at commercial-scale pipe diameters. Use of sodium riser/downcomer } \\
\text { reduces salt piping required in commercial design. Ceramic fiber heaters to be } \\
\text { tested in some locations on the pilot system to derisk their use for CSP. }\end{array}$ \\
\hline $\begin{array}{l}\text { Salt-to-s } \mathrm{CO}_{2} \\
\text { Heat Exchanger }\end{array}$ & $\begin{array}{l}\text { Compact diffusion bonded design uses separate low-temp (stainless steel) and hot- } \\
\text { temp (IN617) cores to reduce cost. }\end{array}$ \\
\hline
\end{tabular}




\begin{tabular}{|l|l|}
\hline Risk Category & Current Status and Notes \\
\hline Plant Sensors * & $\begin{array}{l}\text { Salt chemistry sensor developed and tested by Argonne National Lab. Flowserve } \\
\text { StarPac valves provide pressure and flow sensing, although this remains a high-risk } \\
\text { component. Hot-side flow sensors available but unproven. }\end{array}$ \\
\hline $\begin{array}{l}\text { Component Test } \\
\text { Facilities * }\end{array}$ & $\begin{array}{l}\text { FASTR facility did not become operational until Fall 2020, severely limiting the } \\
\text { available data from this importance test facility. }\end{array}$ \\
\hline $\begin{array}{l}\text { Sodium } \\
\text { Receiver }\end{array}$ & $\begin{array}{l}\text { Extensive modeling and creep-fatigue analysis, along with significant engagement } \\
\text { and fabrication advice from commercial receiver manufacturer John Cockerill, give } \\
\text { high confidence in this liquid-receiver design. }\end{array}$ \\
\hline $\begin{array}{l}\text { Sodium Piping } \\
\text { and System }\end{array}$ & $\begin{array}{l}\text { Sodium system follows well-documented guidelines from nuclear sector. Risk } \\
\text { associated with relative lack of data on corrosion resistance of Ni-alloys at hot-side } \\
\text { temperatures (740 C). Sodium introduces new risk factor associated with potential } \\
\text { fire. Smoke and fire risk mitigated by scrubber system. }\end{array}$ \\
\hline $\begin{array}{l}\text { Ullage Gas } \\
\text { System }\end{array}$ & $\begin{array}{l}\text { Salt vapor pressure higher than expected, leading to unforeseen risks and } \\
\text { additional costs within the ullage gas system. } \\
\text { Tank pressure control (and risk) greatly reduced by utilizing open piping vented with } \\
\text { low flow of ullage gas to the scrubber. }\end{array}$ \\
\hline
\end{tabular}

The Risk Registry for the Liquid Pathway identified over 600 potential risks, which were aggregated into the top risks in 17 component categories, aligned with the risk elements identified in the Roadmap. During Phase 1, 68\% of the top risk elements experienced a reduction in perceived risk, while the remainder were either unchanged or newly discovered.

Phase 2 transitioned the Risk Registry into a Failure Modes \& Effect Analysis (FMEA) tracking process, following procedures for major projects at Sandia. This forms the basis for the Phase 3 risk assessment. More information on the project's Risk Registry can be found in $\S 5$.

\subsection{Criterion \#2}

Evaluate the project management and technical capabilities of the awardees to accomplish the Phase 3 activities, using the Phase 1 / 2 results and other past research. The awardee's Phase 3 proposal should use the knowledge gained by the Topic Area 1 team during Phase 1, and potentially also incorporate knowledge, technologies, or members from Topic Area 2 awardees.

The project team leverages experience from industry and from previous salt and sodium research and testing at Sandia. In recent years, ASTRI has designed, built, and tested several receivers at greater than $700^{\circ} \mathrm{C}$ at CSIRO, and a $700-\mathrm{kW}_{\text {th }}$ sodium unit is under construction. The down selection of a sodium receiver was undertaken by tapping the knowledge of sodium researchers and users at Argonne National Lab, Vast Solar, Creative Engineering, and CEA France, as well as the ASTRI team. Team member B\&P has extensive experience with construction projects at Sandia, including the Molten Salt Test Loop and the AREVA molten salt Fresnel test, both at the NSTTF. The project team is depicted in Figure 2 and details regarding the Phase 3 construction and project management approach are provided in $\S 6.2 .1$.

\subsection{Criterion \#3}

Evaluate the merit of the proposed future (100 MW scale) integrated thermal system to reduce the cost of electricity and advance market adoption of the next generation of CSP systems. 
As detailed in $\S 3$ and highlighted in Figure 3, the estimated LCOE of the liquid pathway design is projected to have a high probability of achieving the $\$ 60 / \mathrm{MWh}_{\mathrm{e}}$ target set by the Gen3 CSP program. Yet commercial success will require many additional factors including the existence of a technology supply chain and the ability to finance and build early-stage commercial plants.

The Liquid Pathway design of a 50-MWe modular unit is motivated by both technical performance and market adoption. The module size offers technical advantages in optical efficiency, allows for adoption of novel low-cost towers, but suffers little in terms of economy of scale for key subsystems because it utilizes the maximum practical molten-salt tank capacity and a modular compact heat exchanger design for the PHX.

Importantly, the 50-MWe unit capacity facilitates early adoption for those locations that may favor smaller capacity generators (e.g., Chile, South Africa, Spain, Australia) [7]. For fire-prone regions like California and Australia, smaller facilities could be located closer to industrial and municipal load centers to reduce the risk associated with long-range transmission lines. The smaller capacity also meshes more readily into the development path of the $\mathrm{sCO}_{2}$ Brayton power cycle, offering nearer-term deployment than with larger, more capital-intense projects. Multi-unit "power parks" provide a solution for markets that seek larger capacity (see Figure 5). Co-located generation units have been projected to yield LCOE cost reduction of up to $19 \%$ via construction learning and shared O\&M infrastructure [4].

The Gen3 CSP Roadmap documents stakeholder preference for a path familiar to industry to reduce risk ([1] p. 33):

"All utilities that participated in the survey think that demonstration projects at nominally 10-MW scale are a necessary and important step to mitigate technology risk if the project design significantly deviates from what has been built previously. An exception may be advanced molten-salt technology, which could gradually evolve from technology available today."

Industry familiarity with liquid HTFs and molten-salt thermal storage, combined with a smallercapacity commercial unit, suggests a shorter step to market than for other pathways. As discussed in $§ 1.2 .1$, the engagement of current CSP-industry suppliers in the development and testing of Gen3 pumps and valves also accelerates the commercial potential of the liquid pathway technology. For example, working with industrial salt suppliers ICL and Albemarle ensures that the proposed Gen3 storage salt will be available in commercial quantities.

The most direct connection with the CSP marketplace lies in Vast Solar's development of sodium/salt systems as represented by their proposed Mount Isa project, ${ }^{1}$ which is nearing financial closure. Vast Solar has been operating the 5-MW th Jemalong pilot unit for the past several years, where they refined their knowledge and expertise with sodium receivers and showcased the advantages of the sodium HTF. The presence of Vast Solar provides close ties to the large mining operations and fringe-of-grid locations in Australia that match with smaller CSP capacity systems.

\footnotetext{
${ }^{1}$ https://www.evwind.es/2020/07/24/australian-mining-town-picked-for-first-large-concentrated-solar-power-plant/76001
} 


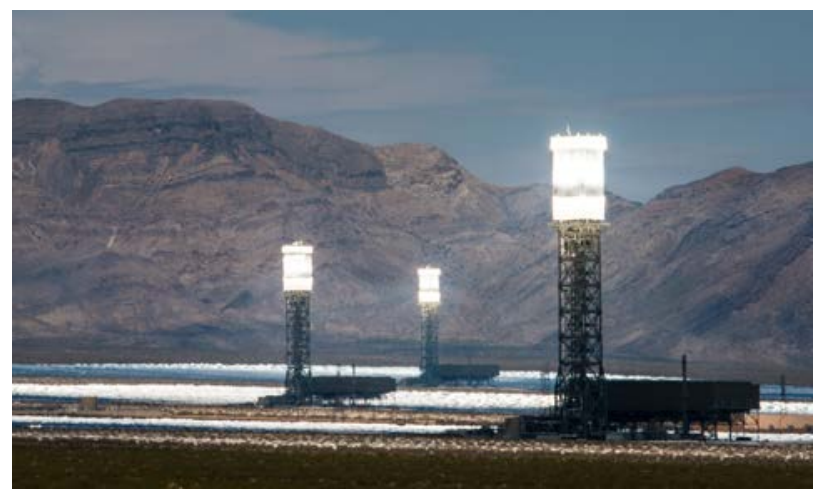

Figure 5. The proposed 50-MW $\mathrm{MW}_{\mathrm{e}}$ modar design would shorten project construction time while allowing for larger, multi-unit facilities if desired. Photo: Ivanpah Solar Electric Generating Station, USA (NREL photo library).

The proposed liquid pathway technology also dovetails with work in the nuclear power sector, where companies such as TerraPower, Moltex, Kairos, and others are working on advanced molten-salt reactor systems with CSP-similar needs for high-temperature salt pumps, valves, and storage systems. This wider field of applications entices investment and helps speed the development and drive down the cost of the liquid pathway technologies. The project's specific engagement with TerraPower is discussed in $\S 1.6$.

This network of multiple stakeholders in liquid-HTF thermal systems provides the necessary critical mass to bridge the pre-commercial demonstration valley with multi-MW test and demonstration and more quickly advance to early commercial deployment. Significantly, the Gen3 technology is nearing this point when markets around the world are acknowledging the need for more carbon-free, dispatchable power such as offered by CSP and modular nuclear power systems [7].

\subsection{Criterion \#4}

Evaluate the extent to which the proposed activities will derisk the critical concerns for the proposed technology in Phase 3.

The basic objectives of the Phase 3 demonstration are listed in $\S 1.4$. The demonstration includes a plan to investigate and retire many risks and seeks to address these at a commercially relevant scale in order to clear the technology for wider investment and adoption by industry players in both the CSP and next-generation nuclear sectors. Technology risks identified in Phase 1 guided the research of Phases 1 and 2 described in $\S 4$. Many of these risks were reduced, while other potential threats were exposed. A new Risk Registry builds on the work on Phase 2 risk assessment ( $\$ 5.1)$ to describe the key areas that must be addressed in the proposed demonstration $\S 5.2$.

\subsection{Criterion \#5}

Evaluate how the results of Phase 3 can be successfully implemented into a future CSP demonstration and adopted for commercial use. This criterion addresses the ability of the pilot plant's design to 'scale up' to a nominal 100-MWe commercial project. Teams should elaborate on the remaining steps necessary to be able to construct a future commercial facility. 
As discussed in a recent DOE Workshop [8], risk related to commercial adoption of a new technology can be mapped to four categories: operability, scalability, market adoption, and cost. The liquid pathway utilizes proven design methods related to pumps, piping, heat exchangers, and solar receivers. Construction methods for liquid-based CSP systems are documented (e.g., [9]) and can be relied upon to guide the proposed Gen3 technology. This includes information on molten salt technologies as well as available data for the design and operation of sodium-based thermal systems coming from the nuclear industry. This similarity to current state-of-the-art provides confidence in the design methods and the ability to scale results from the proposed 1$\mathrm{MW}_{\text {th }}$ demonstration to a commercially relevant size. As stated within the Gen3 Roadmap ([1], quoted above), stakeholders perceive that this similarity to current commercial practice is essential to speed the transition from demonstration to commercial scale.

The range of stakeholders for the Liquid Pathway approach suggest that the Phase 3 system components can be demonstrated at larger scale in future commercial projects before necessitating a full Gen3-style integrated plant. For example, Gen IV reactor developers are proposing multi-MW testing of chloride-salt systems and large sodium/salt heat exchangers are planned in the $50-\mathrm{MW}_{\mathrm{e}}$ Mount Isa project, which will also include commercial demonstration of sodium pumps, valves, and handling procedures. These components and subsystems may be deployed initially at lower temperature and capacity, but the ability to gain commercial experience with them — outside of CSP research funding — is essential to bring the DOE Gen3 vision to the marketplace.

Furthermore, the unit-system scale of 50- $\mathrm{MW}_{\mathrm{e}}$ aids the transition from demonstration to commercial scale. The system size is selected to allow for salt tanks that do not exceed the dimensions of current nitrate-salt tanks. The Gen3 program requires deployment of an $\mathrm{sCO}_{2}$ power cycle that is currently in development. The smaller $50-\mathrm{MW}_{\mathrm{e}}$ capacity will reduce the timeline for development of a commercial $\mathrm{sCO}_{2}$ power cycle that matches with this plant capacity. It is notable that the proposed pathway offers the opportunity to advance the technology first to $\sim 650^{\circ} \mathrm{C}$ receiver temperatures, where materials risk is significantly lower, before evolution to higher temperatures. This route to $>700^{\circ} \mathrm{C}$ operation has also been stated by the DOE-funded STEP Initiative in its development of the $\mathrm{SCO}_{2}$ power cycle 2 . More information on risks associated with the transition from pilot demonstration to commercial practice is provided in $\S 5.3$.

2 https://www.gti.energy/step-demo/ 


\section{Commercial-Scale Design, Performance, and Cost}

This report begins with the envisioned commercial endpoint to highlight why the liquid pathway offers great potential for Gen3 CSP. The report then delves into the learning from Phases 1 and 2 (§4) and the risks and mitigation strategies associated with the chosen pathway ( 5 ), before concluding with the design, objectives, and cost of the proposed pilot-scale system $(\S 6)$.

Throughout the report, the reviewer is guided to sources of additional detail via the larger project file database (see $§ 7$ ).

The conceptual design for the commercial plant is depicted in Figure 6 and was briefly described in $\S 1.1$. This section provides additional detail on the design process, commercial system performance, equipment cost, and overall LCOE. Section 3.1 deals with power cycle performance and cost, followed by sections addressing other subsystems at the assumed commercial scale.

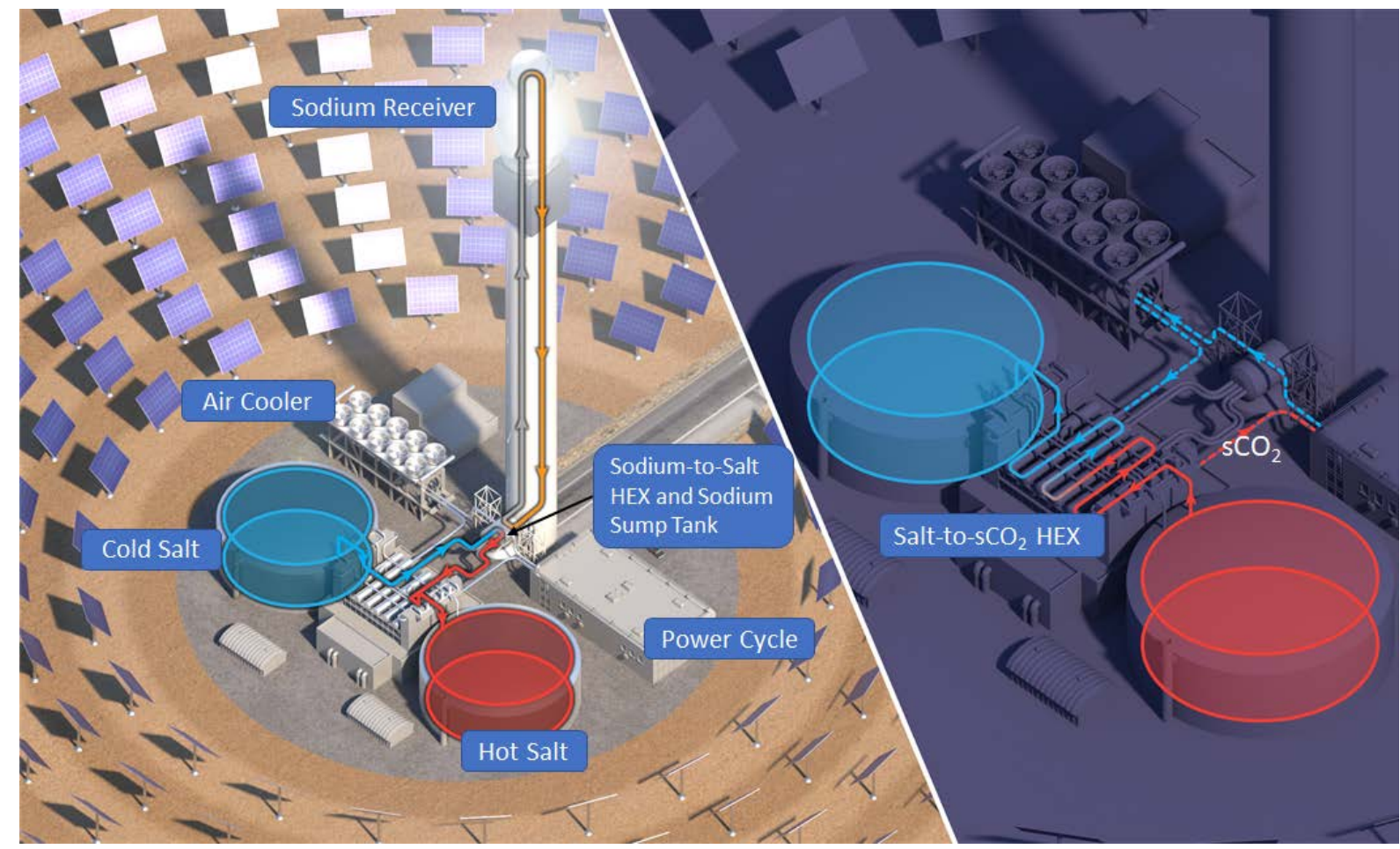

Figure 6. Liquid Pathway commercial system design showing charging of thermal storage (left) and discharging thermal storage to the $\mathrm{SCO}_{2}$ power cycle (right). $\mathrm{HEX}=$ heat exchanger

\subsection{Power Cycle Performance at 50-MWe Scale}

The CSP Gen3 Roadmap [1] identified advanced supercritical $\mathrm{CO}_{2}$ Brayton power cycles, such as the recompression and the partial-cooling configurations, as having the potential to achieve the Gen 3 target of 50\% efficiency, even when combined with dry cooling. The partial-cooling configuration tends to operate over higher pressure ratios across the turbine, so it has higher power density than the recompression cycle [10]. Consequently, the cycle requires less recuperation (i.e., smaller recuperator area). The higher pressure ratio leads to a larger temperature difference across the turbine, and, therefore, the solar receiver, primary heat exchanger and any thermal storage system. For CSP applications with sensible-heat storage, the temperature differential across storage is an important factor in storage cost and overall 
economics. The Liquid Pathway team therefore selected the partial-cooling $\mathrm{sCO}_{2}$ cycle for integration in its commercial design to take advantage of a wider temperature difference vs. the recompression cycle $(210 \mathrm{~K}$ vs. $180 \mathrm{~K})$.

The performance of the power cycle is calculated by implementing a steady-state model of a $\mathrm{sCO}_{2}$ recompression Brayton cycle from Neises and Turchi [10]. The model designs the power cycle based on the required net power output and the parameters listed in Table 2 . This model uses isentropic efficiency relationships to characterize the performance of the turbine and compressors.

Table 2. Power cycle design inputs

\begin{tabular}{|c|c|c|c|}
\hline Parameter & Units & Value & Ref \\
\hline Salt inlet temperature at design & ${ }^{\circ} \mathrm{C}$ & 720 & \\
\hline Salt outlet temperature at design & ${ }^{\circ} \mathrm{C}$ & 500 & \\
\hline $\mathrm{CO}_{2}$ temperature at turbine inlet & ${ }^{\circ} \mathrm{C}$ & 700 & [10] \\
\hline Ambient temperature at design & ${ }^{\circ} \mathrm{C}$ & 35 & \\
\hline Compressor inlet temperature & ${ }^{\circ} \mathrm{C}$ & 41 & [10] \\
\hline Elevation of Daggett, CA & $\mathrm{m}$ & 588 & \\
\hline Net power cycle output & $\mathrm{MW}_{\mathrm{e}}$ & 50 & \\
\hline Compressors technology & - & Centrifugal & [11] \\
\hline Compressors isentropic efficiency & - & 0.87 & {$[11]$} \\
\hline Turbine technology & - & Axial & \\
\hline Turbine isentropic efficiency & - & 0.93 & [11] \\
\hline Compressor outlet pressure & $\mathrm{MPa}$ & 25 & \\
\hline Cold side (high pressure) pressure drop $(\Delta P)$ & $\mathrm{kPa}$ & 140 & [11] \\
\hline Hot side (low pressure) $\Delta P$ & $\mathrm{kPa}$ & 280 & [11] \\
\hline Design minimum allowable temperature difference in LTR & ${ }^{\circ} \mathrm{C}$ & 10 & [10] \\
\hline LTR low pressure side $\Delta P$ as fraction of inlet pressure & - & 0.0311 & [10] \\
\hline LTR high pressure side $\Delta \mathrm{P}$ as fraction of inlet pressure & - & 0.0056 & [11] \\
\hline Design minimum allowable temperature difference in HTR & ${ }^{\circ} \mathrm{C}$ & 10 & [10] \\
\hline HTR low pressure side $\Delta \mathrm{P}$ as fraction of inlet pressure & $\%$ & 3.11 & [11] \\
\hline HTR high pressure side $\Delta \mathrm{P}$ as fraction of inlet pressure & $\%$ & 0.56 & [11] \\
\hline 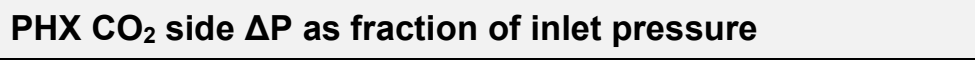 & $\%$ & 0.56 & [11] \\
\hline Fraction of $\mathrm{CO}_{2}$ inlet $\mathrm{P}$ that is design point cooler $\mathrm{CO}_{2} \Delta \mathrm{P}$ & $\%$ & 0.5 & {$[11]$} \\
\hline Fraction of net cycle power consumed by air cooler fan & $\%$ & 2.0 & [12] \\
\hline
\end{tabular}

Modeling of the $\mathrm{SCO}_{2}$ power cycles follows common practice in the art: The recuperators are modeled as counter-flow heat exchangers where the geometry is discretized into subsections of equal heat transfer rate to account for variation in $\mathrm{sCO}_{2}$ properties due to temperature. The total recuperator conductance is the sum of the subsection conductance values. The PHX also uses the counter-flow heat exchanger model, but it is not discretized because the $\mathrm{CO}_{2}$ and salt properties do 
not change rapidly near the turbine inlet temperature. The air cooler is modeled as a triple-pass cross-flow heat exchanger by discretizing the geometry into subsections of equal physical dimensions. This allows tracking of the rapid change in $\mathrm{CO}_{2}$ properties due to temperature near the critical point. The air cooler and the PHX are designed with a target approach temperature, while the recompression fraction is a free parameter that is optimized to maximize cycle efficiency.

Following DOE guidance, the team utilized a power cycle model developed by NREL ${ }^{3}$. NREL implemented the model ${ }^{4}$ in $\mathrm{C}++$ as part of the SAM simulation core, and the ANU developed a Modelica class ${ }^{5}$ so that SolarTherm can access and run the power cycle model within the SAM simulation core based on the required system design parameters. Details of this model development can be found in [13], [14] and [15].

CSP plants frequently operate off design due to load demand and weather, and accurate off-design modeling is important for annual performance estimates. NREL implemented the off-design model as part of the SAM simulation core, but this detailed model is slow when compared to the models in SolarTherm. To speed simulations, a class with a surrogate $\operatorname{model}^{6}$ has been developed by the ASTRI team in SolarTherm to pre-process a fixed set of off-design conditions and then interpolate these data during the annual simulation using the Kriging method [16]. In this way, SolarTherm calculates the temperature and mass flow rate of the chloride salt at the inlet of the PHX and runs the surrogate model to calculate the off-design heat input and cycle thermal efficiency to obtain the gross power output and salt temperature at the outlet of the PHX. Figure 7 shows the absolute deviation of the SolarTherm output from data obtained by running the detailed off-design model from the SAM simulation core. The deviation of the heat input and the gross power output between the Kriging method in SolarTherm and the SAM power cycle model is within $0.5 \%$.
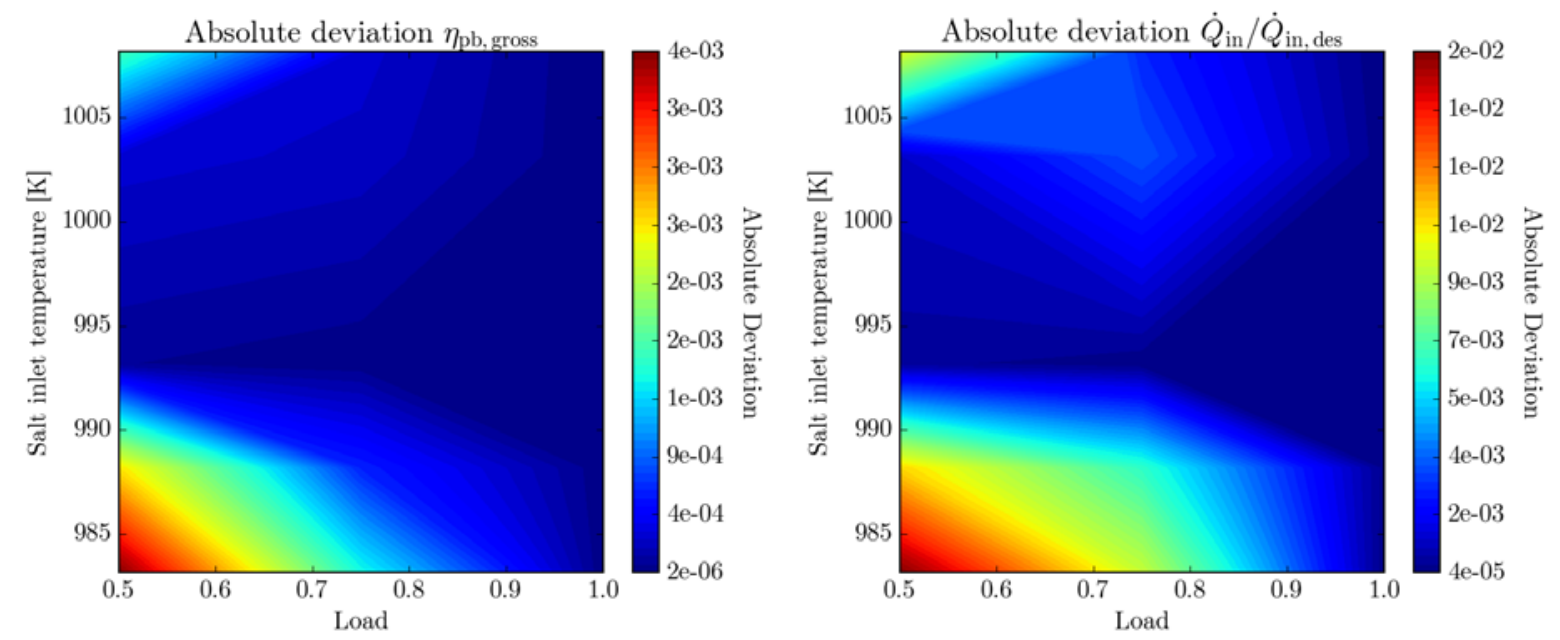

Figure 7. Absolute deviation of SolarTherm output from the detailed data generated from the SAM off-design model for (left) Power cycle gross efficiency and (right) off-design heat power fraction $\left(Q / Q_{\text {des }}\right)$. Ambient temperature $=40^{\circ} \mathrm{C}$.

Images courtesy of ANU

\footnotetext{
${ }^{3}$ Gen 3 CSP Topic $1-\mathrm{sCO}_{2}$ Cycle Modeling Assumptions and Boundary Conditions, issued 02/26/2019

${ }^{4}$ https://github.com/NREL/SAM/tree/develop/samples/CSP/sco2 analysis python V2

5 https://github.com/SolarTherm/SolarTherm/blob/na-salt-hx/SolarTherm/Utilities/designNRELPB.mo

${ }^{6}$ https://github.com/SolarTherm/SolarTherm/blob/na-salt-hx/SolarTherm/Utilities/Kriging OnTheFly.mo
} 
The model described above can be tuned to a target net efficiency. DOE considers $50 \%$ net efficiency at $100-\mathrm{MW}_{\mathrm{e}}$ scale. In scaling down to $50 \mathrm{MW}_{\mathrm{e}}$, it is necessary to account for turbomachinery efficiency decreases and the need for a gearbox. Power-cycle developer Echogen conducted a numerical study of cycle efficiency in support of their STEP Phase II application [personal communication, Tim Held, 10 Nov 2020]. According to Echogen, the main causes of the efficiency variation are turbomachinery and generator efficiency as a function of scale. The results of this study are used to de-rate the net design point power cycle efficiency used for our $50-\mathrm{MW}_{\mathrm{e}}$ scale by two percentage points, i.e., from the DOE stipulated $50 \%$ efficiency to $48 \%$.

\subsection{Commercial-Scale Component Cost Analysis}

Methodology (SolarTherm). Calculation of LCOE in this project was achieved using the ANU's SolarTherm software ${ }^{7}$. A verification of the SolarTherm model was presented at the Gen3 Receiver Down Selection meeting in Bellevue, WA on 26 Feb 2020. In this verification, the performance of a chloride salt system (no sodium) was compared against results from a model running against the NREL SAM code (Jan 2020 beta version). Short-term transients as well as aggregate annual output were carefully compared. Key points of difference arise due to the variable timestep of Modelica, compared to the fixed hourly timestep of SAM. Other minor differences were apparent in off-design power block performance. However, the difference in annual electrical output of the system was found to be less than $1.4 \%$, considered sufficient for the cross-model validation.

Next, the SolarTherm model, with some simplifications for computational efficiency, was examined via parameter sweeps on the solar multiple and storage hours to determine a lowestLCOE configuration. The full detailed model was also invoked via the Sandia DAKOTA tool to provide a sensitivity analysis in relation to cost parameters, using Latin hypercube sampling across the cost parameter ranges.

Commercial-scale cost assumptions. Cost data are drawn from a range of sources, including direct from industry partners, public reports, and where appropriate, from reference values provided by DOE (e.g., for heliostats and the power block). Table 3 summarizes key financial and cost inputs. Some values (where indicated) are reference values that relate to a system of a different scale, and in these cases the costs are adjusted in the SolarTherm implementation to be appropriate to the $50-\mathrm{MW}_{\mathrm{e}}$ scale using power law relationships. Upper and lower bounds are either specified as a value, with a rationale provided, or as a +/- percentage value based on estimates relative to the nominal value. Further information is given about all these assumptions in the descriptions below Table 3.

\footnotetext{
${ }^{7}$ https://github.com/SolarTherm/SolarTherm
} 
Table 3. Financial and cost inputs for commercial-scale LCOE estimate.

In most cases reference values are scaled to the specific conditions of the $50-\mathrm{MW}_{\mathrm{e}}$ commercial-scale designadditional details given in following text and via Folder 02-Calculations, Cost Calculations (see Table 32).

\begin{tabular}{|c|c|c|c|c|c|c|}
\hline & Unit & $\begin{array}{l}\text { Reference } \\
\text { value }\end{array}$ & $\begin{array}{l}\text { Value used } \\
\text { at } 50 \text { MWe } \\
\text { scale }\end{array}$ & $\begin{array}{l}\text { Lower } \\
\text { bound }\end{array}$ & $\begin{array}{l}\text { Upper } \\
\text { bound }\end{array}$ & Description \\
\hline \multicolumn{6}{|c|}{ Financial assumptions } & All from DOE Gen 3 Topic 1 Down select Criteria_Rev 0 Table 2 \\
\hline Periods & years & 30 & 30 & & & \\
\hline Discount rate, real & $\%$ & 4.4 & 4.4 & & & $\begin{array}{l}\text { Converted to real from nominal using the Fisher equation and } 7.01 \% \text { nominal } \\
\text { discount rate and } 2.5 \% \text { inflation from Table } 2 \text { (noted above) }\end{array}$ \\
\hline Fixed O\&M costs & $\$ / k W-y$ & 40 & 40 & & & \\
\hline Variable O\&M costs & $\$ / \mathrm{MWh}$ & 3 & 3 & & & \\
\hline Contingency & $\%$ & 10 & 10 & & & Applied to all costs \\
\hline EPC/owner cost & $\%$ & 9 & 9 & & & Applied to direct costs \\
\hline Land cost & \$acre & 10,000 & 10,000 & & & \\
\hline \multicolumn{7}{|l|}{ Heliostat field } \\
\hline Site improvements & $\$ / \mathrm{m}^{2}$ & 10 & 10 & $-25 \%$ & $+25 \%$ & DOE 2020 SunShot target, Table 5-1 \\
\hline Heliostats & $\$ / m^{2}$ & 75 & 75 & 50 & 100 & $\begin{array}{l}\text { Nominal value based on DOE } 2020 \text { SunShot target, Table 5-1, lower bound on } \\
\text { SunShot } 2030 \text { targets [17], upper bound on current prices [17]. }\end{array}$ \\
\hline Sodium receiver & & & & & & $\begin{array}{l}\text { Receiver cost scaling relationship dependent on diameter and height [18], } \\
\text { adjusted based on cost information from industry partner John Cockerill. }\end{array}$ \\
\hline $\begin{array}{l}\text { Receiver fixed cost } \\
\text { component }\end{array}$ & $\$$ & $4,780,420$ & $4,780,420$ & $-25 \%$ & $+25 \%$ & $\begin{array}{l}\text { Fixed cost for engineering, from [18], adjusted for inflation, then increased } 9.5 \% \\
\text { for } 740 \mathrm{H} \text { materials in header and piping, additional insulation, heat trace, post- } \\
\text { weld heat treatment, and includes receiver insulation. }\end{array}$ \\
\hline $\begin{array}{l}\text { Receiver size } \\
\text { dependent cost } \\
\text { component }\end{array}$ & $\$$ & & $21,480,230$ & $-25 \%$ & $+25 \%$ & $\begin{array}{l}\text { Reference value given as proprietary information from industry partner, inflation } \\
\text { adjusted and increased by } 9.5 \% \text { (as described above). Hence the size dependent } \\
\text { component is this amount, less the fixed cost component. }\end{array}$ \\
\hline \multicolumn{7}{|l|}{ Tower } \\
\hline Tower cost & $\$$ & $16,339,938$ & $16,339,938$ & 7.38E6 & $+25 \%$ & $\begin{array}{l}\text { Reference value comes from the SAM }(2020) \text { for a } 150-m \text { tower. The lower bound } \\
\text { is taken from a study by sbp [19] for a } 150-m \text { tower. }\end{array}$ \\
\hline \multicolumn{7}{|l|}{ Sodium loop } \\
\hline $\begin{array}{l}\text { Sodium valves, ref. } \\
\text { 565-MWe APOLLO } \\
\text { study }\end{array}$ & $\$$ & $1,269,000$ & 907,980 & $-25 \%$ & $+25 \%$ & $\begin{array}{l}\text { Valves are already included in the receiver costing listed above. This line item is } \\
\text { an allowance to account for additional valves due to additional flow paths, } \\
\text { estimated as half the valve cost in the SolarReserve APOLLO report [8]. }\end{array}$ \\
\hline Sump tank & $\$$ & $2,073,649$ & $1,252,129$ & $-25 \%$ & $+25 \%$ & Reference from John Cockerill for their $720-\mathrm{MW}_{\text {th }}$ sodium receiver case study \\
\hline Inlet vessel & $\$$ & 361,522 & 218,298 & $-25 \%$ & $+25 \%$ & Reference from John Cockerill for their $720-\mathrm{MW}_{\text {th }}$ sodium receiver case study. \\
\hline Purification skid & $\$$ & 494,309 & 298,479 & $-25 \%$ & $+25 \%$ & Reference from John Cockerill for their $720-\mathrm{MW}_{\text {th }}$ sodium receiver case study. \\
\hline
\end{tabular}




\begin{tabular}{|c|c|c|c|c|c|c|}
\hline Sodium pumps & $\$$ & $5,475,248$ & $3,800,633$ & $-25 \%$ & $+25 \%$ & $\begin{array}{l}\text { Reference is based on } 4 \times 33 \% \text { pumps at } € 1,121,977 \text { per pump, with costs taken } \\
\text { from a Budget Quotation from Sulzer for a cold salt pump, for the } 543 \mathrm{MW}_{\text {th }} \text { salt } \\
\text { pathway down-selection case. Casing, impeller \& shaft are Inconel } 625 \text {. Pump } \\
\text { manometric head is } 270 \mathrm{~m} \text {. Flow is } 1064 \mathrm{~m}^{3} / \mathrm{h} \text { per pump. Pumps have } 4 \text { stages. }\end{array}$ \\
\hline Argon system & $\$$ & 136,210 & 94,999 & $-25 \%$ & $+25 \%$ & Reference value is from John Cockerill for their $720-\mathrm{MW}_{\text {th }}$ receiver case study. \\
\hline $\begin{array}{l}\text { Instrumentation \& } \\
\text { Control }\end{array}$ & $\$$ & 417,000 & 328,314 & $-25 \%$ & $+25 \%$ & Reference from the SolarReserve APOLLO report [8] at $565 \mathrm{MW}_{\mathrm{e}}$ \\
\hline $\begin{array}{l}\text { Additional piping } \\
\text { allowance, ref. } 720 \\
\text { MWe John Cockerill } \\
\text { study }\end{array}$ & $\$$ & $2,000,000$ & $1,207,663$ & $-25 \%$ & $+25 \%$ & $\begin{array}{l}\text { Most piping costs in the receiver are already covered by the Atacama/John } \\
\text { Cockerill receiver reference cost. This is an additional allowance for larger } \\
\text { diameter piping. }\end{array}$ \\
\hline \multicolumn{6}{|l|}{ Sodium and salt piping } & $\begin{array}{l}\text { Piping materials costs calculated directly; balance of costs scaled linearly with } \\
\text { diameter based on reference costs for a } 28 \text { " diameter pipe. }\end{array}$ \\
\hline $\begin{array}{l}\text { Sodium riser/cold salt } \\
\text { piping material cost }\end{array}$ & $\$ / \mathrm{kg}$ & 8 & 8 & $-25 \%$ & $+25 \%$ & Material is austenitic stainless steel, cost information from John Cockerill \\
\hline $\begin{array}{l}\text { Sodium } \\
\text { downcomer/hot salt } \\
\text { piping material cost }\end{array}$ & $\$ / \mathrm{kg}$ & 80 & 80 & $-25 \%$ & $+25 \%$ & Material is a nickel superalloy, cost information from John Cockerill \\
\hline $\begin{array}{l}\text { Sodium riser/cold salt } \\
\text { piping balance of } \\
\text { costs, ref. } 28 \text { " pipe }\end{array}$ & $\$ / m$ & 5,595 & 5,192 & $-25 \%$ & $+25 \%$ & $\begin{array}{l}\text { Reference value is based on the } 28 \text { " downcomer in the Abengoa report [18], } \\
\text { excludes piping material but includes insulation, trace heat, installation, welds, } \\
\text { wastage, freight, materials handling, testing and inspection, hangers and } \\
\text { supports. }\end{array}$ \\
\hline $\begin{array}{l}\text { Sodium } \\
\text { downcomer/hot salt } \\
\text { piping balance of } \\
\text { costs, ref. } 28 \text { " pipe }\end{array}$ & $\$ / m$ & 8,502 & 7,890 & $-25 \%$ & $+25 \%$ & $\begin{array}{l}\text { As above for the riser, but costs of insulation, heat trace, fittings revised upwards } \\
\text { to account for the higher temperature }\end{array}$ \\
\hline \multicolumn{7}{|l|}{ Salt storage } \\
\hline Tank and salt costs & $\$ / \mathrm{kWh}_{\text {th }}$ & 39.5 & 39.5 & $-15 \%$ & $+15 \%$ & $\begin{array}{l}\text { NREL tank costing model (described below) set to a single tank pair, } 12 \text { hours } \\
\text { storage. Cost breakdown }(\$ / \mathrm{kWh}) \text { : salt } 13.3 \text {, cold tank } 12.6 \text {, hot tank } 13.5 \text {. }\end{array}$ \\
\hline Salt (included above) & $\$ / \mathrm{kg}$ & 0.70 & 0.70 & - & - & Delivered and melted salt based on prices from ICL, see Salt Cost Spreadsheet \\
\hline Cold salt pump & $\$$ & $3,994,270$ & $2,772,615$ & $-25 \%$ & $+25 \%$ & $\begin{array}{l}\text { Reference is based on } 4 \times 33 \% \text { pumps at } € 818,498 \text { per pump, with costs taken } \\
\text { from a Budget Quotation from Sulzer for a hot salt pump at } 543 \mathrm{MW}_{\text {th }} \text { scale. } \\
\text { Casing, impeller \& shaft are Inconel } 625 \text {. Reference pump manometric head is } \\
87.2 \mathrm{~m} \text { and flow is } 1014 \mathrm{~m}^{3} / \mathrm{hr} \text {. }\end{array}$ \\
\hline Hot salt pump & $\$$ & $2,995,703$ & $2,079,462$ & $-25 \%$ & $+25 \%$ & $\begin{array}{l}\text { Reference is based on } 3 \times 50 \% \text { pumps at } € 818,498 \text { per pump, with other details } \\
\text { as for cold salt pump above. }\end{array}$ \\
\hline Salt valves & $\$$ & $2,106,720$ & $2,106,720$ & $-25 \%$ & $+25 \%$ & $\begin{array}{l}\text { Reference based on seven control valves, each } \$ 300,960 \text { based on a } \$ 270 \mathrm{k} \\
\text { estimate by Flowserve for a } 10 " \text { globe valve with bellows seal made from } 316 \mathrm{H} \\
\text { and adding an extra cost allowance for upgrading to a nickel alloy. Installation } \\
\text { included with piping. }\end{array}$ \\
\hline
\end{tabular}




\begin{tabular}{|c|c|c|c|c|c|c|}
\hline $\begin{array}{l}\mathrm{N}_{2} \text { ullage gas system } \\
\text { (for salt) }\end{array}$ & $\$$ & $2,860,000$ & $2,860,000$ & $-25 \%$ & $+25 \%$ & $\begin{array}{l}\text { Reference is for pilot scale ullage gas piping \& installation scaled up for the } \\
\text { number of pumps in the commercial scale, plus commercial-scale acid-gas } \\
\text { scrubber, plus present value estimate for on-site } \mathrm{N}_{2} \text { production throughout } 30-\mathrm{yr} \\
\text { plant life. }\end{array}$ \\
\hline \multicolumn{7}{|l|}{ Power block and HEXs } \\
\hline $\begin{array}{l}\text { Sodium-salt HEX, ref. } \\
10,000 \mathrm{~m} 2 \text { from ANU } \\
\text { sodium receiver study }\end{array}$ & $\$ / \mathrm{m}^{2}$ & 1834 & 1,446 & $-25 \%$ & $+25 \%$ & $\begin{array}{l}\text { Assumes a two-stage heat exchanger, (stainless steel and Inconel). Costs based } \\
\text { on the CMI sodium study heat exchanger but adjusted as described further } \\
\text { below. }\end{array}$ \\
\hline Salt-CO2 PHX & $\$ / \mathrm{kW}_{\text {th }}$ & 229 & 266 & $-25 \%$ & $+25 \%$ & $\begin{array}{l}\text { Reference based on estimates from VPE, for } 110 \mathrm{MW} \text { th, dual core unit. Low-temp } \\
\text { core of stainless steel, high-temp core of alloy } 617 \text {. Installation costs equal } 21 \% \\
\text { of materials cost based on guidance from VPE as described below. }\end{array}$ \\
\hline sCO2 power block & $\$ / \mathrm{kW}_{\mathrm{e}}$ & 600 & 738 & $-25 \%$ & $+25 \%$ & $\begin{array}{l}\text { Reference is from the DOE for a } 100-\mathrm{MW}_{\mathrm{e}} \text { unit (DE-FOA-0001697, Figure 4). } \\
\text { Scaled to } 50-\mathrm{MW}_{\mathrm{e}} \text { by power law as described below. }\end{array}$ \\
\hline
\end{tabular}


Sodium receiver. The commercial-scale receiver design is discussed in $\S 4.8 .1$. Here we focus on the costing of that unit. The team began with a bottom-up costing exercise for the receiver panels; however, based on information from John Cockerill, the total panel cost is typically only about $20-25 \%$ of the total receiver costs, once other items are included, namely structural steel, valves, tanks, pipe hangers, instrumentation, electrical, lifting system, heat tracing, additional piping, transport, project management, insurance and travel. These bottom-up estimates were useful for comparing different receiver concepts, e.g., salt vs. sodium and cylindrical vs. cavity, but given the large non-panel cost fraction, it was felt that too much uncertainty was introduced from the bottom-up costing approach.

Commercial receiver developer John Cockerill shared data with the team concerning its 720$\mathrm{MW}_{\text {th }}$ receiver that is installed at Cerro Dominador in Chile. This is an external cylindrical receiver, with 'solar salt' as the working fluid and dimensions of 20-m diameter x 18.4-m high. The Atacama receiver panels are made from alloy H230, with SS 347H headers and piping. The cost details for this receiver are proprietary, but the information was used to benchmark the sodium receiver design and cost. This receiver has been chosen as a reference case receiver cost in a top-down costing for the current project. However, it is necessary to make some adjustments to the reference case costs for several reasons:

- The headers and piping are upgraded to Ni alloy. Approximately 9 tonnes header mass is calculated for the reference case, and it is assumed that there is an equivalent mass in piping within the receiver. The material cost is calculated from the difference in cost of nickel alloy $(\$ 80 / \mathrm{kg})$ to austenitic stainless steel $(\$ 8 / \mathrm{kg})$, to estimate an additional $3.7 \%$ overall in receiver material cost.

- It is assumed that insulation is $50 \%$ more costly due to the higher temperature range. John Cockerill indicates cost of insulation is about 3\% overall, thus a further $1.5 \%$ is added.

- An additional $0.5 \%$ is added to account for heat trace that can tolerate higher temperature.

- Based on discussions involving John Cockerill, EPRI and Special Metals, it is assumed that post-weld heat treatment can be done on a fully assembled panel. This is necessary for the material selected, Alloy $740 \mathrm{H}$. A $1 \%$ allowance on overall costs is made for the post-weld heat treatment.

- John Cockerill receiver costs exclude installation, and thus a $\$ 1$ million allowance is made, or around $2.8 \%$ of overall costs.

- It is assumed that the cost of $740 \mathrm{H}$ is equivalent to the Haynes 230 used in the Atacama receiver. This assumption is consistent with a quote obtained from Rath Gibson for a large-scale order of $740 \mathrm{H}$ (quote \# 3985789).

Overall these adjustments take the sodium receiver reference cost to $\$ 40.2$ million (at $720 \mathrm{MW}_{\text {th }}$ scale). Next it is necessary to adopt a relationship to adjust the costs depending on the size or capacity of the receiver. Several approaches from other work were considered, including the method in SAM (power law scaling based on receiver area) and the approach taken by Abengoa in [18]. In this study it is argued that "increases in diameter would require additional welds and perhaps panels, while increases in length would simply require longer tubes and a simple increase in the support structure". The resulting scaling expression is as follows: 


$$
C_{r e c}=C_{\text {rec-fixed }}+C_{\text {rec-size }} \times \frac{D}{D_{\text {ref }}} \times\left(\frac{H}{H_{\text {ref }}}\right)^{0.6}
$$

where $C_{\text {rec-fixed }}$ is a fixed cost for engineering and $C_{r e c-s i z e}$ the size-dependent remainder of receiver costs for the reference case. For scaling, the costs relating to the $C_{\text {rec-size }}$ component are scaled linearly with diameter $D$ relative to the reference receiver diameter $D_{r e f}$, and using a power law relationship with exponent 0.6 for height $H$, relative to the reference height $H_{r e f}$. The reasons given by Abengoa for this scaling relationship are consistent with our understanding of cost drivers from discussions with industry partners, and thus this expression is adopted for scaling receiver costs in the present study, using directly calculate receiver size, the reference dimensions of the Atacama receiver, and reference cost values based on the adjusted Atacama receiver costs, split into $C_{\text {rec-fixed }}$ and $C_{\text {rec-size }}$ as given in Table 3.

Riser and downcomer. Riser and downcomer costs are based on detailed information given in the Abengoa study [18], which splits costs into the following categories: Insulation, Heat Trace, Pipe \& Fittings, Welds, Wastage, Freight, Materials Handling, Testing \& Inspection, and Hangars \& Supports.

The basis of these reference costs is the 28" diameter, Schedule 20, SS347H downcomer the Abengoa design. The materials planned for the sodium riser and downcomer are SS316 and Alloy $740 \mathrm{H}$, respectively. The cost data for the $347 \mathrm{H}$ downcomer (excluding pipe material costs) in the Abengoa study is used for the sodium riser, as it is at a similar temperature and has similar dimensions. The balance-of-costs are expressed in $\$ / \mathrm{m}$ for the 28 " reference diameter as per Table 3, and then scaled linearly by diameter/reference diameter to suit the design pipe size. For the sodium downcomer, the temperature is higher than the downcomer in the Abengoa report, and thus the balance-of-costs are revised upwards, multiplying by a factor of $1.5 \mathrm{x}$ for insulation, $4 \mathrm{x}$ for heat trace, and $1.05 \mathrm{x}$ for fittings.

Pipe material costs (SS316 and Alloy 740H) are calculated directly for the Gen3 design case. The length is set by the vertical height of the tower $(150 \mathrm{~m})$ and a further $10-\mathrm{m}$ horizontal distance, noting the heat exchanger is located close to the base of the tower (see Figure 1). A length scaling factor is then applied to account for expansion loops, based on the ASME B31.3 $\mathrm{K}<0.003$ rule, as given in Table 3 .

Tower. The decision to select $2 \times 50 \mathrm{MW}_{\mathrm{e}}$-scale towers was in part influenced by consideration of tower technologies, and opportunities for cost reduction afforded by alternative methods of tower construction applicable to shorter towers. Schlaich Bergermann Partner (sbp) published two recent SolarPACES studies discussing alternative tower technologies. The first of these, Weinrebe et [19] provides an alternative cost curve for tower technologies, significantly lower in cost than the commonly used relationship used in SAM. Little detail is provided about the basis of this curve, although it was mentioned that it was determined "by designing, dimensioning and costing three towers. Design and cost data are based on our sister company's 30 year+ experience in the structural engineering of special structures including towers". In a second publication by Burghartz [20] and in a Masters thesis by the first author [21] (kindly translated from German by sbp and provided to the Gen3 CSP Liquids Pathway team), a comparative design study was made of five different tower technologies (Figure 8). The larger diameter concrete tower (a) performed 
best in terms of rigidity and low deflections, as well as having the advantage of a short construction time. Lowest cost was found with the three-legged hybrid (d) tower and the cablestayed (e) tower, at around half the cost of the concrete tube towers.

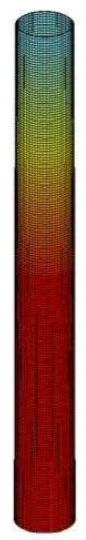

a)

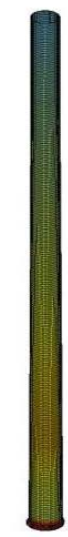

b)

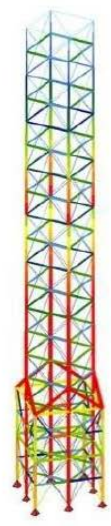

c)

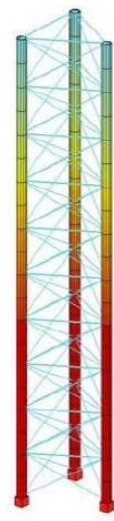

d)

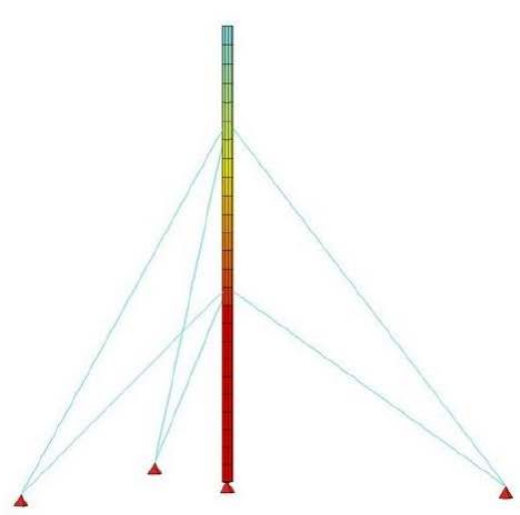

e)

Figure 8. Tower designs investigated by sbp: (a) concrete tube, diameter $22 \mathrm{~m}$; (b) concrete tube, diameter $15 \mathrm{~m}$; (c) lattice steel tower with socket; (d) three-leg hybrid tower with concrete columns and steel bracings; (e) cable-stayed concrete tube with two layers of cables [20].

Another study by Peterseim et al. [22] also examined a 135-m cable stayed concept, at the 50$\mathrm{MW}_{\mathrm{e}}$ scale. It was argued that this technology could cut installation time from three months to one month, and cost $20-40 \%$ less than a conventional concrete tower. Being 6-m wide, it was mentioned that the tower could be manufactured offsite and transported by road as a cost saving measure. Erection methods inspired by large wind turbines and refinery columns were discussed. This type of technology has already been deployed in a pilot scale CSP plant by Aora in Israel, albeit at a height of only $35 \mathrm{~m}$.

Potentially, shorter towers may leverage technologies developed for wind turbines. Towers up to around $160 \mathrm{~m}$ in height are being discussed for next-generation wind turbines [23]. Fully steel lattice tower constructions, widely used for large transmission pylons, may become costeffective for towers of this height, noting the metal-lattice towers at the Ivanpah plant are $140 \mathrm{~m}$ high. In this study, a conservative basis was taken for the nominal value of tower $\operatorname{cost} C_{t}$, based on the SAM relationship which is:

$$
C_{t}=C_{t, \text { fixed }} \times \exp \left(a \times H_{t}\right)
$$

where $C_{t, f i x e d}$ is the fixed tower cost of $\$ 3$ million, the scaling exponent $a$ is 0.0113 and $H_{t}$ is the tower height of $150 \mathrm{~m}$, to give a tower cost of $\$ 16.3$ million. Shorter towers are very likely to open alternative, lower cost construction methods. Therefore the lower bound cost was taken from the relationship published by spb [19], which when fitted to Equation (2), gives values for $C_{t, f i x e d}$ and $a$ of $\$ 2.7$ million and 0.00671 respectively, and a resulting tower cost of $\$ 7.4$ million.

Sodium flow loop costs. In 2016, John Cockerill (then CMI) undertook a study of the feasibility of a full scale sodium receiver, by modifying their existing molten-salt receiver design, with the work published internally as a Masters thesis by a student intern [24]. The work was shared with 
the ANU, and permission has been granted by John Cockerill to use selected information to support the Liquid Pathway proposal. The study included a simplified scale-down of the salt receiver (to allow higher flux), and development of a design for a sodium loop integrated at the top of the tower. As part of this study, John Cockerill approached the market to obtain quotes for the key components shown in Figure 9. This information forms the basis of our current costing of the sodium loop.

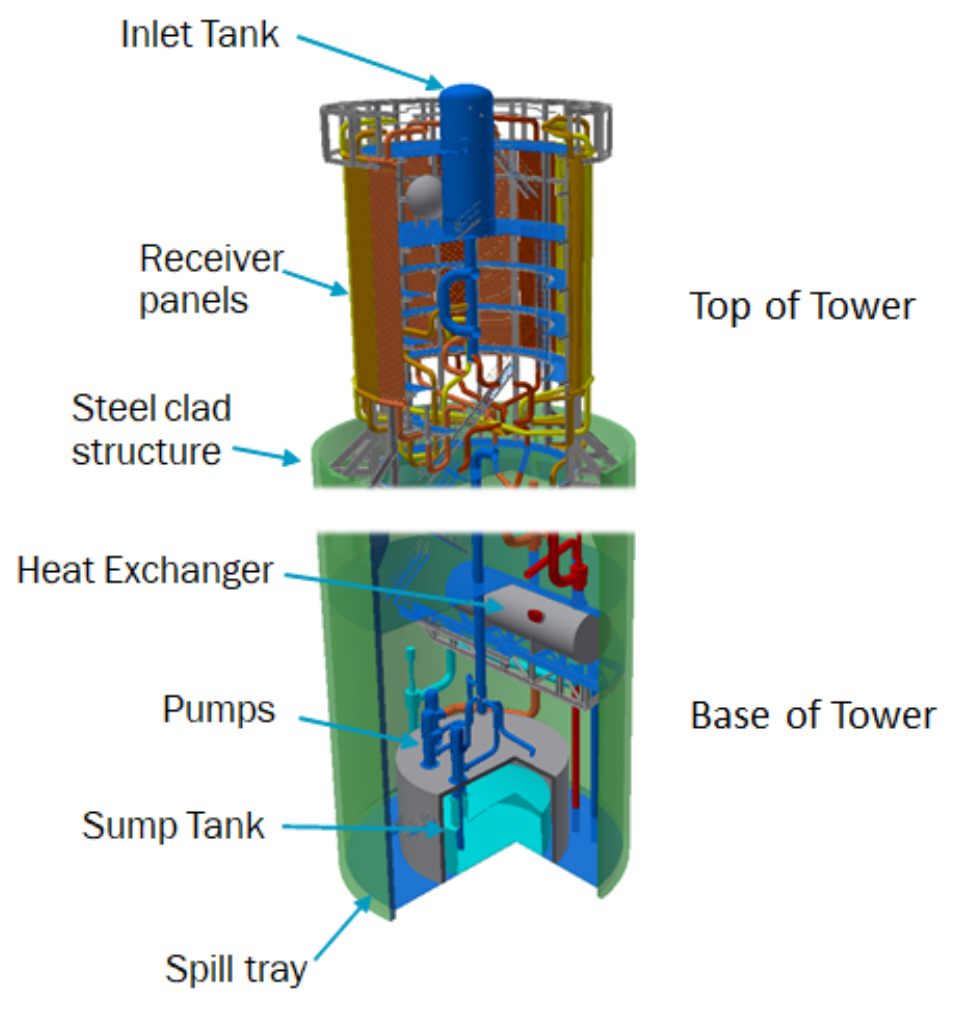

Figure 9. Sodium receiver concept adapted from John Cockerill [24]. While the referenced study placed all components at the top of the tower, the Liquid Pathway design locates the heat exchanger, pumps and sump tank adjacent to the base of the tower (as depicted in Figure 6).

The scale of the design was the same as John Cockerill's Atacama receiver $\left(720 \mathrm{MW}_{\text {th }}\right)$. Costs were shared for the sump tank, inlet tank, argon system and purification skid (cold trap), and inflation adjusted using the CEPCI index (2016 to Jun2020). These form the reference costs in Table 3. Costs are scaled using a power law with exponent 0.7 in all cases except for the argon system, which is assumed to have more fixed cost components and an exponent of 0.5 is used.

It is expected a commercial-scale mechanical sodium pump will have similar complexity and materials to a salt pump, and thus the cost estimate is based on data provided by Sulzer for a cold salt pump, originally intended to lift molten salt the full tower height of a single tower (salt configuration taken to down-selection). This pump configuration has 4 × 33\% pumps, each costing $€ 1,121,977$ per pump. Casing, impeller \& shaft are Inconel 625 , pump manometric head $270 \mathrm{~m}$, flow $1064 \mathrm{~m}^{3} / \mathrm{hr}$, and the pump has four bowls (i.e., a 4-stage pump). The detailed data sheet can be found in Contractor \& Collaborator Reports (see Table 32). 
Valves already form part of the reference receiver cost, based on the Atacama receiver. However, the Gen3 design has four flow paths rather than two, so an additional allowance is made for more valves. The valve costs of $\$ 2.5$ million from the SolarReserve APOLLO study [8] are used as a basis for the estimate. This receiver has 12 parallel flow paths hence 12 control valves, plus more stringent requirements for temperature monitoring/control due to the chloride salt working fluid, so likely to be on the upper end of valve costs. Thus, the additional cost allowance is estimated as half this figure.

Similarly, piping within the receiver is part of the reference receiver cost, based on the Atacama receiver. However, because the Atacama receiver was a salt receiver, we assume some additional cost in a sodium loop due to increased pipe diameter (due to lower $C p$ ) and additional lengths due to addition sodium equipment such as the cold trap, estimated as \$2 million extra.

Finally, we assume an additional allowance for instrumentation and control (I\&C) relating to sodium equipment, using as the reference value the I\&C estimate from the APOLLO study, and using a 0.5 exponent for the power law scaling as much of this will be scale independent cost.

Sodium-Salt heat exchanger cost. The sodium-salt heat exchanger estimates are based on costings for the $543 \mathrm{MW}_{\text {th }}$ down-selection case. Two heat exchangers are connected in series, with the first heat exchanger in stainless steel $(316$ or $347 \mathrm{H})$, and the second heat exchanger in Inconel $(\mathrm{H} 230$ or $740 \mathrm{H})$. The total size of sodium-salt heat exchanger for the $543-\mathrm{MW}_{\text {th }}$ system is approximately $10,000 \mathrm{~m}^{2}$ based on the Master's thesis of Guccione [25], and it is assumed that this area is divided evenly between the stainless steel and nickel alloy heat exchangers.

The cost estimate for the stainless steel heat exchanger is based on the John Cockerill (then CMI) 2016 study of a full scale sodium receiver [24]. The CMI study included a 5370- $\mathrm{m}^{2}$ stainless steel shell and tube sodium-salt heat exchanger, with a $60^{\circ} \mathrm{C}$ pinch point, and operating at lower temperatures than those for the Gen3 system. The cost estimate for this heat exchanger was $\$ 5.5$ million, which included $\$ 1$ million of engineering. Allowing for CEPCI index adjustment to June 2020 , the cost per square meter for this heat exchanger is $\$ 1054$. This cost per square meter is used for the costing of the stainless steel heat exchanger in the current costing exercise (and using a 0.7 exponent for the power law scaling), with the area of the heat exchanger determined in SolarTherm.

To obtain an estimate for the nickel alloy heat exchanger in the 543-MW $\mathrm{MW}_{\text {th }}$ system, the CMI study heat exchanger costs were adjusted due to different size (assumed to scale linearly with area), material (347H@ @8/kg changed to alloy $230 @ \$ 80 / \mathrm{kg}$ ), and an assumed increase in fabrication costs for the nickel alloy material. Engineering costs were assumed to be the same as the CMI study, and the total costs and engineering costs were adjusted for inflation adjusted using the CEPCI index (2016-Jun2020). It was assumed that 15\% of the CMI study heat exchanger costs were metal material costs, with the remaining $85 \%$ incorporating the fabrication and assembly costs and other balance of plant items such as insulation, electrical, etc. For the fabrication and balance of plant costs, it was assumed these also scale linearly with area and increase by $50 \%$ due to the increased costs associated with nickel alloy fabrication, as well increased costs due to the higher temperature requirements such as insulation and heat tracing. 
The total cost per square meter for the nickel alloy heat exchanger in the 543-MW $\mathrm{MW}_{\text {th }}$ sodium-salt system was $\$ 2614 / \mathrm{m}^{2}$. This cost per square meter is used as the basis of the nickel alloy heat exchanger costs for the current costing exercise (and using a 0.7 exponent for the power law scaling), with the area of the heat exchanger determined in SolarTherm.

Salt-to-sCO $\boldsymbol{O}_{2} \boldsymbol{P H X}$ cost. The 110-MW th PHX is a PCHE design, divided into two sections: a lowtemperature stainless steel core (SS316) and a high-temperature Ni-alloy core (alloy 617). Based on estimates from project member VPE, the material costs are estimated as \$4.3 million for a 54 $\mathrm{MW}_{\text {th }}$ low-temp section and $\$ 16.5$ million for a $56 \mathrm{MW}_{\text {th }}$ high-temp section. Installation costs assume a labor-to-materials ratio based on a shell-and-tube steam generation PHX from SAM2013, divided by three because a PCHE for salt-to-sCO $\mathrm{CO}_{2}$ heat transfer is considerably smaller and lighter than a shell-and-tube unit for steam generation and superheat (advice from VPE). The resulting multiplier for the PCHE installation was $21 \%$ of materials cost.

Commercial-scale Gen3 salt tank cost. The tank cost model is based on a spreadsheet developed by project partner SolarReserve and shared with NREL prior to them declaring bankruptcy and withdrawing from the project in 2019. SolarReserve's tank cost model was developed for current nitrate salt conditions but provides a useful starting point for the Gen 3 cost model. For example, the carbon-steel shell and foundation for the internally insulated Gen3 tank designs can be compared with the low temperature nitrate-salt tank (Gen2) design. Building on the SolarReserve spreadsheet, a cost model for the Gen3 lined-tank design was developed by NREL using information from JT Thorpe for refractory material and labor costs for the specific refractory materials and barrier design being proposed. The tank cost was also informed by the Phase 1 report from Job Industrial that provided an estimate of the commercial-scale internally insulated tank design. A breakdown of the costs of each component is shown in Figure 10, which yields a thermal energy storage cost of $\$ 39.5 / \mathrm{kWh}_{\text {th. }}$. Further details can be found in Folder 02Calculations, Cost Calculations, Commercial-Scale System (see Table 32).

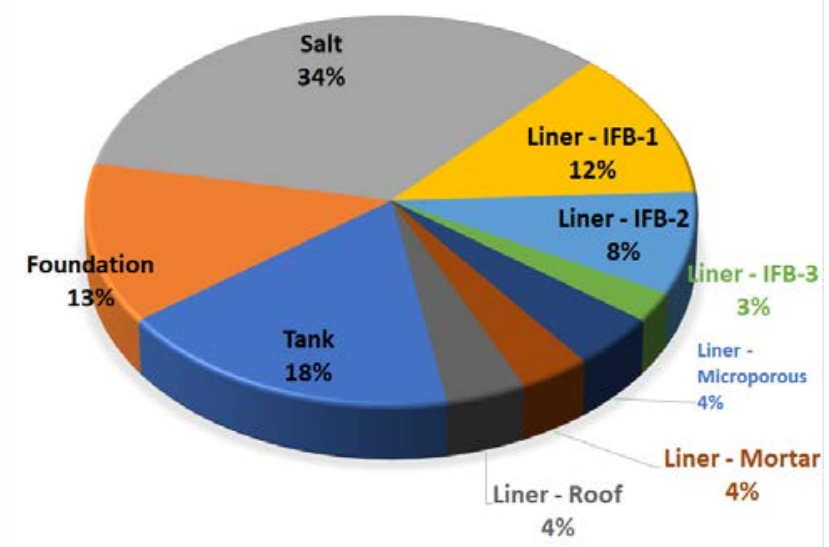

Figure 10. Breakdown of costs for internally insulated, carbon-steel salt tanks. The cost is split roughly evenly between the salt, the refractory liner, and the tank shell and foundation.

Project partner ICL estimated delivered cost for anhydrous carnallite (AC) - the primary feedstock for the ternary-chloride storage salt — as $\$ 485 /$ tonne plus $\$ 120 /$ tonne for shipping (Israel to San Diego) at a 50,000 tonne scale. When blended with a small amount of halite $(\mathrm{NaCl})$ and melted the estimated cost is just under $\$ 700 /$ tonne $(\$ 0.70 / \mathrm{kg})$, see Table 4. 
Table 4. Estimated cost for melted salt at a representative commercial-plant scale

\begin{tabular}{|c|c|c|c|}
\hline \multicolumn{4}{|c|}{ Salt inventory 45,850 tonnes from Gen 3 Tank Spreadsheet rev18 (compare to 47,014 tonnes from Table 12 in Gen 3 Roadmap) } \\
\hline Total inventory of Salt (tonne) & 45,850 & \multicolumn{2}{|c|}{ For $2 \times 50 \mathrm{MWe}$, net units } \\
\hline Salt loss during melting & $5.0 \%$ & \multicolumn{2}{|c|}{$\mathrm{HCl}+$ moisture release and $\mathrm{MgO}$ sludge } \\
\hline Cost of Salt loaded into Tanks & MT & Cost (\$/MT) & Cost (\$) \\
\hline AC & 40,828 & 485 & $19,801,567$ \\
\hline Halite & 7,263 & 50 & 363,132 \\
\hline Shipping (AC from Israel, $\mathrm{NaCl}$ from Chile) & & & $5,335,115$ \\
\hline $\mathrm{Mg}$ & 46 & 2220 & 101,787 \\
\hline Melter (amortized cost) & & 56 & $2,690,349$ \\
\hline \multirow[t]{2}{*}{ Melting (power cost) } & 48,136 & 47 & $2,264,837$ \\
\hline & & & $30,556,789$ \\
\hline Cost accounting for losses during melting ( $5 \%$ ) & & & $32,084,628$ \\
\hline Cost per tonne & & & 699.8 \\
\hline
\end{tabular}

Costs for salt melting are based on the protocol discussed in $\S 4.1 .1$. Specific power costs are taken from the power consumption per tonne estimated for the 1 tonne/h pilot-scale melter. The commercial-scale melter capital cost is scaled up 16-fold from the pilot scale using a 0.7 exponent for the power law scaling. The capital cost is amortized over 20 units. At this capacity, the commercial-scale system would require about 60 days to melt the salt for a single $50-\mathrm{MW}_{\mathrm{e}}$ unit.

Salt pump, piping and valve costs. Reference pump costs are taken from a Budget Quotation from Sulzer done for the 543-MW th scale single-tower chloride salt configuration considered at the sodium-salt down selection, with costs $€ 818,498$ per pump (approx. $\$ 1.00$ million). It is assumed the material of construction for the casing, impellor and shaft (quoted for Inconel 625) is the same for both hot and cold pumps. The reference pump is a single stage pump with manometric head $87.2 \mathrm{~m}$, and flow $1064 \mathrm{~m}^{3} / \mathrm{hr}$. Full details can be found on the datasheet from Sulzer (Folder 12-Project Reports, Salt Pumps, see Table 32). The pumps for the 50-MW commercial system are assumed to have the same head requirement, but proportionally lower flow requirement. The cold side, with its higher overall flow requirements is configured in a $4 \mathrm{x}$ $33 \%$ pump arrangement, and the hot side is a $3 \times 50 \%$ arrangement.

Pricing the molten salt valves was obtained from Flowserve, based on their current nitrate salt valves and $R \& D$ on chloride salt valves. Based on the Abengoa study [18], 17 salt valves were specified for a two-tower system including the riser, downcomer and receiver sections. The Gen3 commercial design assumes seven salt valves for a single $50-\mathrm{MW}_{\mathrm{e}}$ tower, acknowledging that salt flows only to the sodium-salt HX at the base of the tower. Using the Flowserve estimate of $\$ 270 \mathrm{k}$ for 10" globe valves with bellows seals, and adding an additional allowance of \$31k assuming use of Ni alloy rather than SS316 (and at typical valve mass of 430kg for a 10" globe valve $^{8}$ ) indicates a salt valve cost aggregating to $\$ 2.12$ million.

There is assumed to be $20 \mathrm{~m}$ of horizontal piping, plus expansion loops, in each direction between the salt storage tanks and the sodium-salt heat exchanger, and a further $10 \mathrm{~m}$ of horizontal piping, plus expansion loops, in each direction between the salt storage tanks and the

${ }^{8}$ https://www.scribd.com/document/463887811/Tyical-Weight-for-Gate-and-Globe-Valves 
PHX that is mounted between the tanks. The salt piping is sized according to ASME B31.1, and uses the same cost assumptions described above for the riser and downcomer are used to estimate the cost of this piping.

Salt ullage gas system cost. The salt pumps require a continual sweep of heated nitrogen gas to protect pump components from possible salt vapor deposition and freezing. In the pilot unit this gas sweep rate is approximately $5 \mathrm{scfm}\left(8 \mathrm{Nm}^{3} / \mathrm{h}\right)$ per pump. Including other nitrogen use and the two pumps bring the pilot-scale consumption rate to $15 \mathrm{scfm}\left(24 \mathrm{Nm}^{3} / \mathrm{h}\right)$. Based on input from the team's salt pump experts, the estimated sweep rate is independent of pump size. Thus, the nitrogen ullage gas system size and consumption rate for the commercial system is sized based on the number of pumps (seven) for the commercial system versus the two pumps in the pilot scale system. Ullage gas piping cost is scaled up by $(7 / 2)^{\wedge} 0.7$. Ullage gas system controls cost are added without scaling. Nitrogen supply is assumed to be an operating cost. This is accounted for in the LCOE by estimating the present value of the of the nitrogen consumption rate assuming on-site nitrogen cost of $\$ 0.21$ per $100 \mathrm{ft}^{3}$ [26], indexed to 2019 and added to the system CAPEX.

The ullage gas system includes an acid gas scrubber to prevent emissions of possible $\mathrm{HCl}$ or salt vapors. This scrubber is used during initial salt melting and later for scrubbing of the vented ullage gases. Turnkey acid-gas scrubber systems are available from numerous suppliers. The system is oversized to allow for dilution air to cool the incoming ullage gas. The system cost is estimated from EconExpert software for a 1-m diameter packed-bed column. Auxiliary equipment is included in the cost.

Power cycle cost. The CSP Gen3 program has set a cost target of $\$ 600 / \mathrm{kWe}$ for a $100-\mathrm{MW}_{\mathrm{e}}$ supercritical $\mathrm{CO}_{2}$ recompression Brayton cycle. Compared to the recompression cycle, the extra compressor in the partial-cooling configuration is offset by smaller recuperators. Accordingly, is it assumed that the partial-cooling cycle can achieve the same cost-per-capacity as the recompression configuration at the same scale. The specific-capacity cost is scaled to the smaller size using a using a 0.7 exponent for the power law scaling. This results in a power cycle cost of $\$ 738 / \mathrm{kWe}$ at the $50-\mathrm{MW}_{\mathrm{e}}$ scale. Scale impacts to cycle performance were discussed in $\$ 3.1$.

\subsection{System Simulation and LCOE Results}

Annual performance, total system costs, and the consequent LCOE for the commercial-scale system have been calculated and are presented in this section. The system performance model, component costs and financial parameters are described in the sections immediately above. The commercial-scale system consists of two fully duplicated 50-MWe systems, built side-by-side, to form a $100-\mathrm{MW}_{\mathrm{e}}$ complex. The two towers would share administration facilities, control room, and O\&M staff. These potential savings are not captured in the costing as the estimate is made for a complete $50-\mathrm{MW}_{\mathrm{e}}$ unit and then doubled for the two-tower complex. The $50-\mathrm{MW}_{\mathrm{e}}$ unit is described in Table 5. The breakdown of capital costs is shown in Figure 11, with values and subtotals also reproduced in Table 6. 
Table 5. High-level performance and cost parameters for the $50-\mathrm{MW}_{\mathrm{e}}$ unit

\begin{tabular}{|c|c|}
\hline Item & $50 \mathrm{MW}_{\mathrm{e}}$ module \\
\hline Energy per year (MWh): & 391,982 \\
\hline Capacity factor (\%): & 89.5 \\
\hline Receiver thermal input at design point $\left(\mathrm{MW}_{\mathrm{th}}\right)$ : & 385 \\
\hline Receiver thermal output at design point $\left(\mathrm{MW}_{\mathrm{th}}\right)$ : & 350 \\
\hline Annual field efficiency (\%) & 48.0 \\
\hline Annual solar to thermal efficiency (\%): & 41.3 \\
\hline Annual solar to electric efficiency (\%): & 19.3 \\
\hline $\begin{array}{l}\text { Power block gross rating at design point } \\
\left(\mathrm{MW}_{\mathrm{e}}\right) \text { : }\end{array}$ & 55.6 \\
\hline Power block efficiency at design point (\%): & 47.9 \\
\hline Full load hours of storage (h): & 12.0 \\
\hline Storage capacity $\left(\mathrm{MWh}_{\mathrm{t}}\right)$ : & 1,393 \\
\hline Total salt inventory, working and heel (tonnes): & 22,925 \\
\hline Solar multiple: & 3.0 \\
\hline Receiver diameter $(\mathrm{m})$ : & 14.0 \\
\hline Receiver height (m): & 14.5 \\
\hline Tower height $(\mathrm{m})$ : & 150 \\
\hline Number of heliostats: & 14,461 \\
\hline Number of heliostats per module: & 14,461 \\
\hline Single heliostat mirror area $\left(\mathrm{m}^{2}\right)$ : & 50.0 \\
\hline Total field area $\left(\mathrm{m}^{2}\right)$ : & 722,832 \\
\hline
\end{tabular}




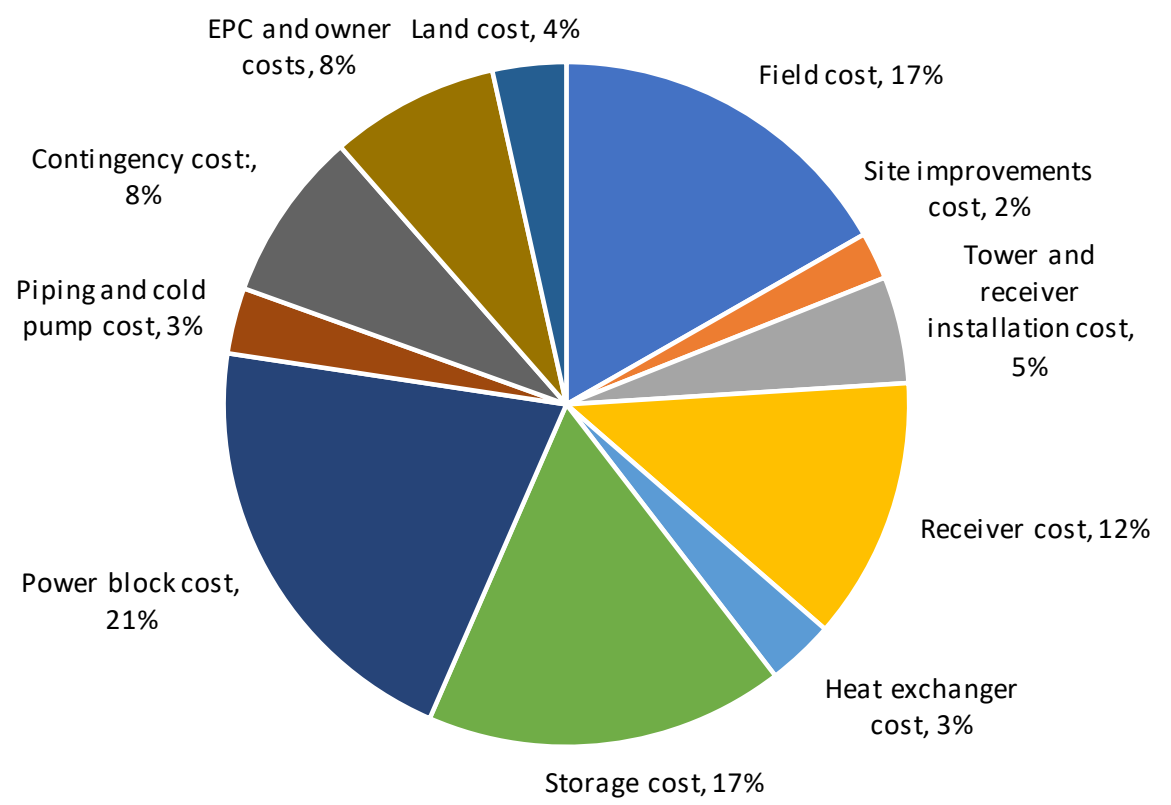

Figure 11. Breakdown of the total capital costs for the commercial-scale sodium-salt tower $2 \times 50$ $\mathrm{MW}_{\mathrm{e}}$ system

The commercial-scale system achieves a capacity factor of $89.5 \%$, an annual field efficiency of $48.0 \%$, and an annual solar-to-electric efficiency of $19.3 \%$. The high capacity factor of the system is reached through the $14 \%$ oversizing of the field relative to the receiver at the equinox noon design point Meanwhile, significant curtailment of the heliostat field results in relatively low annual field efficiency, solar-to-thermal efficiency and solar-to-electric efficiency. However, this is found to be beneficial due to the improved utilization turbine, storage and receiver and storage. The performance parameters for the commercial-scale system can be seen in Table 5 . Total capital cost (installed) of the two-tower complex is $\$ 650$ million.

Table 6. Capital cost breakdown for the commercial system. All costs in USD.

\begin{tabular}{|c|c|c|c|}
\hline \multicolumn{2}{|l|}{ Item } & $\begin{array}{l}1 \times 50 \mathrm{MWe} \\
\text { module }\end{array}$ & $\begin{array}{l}100 \mathrm{MWe}_{\mathrm{e}} \text { system } \\
(2 \times 50 \mathrm{MW})\end{array}$ \\
\hline \multicolumn{4}{|c|}{ Heliostat field } \\
\hline & Heliostats & $\$ 54,212,373$ & $\$ 108,424,746$ \\
\hline & Site improvements & $\$ 7,228,316$ & $\$ 14,456,633$ \\
\hline \multicolumn{2}{|c|}{ Sodium receiver } & $\$ 26,260,650$ & $\$ 52,521,300$ \\
\hline \multicolumn{2}{|l|}{ Tower } & $\$ 16,339,938$ & $\$ 32,679,876$ \\
\hline \multicolumn{4}{|c|}{ Sodium loop } \\
\hline & Sodium valves & $\$ 907,980$ & $\$ 1,815,960$ \\
\hline & Sump tank & $\$ 1,252,129$ & $\$ 2,504,259$ \\
\hline & Inlet vessel & $\$ 218,298$ & $\$ 436,597$ \\
\hline & Purification skid & $\$ 298,479$ & $\$ 596,959$ \\
\hline
\end{tabular}




\begin{tabular}{|c|c|c|c|}
\hline \multicolumn{2}{|l|}{ Item } & $\begin{array}{l}1 \times 50 \mathrm{MWe}_{\mathrm{e}} \\
\text { module }\end{array}$ & $\begin{array}{l}100 \mathrm{MWe}_{\mathrm{e}} \text { system } \\
(2 \times 50 \mathrm{MW})\end{array}$ \\
\hline & Sodium pumps & $\$ 3,800,633$ & $\$ 7,601,267$ \\
\hline & Argon system & $\$ 94,999$ & $\$ 189,999$ \\
\hline & Instrumentation and control & $\$ 328,314$ & $\$ 656,628$ \\
\hline & Additional sodium piping & $\$ 1,207,663$ & $\$ 2,415,326$ \\
\hline \multicolumn{4}{|c|}{ Sodium and salt piping } \\
\hline & Riser $^{\dagger}$ & $\$ 1,426,598$ & $\$ 2,853,197$ \\
\hline & Downcomer ${ }^{\dagger}$ & $\$ 4,533,284$ & $\$ 9,066,568$ \\
\hline & Salt piping & $\$ 697,596$ & $\$ 1,395,192$ \\
\hline \multicolumn{4}{|l|}{ Salt storage } \\
\hline & Tank and salt costs & $\$ 54,968,250$ & $\$ 109,936,501$ \\
\hline & Cold salt pump & $\$ 2,772,615$ & $\$ 5,545,230$ \\
\hline & Hot salt pump & $\$ 2,079,462$ & $\$ 4,158,924$ \\
\hline & Salt valves & $\$ 2,106,720$ & $\$ 4,213,440$ \\
\hline & $\mathrm{N}_{2}$ ullage gas system & $\$ 2,860,000$ & $\$ 5,720,000$ \\
\hline \multicolumn{4}{|c|}{ Power block and HXs } \\
\hline & Sodium-to-salt HX & $\$ 10,290,385$ & $\$ 20,580,770$ \\
\hline & Salt-to- $\mathrm{CO}_{2} \mathrm{PHX}$ & $\$ 26,576,576$ & $\$ 53,153,151$ \\
\hline & $\mathrm{s}-\mathrm{CO}_{2}$ power block & $\$ 41,025,831$ & $\$ 82,051,663$ \\
\hline \multicolumn{2}{|c|}{ Direct capital cost subtotal } & $\$ 261,487,093$ & $\$ 522,974,186$ \\
\hline \multicolumn{2}{|l|}{ Contingency $(10 \%)$} & $\$ 26,148,709$ & $\$ 52,297,419$ \\
\hline \multicolumn{2}{|c|}{ Total direct capital cost } & $\$ 287,635,802$ & $\$ 575,271,604$ \\
\hline \multicolumn{2}{|c|}{ EPC and owner costs $(9 \%)$} & $\$ 25,887,222$ & $\$ 51,774,444$ \\
\hline \multicolumn{2}{|l|}{ Land cost } & $\$ 11,260,647$ & $\$ 22,521,293$ \\
\hline \multicolumn{2}{|c|}{ Total capital (installed cost) } & $\$ 324,783,671$ & $\$ 649,567,342$ \\
\hline
\end{tabular}

${ }^{\dagger}$ Includes $10 \mathrm{~m}$ horizontal sodium piping at the base of the tower

The other key aspect of this design is the compact receiver has been achieved in this design as a result of the high fluxes that can be sustained by $740 \mathrm{H}$ receiver tubes with a sodium working fluid at high temperature. These high fluxes are justified based on the detailed creep-fatigue analysis with the optimised aiming strategy, and the mid-sized $50 \mathrm{~m}^{2}$ heliostats which facilitate improved flux profiles compared to larger heliostats.

For an indication of the dynamics of the system, Figure 12 shows the behaviour of the system during a sequence of summer and winter days. The summer dynamics show the curtailment of the solar field in the afternoons, and occasional power block trips during cloudy days. The winter dynamics shows more frequent emptying of the storage, as well as, interestingly, solar field curtailment still occurring through the middle hours of some days. 

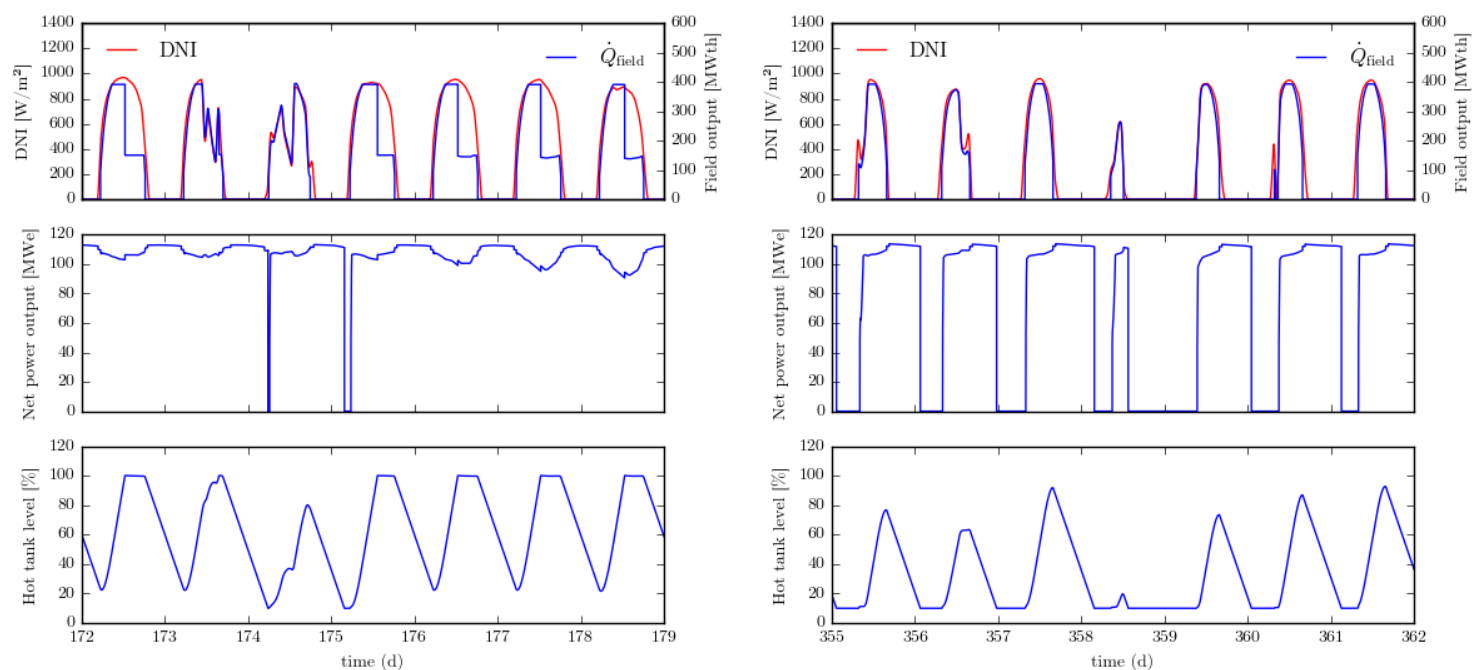

Figure 12. Dynamics of the commercial system in summer (left) and winter (right)

Images courtesy of ANU

Lastly, a sensitivity analysis applied to the commercial system cost parameters (as detailed in $\S$ 3.2 ), is shown in Figure 13. For most cost parameters, a range of $\pm 25 \%$ relative to the reference value was chosen. However, for the heliostat field a reference value of $\$ 75 / \mathrm{m}^{2}$ and uncertainty range of 50 to $100 \$ / \mathrm{m}^{2}$ was applied, which gives a lower-bound reduction of $-33 \%$. More importantly, the lower bound for the tower cost is the estimate from the sbp study. As a result, the probable LCOE distribution is skewed slightly towards LCOE values below the nominal result of $\$ 58.4 / \mathrm{MWh}_{\mathrm{e}}$.

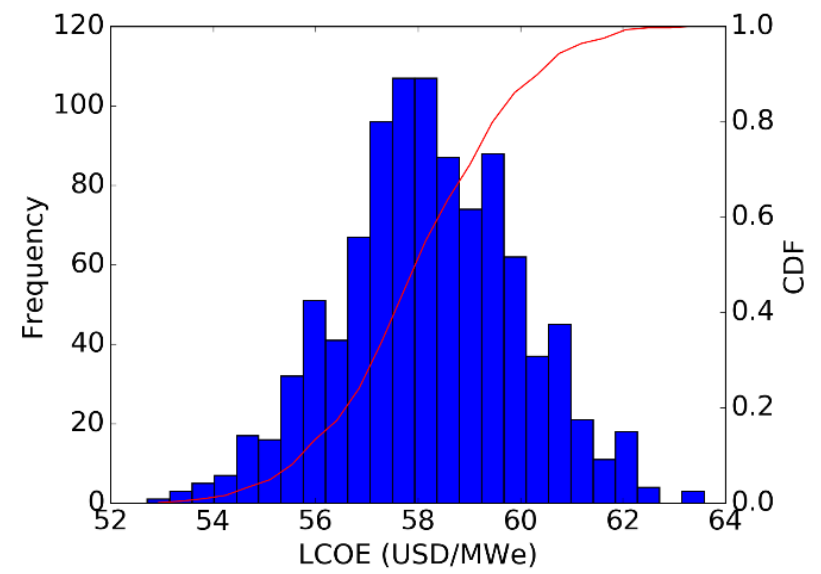

Figure 13. Probability distribution for the LCOE of the commercial system. The mean value for the commercial system of $\$ 58.4 / \mathrm{MWhe}$ meets the CSP Gen3 target value of less than \$60/MWhe.

Image courtesy of ANU

For the tower costs, in particular, more work is warranted to confirm whether the sbp costings are realistic. The parameters which are found through ranked regression analysis (Figure 14) shows the relative importance of different cost uncertainties, with the specified ranges, on the calculated LCOE. The heliostat field cost per area, power block cost, tank cost and tower cost are seen to be the most significant parameters. 


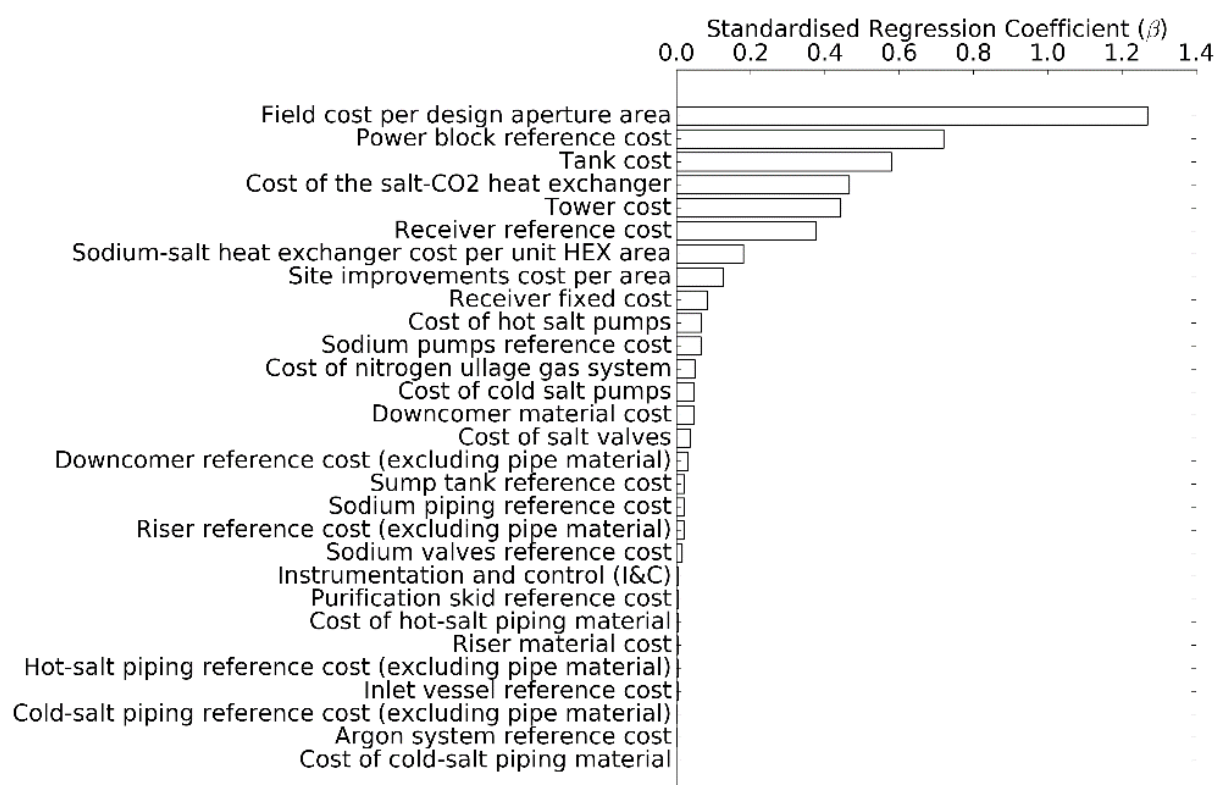

Figure 14. Ranked regression analysis, showing the relative impact of cost uncertainties on LCOE Image courtesy of ANU

Opportunities for further LCOE reduction. A conservative design philosophy has been adopted in developing the commercial-scale system design, such that the plant has both a design and an operation strategy as similar as possible to conventional nitrate salt CSP power tower plants. However, several avenues for further LCOE reduction are identified that take advantage of the sodium configuration and may be considered in future.

For the receiver, there are performance improvements to be gained by working on receiver pipe and flow-pathing optimization including use of non-standard pipe sizes, adopting variable pipe diameters in different banks, and using pipe banks of different dimensions. These improvements would enable designs to better fit the specific thermophysical properties of sodium and improve the performance of the receiver in off-design conditions. Such design approaches may also yield benefits in Gen 2 system design. Cost reduction in the receiver could also be achieved by using lower cost alloys in the colder sections of the receiver, similar to what is done in multi-stage heat exchangers commercially. Another interesting option, unavailable for nitrate salts designs, is to have a single flow pass per tube bank (i.e., avoid multiple banks in series) to simplify the receiver design and piping within the receiver.

Another opportunity for performance gain is to design for a closed circulating sodium loop. The loop would be initially filled from the sump tank with a conventional free-surface mechanical pump, but after filling, would be closed and circulated via one or more EM pumps. This method avoids the hydrostatic pressure losses between the bottom of the tower and the top of the receiver. It is estimated the reduction in power plant parasitic energy consumption from this strategy is around $45 \%$ relative to the base case, and would lower LCOE by approximately $\$ 1.5 / \mathrm{MWh}$.

Lasty, the $50-\mathrm{MW}_{\mathrm{e}}$ unit module would be numbered up for larger power generation needs. As documented in [4], four-unit power parks (i.e., $4 \times 50-\mathrm{MW}_{\mathrm{e}}$ ) have been estimated to realize a $19 \%$ lower LCOE versus the single-unit costs calculated here. 


\section{Phase 1 \& 2 Results: Component Development Research}

\subsection{Salt Chemistry}

Working with members of the DOE-funded Salt Collective, the Liquid Pathway team finalized thermophysical properties of the proposed ternary-chloride energy storage salt. These properties were used for all final-system design work. The nominal salt composition is $46 \% \mathrm{MgCl}_{2}, 39 \%$ $\mathrm{KCl}$, and $15 \% \mathrm{NaCl}$ by weight. The salt is sourced from industrial suppliers, notably ICL in Israel and Albemarle Chemicals in USA. Industrial grade anhydrous carnellite (a mix of $\mathrm{MgCl}_{2}, \mathrm{KCl}$, $\mathrm{NaCl})$ is blended with additional halite $(\mathrm{NaCl})$ to produce the desired salt composition. A small amount of magnesium metal $(\sim 0.1 \mathrm{wt} \%)$ is added during the melting process to remove impurities. Details on the salt properties and salt melting protocols may be found in [27], [28], and [29].
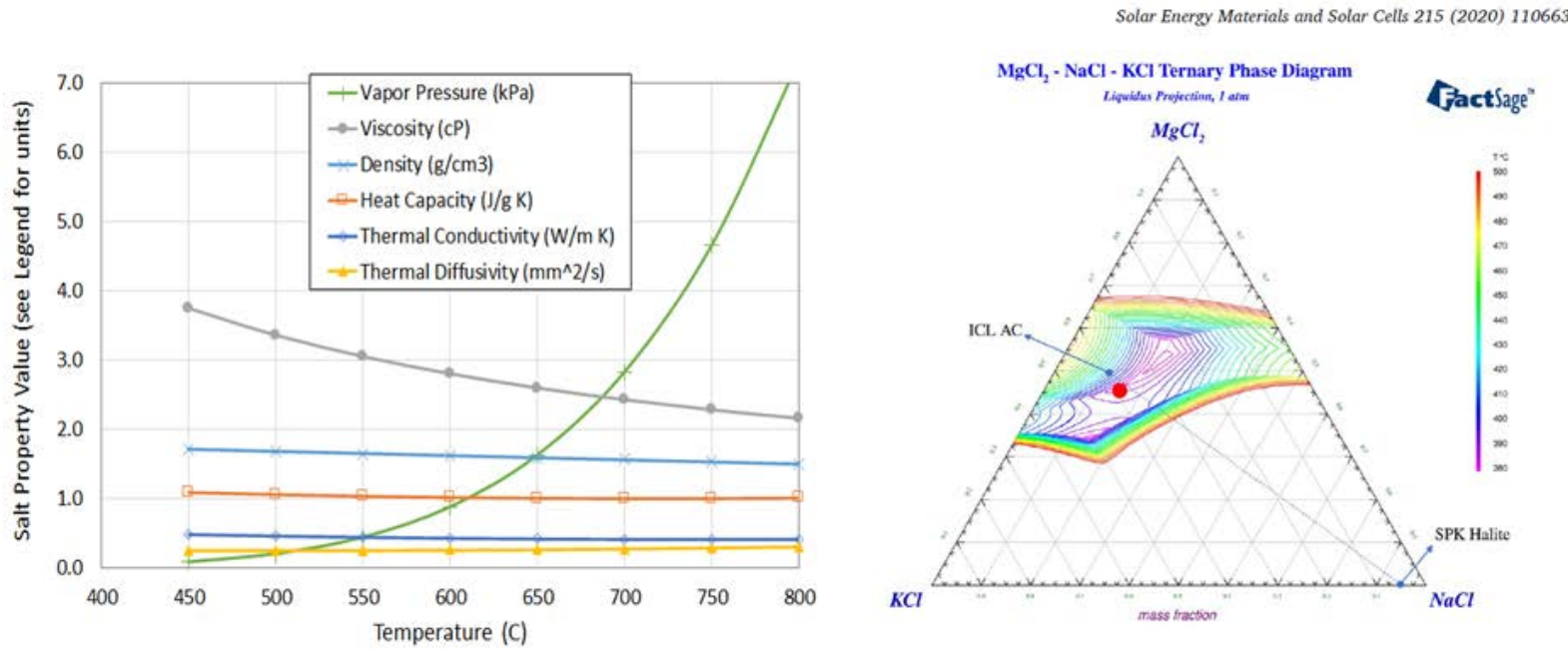

Figure 15. Ternary chloride salt properties (left). The salt composition (red dot) is slightly offeutectic, with a melting point of approximately $400^{\circ} \mathrm{C}$. Melting point is not particularly sensitive to composition as indicated by the phase diagram at right.

\subsubsection{Salt Melter}

The salt melter's operation follows a melting protocol developed under the wider Gen3 program as described by Zhao \& Vidal [27] and outlined in Figure 16. The pilot-scale melter uses a refractory-lined furnace heated by immersed electrodes, following the design used in the melter/chlorinators used in ICL's Dead Sea Magnesium works. The melter design was developed by Hatch (Mississauga, ON) with input from ICL and Hatch's own experience in the metals refining industries. The system is designed to operate continuously, with allowances made for variation in flow rate. Target flow rate is 1 tonne/h, thus allowing for the full salt inventory of approximately 185 tonnes to be melted over about nine days. Magnesium metal addition is included, and baffled zones designed to allow for $\mathrm{MgO}$ sludge settling. Salt will be transported from the melter via pump through a particle filter into the hot salt tank. The melter layout is highlighted in Figure 17. A full description of the melter can be accessed via Table 32. 


\section{Delivered}

Salt

- Anhydrous carnallite: $49 \% \mathrm{MgCl}_{2}, 38 \% \mathrm{KCl}, 12 \% \mathrm{NaCl}_{1}<1.5 \% \mathrm{H}_{2} \mathrm{O}$ by wt.

- Halite: $\mathrm{NaCl}$

\section{Dehydration}

and hydrolysis

$117^{\circ}$ to $400^{\circ} \mathrm{C}$

$\mathrm{MgCl}_{2} \cdot x \mathrm{H}_{2} \mathrm{O} \rightarrow \mathrm{MgOHCl}+\mathrm{HCl}(g)$

\section{Thermal}

decomposition

of $\mathrm{MgOHCl}$

$$
\begin{aligned}
& >550{ }^{\circ} \mathrm{C} \\
& \mathrm{MgOHCl} \rightarrow \mathrm{MgO}(s)+\operatorname{HCl}(g)
\end{aligned}
$$

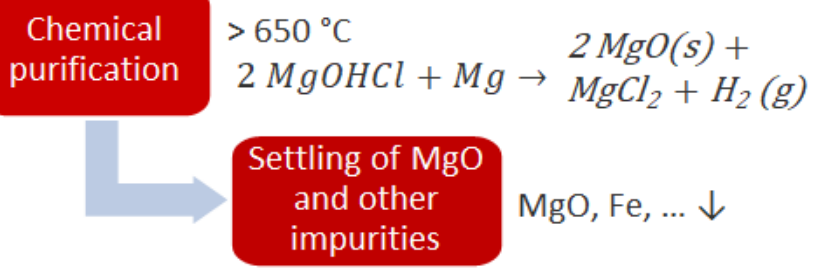

Figure 16. Melter/purifier sequence

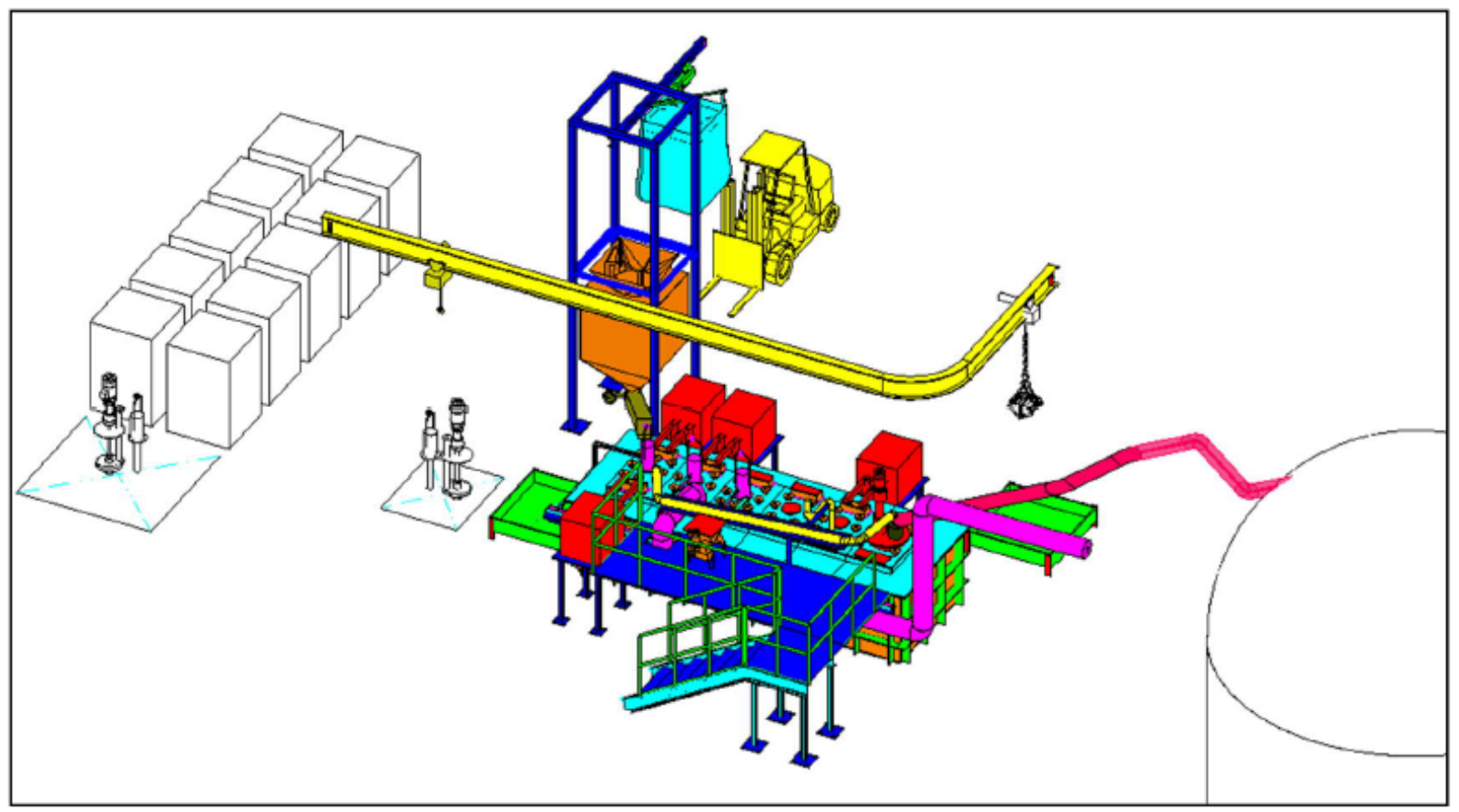

Figure 17. Pilot-scale salt melter layout showing the salt transfer line (red) to the hot tank and sparge-gas transfer line (purple) heading to the scrubber (not shown)

Image courtesy of Hatch

The general melter sequence is as follows:

- Anhydrous carnellite and halite are loaded into Chamber 1 for melting

- Chambers 1 and 2 are electrically heated and sparged with dry nitrogen that is vented to the system acid-gas scrubber. $\mathrm{HCl}$ will be evolved in this section due to dehydration and thermal decomposition of $\mathrm{MgOHCl}$ as shown in Figure 16. 
- Chamber 3 is sparged with dry nitrogen to provide mixing as magnesium metal is added to a concentration of $0.1 \mathrm{wt} \%(1000 \mathrm{mg} / \mathrm{kg})$ in the melt. This chemical purification process may evolve hydrogen gas. A high flow rate of dry air will sweep this section's headspace and vent to atmosphere.

- Chambers 4-6 allow for purification reactions to complete and provide settlings zone for $\mathrm{MgO}$ removal. If necessary, a mechanical scope can remove solids from the bottom of chamber 4 . The chambers are baffled to slow the salt progression and allow settling. Chamber 6 includes a salt chemistry sensor and transfer pump.

- Chambers 3-6 are swept with dry air. This sweep is necessary to ensure a low concentration of hydrogen under worse-case conditions. Nitrogen was considered for this sweep, but the nitrogen consumption rate exceeded that of the pilot system infrastructure.

- A salt melt recirculation line will be available to return salt to the melter zone during system startup or if a process hold is required during salt transfer to the hot-salt tank.

The pilot-scale system specifies an acid-gas scrubber system manufactured by Tri-Mer Corporation. Tri-Mer's cloud chamber scrubber technology (https://tri-mer.com/wet-scrubbers /wet-scrubber.html) consists of a pre-conditioning chamber where particles larger than 10 micron are removed, smaller particles are grown to a more easily captured size, and the first stage of gas scrubbing occurs. The incoming gas stream is also cooled. The pre-conditioned gas then enters a positively charged cloud generation vessel for removal of neutral and negative particles over 0.1 micron, and the second stage of gas scrubbing occurs. Condensable salt vapors are also captured. The scrubbed gas now enters the negatively charged chamber for removal of positive particles and residual neutral fine particles, and the third stage of gas scrubbing occurs. The cleaned air passes through a mist eliminator and goes to the stack. The gas scrubber system is first used for the melter off gas and later used to clean ullage gas vented from the operating pilot-scale tanks.

\subsubsection{Chloride Salt Chemical Sensor}

With support from DOE, Argonne National Lab developed electrochemical sensors capable of monitoring molten salts in a variety of industrial applications [30]. These sensors are comprised of an array of electrodes immersed in the salt. By applying voltage waveforms to the electrodes and interpreting the current response, information about the chemical condition of the salt can be ascertained. These sensors are capable of providing measurements of salt composition, salt redox state, and the salt level in a variety of challenging environments, including large-scale flow systems. Specific to the Gen3 CSP salt $\left(\mathrm{MgCl}_{2}-\mathrm{KCl}-\mathrm{NaCl}\right)$, Argonne has developed measurement capabilities for the salt potential, corrosion product concentrations (e.g., $\mathrm{Cr}^{2+}$, $\left.\mathrm{Fe}^{2+}\right)$, and salt impurity concentrations $\left(\mathrm{O}^{2-}, \mathrm{MgOHCl}\right)$. These measurements are essential to monitor and control the corrosion potential of the salt on the facility's containment alloys.

These sensors have been successfully deployed in a variety of CSP-relevant equipment, including use in three thermal convection loops and in the FASTR loop's large-scale salt purification system. The sensor installed in the FASTR purification system was able to successfully monitor the challenging chemical environment throughout the salt cleaning procedure and was able to provide positive endpoint determination for the process. Two additional sensors, one for the FASTR loop's storage tank and one for the loop's recirculation line, are awaiting installation and operation. These sensors will provide in situ measurements of the salt health and provide guidance for the initiation of any corrosion control measures. 
To date, tests as long as 60 days in the CSP salt have proven the longevity and stability of the sensor design. Additionally, Argonne has operated similar sensors continuously for more than a year and a half in other chloride salts with no observable degradation of the measurement quality. Measurements of $\mathrm{Cr}^{2+}$ and $\mathrm{Fe}^{2+}$ concentrations in the CSP salt using voltametric and potentiometric approaches have shown a relative error of less than $4 \%$ over a complete range of expected values (up to $\sim 3000 \mathrm{ppm}$ ) and long-term relative standard deviations less than $1 \%$. Lower detection limits of less than 1 ppm are achievable. Multiple sensors will be deployed in the pilot-scale demonstration system to track salt chemistry and validate the use of the sensors for salt corrosion control monitoring.

\subsubsection{Alloy Materials for Chloride Salts}

NREL hosted a Salt Chemistry Workshop in February 2019, to review the state of knowledge with respect to salt chemistry and salt-containment options. The workshop included project team members and subject matter experts from Oak Ridge National Laboratories (ORNL), Argonne National Laboratory, Idaho National Lab, Rensselaer Polytechnic Institute, University of Wisconsin-Madison, University of Arizona, Special Metals, EPRI, and Sporian Microsystems. During this workshop the team compiled a list of practical candidate materials for the cold and hot side salt piping (Table 7). Several suggested alloys were removed from the original materials selection list during the meeting for various reasons, mostly due to lack of data, low availability, not ASME code qualified or identifiably better options. Alloys considered, but excluded for these reasons, included $\mathrm{H} 244,800 \mathrm{H}, \mathrm{H} 242, \mathrm{H} 282$, and $\mathrm{H} 233$. These materials may eventually prove useful but were eliminated due to the aggressive schedule of the Gen 3 program.

Table 7. Candidate alloy list developed at the Salt Chemistry Workshop in Golden, CO

\begin{tabular}{|c|c|c|}
\hline Alloy & Target use & Comments \\
\hline $316 \mathrm{H}$ & Ullage gas lines & Common stainless for auxiliary service \\
\hline $347 \mathrm{H}$ & cold salt piping & $\begin{array}{l}\text { familiar to CSP industry; stay }<500 C \text { to avoid potential } \\
\text { stress relaxation cracking }\end{array}$ \\
\hline $304 \mathrm{H}$ & cold salt piping & Common stainless alloy \\
\hline C-276 & cold salt piping & $\begin{array}{l}\text { Suggested by ORNL, tested by DLR and U. Arizona in } \\
\text { chlorides with good performance. Selected by ORNL for } \\
\text { FASTR loop. Code qualified to } 538^{\circ} \mathrm{C} \text {. }\end{array}$ \\
\hline HR 120 & cold salt piping & Good strength at temp, but availability may be a problem. \\
\hline Inconel 600 & cold salt piping & $\begin{array}{l}\text { Lower Cr than } 625 \text { or } 617 \text { should be less susceptible to } \\
\text { corrosion. Not as strong at temp. Used by ORNL in fluoride- } \\
\text { salt loop }\end{array}$ \\
\hline Inconel 625 & cold salt piping & $\begin{array}{l}\text { Common high-nickel alloy. ORNL favors IN } 600 \text { in Cl-salts. } \\
\text { Code qualified to } 593^{\circ} \mathrm{C} \text {. }\end{array}$ \\
\hline Haynes 230 & receiver, $\mathrm{PHX}$ & Has been the benchmark for $\mathrm{Gen} 3$ and $\mathrm{sCO}_{2}$ research \\
\hline Inconel $740 \mathrm{H}$ & receiver, $\mathrm{PHX}$ & High strength, code qualified \\
\hline Inconel 617 & hot salt piping, $\mathrm{PHX}$ & Common high-nickel alloy. ORNL favors IN 600 in Cl-salts. \\
\hline
\end{tabular}

Strength. An appropriate means of comparing alloy strength at temperature is via the ASME Boiler \& Pressure Vessel Code (BPVC). Allowable stress values for seamless piping for each candidate material from the ASME code as a function of temperature are shown in Figure 18. 
One notes that a) the Inconel 600 allowable stress reduces rapidly around $450^{\circ} \mathrm{C}$ and b) $\mathrm{C}-276$ and Inconel 625 are only rated in ASME B31.1 to $538^{\circ} \mathrm{C}$ and $593^{\circ} \mathrm{C}$, respectively. For the hot temperature piping, Inconel $740 \mathrm{H}$ provides considerably more strength than any other material, with next strongest being Inconel 617 and Haynes 230. It is important to note that data in Figure 18 are considered as a relative measure of alloy strength as a function of temperature. However, despite impressive strength values associated with Inconel $740 \mathrm{H}$, the material is difficult for component manufacturability in casting processes, required for pump and valve components.

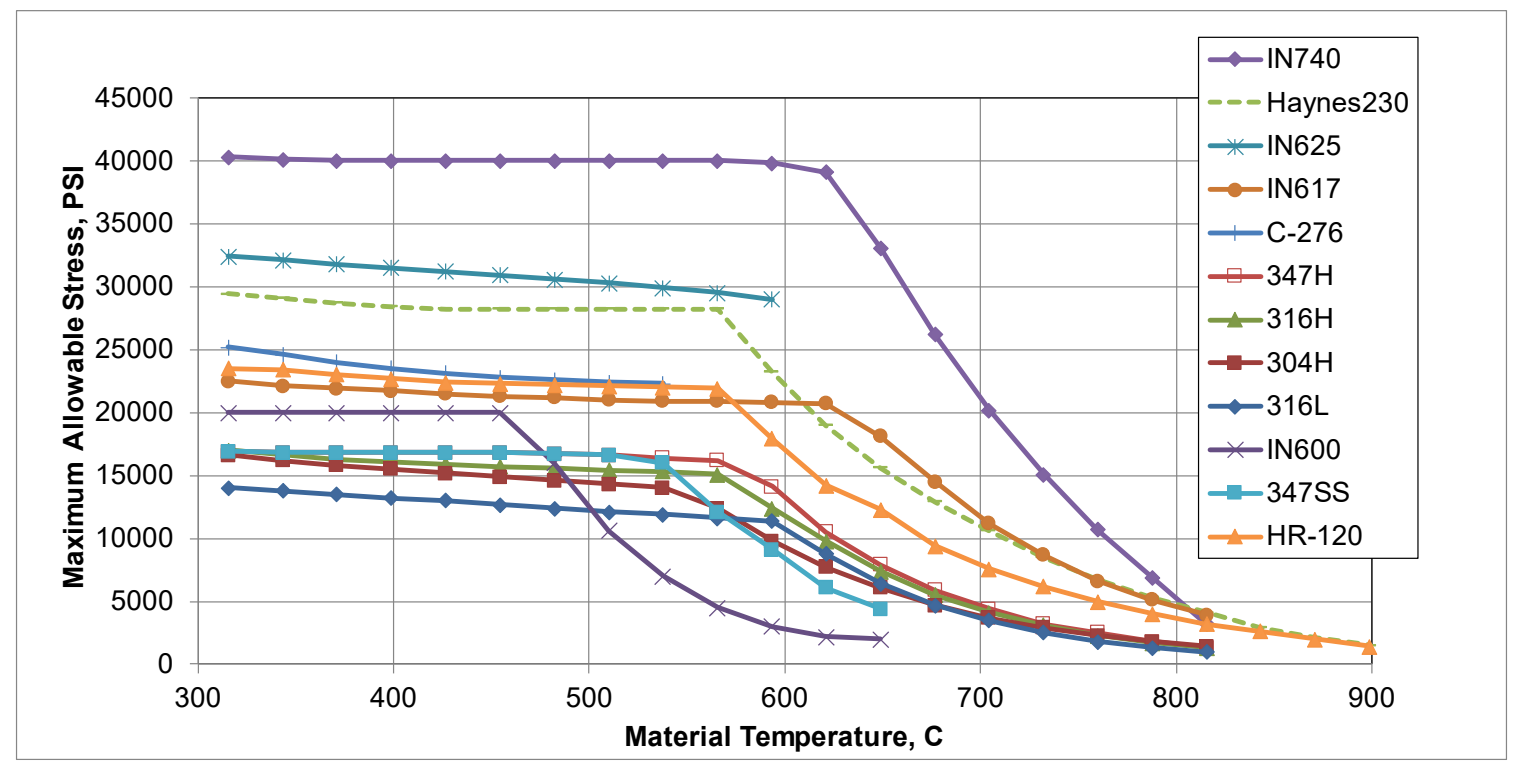

Figure 18. Candidate material allowable stress per ASME code [31]

In addition to internal fluid pressure, the piping network must withstand dead loads from the weight of the pipe, piping components, insulation, and heaters, as well as stress from thermal expansion. The project's 30\% Design Report [FY19Q2 Report] analyzed a piping layout for 2.5inch Sch80 347H and IN 617 on the cold-side and hot-side piping, respectively. Both were found to have sufficient strength in these applications.

On the basis of their analysis, B\&P reported that thermal expansion stress tended to be the governing stress for design, exceeding the hydrostatic stress by a factor of four. B\&P also examined the potential of $347 \mathrm{H}$ for the hot-side piping. Although the hydrostatic strength was adequate, $347 \mathrm{H}$ was found to have insufficient strength to withstand the expansion stress. This illustrates that a complete piping layout analysis is required to properly assess material strength. Subsequent analysis confirmed the suitability of austenitic stainless steel for the cold side conditions on the basis of strength. Nickel alloys such as IN617, H230, IN740H are required for hot side conditions.

Cost. During Phase 1 of the project, price quotes for representative diameter Sch80 pipe were obtained by Sandia from Arch City Steel \& Alloy (Fenton, MO), see Figure 19. These data were used as part of the initial alloy selection screening and later replaced with pricing from fabricators to estimate pilot-scale and commercial-scale system. Commercial-scale quantity costs in particular are significantly lower, see $\S 3.2$. 


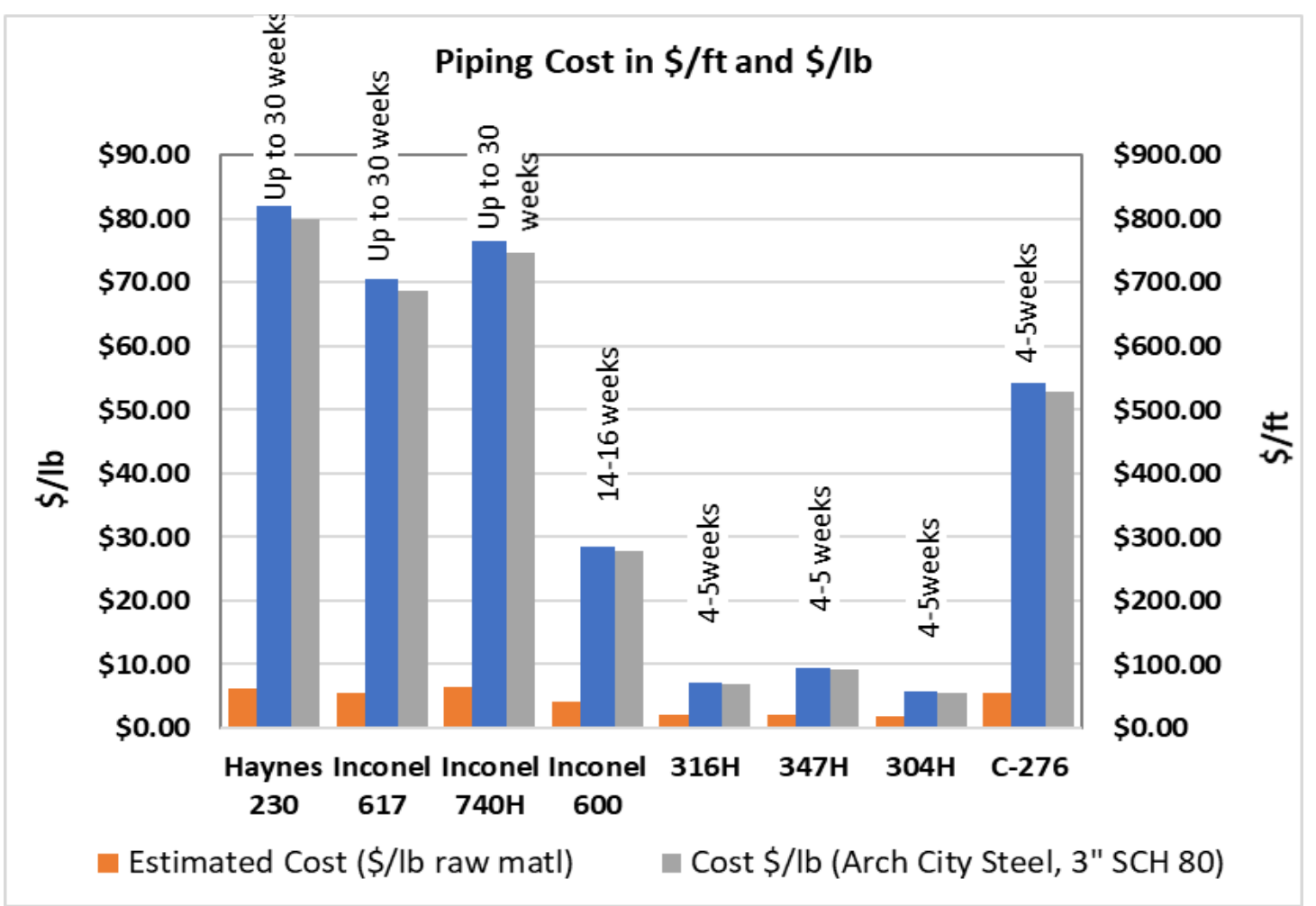

Figure 19. Piping costs based on raw material prices (not used) and quotes from Arch City Steel per mass (blue bar) and per unit length (grey bar) for 3" Schedule 80 pipe. Lead times are also taken from the Arch City Steel quotes.

Image courtesy of Sandia

The cost estimates in Figure 19 illustrate the significant cost advantage for stainless steels. At the piping size planned for the pilot unit, stainless steel has sufficient strength for the cold-side application. The higher strength, high-nickel materials are favored for the hot-side piping and are likely the only suitable candidates for that application based on the strength criterion.

Corrosion Resistance. While cost and strength can be reasonably quantified, corrosion allowance is much more difficult to pin down based on the subset of materials for which good corrosion data are available. Figure 20 summarizes the corrosion data for the alloys under consideration that could be culled from the literature. (Full references, and additional details including experimental conditions, can be found in the project's Alloy Recommendations Milestone ST-1.1.1) Figure 20 shows corrosion rates under various atmospheres and salt compositions. The most data exist for stainless steels, C-276 and Haynes 230. No corrosion data were found for Inconel 617 or Inconel $740 \mathrm{H}$ in $\mathrm{MgCl}_{2}$ salt. It is difficult to compare the corrosion results directly, as the experimental conditions between papers were not consistent, but austenitic stainless steels and Haynes 230 show relatively low corrosion rates for their targeted temperature regime. $\mathrm{C} 276$ is a favored alloy due to its relatively wide usage and good corrosion resistance; however, it has insufficient strength and is not code qualified for the hot salt conditions. C276 remains a good choice for sensors, valve bodies, filter assemblies, and coatings. 300 -series stainless is selected for the cold side piping due to its cost advantages. 


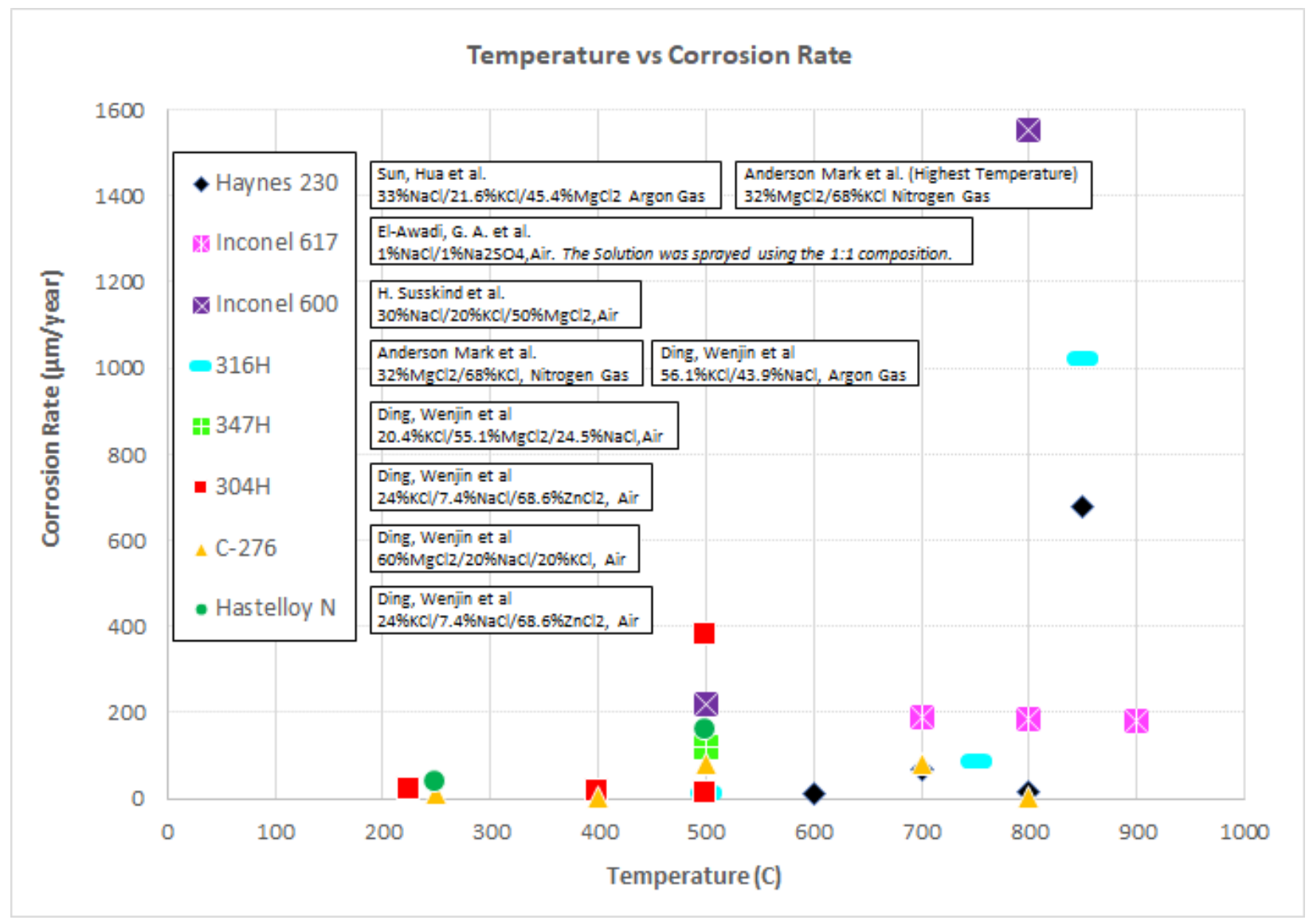

Figure 20. Compiled corrosion data for alloys under consideration

Image courtesy of Sandia

Recommendations. Based on the data compiled during Phase 1 it was decided to use $304 \mathrm{H}$ piping for the cold side piping, with $\mathrm{C} 276$ selected for the valve bodies and filters. C276 is also the alloy that ORNL selected for its FASTR loop, based on their review of suitability and availability. H230 was selected for the hot-side piping and valves. This alloy has been the benchmark material for Gen3 and $\mathrm{sCO}_{2}$ testing and has accumulated a wide set of data.

Coatings are proposed to enhance corrosion resistance in commercial-scale piping systems. However, the 2 " piping size at the pilot scale is too small for the preferred thermal-spray pipe coatings [6].

\subsection{Salt Tank Materials of Construction}

Analysis prior to the Gen3 Liquid Pathway project indicated that chloride salt tanks would require internal insulation to protect the containment shell from the thermal and chemical properties of the salt [1], [32]. This design was further indicated by discussions with the magnesium industry through our project partner ICL and their Dead Sea Magnesium subsidiary. That industry uses internal refractory insulation to lower the wall temperature and allow molten magnesium salt tanks to be constructed from carbon steel - the design approach followed by the Gen3 project. The composition of the internal liner requires careful consideration to maximize the efficacy of multiple parameters including corrosion resistance, strength at operating temperature, durability, and cost. 
The most critical component is the material at the interface with the molten salt, known as the "hot face". The hot face must be chemically compatible with the salt and prevent molten salt from wetting of the underlying insulating layers. Preventing ingress of the salt is achieved by selecting a low-porosity hot face refractory that exhibits chemical stability in the presence of the salt. During Phases 1, three refractory candidates were studied based on knowledge of successful aluminosilicate hot face materials used in the magnesium electrolysis industry [33]. In addition, a 3-mm metallic hot face was considered, similar to research and testing in the 1980s with solar salt [34]; however, this design was projected to be significantly more expensive based on the cost of H230 used in Phase 1. Later analysis using Phase 2 cost values for H230 suggested this design may be competitive with the refractory hot face design, but the latter was already in final design. It is notable that the prior testing at Sandia of a 7-MW th pilot scale tank was technically successful, but the design was more expensive than the stainless-steel externally insulated tank that eventually was adopted for the standard in solar salt hot tanks.

\subsubsection{Hot Face Brick Selection}

A variety of candidate hot face materials were screened by the team based on material makeup, porosity, and industry experience. From this list, three hot face candidates completed refractory cup tests following ceramic-industry protocols, Figure 21 . The cup was charged with purified salt, heated to $720^{\circ} \mathrm{C}$, and held for 100 hours at that temperature under nitrogen atmosphere. Two low-porosity bricks, Duro Type II and HD 45 successfully passed the salt cup test and graduated to further testing.

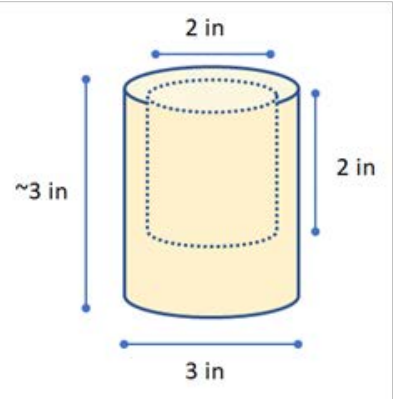

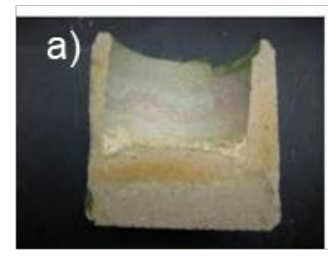
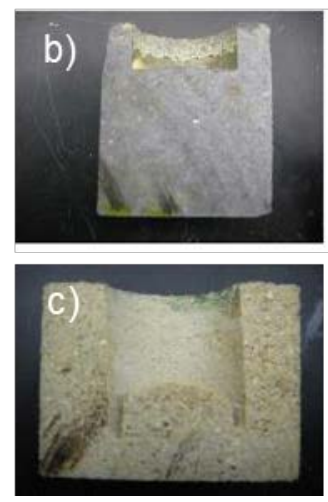
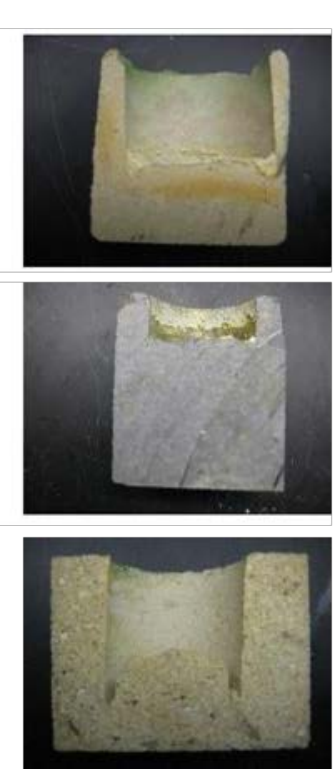
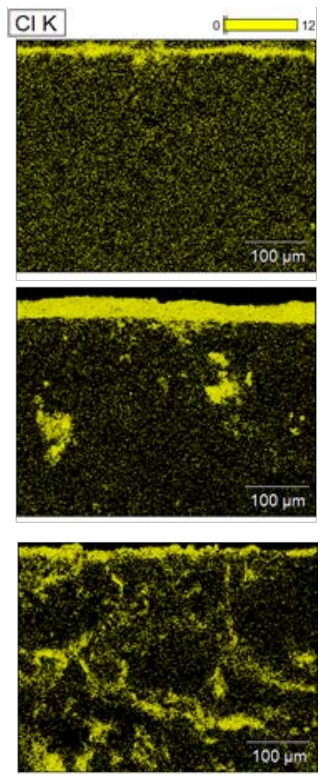

Figure 21. Sectioned cup tests after 100-hour salt exposure. Cup dimensions shown on the left. Sectioned cups of Duro Type II (a), HD 45 (b), and Patriot (c), with EDS map showing presence of chlorine where the top of the EDS image was the surface in contact with the salt.

Further analysis with X-ray computed tomography (X-ray CT) of virgin and salt-immersed hot face materials was undertaken to compare salt penetration levels of the two bricks. This analysis was done in collaboration with the Electrochemical Innovation Laboratory at the University College London in the UK. These results are summarized here and described in detail in a submitted journal article [35]. 
X-ray CT allows for 3D scans of the refractory and identifies total and interconnected pore volume. Figure 22 shows volume renderings of the surface-connected pores in both materials to visualize the different character of the porous networks. Qualitatively it is clear that salt ingress is much lower in Duro Type II due to fewer interconnected pore networks. Having segmented the high grayscale inclusions in the virgin sample, and assuming a similar composition in the immersed sample, implies approximately $0.3 \%$ phase fraction $(\sim 7 \%$ original pore network $)$ attributable to salt ingress in Duro Type II.
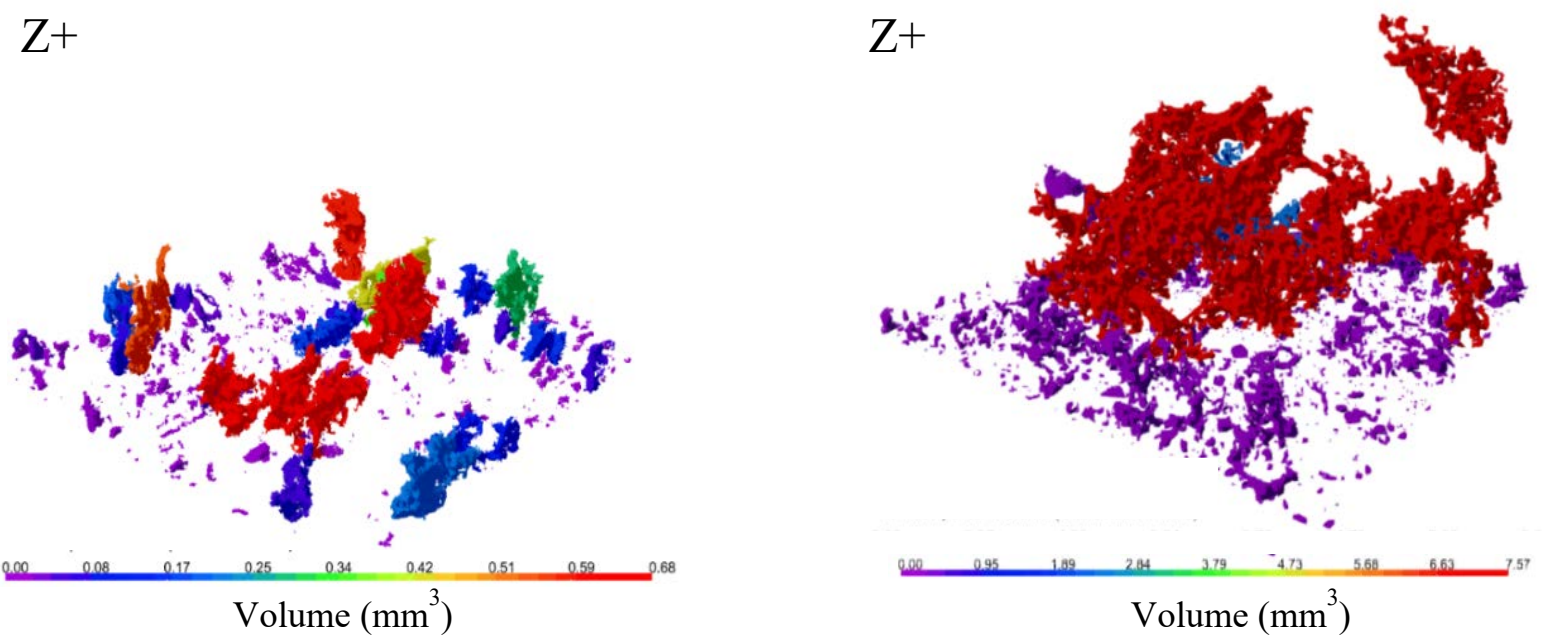

Figure 22. Volume renderings of the surface-connected porous networks for (left) Duro Type II and (right) HD-45, where the color indicates the volume of individual connected-pore networks. Penetration from the Z-face of the cubic sample is shown.

The X-ray CT images demonstrated that there were porous networks connected to the surface of the analyzed volume (very close to actual sample surface) in both cases. This analysis also highlighted that although the pore phase fraction of HD-45 matched the manufacturer's specifications, that for Duro Type II was significantly less (by $50 \%$ ) than nominally specified. This suggests that there are finer pore networks beneath the XCT resolution used here. These analyses highlight why Duro Type II became the focus of subsequent chemical compatibility testing. For 1000-hour tests, Duro Type II coupons were cut and immersed in molten salt at $720^{\circ} \mathrm{C}$. Following the salt exposure, the coupons were cross-sectioned, mounted in phenolic resin, and polished for analysis. The mounted coupons were sputtered with a 10-nm layer of palladium/gold to increase conductivity and analyzed with SEM/EDS.

Figure 23 shows the chlorine and magnesium EDS maps of the cross-sectional refractory/salt interface for all tested durations. The refractory/salt interface is at the top of the image, with the bulk of the material extending to the bottom. The data suggest that molten chloride salt does not penetrate deeply into the material. With the given rate, one can expect a penetration depth of 2.0 $\mathrm{mm}$ after 20 years and $2.9 \mathrm{~mm}$ after 30 years of continuous exposure. This is a very small fraction of the expected 114 to $230 \mathrm{~mm}$ brick thickness (based on standard 4.5-inch or 9-inch bricks), although caution must be applied when extrapolating to multi-year periods. 

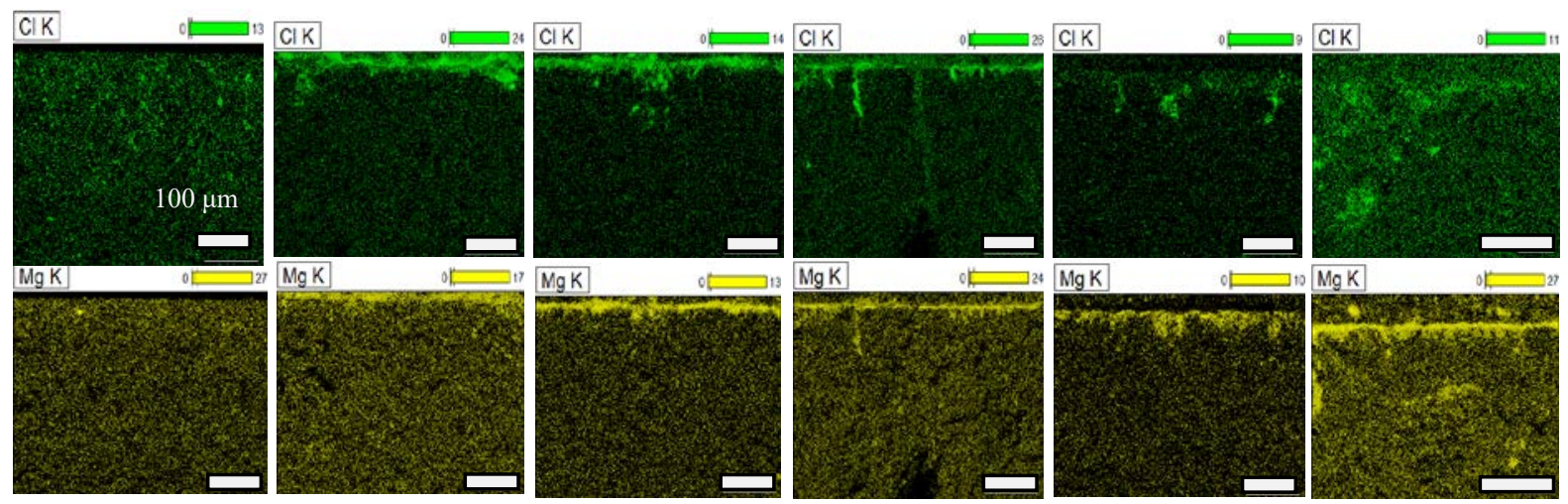

Figure 23. Salt Permeation into Duro Type II as a function of time. EDS maps of $\mathrm{Cl}$ and $\mathrm{Mg}$ of cross sectioned native Duro Type II and Duro Type II immersed in molten chloride salt for 50, 100, 500, 1000 , and 3000 hours (left to right, respectively). Note that each data point is a different refractory sample. Salt permeation is measured as the depth of $\mathrm{Cl}$ into the bulk of the material.

The limited salt permeation into the Duro Type II brick is believed to be partly due to the formation of a secondary phase at the salt/refractory interface. In addition to the strong presence of surface magnesium in the EDS maps, X-ray diffraction confirms the formation of the magnesium silicate phase, forsterite $\left(\mathrm{Mg}_{2} \mathrm{SiO}_{4}\right)$. Forsterite is believed to form on the surface and in cracks and pores in the Duro Type II brick, impeding salt penetration into the brick. Forsterite is a reported product of reactions involving $\mathrm{SiO}_{2}$ and $\mathrm{MgO}$ with molten $\mathrm{MgCl}_{2}$ [36] and molten $\mathrm{NaCl} / \mathrm{KCl}[36]$.

Figure 24 shows the X-ray diffractograms of virgin Duro Type II (a) and Duro Type II that has been immersed in salt for 3000 hours (b). The crosses $(\dagger)$ in Figure $24 \mathrm{~b}$ identify a forsterite phase that has formed on the material due to contact with molten salt. The exposure of Duro Type II to molten salt also removes the amorphous content, which is present in the virgin Duro Type II. To test this theory, a pure fused silica refractory was immersed in the ternary chloride salt for 50 hours at $720^{\circ} \mathrm{C}$, to evaluate the importance of both the polydispersity and presence of amorphous content in Duro Type II. XRD analysis showed no evidence of forsterite formation on the material surface. In a second experiment, Duro Type II was immersed in molten $\mathrm{NaCl} / \mathrm{KCl}$ binary at $720^{\circ} \mathrm{C}$ for 50 hours. Similarly, no evidence of forsterite was observed in $\mathrm{XRD}$ analysis. These tests indicate the presence of $\mathrm{MgCl}_{2}$, and the particular composition of Duro Type II (heterogenous with amorphous content) is required to form the beneficial forsterite.

Next, scanning acoustic microscopy was used to compare the entire surface of an untreated Duro Type II coupon and a coupon after immersion in molten salt for 3000 hours (Figure 24c and d, respectively). The surface of the treated sample displays more condensed grey space, which indicates a greater surface coverage and fewer porous regions extending into the material bulk. This hypothesis is further reinforced by the corresponded EDS magnesium maps of the untreated and treated coupons surfaces (Figure 24e and f). The development of the forsterite layer creates broad magnesium deposits with fewer large pores than the untreated coupon. 

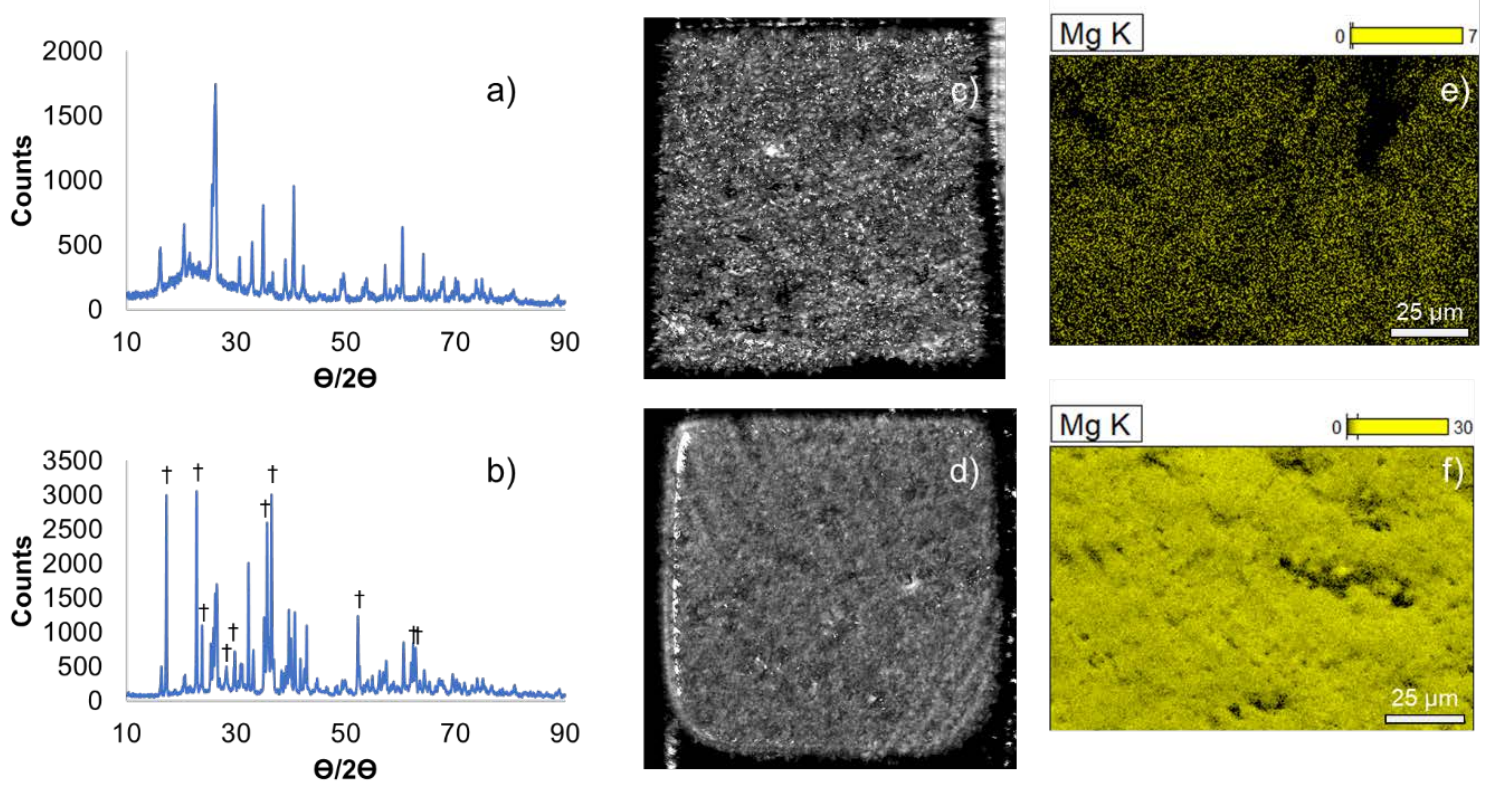

Figure 24. Virgin Duro Type II (top row) and Duro Type II immersed in salt for $\mathbf{3 0 0 0}$ hours (bottom row). From left to right: X-ray diffractograms ( $a$ and $b$ ), scanning acoustic microscopy of coupon surfaces ( $c$ and $d$ ), and EDS Mg maps (e and f). The $\dagger$ symbols in (b) highlight peaks that belong to the forsterite secondary phase.

The mechanical properties of Duro Type II were investigated to determine whether long-term exposure to molten salt and formation of surface forsterite affects the compressive strength. The native brick has a reported cold crushing strength (CCS) of $114 \mathrm{MPa}$. Table 8 shows the data generated from mechanical compression testing. The average and standard deviation of the virgin and immersed specimens were 113.2 $\mathrm{MPa} \pm 8.7 \mathrm{MPa}$ and $113.8 \mathrm{MPa} \pm 7.5 \mathrm{MPa}$.

Student's $t$ test was performed on the data to determine any statistical differences in the data set within $95 \%$ confidence and a t-value was calculated. The t-value and critical value for a onetailed test with a $95 \%$ confidence interval were 0.05 and 1.895 , respectively. As the $t$ value is less than the critical value, the data are deemed to not be statistically different and indicate that long-term exposure and secondary phase formation of forsterite on the material surface do not affect mechanical compatibility of Duro Type II with molten chloride salt.

Table 8. Cold crush strength (CCS) of Native Duro Type II and Duro Type II after immersion in molten chloride salt for 3,000 continuous hours. No statistical difference seen in crush strength.

\begin{tabular}{|l|l|l|l|}
\hline \multicolumn{2}{|l|}{ Duro Type II - Native } & \multicolumn{2}{l|}{ Duro Type II After 3,000 h Salt Exposure } \\
\hline Sample Number & CCS (MPa) & Sample Number & CCS (MPa) \\
\hline 1 & 111.8 & 1 & 116.5 \\
\hline 2 & 109.9 & 2 & 103.0 \\
\hline 3 & 119.9 & 3 & 115.3 \\
\hline 4 & 101.2 & 4 & 120.4 \\
\hline 5 & 123.2 & & \\
\hline Mean & 113.2 & Mean & 113.8 \\
\hline StDev & 8.7 & StDev & 7.5 \\
\hline
\end{tabular}


For comparison, an insulting firebrick (IFB) was subjected to similar mechanical testing. Should molten salt permeate through the hot face refractory layer, the IFB will become wetted with salt. The virgin material was measured to have a CCS of $0.97 \mathrm{MPa} \pm 0.08 \mathrm{MPa}$, which is within the CCS reported by the manufacturer $(1.00 \mathrm{MPa})$. Three samples were then immersed in salt for 50 hours at $720^{\circ} \mathrm{C}$. The high porosity $(>80 \%)$ of the material results in the open pores being filled with salt. The CCS of the salt wetted IFB decreased dramatically to $0.05 \mathrm{MPa} \pm 0.07 \mathrm{MPa}$, clearly demonstrating the deleterious impact of salt contact. This study further emphasizes the need to prevent the salt from permeating through the hot face and contacting the insulation layer.

\subsubsection{Liner Mortar}

While Duro Type II brick demonstrates adequate thermal, chemical, and mechanical stability in molten salt, the mortar used to join bricks is a potential point of weakness. Porosity in the mortar joints could allow salt to reach the underlying insulating firebrick layer.

Initial screening of commercially available mortars did not identify a suitable candidate. However, the success of the Duro Type II brick led the project team to hypothesize that a mortar formed of powdered Duro Type II may form an effective mortar to prevent salt permeation. After discussion with Koch Knight, manufacturers of Duro brick, a mortar based on that brick's material was produced by Koch Knight for testing by NREL.

Koch Knight generated a Duro powder with trimodal particle size distribution that optimizes two parameters: maximal particle packing density and minimal required binder solution to provide ideal mortar rheology. Particle packing is important to create a dense structure which limits open porosity available for salt permeation. It also is believed to be necessary to facilitate the formation of forsterite, rather than $\mathrm{MgO}$ as the secondary phase. Literature reports that if $\mathrm{MgO}$ and $\mathrm{SiO}_{2}$ are not in close physical proximity or in proper proportions, formation of forsterite is less favorable, as had been observed experimentally by the project team. After testing various blends, an optimized formulation was selected and was used to form a brick-and-mortar composite for chemical compatibility testing in molten salt.

The brick-and-mortar composites were next compressed at $720^{\circ} \mathrm{C}$ to $10 \mathrm{MPa}$ and $75 \mathrm{MPa}$ to mimic the type of thermal compressive stress that would be expected in the preheated pilot-unit tanks. X-ray CT was performed to assess whether high temperature compression eliminates the native porosity in the Duro mortar. Figure 25 shows the 3D porosity of the Duro brick and mortar composite after compression at $10 \mathrm{MPa}$ and $75 \mathrm{MPa}$. While compression does reduce the number of porous regions (colored areas in the figures), it does not completely eliminate porosity.

Subsequent exposure of the $75 \mathrm{MPa}$-compressed specimen to salt at $720^{\circ} \mathrm{C}$ indicated extensive permeation of salt into the joint, as shown in the EDS maps of the cross-sectioned brick and mortar composite (Figure 26). However, line scans of the specimen indicate that unlike magnesium and chlorine, potassium and sodium concentration do not rise significantly above the baseline signal. This suggests that magnesium may be selectively observed because forsterite is forming in the joint and preventing further salt ingress. (X-ray diffractograms of the mortar before and after a 50-hour salt exposure test confirmed the formation of forsterite.) To address this risk, the team recommends a small tank with full-size bricks and mortar joints be tested at the outset of Phase 3 to validate the ability of mortar joints to seal. 

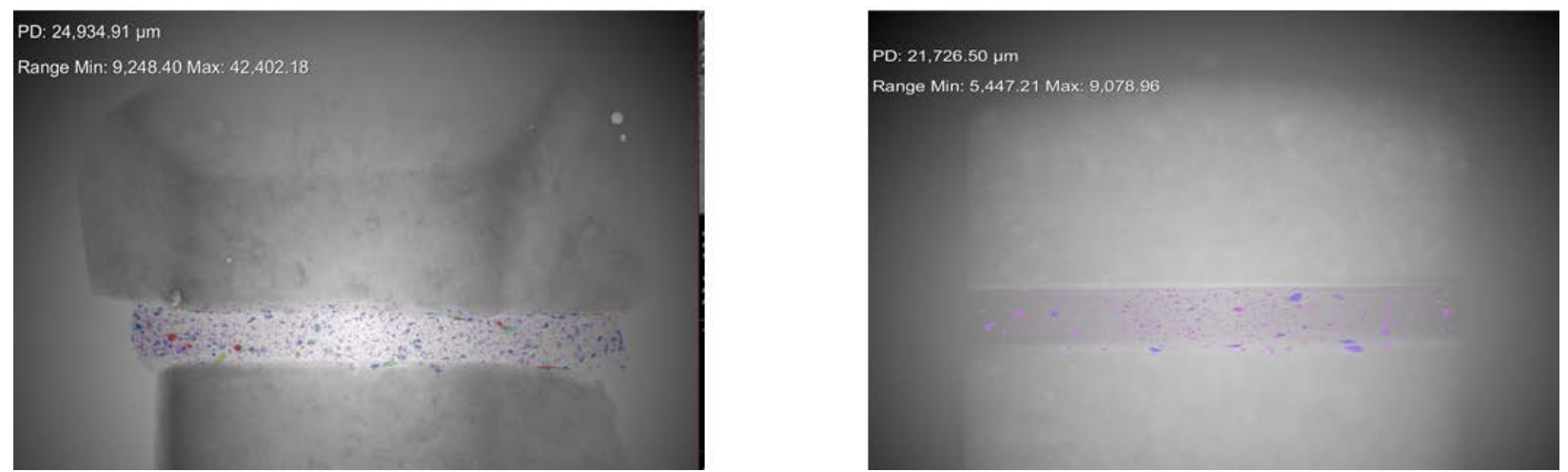

Figure 25. X-ray CT representation of colored porous regions in the mortar joint after compaction at $720^{\circ} \mathrm{C}$ to $10 \mathrm{MPa}$ (left) and $75 \mathrm{MPa}$ (right) suggest reduction, but not elimination of porous regions.
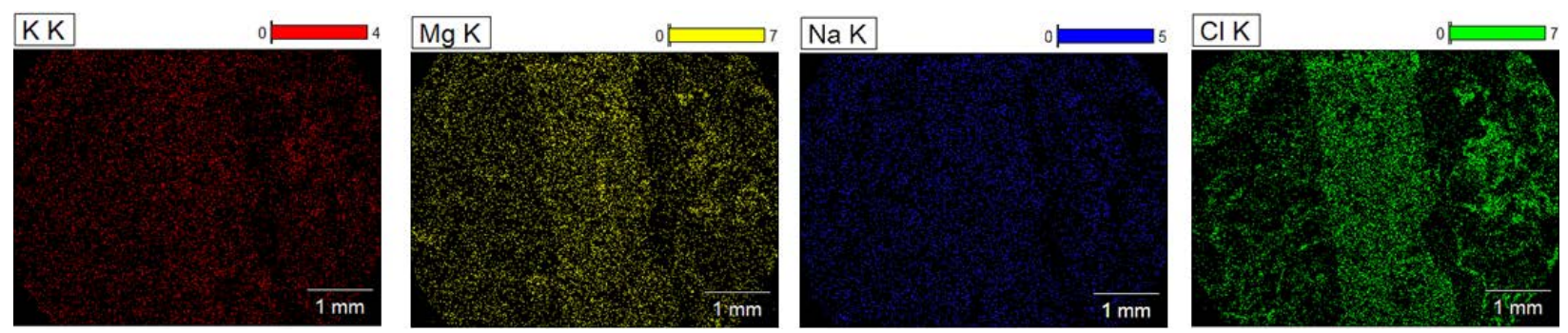

Figure 26. EDS maps of potassium (K), magnesium $(\mathrm{Mg})$, sodium $(\mathrm{Na})$ and chlorine $(\mathrm{Cl})$ of crosssectioned brick and mortar specimen after 50 -hour exposure to molten salt at $720^{\circ} \mathrm{C}$.

\subsubsection{Mortar/Brick Mechanical Properties}

FEA modeling of the proposed tank design indicated that additional knowledge of the mechanical properties of the brick/mortar composite were needed to develop an accurate representation of the stresses transferred to the tank shell and minimize the number of expansion joints in the design. With increasing temperature, mortar joints soften and compress, which buffers much of the growth of the bricks due to thermal expansion. Accordingly, mechanical stress/strain experiments were performed at various temperatures (room temperature, $350^{\circ} \mathrm{C}$, and $720^{\circ} \mathrm{C}$ ) to quantify the compressibility of Duro mortar and provide better inputs to the FEA model.

Stress was measured by the compressive load cell, and strain was measured by the displacement of the specimen under load. Multiple samples were tested for each temperature regime, and the strains were normalized for each sample to a common stress. The test data were used to solve for the mortar modulus for each temperature, and the composite modulus was scaled up to match the full-size refractory design (9" brick, 3/16" mortar joint). This translation was necessary because the lab tests had a greater ratio of mortar to brick than will exist in the commercial construction.

Calculations were performed to scale the modulus data to full size modulus of elasticity. Two items must be noted. Firstly, a transition in the slope of the stress/strain curve is seen at about 8 $\mathrm{MPa}$ that is attributed to compaction of the mortar. Moduli for the regimes $<8 \mathrm{MPa}$ and $>8 \mathrm{MPa}$ were calculated and attempts were made to use both sets of values in ANSYS models. However, ANSYS requires a solid material to soften as it is stressed, whereas the composite material stiffens beyond the $8 \mathrm{MPa}$ threshold as its strength becomes governed by the brick itself. For this reason, only the moduli value greater than $8 \mathrm{MPa}$ were used. This also adheres to a more 
conservative representation of tank behavior. Secondly, the values for room temperature and $350^{\circ} \mathrm{C}$ were extremely similar. It is recommended that these values be combined using the larger moduli. Thus, the following moduli of elasticity for the brick/mortar composites are used for subsequent ANSYS modeling: $6780 \mathrm{MPa}$ up to $350^{\circ} \mathrm{C}$ and $6170 \mathrm{MPa}$ at $720^{\circ} \mathrm{C}$.

\subsection{Salt Tank Design}

The salt tank design consists of the refractory liner, refractory mounting, expansion joints, roof insulation, and foundation cooling for both the commercial scale and pilot scale systems. Heat loss from the salt tank is first estimated by 1-dimensional heat transfer through the multilayer wall, which serves as an initial design point for more advanced tank modeling. Finite element analysis (FEA) further refines the design to predict 3-D thermal profiles and mechanical stress of a commercial-scale, internally lined salt tank.

The proposed refractory liner is a three-component design, composed of a dense, chemically resistant brick at the salt interface (hot face), an insulating firebrick (IFB) layer, and a microporous insulating board adhered to the inner tank shell. In the project work, the team initially analyzed both "hot wall" and "cold wall" designs before selecting a cold-wall design that is consistent with use in the magnesium industry. A hot wall design assumes the refractory liner is wetted and a stainless-steel tank shell is kept at approximately $500^{\circ} \mathrm{C}$. In the selected cold wall design the refractory liner is kept dry allowing for a carbon steel tank shell that is kept at less than $100^{\circ} \mathrm{C}$.

\subsubsection{Overview of Selection of the Cold Walls Tank Design}

The thermal conductivity of refractory materials is inversely proportional to their porosity. Hence, high-porosity refractories are needed for good insulation. Considering the hydrostatic pressure within the salt tank and the low viscosity and wetting ability of the chloride salts, keeping such a liner dry is a major challenge. Thus, it is important to create an impermeable layer in contact with the salt to protect underlying insulating layers and to understand how thermal conductivity of the liner changes in the event of salt wetting.

The effective thermal conductivity of the overall system changes if the pores are filled with something other than air, e.g., molten salt. If molten salt infiltrates the refractory and completely wets the pores, the thermal conductivity of air $\left(\kappa_{\mathrm{a}}=0.07 \mathrm{~W} / \mathrm{m} \cdot \mathrm{K}\right.$ at $\left.800^{\circ} \mathrm{C}\right)$ is replaced by that of salt $\left(\kappa_{\text {salt }} \approx 0.44 \mathrm{~W} / \mathrm{m} \cdot \mathrm{K}\right.$ at $\left.800^{\circ} \mathrm{C}\right)$ and the overall effective thermal conductivity $\left(\kappa_{\mathrm{e}}\right)$ of the liner increases (Table 9).

Table 9. Calculated effective thermal conductivity $\left(K_{\mathrm{e}}\right)$ of commercially available refractories at hot tank operating temperature $\left(720^{\circ} \mathrm{C}\right)$ in air and after salt infiltration. The hot face bricks and reference brick are mullite-based materials, and the insulating firebrick is anorthite based.

\begin{tabular}{|l|l|l|l|l|}
\hline Refractory & Porosity, $\varepsilon$ & $\begin{array}{l}\text { Ke(in air) } \\
(\mathrm{W} / \mathrm{m} \cdot \mathrm{K})\end{array}$ & $\begin{array}{l}\text { Ke(in salt) } \\
(\mathrm{W} / \mathrm{m} \cdot \mathrm{K})\end{array}$ & \% Change \\
\hline HD-45 hot face brick & $6 \%$ & 1.37 & 1.43 & $+4 \%$ \\
\hline Duro Type II hot face brick & $8 \%$ & 1.95 & 2.00 & $+3 \%$ \\
\hline Insulating firebrick & $80 \%$ & 0.20 & 0.77 & $+285 \%$ \\
\hline Reference brick (calculated) & $57 \%$ & 0.43 & 0.75 & $+\mathbf{7 4 \%}$ \\
\hline Reference brick (measured) [32] & $57 \%$ & 0.43 & 0.73 & $+\mathbf{7 0 \%}$ \\
\hline
\end{tabular}


The change in effective thermal conductivity is directly proportional to the porosity of the refractory. The effective thermal conductivity of highly porous insulating firebrick increases by $285 \%$, whereas the thermal conductivity of denser hot face refractory increases by only $3-4 \%$.

Clearly one must account for changes in thermal conductivity from salt wetting to estimate heat loss from a salt-wetted liner. The calculated values were validated against the measured increase in thermal conductivity of wetted IFBs in a reported study [32] as indicated by the "reference brick" values in Table 9. The model exhibited good agreement with the published data.

Having developed the framework for calculating liner thermal conductivity, the 3-layer liner design used in the magnesium industry - hot face brick at the salt interface, IFB, and microporous insulating boards at the refractory/carbon-steel interface - can be evaluated under both dry and salt-wetted conditions. Figure 27 shows a rendering of a lined hot tank (salt at $720^{\circ} \mathrm{C}$ ) that is internally lined with the 3-layered refractory liner mentioned above, with roof insulation composed of ceramic fiber blanket. Note that heat loss targets for the Gen 3 tank, set at less than $2 \%$ over a 24 -hour period, corresponds to heat loss $\leq 276 \mathrm{~W} / \mathrm{m}^{2}$.
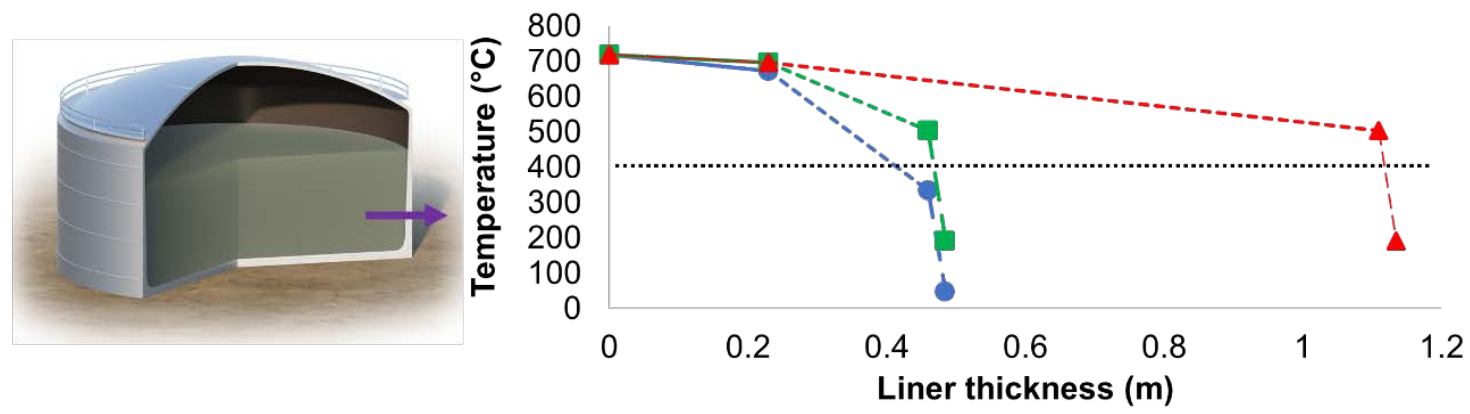

Figure 27. 1-D heat transfer analysis through a refractory liner design when dry (blue circles), the same refractory liner configuration when wetted by salt (green squares), and a wetted liner design when wetted (red triangles). The markers define the regions of the three liner materials: hot face, insulating firebrick, microporous insulation. The horizontal black dashed line denotes the temperature at which the chloride salt freezes $\left(\sim 400^{\circ} \mathrm{C}\right)$.

This simple analysis indicates that a wetted "hot wall" liner design is nearly $1.2 \mathrm{~m}$ thick (triangles), which is neither cost-effective nor practical to construct. Moreover, the salt is predicted to freeze in the microporous insulating layer. This material would likely fail if contacted by salt, resulting in potential failure of the tank. A "cold wall" liner design that becomes wetted (squares) will see heat flux increase to $436 \mathrm{~W} / \mathrm{m}^{2}$, which dramatically lowers the thermal efficiency of the hot tank. The model predicts that this configuration will also result in a freeze layer developing in the microporous insulating layer. Only a cold wall liner configuration that is kept dry (circles) is deemed as a feasible solution for an internally lined molten chloride tank. Hence the integrity of the hot face material is critical to prevent ingress of salt into the primary insulation regions of the liner.

It should be noted that a preferred, failsafe design would consist of a salt-wettable material that retains its strength and insulating ability when wetted; however, although several alternatives were tested, no such material was identified during the project. 


\subsubsection{Thermomechanical Modeling of the Commercial-Scale Salt Tank}

The thermomechanical performance of the commercial tank design was modeled using FEA using ANSYS software. The early thermal and stress models showed significant overstress areas in the tank wall and floor due to the differential expansion between the refractory and the steel tank. Using the original three-layered liner (hot face/IFB/microporous insulation), the radiused refractory corner created a cold spot in the floor/wall of the tank. The stresses induced from this temperature gradient exceeded the ultimate strength of the refractory materials. Total displacement due to thermal expansion was shown to close all expansion joints and yet the initial design was predicted to induce a mechanical stress on the tank wall and regions of the floor that exceeded API 650 limits.

To address these issues, the IFBs in the tank corner were substituted with cheaper and less efficient superduty firebricks, which evened the thermal profile between the wall and floor. These superduty firebricks are represented in orange in Figure 30b. Figure 28a shows ANSYS heat transfer shell temperature results which demonstrate that this configuration results in compatible temperature readings throughout the tank corner $\left(51.7^{\circ} \mathrm{C} \pm 13.4^{\circ} \mathrm{C}\right)$. The ANSYS thermal model provides a shell temperature at specified coordinates (e.g., floor, wall, roof). The overall heat flux from the tank is estimated to be in the range of 232 and $260 \mathrm{~W} / \mathrm{m}^{2}$, which is below the target set by the $2 \%$ heat loss criteria $\left(\leq 276 \mathrm{~W} / \mathrm{m}^{2}\right)$.

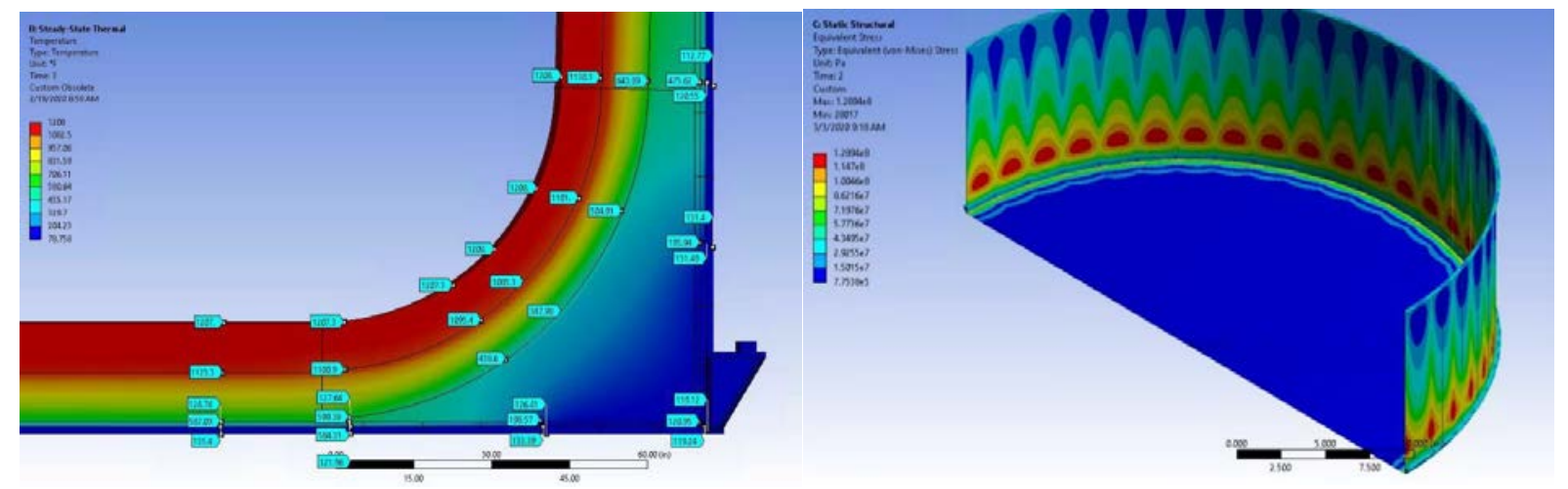

Figure 28. ANSYS thermal profile between the wall and floor (a) and mechanical stress, including salt hydrostatic pressure, transmitted to the tank shell (b). Both metrics meet project targets.

Image courtesy of Job Industrial

Corrugated metal expansion joints with flexible graphite have been selected for this application (Figure 29a). The corrugated metal joints are available in different sizes and alloys. C276 is a preferred alloy due to its good chemical resistance. The expansion joints are selected to meet the specific mechanical requirements of the liner, such as the overall thickness of the joint and the amount of compression needed to seal the joint upon liner heat up. When calculating expansion joint size, compression in the mortar joints was assumed to reduce overall lining expansion. In addition, directly under each expansion joint is a thin layer of graphite foil to prevent the brick layers close to the expansion joint from bonding together. These have been proven highly effective as high temperature gaskets in petrochemical plants and refineries [37]. The liner floor consists of a series of 12-sided expansion rings that avoid intersections between expansion joints. The expansion joints are placed between bricks periodically throughout the liner in vertical and horizontal orientations (Figure 29b). 


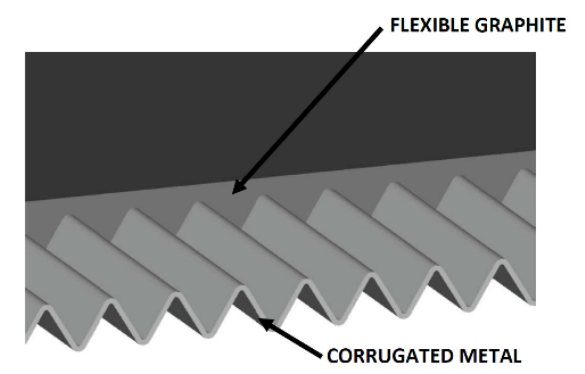

CORRUGATED METAL FLEXIBLE GRAPHITE EXPANSION JOINT

CORRUGATED METAL FLEXIBLE GRAPHITE EXPANSION JOINT

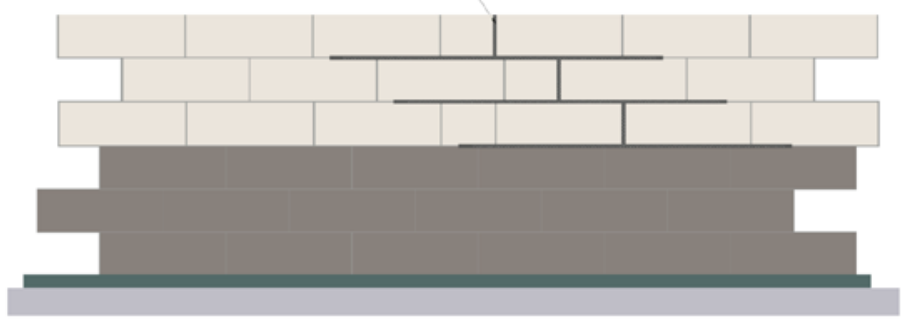

Figure 29. Greater detail of brick mortar and expansion joints. Recommended expansion joints are corrugated metal expansion joints with flexible graphite (left) and these are positioned between bricks periodically throughout the liner in vertical and horizontal orientations (right).

A mortar joint thickness of 2-4 $\mathrm{mm}$ is recommended for the hot face bricks. The thin joints will be employed for this application for corrosion mitigation. Similarly, $2 \mathrm{~mm}$ mortar joints will be used for backup insulation layers. Inorganic potassium silicate-based mortars are favored for all layers due to their high thermal stability and use in corrosive environments. In addition, this inorganic-based approach avoids the use of aqueous-based binders, which may unintentionally introduce moisture into the system.

At the end of Phase 1, the commercial-scale tank was modeled with a significant number of expansion joints to minimize thermo-mechanical stress. As will be noted in the following section, Phase 2 measurements of the brick mortar composite and inclusion of small gaps near the tank shell during liner construction are expected to reduce the overall number of needed expansion joints in a commercial design. However, the team did not have the resources to revise the commercial-scale design within the current project.

\subsubsection{Commercial-Scale Tank Design Summary}

The commercial salt tanks use a multi-layer refractory liner to protect a carbon steel shell from the thermal and chemical challenges of the salt. The proposed refractory liner is a threecomponent design, composed of a dense, chemically resistant brick at the salt interface (hot face), an insulating firebrick (IFB) layer, and a microporous insulating board adhered to the inner tank shell. Both tanks use the same liner design.

Figure 30 shows the conceptual design for the refractory-lined salt tanks. The tank is proposed as butt-welded construction with a bottom-to-shell junction of conventional construction, as shown in industry standards such as API Standard 650 Welded Steel Tanks for Oil Storage (API 650). API 650 requires weld preheating for welds thicker than 1-1/4 inches $(31.7 \mathrm{~mm})$. The final tank design utilizes 1-1/4" plate for both the tank bottom and shell and avoids the weld preheating requirement.

Figure 30b shows the wall-to-floor detail, which highlights a radiused brick profile. The radiused brick base adds stability to the brick wall and prevents a hinge from forming where the floor meets the wall. The floor and wall use special tapered key bricks to maintain a smooth radius. Initial thermal modeling of the three-layer liner: hot face, IFB, microporous insulation, showed cold spots in the corners of the tank, which induced mechanical stresses exceeding API 650 limits. Accordingly, the insulation in the tank corner was modified with lower cost, higher 
thermal conductivity fireclay bricks (orange-colored bricks) and optimized to harmonize the thermal profile between the floor and wall of the tank.

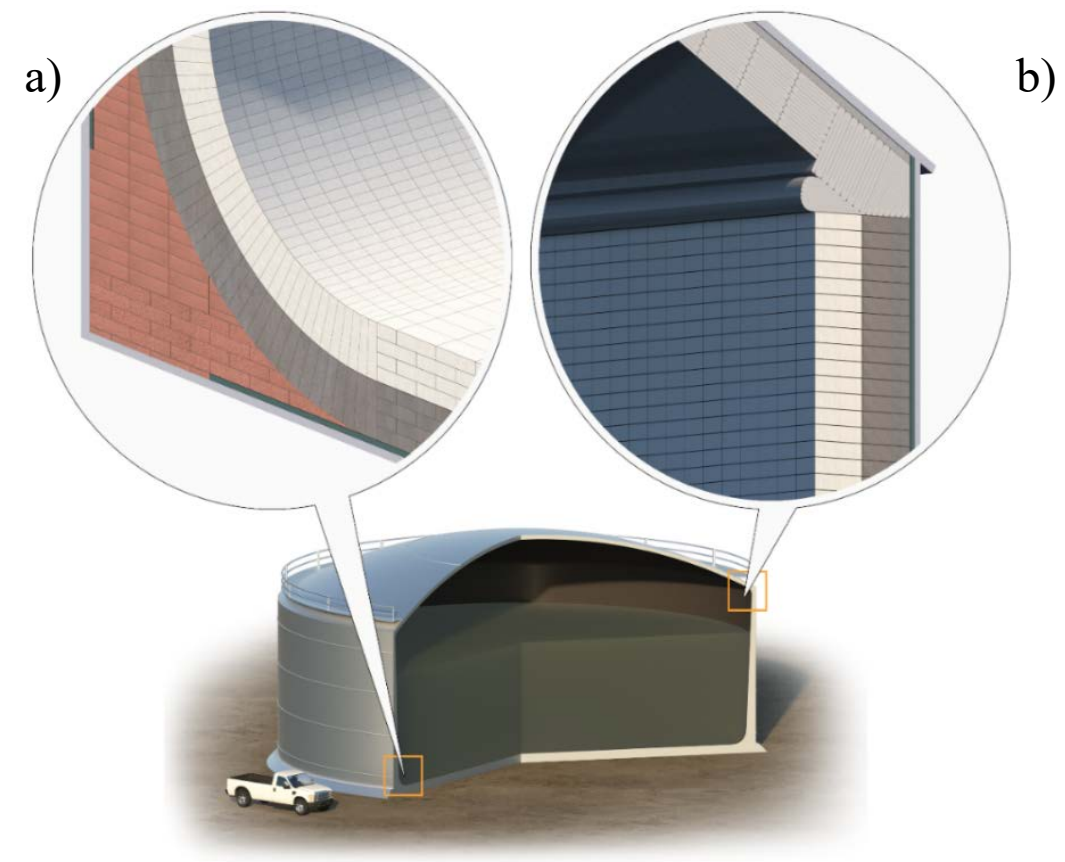

Figure 30. Design of commercial-scale salt tank refractory liner. Different refractory materials are selected to balance the heat flux through the insulating liner, e.g., wall-floor (a) and wall-roof (b) intersections.

Figure 30c shows the top of the refractory wall where the wall transitions to the roof of the tank. Important here are the use of marine anchors to fasten the upper refractory wall to the tank shell. Given the size of the refractory liner, these anchors are required to keep the liner attached to the wall. The marine anchors can be manufactured out of salt-compatible alloy (e.g., C276) and they are not welded to the tank. Thermal expansion joints are included in the wall and floor to allow the liner to expand to its hot dimensions without damaging the steel shell, which remains at nearambient temperature. The mortar joints and thermal-expansion joints are considered the major risks in the tank design. More detail on these points can be found in $\S 4.2 .2$. Representative commercial tank dimensions are shown in Figure 31. Tanks capable of providing 12 hours of energy storage for a 50-MWe net are approximately 42-m diameter by $11-\mathrm{m}$ high. More information on the commercial-scale design can be found in Folder 14-Project Reports, Salt Tanks, see Table 32. 


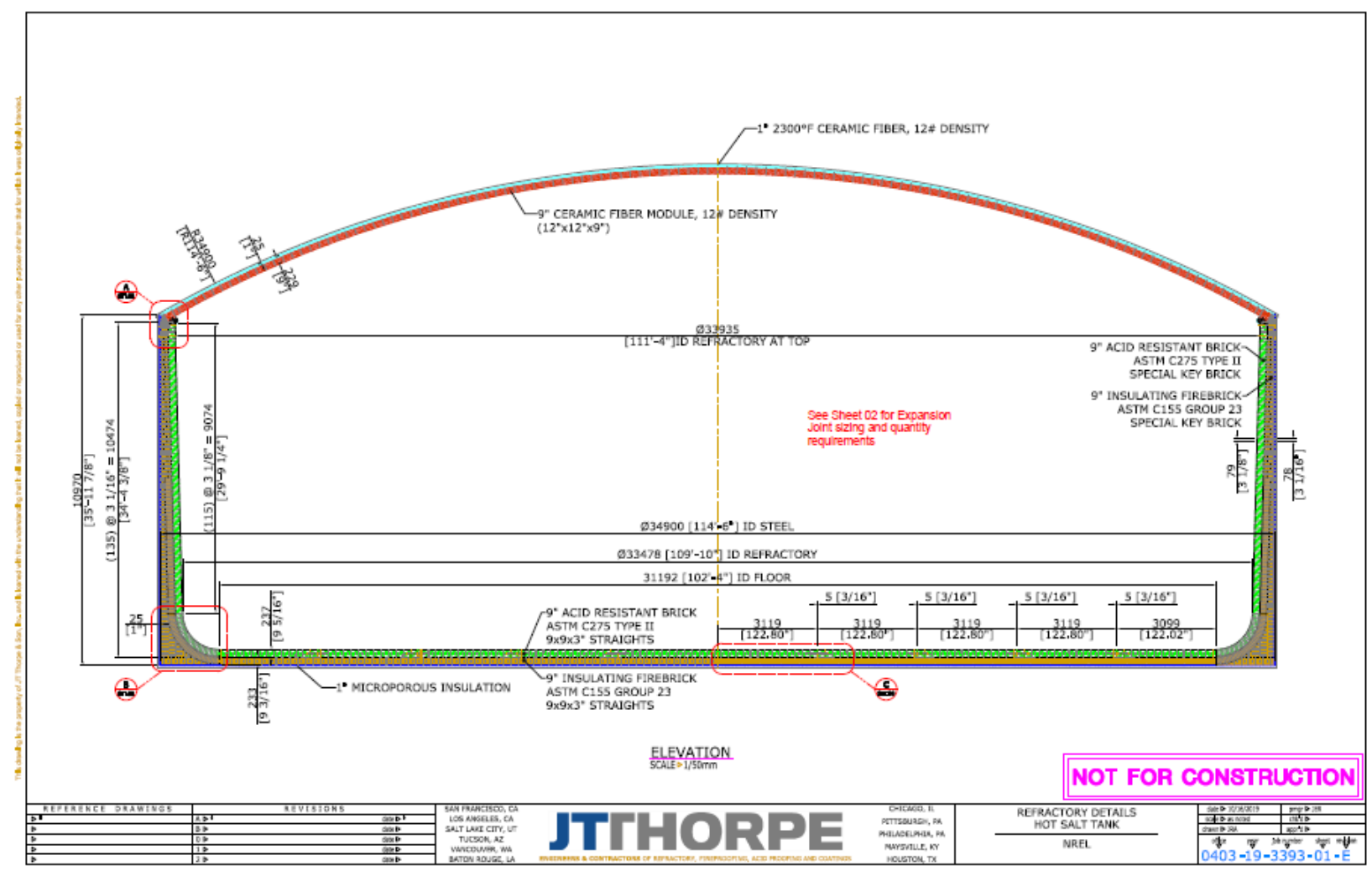

Figure 31. Representative commercial-scale tank design

Image courtesy of JT Thorpe

\subsubsection{Pilot-Scale Tank Design}

The purpose of the pilot-scale tanks is to address and derisk questions regarding performance of the commercial-scale design, including heat flux and mortar and expansion-joint integrity. The dimensions of the proposed pilot-scale salt tanks are shown in Figure 32 and specify an overall tank height of $22.5 \mathrm{ft}(6.86 \mathrm{~m})$ and an outer diameter of $21 \mathrm{ft}(6.40 \mathrm{~m})$. Total salt inventory is approximately 185 tonnes. The salt return line in each tank is a simple dip tube with three eductors oriented $120^{\circ}$ apart from each other and with a slight upward angle to reduce thermal stratification within the salt tanks. Each tank contains a single pump, a single immersion heater for freeze protection, and a 30-inch manway, which will be used for accessing the tank interior during construction. This manway will also be used for tank preheating and purging prior to introduction of molten salt. The tanks also include a crossover line to maintain a balanced headspace gas pressure and allow salt vapors to pass between the two tanks and out to an acidgas scrubber. Additional detail on the pilot-scale tanks can be found in Folder 02-Drawings, Process Piping Drawing Sequence 50-119, see Table 32. 

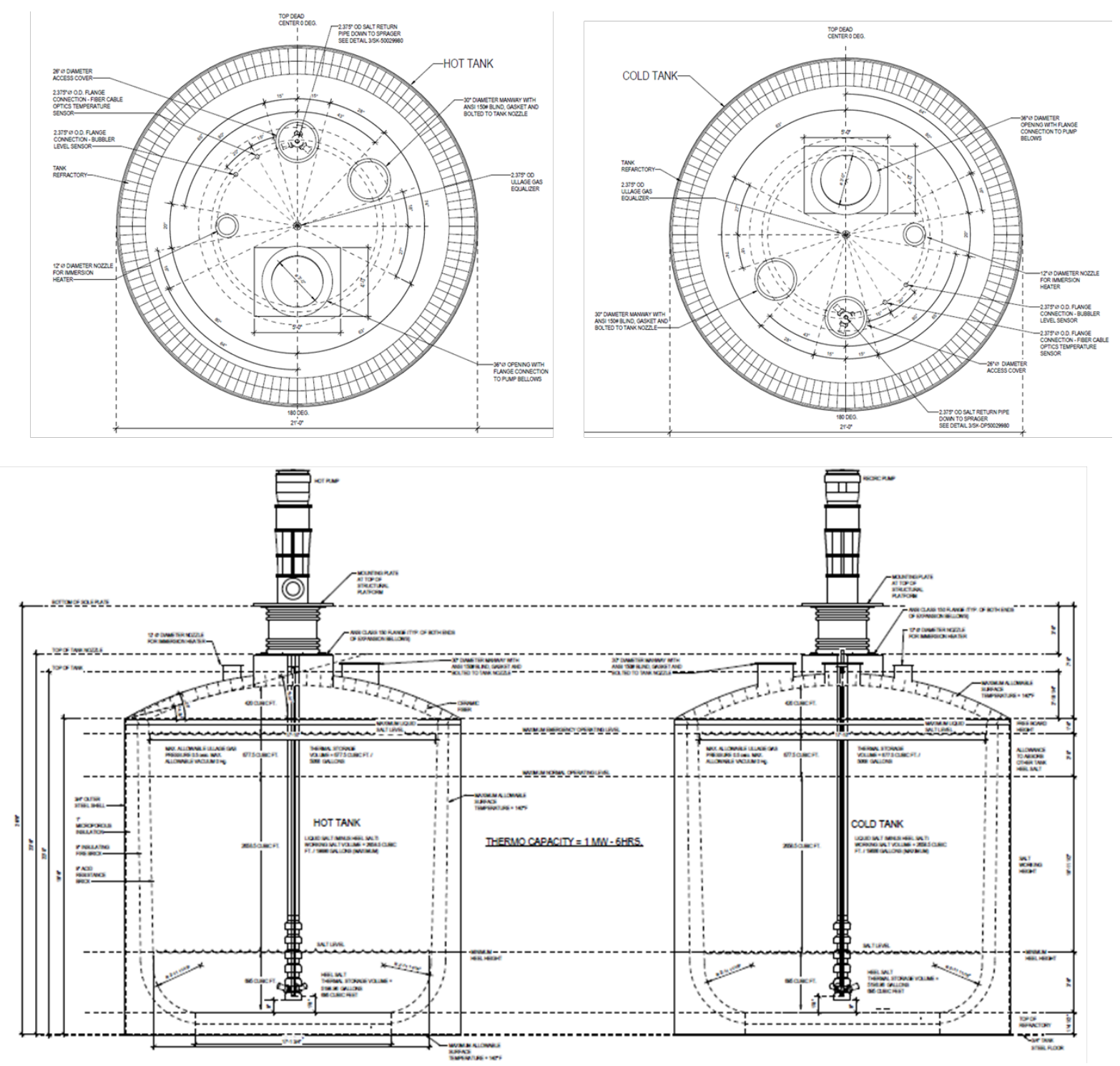

Figure 32. Dimensional drawings for the pilot-scale hot and cold tanks. Both tanks use the same liner design. Expansion joints in the floor and walls will test the ability of these joints to seal and maintain their integrity. Higher resolution image in Folder 12-Project Reports, Salt Tanks.

Image courtesy of Sandia

\subsubsection{Thermomechanical Modeling of the Pilot-Scale Salt Tank}

As in the case of the commercial-scale design, the pilot-scale tank shell is based on API Standard 650. The API 650 allowable (or design) stress limits for ASTM SA-516 Gr 70 material is 173 $\mathrm{MPa}(25.3 \mathrm{ksi})$, and physical properties (thermal expansion, modulus of elasticity, thermal conduction) were taken from ASME BPVC Section 2 Part D. The use of the experimentally derived modulus data obtained during Phase 2 results in less stress than what was reported in Phase 1 work on the commercial-scale design. The team is more confident in this model, as it more closely resembles expected behavior. All stresses are well within API 650 allowable limits and the temperature and heat flux remain within the project targets. Values were sampled across the floor and wall of the tank. Shell temperature is $30.5^{\circ} \mathrm{C} \pm 1.9^{\circ} \mathrm{C}$, and heat flux values are $240.2 \mathrm{~W} / \mathrm{m}^{2} \pm 29.8 \mathrm{~W} / \mathrm{m}^{2}$. 
During the pilot-scale tank design work it was determined that including a small gap (about $1 / 16$ ") between the refractory and the tank wall in the bottom corner area of the tank-a common practice in refractory liners - would significantly reduce tank shell stress during heat up. Such gaps are made by adhering a sacrificial template to the tank shell (e.g., cardboard or foam) or inserting a metal shim that is removed as the brick layers are added. This approach allows expansion joints to be reduced and potentially removed completely from the pilot-scale design. However, expansion joints cannot be completely eliminated from a commercial-scale tank, so three expansion joints will be included and tested in the pilot unit.

The thermomechanical stress on the tank shell was modeled in ANSYS. Given the modifications to the tank design in Phase 2 and the variability in some of the model input properties, a sensitivity analysis was performed. Several load cases were evaluated, but only the base (ideal) scenario and the high stress scenario are reported here in Figure 33.
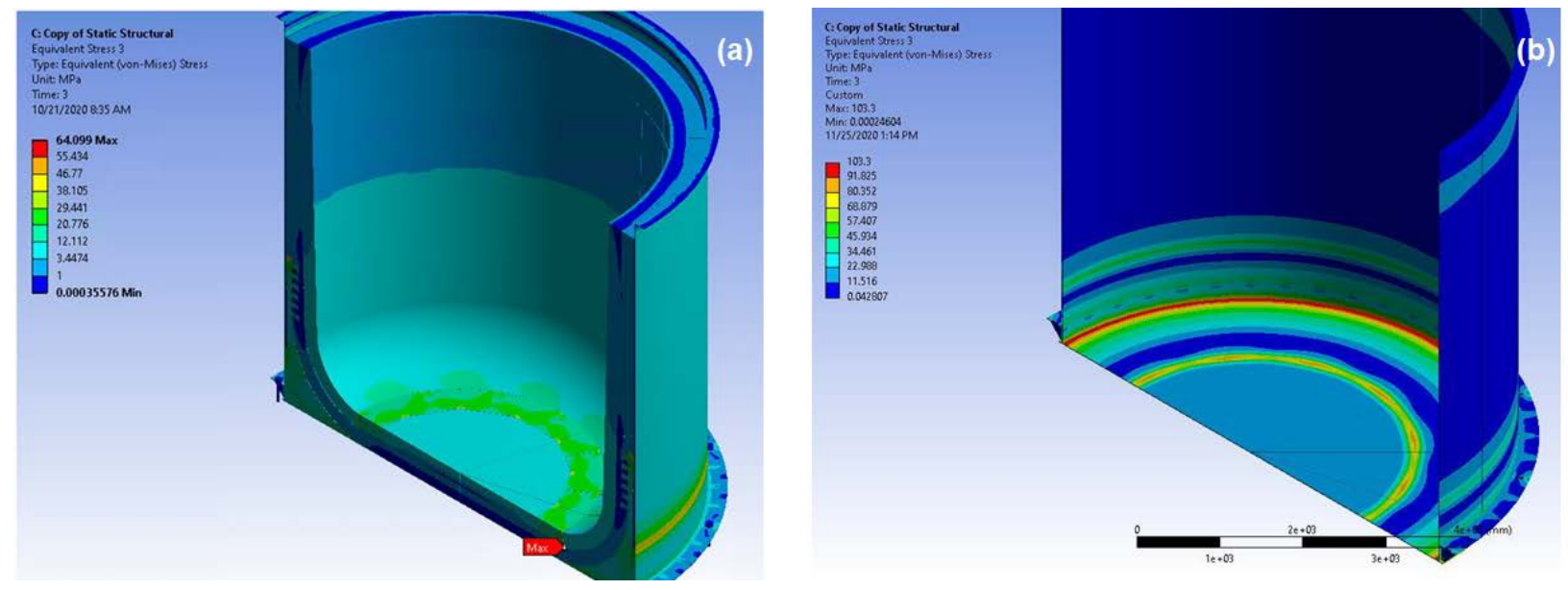

Figure 33. Predicted stress on pilot unit tank shell under ideal conditions with floor and tank wall temperature difference $\leq 10^{\circ} \mathrm{C}$ (a) and under high stress conditions with floor and tank wall temperature difference of $40^{\circ} \mathrm{C}(\mathrm{b})$.

Image courtesy of Job Industrial

The base case simulated an ideal scenario where convective heat transfer is the same across the floor and wall, and temperature variations are maintained within $10^{\circ} \mathrm{C}$ (Figure 33a). The most extreme case simulated a cold/rainy day, which induces a relatively large $\left(40^{\circ} \mathrm{C}\right)$ temperature difference between floor and wall (Figure 33b). While localized areas do see substantial stress increases (approximately $40 \mathrm{MPa}$ to $100 \mathrm{MPa}$ in the base and high stress cases, respectively), maximum stress values do not exceed API 650 limits (173 MPa). This sensitivity analysis highlights the stoutness of the tanks and demonstrates their durability even in extreme cases. However, the tank foundation cooling system should limit temperature gradients in the tank steel to a maximum of $25^{\circ} \mathrm{C}$, which is well within the bounds shown in Figure 33.

\subsubsection{Tank Foundation and Cooling System}

Both the commercial and pilot scale tanks utilize similar foundation designs - which directly supports evaluation criteria \#4 and \#5 (\$2). The approach uses a mat foundation supported by piles to keep overall and differential settlements to a minimum. Differential settlements increase the risk of cracking in the refractory, which is likely to lead to tank failures. Using geotechnical 
data from the Sandia site, foundation designs were generated. In the case of the pilot unit, tank settlements have been determined to be $7.1 \mathrm{~mm}$ maximum, the majority of which is assumed to be realized as soon as the tank is filled. The maximum differential settlement over 10 feet is estimated at approximately $1.3 \mathrm{~mm}$.

The foundation cooling system evolved from Phase 1 to Phase 2 of the project. A preliminary analysis of air-cooling options identified difficulties with temperature gradients in the commercial tank floor and limited control capabilities due to use of ambient air for cooling. As a result, a closed circuit, hydronic, in-slab water cooling system was proposed for the Phase 1 commercial-scale tank foundation. However, due to complexity and cost, the air-cooling system design was revisited for Phase 2.

In an ambient air-cooled system, only changes in cooling air flowrate can be used to moderate the tank floor temperature. This is challenging in variable environmental conditions: for example, windy and rainy vs. calm and dry. The team's solution is a system with highly variable airflow, relatively high-pressure capacity, and on-the-fly flow balancing combined with greater contact between the tank shell and the cooling channels.

The proposed air-cooled design utilizes square and rectangular tubes to maximize surface contact with the tank bottom. Neighboring tubes flow counter current. The tubes are mounted side-byside and welded together into a continuous mat. Not only does this provide structural support, but also has the effect of reducing the temperature gradient along the length of each tube. The pilot-scale tank is much less sensitive to temperature differences due to its small size, and only manual adjustments will be provided for airflow to the tubes. On a commercial tank it is anticipated that individual controls will be required for small groups of tubes to make sure that floor temperature variations are minimized. The pilot-scale design will be much less complex but should provide good indication of the control possible by adjusting individual airflows in cooling channels. This testing will be important input to the design of an air-cooled commercialscale tank foundation.

A system of ductwork and fans is necessary to feed cooling air to each of the cooling tubes in the right quantity to meet the cooling requirement at any given time. The cooling tubes each have a balancing gate that will be used to manually balance the airflow through the tubes. The tubes crossing under the middle of the tank will require the most airflow, while the tubes farthest on the outsides will require the least because they will pass under the shortest length of tank floor. It is important to balance the airflow to maintain a uniform floor temperature. Moderation of blowers will be performed manually based on the environmental conditions. However, airflow rates varying from $44 \mathrm{~L} / \mathrm{s}$ to $144 \mathrm{~L} / \mathrm{s}$ per channel may be expected in normal operation.

\subsubsection{Pilot-Scale Tank Preheating Protocol}

Following leads from JT Thorpe, NREL consulted tank preheating service providers in Q8. The basic design includes combustion gas preheating followed with a hot nitrogen purge to remove moisture and other combustion products.

NREL has been in discussion with two companies to help develop a tank preheating protocol: Hotwork and TEAM, Inc. Both companies recommend preheating the tanks with combustion gas and providing a post-heatup sweep of the residual moisture and air with hot nitrogen prior to 
introduction of the salt. In order to accommodate both combustion burner and nitrogen sweep equipment, the ports in the tank roof were modified by B\&P. The left side roof drawing in Figure 32 can be used as a reference. The liner preheat schedule recommended by JT Thorpe is as follows:

- 24-hour curing period at ambient temperature after the installation

- Heating continuously using propane gas burners at $50^{\circ} \mathrm{F} / \mathrm{h}(28 \mathrm{~K} / \mathrm{h})$ from ambient to $1400^{\circ} \mathrm{F}\left(760^{\circ} \mathrm{C}\right)$ with no hold times. This equates to a heatup of the hot tank over at $27-$ hour period.

- Nitrogen purge with gas preheated using a gas-to-gas heat exchanger with a diesel generator. The maximum temperature of the nitrogen is expected to be $800-1100^{\circ} \mathrm{F}$ $\left(426-593^{\circ} \mathrm{C}\right)$. Four volume turnovers will be sufficient to sweep the tanks, requiring a minimum total nitrogen volume of $\sim 80,000 \operatorname{scf}\left(2265 \mathrm{~m}^{3}\right)$ of nitrogen for a duration of $\geq 12$ hours for both hot and cold salt tanks.

For preheating the two tanks the work schedule is planned over six days, which includes site access, setup, fire time, and removal of the equipment. NREL will be required to subcontract the nitrogen purge service, as the preheating services do not specialize in hot nitrogen sweeping. NREL has been in contact with two contractors that can provide the hot nitrogen purge after preheating with propane combustion burners.

Given the thermal mass of the heated refractory liner and the short duration of the nitrogen purge, it is not expected that the colder nitrogen sweep will substantially cool down the liner. JT Thorpe anticipates no risk of thermal shock or opening of expansion joints during the nitrogen sweep process.

The preheat and nitrogen purge services will prepare their equipment above the tanks or fit their equipment on ground level with transport hoses extending to the tank roof (nominally 20 ' high). The tanks are equipped with a support structure above the tank roofs, intended for supporting the pumps, immersion heaters, supply lines, and analytical equipment. The preheat and nitrogen purge services will install their equipment above the tanks and will utilize different inlet and outlet ports, in order to streamline the transition from heatup to nitrogen sweep. Existing ports and penetrations on the tank roofs will be used for the tank preheating.

It is assumed that up to 1000 gallons $\left(3.8 \mathrm{~m}^{3}\right)$ of liquid propane will be needed to preheat both tanks. The tanks will be fully outfitted prior to heatup, in order to minimize heat loss (i.e., pumps, immersion heaters, and return line assemblies will be installed). Other notes:

- The preheating blowers will use the 30" manway for combustion gas input into each tank and exhaust through an outlet exhaust chimney in the same 30" manway

- Following heatup of tanks to $1400^{\circ} \mathrm{F}\left(760^{\circ} \mathrm{C}\right)$, the contractor will remove their inlet nozzles and exhaust chimney. Once preheat equipment is cleared from the area, the nitrogen purging will commence as soon as possible to minimize heat loss.

- Existing ports and penetrations on the tank roofs will be used for the nitrogen purge. The total amount of nitrogen needed for four volume turnovers of both tanks is approximately $80,000 \operatorname{scf}\left(2265 \mathrm{~m}^{3}\right)$.

- Hot nitrogen inlet will use the salt return pipe. This pipe extends to the bottom of the tank and terminates with three eductors designed to promote salt mixing inside 
the tank. The nitrogen purge contractor must advise whether this port will need to be equipped with fittings to accommodate their equipment.

- The nitrogen outlet will use the ullage gas equalizer/outlet line.

- Once the nitrogen sweep is complete, the contractor will remove all equipment from the tanks, whereupon molten salt will be introduced from the melter unit into the hot tank as soon as possible.

NREL has received a quote of $\$ 127,500$ for preheating and nitrogen purge, including fuel and gas costs.

\subsection{Salt Pumps}

The Gen3 Liquid Pathway benefitted from three salt pump suppliers - Sulzer, Flowserve, and Hayward Taylor-investigating chloride salt pumps in the wider Gen3 program. Sulzer and Flowserve both provided quotes for the pilot scale pumps, which have been incorporated into the system cost estimate. Hayward Taylor opted not to submit a quote but remains interested in bidding on the construction project should we graduate to Phase 3. Each pump team was supplied with salt property data, flow, and head-pressure values in order to design and bid the pilot-scale pumps.

\subsubsection{Pilot-Scale Pump Design, Sulzer}

A Topic 2 team lead by Powdermet, with their pump-technology partner Sulzer Corporation, selected an Ensival-Moret vertical turbine pump design which has been used in molten nitrate salts as the pump to be modified to use in chloride salts. The Powdermet project is focused on hard-coat and chemical-protective materials being developed for the bushings and sleeves. The selected pump is an API VS1 design vertical turbine design. The pump is a closed impeller type, 209-mm diameter, two-stage design with a design efficiency of $56.3 \%$. The pump curves for the hot pump are shown in Figure 34. This pump curve is also based on a rated flow of $35.2 \mathrm{~m}^{3} / \mathrm{h}$ and a head loss of $28.8 \mathrm{~m}$. The pump curves and pump performance levels are provided for four primary operational states: (i) rated point, empty tank, (ii) rated point, full tank, (iii) runout, and (iv) minimum continuous flow. The pump performances were determined for variable speeds between $60 \mathrm{~Hz}$ to $36 \mathrm{~Hz}$ for the hot pump. The cold pump is based on a rated flow of $25 \mathrm{~m}^{3} / \mathrm{h}$ and a head loss of $80.1 \mathrm{~m}$, see Figure 35.

The bowl assemblies for the pilot-scale system will have a bushing between each impeller/bowl assembly with a replaceable wear sleeve attached to the shaft. Molten salt will be used to lubricate each of these bushings. These bushings will have a running clearance of 0.003 in./0.005 in. diametrical clearance which should permit a $25-\mu \mathrm{m}$ particle (determined by research at $\mathrm{U}$. Wisconsin) to pass between the sleeve and bushing. Details on the Sulzer pump design can be found via Table 32 under Folder 12-Project Reports, Salt Pumps. 


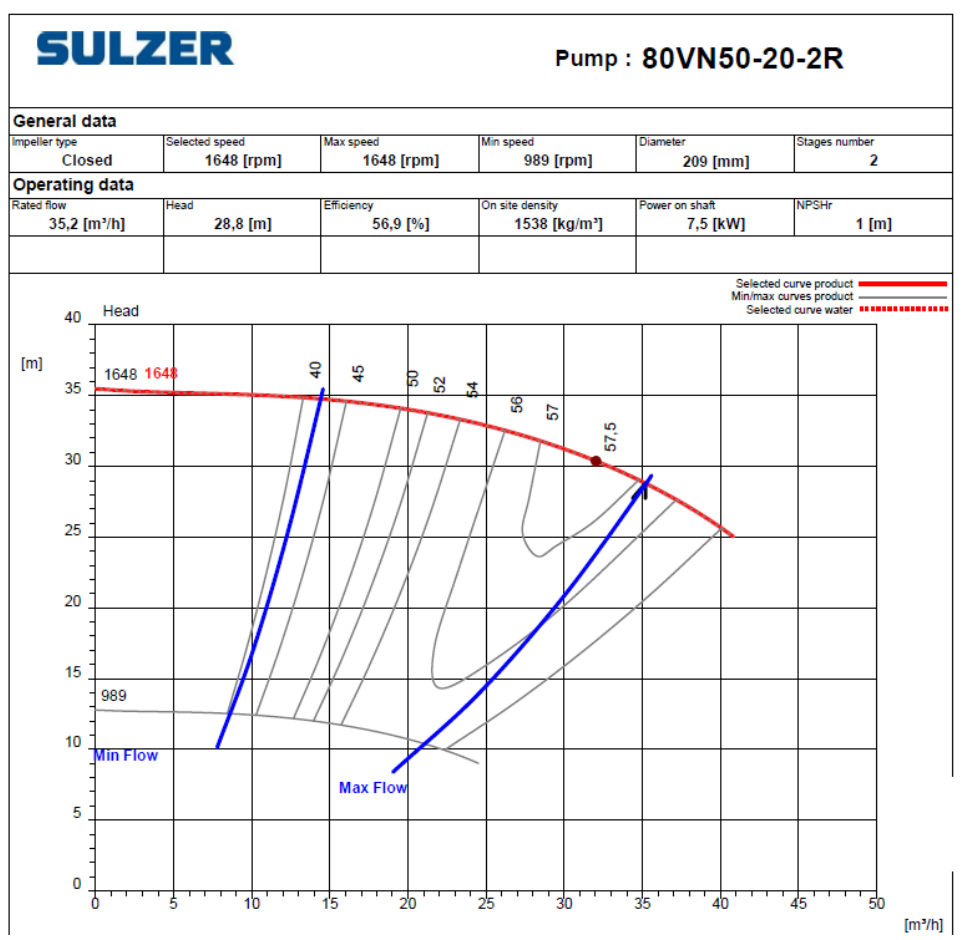

Figure 34. Sulzer hot-salt pump curves (head vs. flow). The hot pump is a two-stage design. Image courtesy of Sulzer

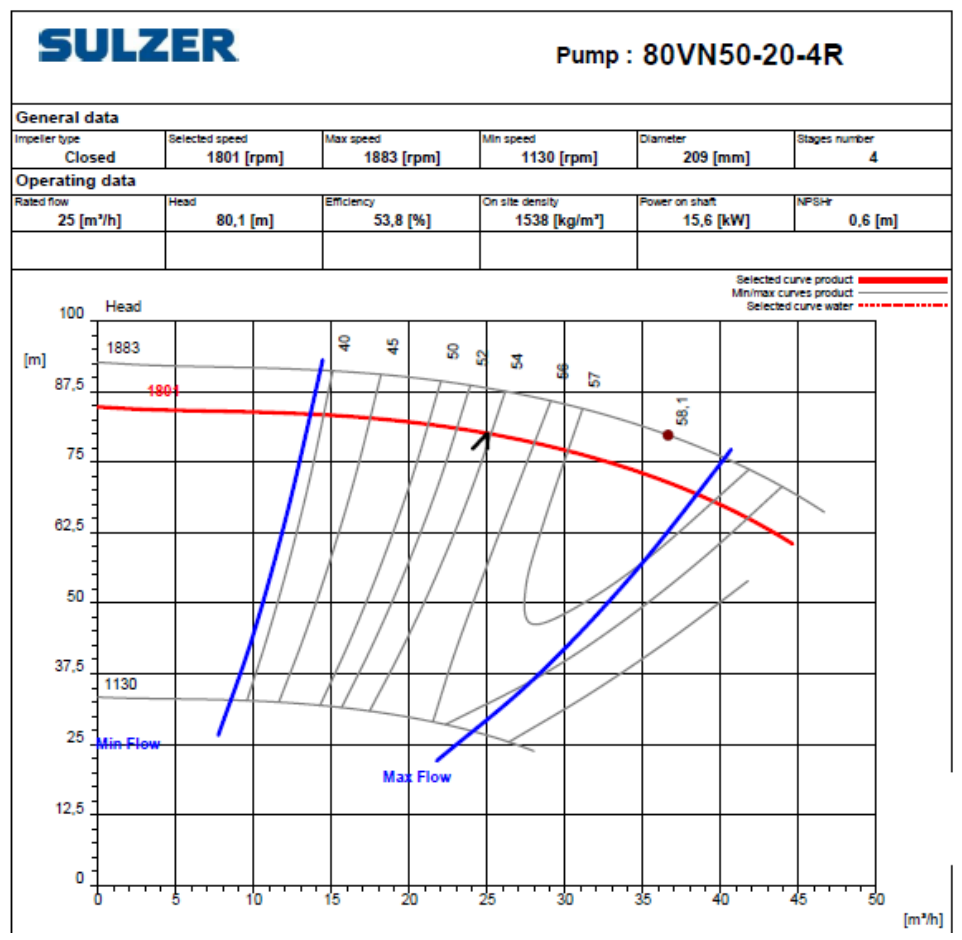

Figure 35. Sulzer cold-salt pump curves. The pilot-scale cold pump requires four stages (aka bowls) to deliver salt to the receiver level on the tower.

Image courtesy of Sulzer 
The Sulzer design work also developed requirements for $\mathrm{N}_{2}$ injection that is used to purge salt vapors from the upper pump shaft region. It has been decided to evaluate the introduction of the hard face floating rings in order to reduce the consumption of $\mathrm{N}_{2}$ that could be also introduced for the CSP Gen3 Liquid Pathway pumps. This investigation is still on-going and the possible integration in the existing validation pump design of floating carbon ring seal designs of two different suppliers are presently reviewed. The present design includes the larger nitrogen purge rate of approximately $5 \mathrm{scfm}$ per pump. $\left(8.5 \mathrm{Nm}^{3} / \mathrm{h}\right)$.

Sulzer undertook additional pump thermal analysis and particle clearance assessment for the pilot system design. Flowserve, under a related Topic 2 award, designed a pilot-scale salt pump and undertook a vibrational analysis associated with the pilot-scale civil works. This analysis led to inclusion of additional bracing on the pump platform. These studies can be found in Folder 12-Project Reports, Salt Pumps, see Table 32.

\subsubsection{Powdermet Cermet Coating Studies}

Materials studies R\&D led by Powdermet provided bearings and coatings for pumps. Over the last three years Sulzer collaborated with researchers at the University of Wisconsin - Madison (UWisc) for tribology testing of coatings. This testing was based on several grades of Powdermet's HybriMet cermet including the top performing HybriMet NiWC3b. Pin-on-disk wear data that show that NiWC3b to have a wear rate that is $20 \%$ of native $\mathrm{H} 230$ in the ternary chloride salt at $720^{\circ} \mathrm{C}$. The UWisc's Tribology Test Bed currently has $70 \mathrm{~kg}$ of purified ternary chloride salt in a holding vessel ready to be transferred to the test bed for additional tests.

Powdermet is evaluating spray-coated bowl components as well. It will be very difficult to spray coat the inside of the bowl passageways, but the leading edges can be coated which will add life to the high wear areas of the internal pump components. Mass loss and comparative corrosion tests were conducted in $720^{\circ} \mathrm{C}$ ternary chloride salt where the results can be seen in Figure 36 . Alloy 617 and 625 were coated with Cermet NiWC3b on one side. For control purpose samples of alloy 625 and 230 were tested without coating.

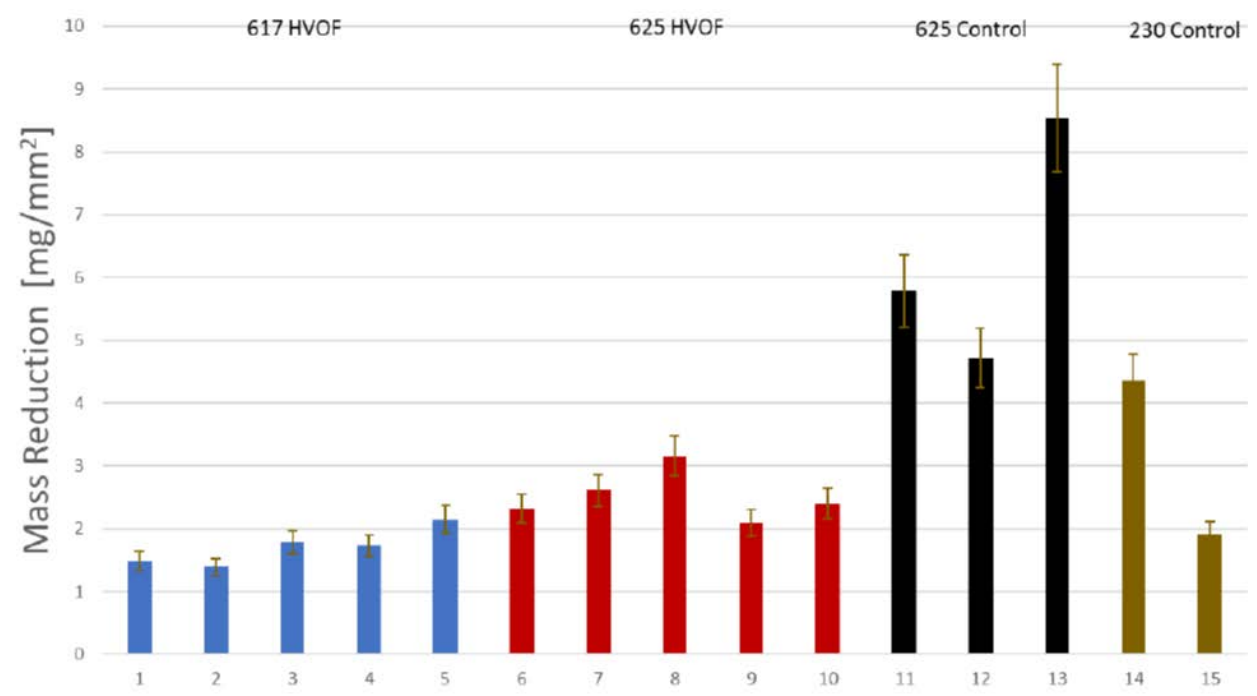

Figure 36. Static corrosion mass reduction tests in hot $\left(720^{\circ} \mathrm{C}\right)$ molten chloride salt Image courtesy of Powdermet 
The corrosion results indicated that Inconel 625 showed an average mass loss of $6.5 \mathrm{mg} / \mathrm{mm}^{2}$. Alloy 230 has a mass loss of approximately $3 \mathrm{mg} / \mathrm{mm}^{2}$, however with a high scattering. The coated samples show mass loss of less than $2 \mathrm{mg} / \mathrm{mm}^{2}$ for Inconel 617 and approx. $2.5 \mathrm{mg} / \mathrm{mm}^{2}$ for Inconel 625. This indicates that the Cermet shows better corrosion protection than all bare alloys including Haynes 230 and that Inconel 617 is superior to Inconel 625 in terms of corrosion resistance.

\subsubsection{Pilot-Scale Pump Design, Flowserve}

Another Topic 2 project, led by MIT, includes a Flowserve design of a vertical-turbine pump for molten-chloride applications. Flowserve has been an industry leader in the development of multistage vertical turbine molten nitrate salt pumps for CSP solar plants around the world. Their molten salt pumps have a strong history of being employed in R\&D projects. They have incorporated into an API VS1 design vertical turbine pump many features which has afforded respect in supplying molten salt pumps. Features such as a water-cooled thrust bearing housing, which is replaceable without pulling the pump is very important as it is often a first failure point with commercial salt pumps. Another key feature is the design of fans that effectively reduce heat migrating up the shaft to the thrust bearings.

Flowserve pump curves and design information can be found in the supporting information as outlined in Table 32, Folder 12-Project Reports, Salt Pumps. These pump curves for the cold and hot pump are based on a head pressure of $91.8 \mathrm{~m}$ and $36.2 \mathrm{~m}$, as well as operational temperature ratings of $500^{\circ} \mathrm{C}$ and $735^{\circ} \mathrm{C}$ respectively. The Flowserve cold salt pump will require 12 stages (aka, bowls) and hot salt pump four bowls to achieve the desired head pressure. While bowls are readily added to provide additional pressure capability, each represents a failure point within the pump where thermal-mechanical gradients and stresses can facilitate potential material issues and galling. Fewer bowls typically improves pump reliability.

Flowserve provided price estimates for the commercial-scale system that were consistent with the estimates obtained from Sulzer. However, the Sulzer quote was more detailed and was used for the costing exercise discussed in $\$ 3.2$.

\subsection{Salt Valves}

As summarized below, globe valves are currently favored for use in molten salt systems, especially at the size required for the pilot-scale facility. Gate valves have been used in commercial plants but lack the operational throttling range compared to globe valves. Tripleoffset butterfly valves show promise for use as lower-cost diversion valves in commercial plants. In all cases, welded construction is recommended, and materials of construction must be selected to avoid cold-welding of components due to the fluxing nature of the chloride salts. Dissimilar facing materials and coatings are recommended to address this concern.

\subsubsection{Salt Valve Requirements}

The Liquid Pathway project was not tasked with developing molten salt valves but was responsible for integration of knowledge from Gen2 molten-salt systems and other valve-related projects funded by DOE. General guidelines for molten-salt service are described next, followed by a summary of Gen3 salt valve work. 
Materials. Chloride salts at high temperature may act as a flux, stripping away protective oxide layers. Literature on chloride salt corrosion and material compatibility focus on the use of high temperature nickel-based alloys such as C276, IN617, and H230, especially at hot salt conditions. Lower cost materials are only possible if chloride salt purification [27] and corrosion inhibition concepts are realized [38]. The fluxing nature of halide salts must be addressed by choosing metallic coatings or dissimilar metals for mating surfaces. Cermets have shown promising results as candidates for protecting valve internals [39]. Low-Cr Colmonoy 5 and boriding are also candidates for coatings.

End Connections. Butt-welded ends are recommended in all salt valve applications to avoid inevitable flange leaks associated with daily thermal cycles and process transients. Where mechanical joints are unavoidable compact flange design (e.g., Grayloc ${ }^{\circledR}$ Compact Flange) or Ring Type Joint (RTJ) flange is recommended. The compact flange design has lower mass resulting in reduced thermal gradients and more easily managed trace heating. Compact flange premium will be partially mitigated for elevated temperature applications, demanding high nickel specialty alloys due to the reduced overall mass. When flanges are used, higher than required ANSI pressure class has been alleged to experience fewer leaks, though this practice should be limited to areas of relatively stable thermal conditions. Also, flanges should be located in horizontal runs, use dedicated trace heating with removable enclosure, and incorporate leak barriers and drip pans to prevent salt leaks from spreading into adjacent piping.

Stem Packing. Unlike in nitrate salts, valve sealing materials of carbon/graphite are acceptable in contact with molten chloride salt. In hot salt service leaks progressed quickly due to the influence of process temperature entering the bonnet extension [9] [40]. While chloride salt is non-oxidizing, the hot side conditions may lead to oxidation via air, should that reach the seal. A hermetic seal is recommended as the best practice to prevent seal leakage on valves in critical service. This can only be accomplished using a bellows seal and currently a globe valve is the only suitable application for salt control and isolation with bellows seal technology [9].

The rotary action of triple-offset butterfly valves has been shown to place less stress on the packing in comparison to translating stem [41]. A financial argument could be made to support the use of this style of valve for large bore isolation applications, due to the significant difference in capital cost for large bore globe valves with a bellows seal. However, cost trade-offs on lost revenue associated with a valve malfunction should be considered since butterfly valves due have inherent design reliability issues. There may also be support from CSP stakeholders to develop a qualification programs, for large bore rotary valve sealing technology.

Body-to-Bonnet Gaskets. Thermal cycling and transient process temperature can lead to leakage from body-to-bonnet seals. The seal should be designed for metal O-ring or C-ring seals. The bonnet bolting should also be qualified for high torque and consideration given to using torqueto-yield studs in applications anticipating exposure to transient thermal process conditions (e.g., CSP receiver outlet conditions).

Globe Valve. Globe valves are favored for molten salt service. Operational experience and consultation with valve manufacturers concluded that the following trim details were advisable:

- Plug - full continuous hardfacing.

- Seat - full bore hardfacing. 
- Stem - lower \& upper gallery assembly hardfacing, upper gallery hardfacing to extend beyond full-stroke area of packing assembly.

- Bellows Seal - use of shroudless Inconel 625 LCF bellows seal on control valves and critical service shutoff applications.

- Body to Bonnet - metal O-ring (silver coated, tubular Inconel seal); and body thread design to accommodate high-torque or torque-to-yield (TTY) studs.

- Trace Heating - dedicated heating zone(s) on bonnet assembly and body; and, in addition to typical surface temperature probes, two extra temperature measurements: i) internal cold end bonnet / bellows, and ii) valve body upper gallery region.

Opponents to bellows seals raise concern over capital cost and risk of seal damage if frozen salt is present when the valve is stroked. While valid concerns, the loss of revenue and associated costs for overhaul of the Crescent Dunes receiver inlet control valves support specification of bellows in control service. Improved monitoring and control of valve and bonnet trace heating can address risk of salt freeze damaging the bellows. Requiring a secondary steam seal with leak detection eliminates risk of blow-out.

Triple-Offset Butterfly Valve. Triple-offset butterfly valves have been used successfully for isolation and provide a lower cost option to globe valves. However, wafer and conventional flange configurations should be avoided due to difficulty resolving leaks as referenced in early molten salt test programs [42]. It is recommended that butt-welded end configuration be specified with factory installed pups of one pipe diameter length. An extended bonnet is required for managing packing temperature.

Gate Valve. While gate valves were used successfully on Solar Two as replacements for failing ball valves, commercial off-the-shelf designs require customization and qualification for high temperature molten salt service. However, for reliability and common spares inventory, designers typically opt for globe type valves. Scenarios where pressure loss is a concern may drive the decision to use gate valves.

Typical gate valve designs are not heavy wall, like globe valves. Thermal cycling will cause the piping system to move around, subjecting the body to various bending and torsional loads. If the body distorts over time, the plug may start to bind and or fail to provide tight shut-off.

The seat area of a gate valve is typically larger, and seating surfaces move parallel to each other. As discussed earlier, cold welding in high temperature salt applications is a concern. If the valve is closed for a long enough period, corrosion products will fuse the seat and plug, leading to binding or stuck valve. Seating force is high in gate valves which will contribute to the issue of binding. Globe or triple-offset butterfly valves, by comparison, have seating surfaces that act normal to each other with less contact area and requiring lower forces.

Another scenario that can create binding is when a valve is closed when it is too hot. The seat will shrink around the plug as the valve cools, potentially causing a stuck valve. This is not unique to molten salt, but thermal transients expected in high temperature service may limit gate valve applications to cold service where temperature variation is moderated. Stem packing would be similar to globe valves. Linear actuation does permit the use of bellows seal design for gate valves. For these reasons, gate valves are presently not recommended for molten chloride salt 
service; however recent discussion with Flowserve indicate there may be development to qualify gate valves for high temperature chloride salt service depending on down-selected subcomponent compatible materials.

Ball Valve. Most suppliers do not recommend use of using ball valves in molten salt service. Ball valves typically cannot handle the same bending and torsional loads as globe valves. Comparatively tight clearances of ball valve are more susceptible to binding as the result of distortion from thermal cycling, vibration, and hydraulic shock. Field experience at Solar Two documents numerous failures of ball valves, ranging from internal leaks (bypass), high internal static friction, and external leaks [40]. However, recent research work with valves companies Jarecki and Gosco have suggested that inset, boronized-nickel coated ball valves can minimize seizing issues while still facilitating a reliable shut-off operation at high-temperatures.

Check Valves. Check valves offer a means to eliminate cost and failure points in the molten salt transport system. Commercial CSP tower projects require multiple cold and hot salt pumps operating in parallel. The use of check valves could reduce cost by eliminating shut-off valves. Swing check and tilting disc designs are the best candidates. However, EPC companies, particularly in Europe, have optioned to exclude check valves in salt service over concerns that the valves will not function properly. (NOTE: Similar to the note above for gate valves, discussion with Flowserve indicated that development initiatives are in process to qualify check valves for high temperature chloride salt service that incorporate cermet components and coatings that will help promote the use of check valves.)

Freeze protection heating. Ceramic fiber $(\mathrm{CF})$ heaters have been identified as a preferred heat trace approach for Gen3 salt piping. However, much of the heat trace in the pilot unit has been replaced with lower cost options due to the relatively short operational life and cost challenges of the pilot system. CF heaters are planned on the system valves and will be tested with the flow control valve (FCV) at FASTR (see next section).

\subsubsection{Gen3 Salt Valve Development}

Salt valve development was not a task within the Liquid Pathway project, but concern regarding the estimated cost and performance of valves in chloride salt led the team to purchase a 2 " flow control globe valve for testing within the FASTR loop at ORNL (Figure 37). The objectives for this testing are to evaluate or characterize (i) actuation performance over varying temperatures, (ii) salt containment efficacy with the packing and $\mathrm{N}_{2}$ ullage gas purge port, (iii) $C_{\mathrm{v}}$ operational performance, and (iv) thermal gradients for varying $\mathrm{CF}$ heating profiles and salt temperature. The valve has two packing sets to control liquid-phase salt leakage, separated by a nitrogen ullage gas purge port. This valve design will not include a bellows seal due to cost and schedule but will provide a means of characterizing the design of packing and gas purge port for mitigating salt-leakage at temperatures up to $720^{\circ} \mathrm{C}$. Instrumentation of the FCV and associated heaters will evaluate thermal gradients that occur due to its design and selected materials. The valve will be forged from Hastelloy C-276 material, which will provide higher strength than a casting at these high temperatures. Testing was planned for fall 2020, but FASTR has experienced delays due to availability of other components. This testing is currently being pursued with other DOE-funded salt valve related projects. 
Additionally, a 2" Gosco ball valve test was facilitated at Sandia. The SS316H valve was developed to operate with the Gen3 ternary chloride salts at high temperatures, leveraging a boronized-Ni coated recessed-groove ball. This experiment also evaluated the efficacy of a novel bi-material (graphite and thermiculite) spiral-wound gasket for raised-faced flanges. The test program plans to actuate repeatedly at successive temperatures up to $720^{\circ} \mathrm{C}$.

The team was able to complete testing at the first temperature point of $530^{\circ} \mathrm{C}$ and actuate it successfully without any visible leaks from the new spiral-wound gaskets. Further testing was not able to be completed prior to this reporting date. At last status the test was paused due to a $\mathrm{N}_{2}$ ullage gas issue that occurred downstream from the valve due to improper heating on this ullage gas line. The testing and further evaluation of the valve's internal integrity however is still ongoing.
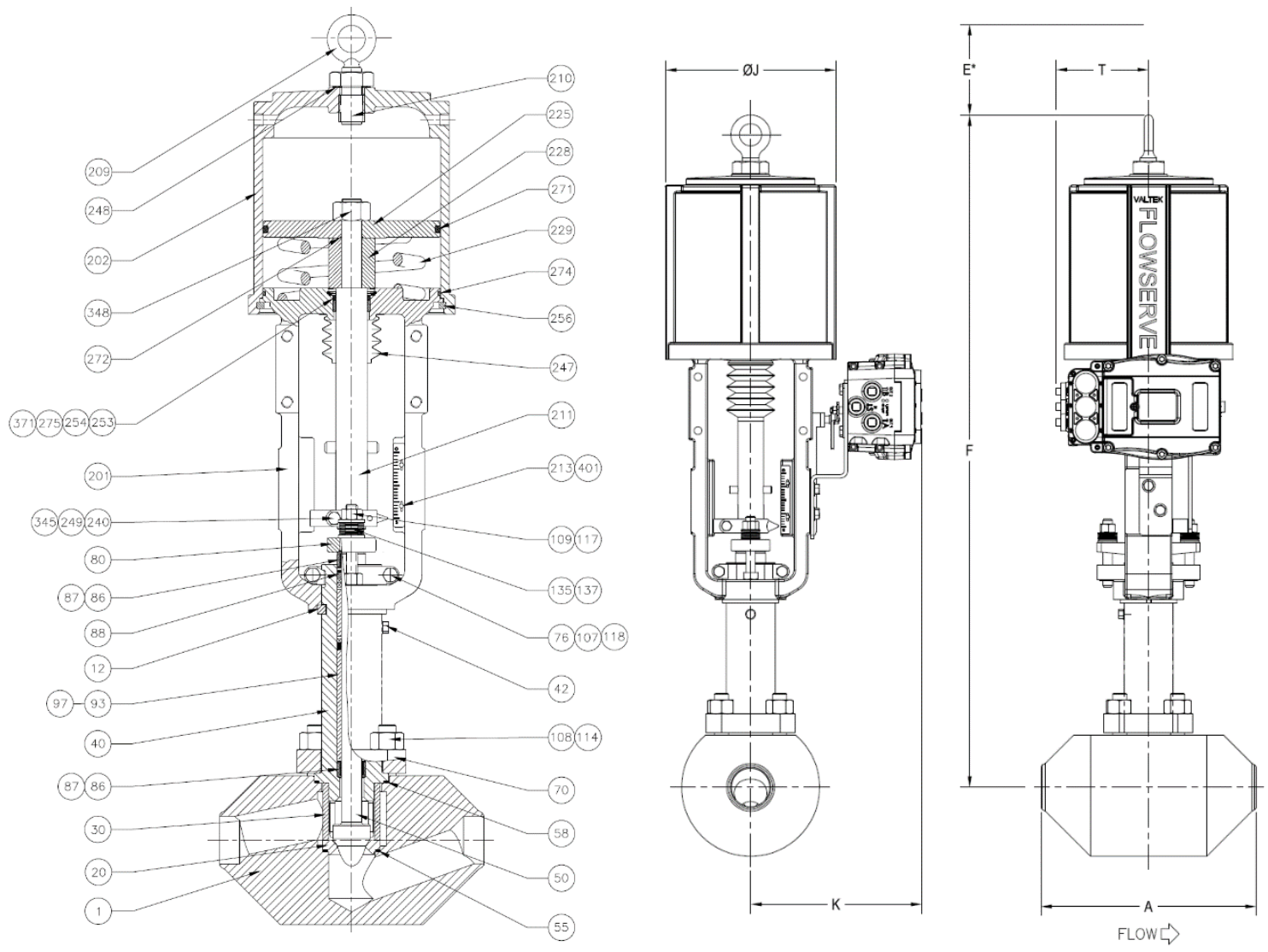

Figure 37. Globe valve procured for testing at FASTR loop

Image courtesy of Flowserve

Advanced Valve Development. A separate DOE project is funded to develop an advanced molten salt valve capable of operation up to $750^{\circ} \mathrm{C}$ with the $\mathrm{Gen} 3$ ternary-chloride salt. This project is a collaborative partnership between Sandia, Flowserve Corp. and Kairos Power LLC. The team has developed two designs for the advanced molten salt valve to provide leak-resistance and reliable operation. Project details can be found in Folder 12-Project Reports, Salt Valves, Adv Molten-Salt Valve Project, see Table 32. 
The first design is for a 2" CL 900 valve layout, created with a bellows seal and a back-up set of twin packing. As shown in Figure 38, this design includes a bellows gas purge port, a bellows pressurization port, and a packing pressurization port. The bellows-gas purge port allows accumulated gas to be purged from the top of the bellows thus reducing the corrosive effects of the gas. The bellows pressurization port allows the inside of the bellows to be pressurized so the differential pressure across the bellows is reduced, thus significantly increasing the cycle life of the bellows. The packing pressurization port pressurizes the packing so that if the packing leaks, the pressurization gas leaks into the valve instead of molten salt leaking out of the valve.

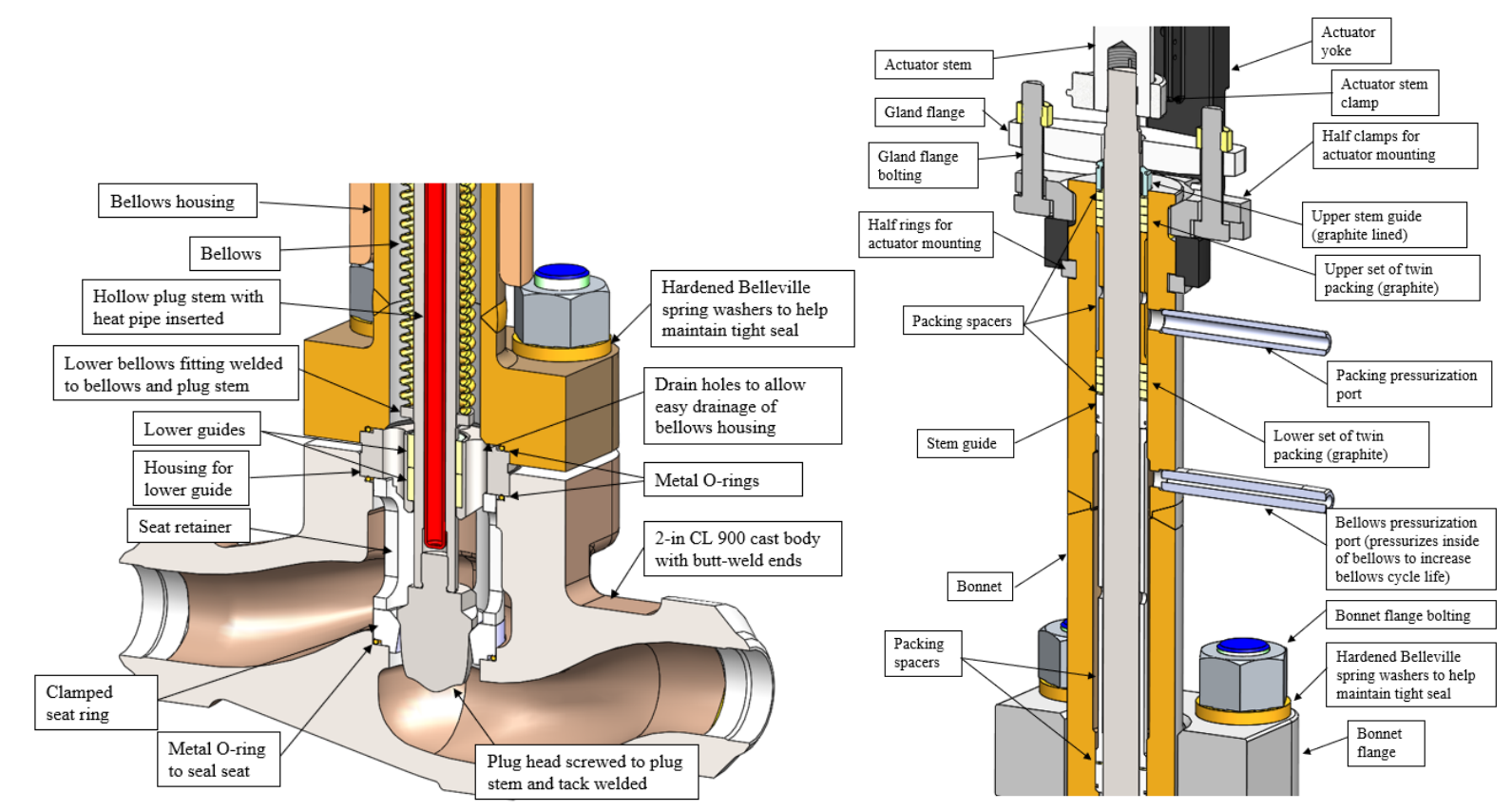

Figure 38. Globe valve design for molten-salt service featuring a bellows seal design

Image courtesy of Sandia

The second globe valve design, Figure 39, does not have a bellows seal but has a quick-change packing canister system which allows the packing to be easily changed out. This design is also significantly less expensive. The packing canister also utilizes a packing pressurization port which pressurizes the packing so if the packing leaks, pressurization gas leaks into the valve instead of molten salt leaking out of the valve. 

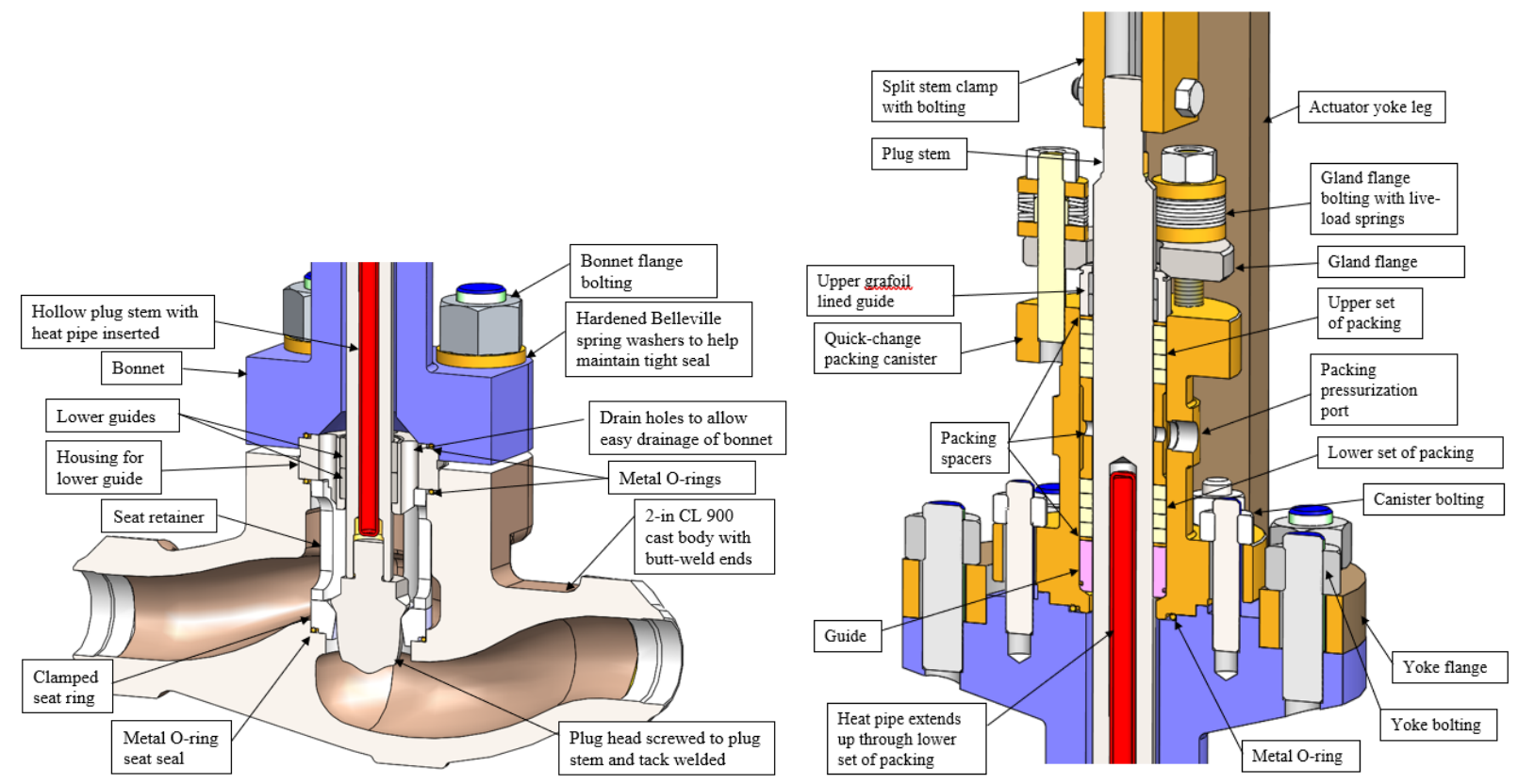

Figure 39. Globe valve design for molten-salt service featuring a quick-change packing canister

Image courtesy of Sandia

In addition to the overall valve mechanical design, Flowserve has recently developed several options for integrated thermal management and monitoring systems. The Self-contained Thermal Management system (STM), Figure 40, is a removable shell clamped around the bonnet or critical parts of the valve with built in heat tracing, thermal sensors, and controls that monitor the state of the valve to keep it from freezing up or determine when it is safe to stroke the valve.
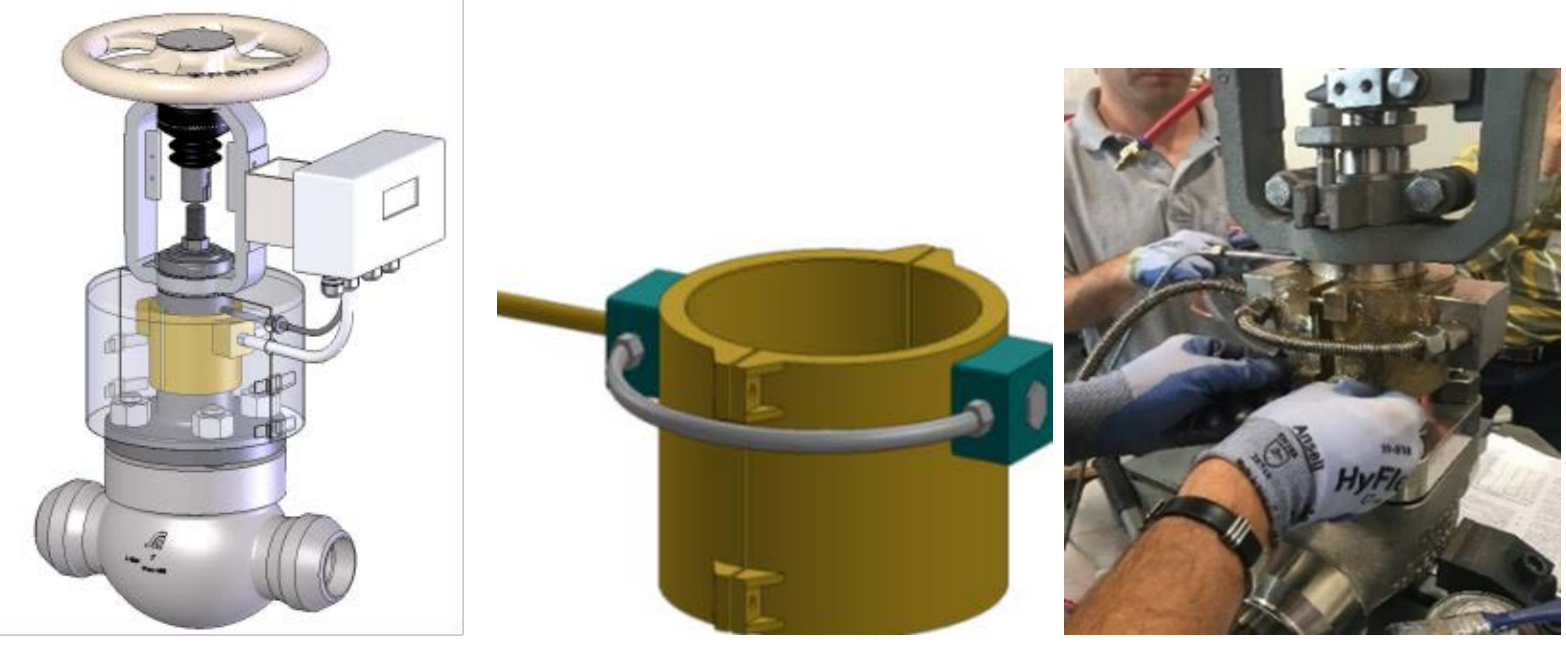

Figure 40. Valve self-contained thermal management system

Images courtesy of Sandia

Another feature is a hydraulic dampener, which is a hydraulic cylinder shock absorber that is fitted to a pneumatic actuator for absorbing pressure spikes and keeping the valve stable. It is an alternative to using hydraulic actuators which would be the first recommendation for valves that 
might see pressure spikes. A specialized trim is provided for either control curve characteristics or for anti-cavitation or passive pressure surge control. Additionally, an added StarPAC design offers a unique feature of providing pressure measurement on both inlet and outlet sides of the valve, which can be used to characterize flow across the valve. This flow measurement ability can offer plant operators more flexibility and control, particularly at high temperatures.

Observations during design showed that spring energized washers under the bonnet bolting with the pressurized metal O-ring seals were found to work very well in keeping the valve sealed during semi-rapid thermal gradient transitions such as what could occur during pilot system operations.

The vendor recommends globe valve ramp temperatures for preheating the valves to be less than $35^{\circ} \mathrm{C} / \mathrm{min}$. Additionally, the valve team noted that maintaining a temperature of at least $500^{\circ} \mathrm{C}$ to avoid salt deposition from vapors. (The bulk salt solidification temperature is $\sim 400^{\circ} \mathrm{C}$, while salt vapors may deposit at temperature of $\sim 480^{\circ} \mathrm{C}^{9}$ ). Finally, valve orientation in the system will be critical to ensure gasses don't become trapped in the bonnet to minimize damage if both the bellows seal and packing fails.

\subsection{PHX and $\mathrm{SCO}_{2}$ Heat Rejection System}

The primary heat exchanger (PHX) transfers heat from salt to the $\mathrm{sCO}_{2}$ fluid to drive the power cycle. Testing the PHX is an objective of the pilot-scale system, although there is no power turbine on the small-scale $\mathrm{sCO}_{2}$ loop. The $1-\mathrm{MW}_{\text {th }}$ pilot-scale $\mathrm{PHX}$ will be constructed as a PCHE design. PCHEs are becoming commonplace in industry and several suppliers (e.g., Heatric, Hexces, and Vacuum Process Engineers, VPE) are known to the team.

Project member VPE has identified and tested shim manufacturing and bonding for alloys of interest under the Liquid Pathway project. A single core, Alloy 617 (N06617) unit has been selected based on results from shim fabrication, diffusion bonding, and component integration design efforts described in more detail below. Alloy 617 has acceptable compatibility with both hot salt and $\mathrm{SCO}_{2}$, has an existing chemical etching supply chain, and is expected to be able to meet diffusion bonding qualification requirements under the ASME BPV Code. Internal and external trace heating will be used for freeze protection and freeze recovery, and a combination of excess flow and check valves on the $\mathrm{sCO}_{2}$ system and salt dump tanks with burst disks will be used to mitigate the consequence from an internal failure causing pressurization of liquid salt with high pressure $\mathrm{SCO}_{2}$. A split material unit (different hot and cold zone materials) is still expected for the commercial-scale system to provide a cost savings of nearly $30 \%$ vs. a singlecore design.

Several alternatives to chemical etching for shim fabrication were explored for nickel alloys N06617 and N06230 including electrochemical machining, mechanical, laser milling, and hybrid additive manufacturing as summarized in Table 10. Mechanical machining was initially selected as the most practical alternative to chemical etching, however further work with a foreign chemical etcher has demonstrated that etching N06617 at scale is practical. This etcher was used to produce shims for a MW-scale Heatric PCHE and is currently contracted to produce N06617 shims for the high-temperature recuperator (HTR) for the $\mathrm{Gen} 3 \mathrm{CSP} \mathrm{sCO}_{2}$ coolant loop.

\footnotetext{
${ }^{9}$ Binary-chloride salt vapors, e.g., $\mathrm{KMgCl}_{3}$, may freeze at higher temperatures than the bulk salt.
} 
Table 10. Summary of shim fabrication results from this and other projects

\begin{tabular}{|l|l|l|l|l|l|}
\hline Method & $\begin{array}{l}\text { Chemical } \\
\text { Etching }\end{array}$ & $\begin{array}{l}\text { Electro- } \\
\text { chemical } \\
\text { Machining }\end{array}$ & $\begin{array}{l}\text { CNC } \\
\text { Mechanical } \\
\text { Milling }\end{array}$ & $\begin{array}{l}\text { Laser } \\
\text { Milling }\end{array}$ & $\begin{array}{l}\text { Hybrid } \\
\text { Additive }\end{array}$ \\
\hline Quality & Acceptable & Acceptable & Acceptable & Acceptable & Acceptable \\
\hline Cost & Low & High & Moderate & Moderate & Low \\
\hline Throughput & Moderate & High & Low & Low & High \\
\hline $\begin{array}{l}\text { Suitability for } \\
\text { Nickel Alloys }\end{array}$ & $\begin{array}{l}\text { Only feasible } \\
\text { for N06617 }\end{array}$ & Any alloy & Any alloy & Any alloy & $\begin{array}{l}\text { Only N06230 } \\
\text { tested }\end{array}$ \\
\hline
\end{tabular}

Pilot-Scale Design. The specific design options for the 1-MW th $\mathrm{PHX}$ are shown in Table 11 with the mass, height, and UA of the commercial-scale $\sim 100-\mathrm{MW}_{\text {th }}$ unit scaling linearly with duty. Two design options were pursued using either a single PHX core comprised of a high nickel alloy or two cores in series split into nickel alloy and stainless-steel units to reduce the overall cost of the $\mathrm{PHX}$. This was feasible because the high heat transfer coefficients of both the molten salt and $\mathrm{sCO}_{2}$ enable a close approach temperature of only $20^{\circ} \mathrm{C}$, leading to about half of the single core design operating at temperatures below $615^{\circ} \mathrm{C}$. Splitting the heat exchanger does increase the overall length and pressure drop of both fluids but results in only two thirds the cost of the single core heat exchanger and will allow for separate maintenance and replacement in the pilot plant. The singlecore unit was chosen for the pilot scale system as the increased cost was acceptable given the tradeoff in reduced complexity. Additional detail on the PHX can be found in Folder 12-Project Reports, $\mathrm{PHX}$ and for the $\mathrm{sCO}_{2}$ System at Folder 14-sCO $\mathrm{S}_{2}$ Subsystem, see Table 32.

Table 11. 1-MW $\mathrm{MW}_{\text {th }}$ pilot-scale heat exchanger designs. A single-core design will be used for simplicity despite the slightly higher cost.

\begin{tabular}{|l|l|l|l|}
\hline Metric & Single & Split-Ni & Split-SS \\
\hline Relative Cost & $8.4 \mathrm{x}$ & $4.7 \mathrm{x}$ & $1 \mathrm{x}$ \\
\hline MAWP / bar & 280 & 280 & 280 \\
\hline MDMT / ${ }^{\circ} \mathrm{C}$ & 726 & 726 & 625 \\
\hline Material & 617 & 617 & $316 \mathrm{SS}$ \\
\hline Salt dP / bar & 0.32 & 0.28 & 0.33 \\
\hline $\mathrm{sCO}_{2} \mathrm{dP} / \mathrm{bar}$ & 2.2 & 1.9 & 1.0 \\
\hline Mass / kg $^{\mathrm{k}}$ & 1200 & 680 & 530 \\
\hline Length / ft & 3.1 & 2.1 & 2 \\
\hline Width / ft & 1.2 & 1.0 & 1.0 \\
\hline Height / ft & 1.4 & 1.3 & 1.1 \\
\hline UA / kW/K & 47 & 22 & 20 \\
\hline
\end{tabular}

Each of the three Gen3 pathway proposals will integrate with an $\mathrm{sCO}_{2}$ system at the $\mathrm{PHX}$ that will include a heat rejection system. This subsystem represents the power cycle for the pilotscale tests. The cost of this $\mathrm{sCO}_{2}$ system is borne by a separately funded project that collaborates with each Gen3 Topic 1 awardee. The $\mathrm{PHX} / \mathrm{sCO}_{2}$ layout configuration for the Gen3 Liquid 
Pathway system involved a number of component design selections, particularly regarding air compressor and the chiller NQVA-30 cooling system. The current electrical design considers a maximum draw of $583 \mathrm{~A}$ ( $325 \mathrm{~kW}$ at 0.7 power factor). The system design as shown in Figure 41, consists of a 16' $\times 16$ ' footprint where the present configuration is included within the overall ground-level system. Additionally, an air-driven fill pump was added to the design.

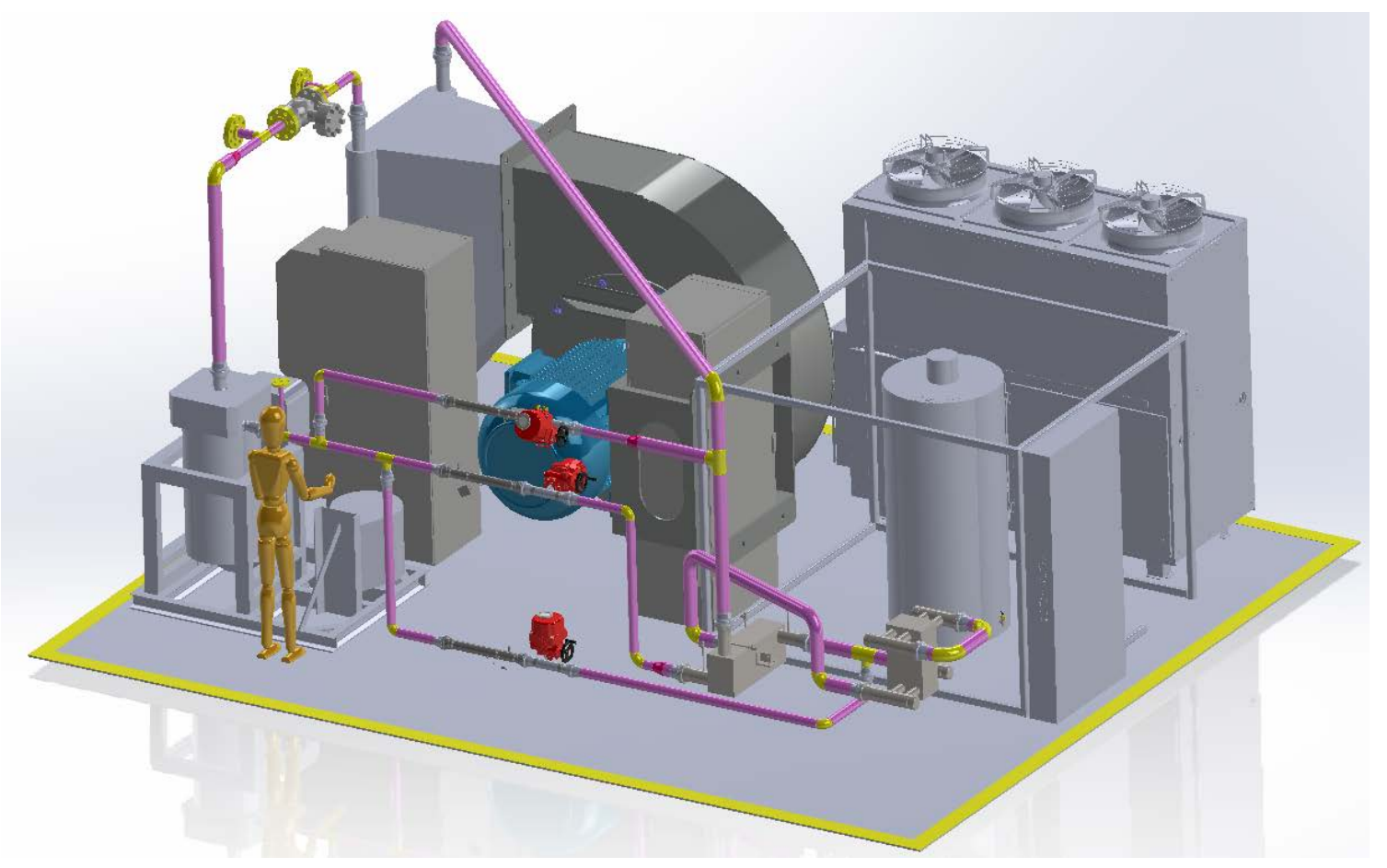

Figure 41. $\mathrm{sCO}_{2}$ system for the Gen3 Liquid Pathway system

Image courtesy of Sandia

\subsection{Sodium Materials Compatibility}

\subsubsection{Alloy Compatibility With Sodium - Literature Review}

Liquid sodium has been utilized as an HTF for thermal energy transport for many decades [43], [43], and molten sodium is known for its good compatibility with most structural alloys, stainless steels in particular, up to around $650^{\circ} \mathrm{C}$ (see Figure 42 , left). In hot liquid sodium systems, satisfactory performance of structural alloys depends in part on the alloy compatibility (and species present) with sodium and the phase (i.e., thermal) stability of the alloy [44]. Because there is extensive data on the suitability of austenitic stainless steel with liquid sodium at temperature less than $650^{\circ} \mathrm{C}$, this review will focus on issues associated with use at higher temperatures.

Suzuki et al. [45] demonstrated the effect of Ni content on the corrosion of six austenitic steel alloys in sodium at $700^{\circ} \mathrm{C}$, see Figure 42 , right. They showed that corrosion is affected by the selective dissolution of $\mathrm{Ni}$ and $\mathrm{Cr}$. Surface regression (which could be indicative of corrosion rate) was estimated to increase from $6 \mu \mathrm{m}$ to $9 \mu \mathrm{m}$ when the Ni content increased from $14 \mathrm{wt} \%$ to $43 \mathrm{wt} \%$ after $8000 \mathrm{~h}$ of exposure. A similar trend in surface regression had been previously reported for alloys SS316 (14 wt \% Ni) $=14 \mu \mathrm{m}$; PE16 (42 wt \% Ni) $=19 \mu \mathrm{m}$; Inconel $706(44 \%$ $\mathrm{Ni})=25 \mu \mathrm{m}[46]$. The same authors calculated a cumulative damage depth (wall thinning + 
degraded zone + intergranular attack) SS316 $=27 \mu \mathrm{m}, \mathrm{PE} 16=125 \mu \mathrm{m}, \mathrm{IN} 706=57 \mu \mathrm{m}$ over the $8000-\mathrm{h}$ period. While the trend of corrosion rate clearly increases with Ni content, the absolute values are not excessive and may be manageable in applications where the thermal strength of $\mathrm{Ni}$ alloys is required.
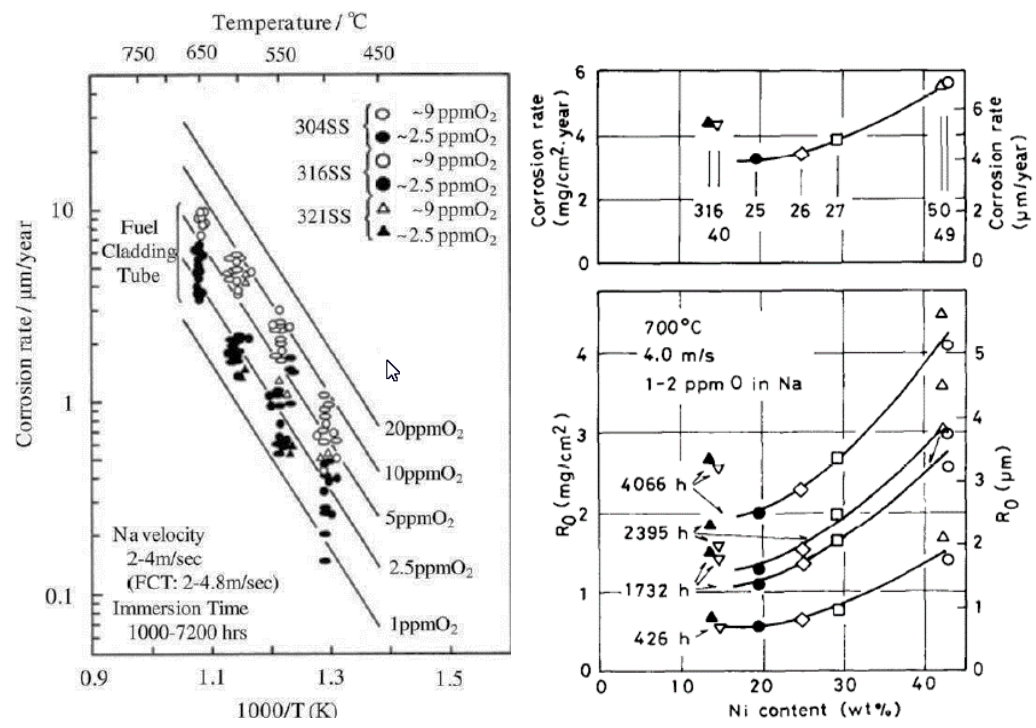

Figure 42. Left: Corrosion rate of austenitic stainless steels in liquid sodium as a function of oxygen concentration and temperature up to $650^{\circ} \mathrm{C}$ [47]. Right: Influence of nickel content on corrosion rate of 316 and six other austenitic steel alloys in sodium at $700^{\circ} \mathrm{C}$ [45].

An extreme example is noted in a review by Lai [48] where nickel alloy 617 is reportedly tested in sodium at a temperature of $1000^{\circ} \mathrm{C}$ for 1000 hours. The sample weight change was 13 to 25 $\mathrm{mg} / \mathrm{cm} 3$, with an estimated materials removal depth of 17 to $31 \mu \mathrm{m}$ [49]. The data are not acceptable for design, but the survival under such aggressive conditions is encouraging.

Corrosion in liquid sodium is typically driven by chemical reactions at the solid surface with non-metallic impurities. The varying solubility of the different elements due to thermal gradient effects at different sections of the system (i.e., hot sections versus cold sections), mechanical stresses, geometry of the influenced sections, and the liquid metal flow rate are other factors which influence corrosion [50]-[53]. The major concern is the presence of non-metallic impurities, oxygen and carbon in particular, as these impurities drive corrosion either through the dissolution of alloying elements of the metal container or chemical reaction of non-metallic constituents with liquid sodium. Carbon, if present, can drive carburization and enhance corrosion in liquid sodium. Significant levels of carburisation of several alloys, including 316, have been observed at $600^{\circ} \mathrm{C}$ over periods of time up to $5000 \mathrm{hrs}$ [54]; higher temperatures will accelerate carburization to greater depths. Surface carburisation of alloys would be expected to reduce fatigue resistance of the material and if complete carburisation of the tubes occurs, fracture toughness will be adversely affected.

The solubility of most of metallic elements in liquid sodium is less than a few ppm at temperatures below $650^{\circ} \mathrm{C}$. In contrast, solubility, especially of non-metallic elements (e.g., oxygen, carbon), is higher at elevated temperature [52], such as relevant for the Gen3 piping and receiver conditions. This solubility may result in the transportation of elements in the liquid 
sodium that leads to the formation of equilibrium solid phases - stable carbides, oxides and nitrides or their derivatives (mixed carbides, oxides or nitrides).

Selective leaching of alloying elements from the surface of structural alloys is another possibility. In response, relevant species (such as $\mathrm{Cr}, \mathrm{Mn}, \mathrm{Ni}$ or $\mathrm{Si}$ ) from the bulk of the alloy diffuse to the surface, but at a rate slower than that of corrosion, leading to composition and microstructural changes in the alloy. This could ultimately result in changes in the mechanical properties of the alloy and reduce creep and fatigue life [44], [53], [54]. There is evidence that increasing the Ni content leads to accelerated corrosion and more importantly that the nickel alloys, despite higher mechanical strength at high temperatures, are less compatible with sodium than steel (Fe) alloys [55], [56], [57].

In service with liquid sodium, metal alloys may undergo changes to both their physical and mechanical properties and are thus susceptible to degradation through mechanisms such as corrosion, carburization, liquid metal embrittlement (LME), selective leaching, erosion, thermal fatigue, and creep (or a combination of them).

Various studies have shown some susceptibility of materials of construction to LME from liquid sodium. LME often produces a significant reduction in the fracture toughness of alloys, but difficulties in initiating LME cracks due to the presence of oxide films on the candidate material surface can mean that LME can be masked in some experimental conditions. Several authors, including Hemery et al. [58] have demonstrated that LME occurs in austenitic stainless steels at temperatures up to $650^{\circ} \mathrm{C}$ by pre-wetting the steels to remove the effects of the oxide films. In general, observations of LME have suggested that the effect is most severe at temperatures near the melting point of the embrittling liquid metal. This is of particularly concern in solar receiver designs where the receiver is cooled overnight prior to the reintroduction of the liquid sodium. At this stage, there are limited studies on the effects of liquid sodium on LME at temperatures in excess of $650 \mathrm{oC}$.

Lastly, Suzuki, et al. [45] note that molybdenum has favorable resistance to attack by sodium [45]. One path to take advantage of this attribute is to apply molybdenum-based coatings such as Tribaloy 700 to nickel-alloys. 


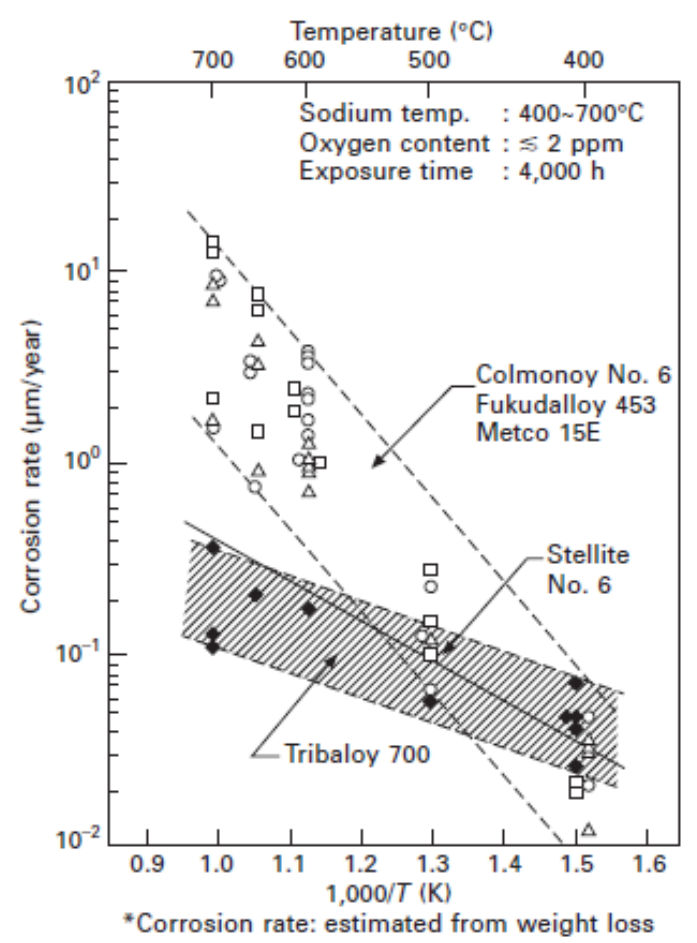

Figure 43. Molybdenum-based coatings such as Tribaloy 700 exhibit good resistance to sodium at temperature.

Image from [57]

In summary, current knowledge of the thermo-chemical compatibility of liquid sodium with metal alloys (mostly steel alloys) up to temperatures around $650^{\circ} \mathrm{C}$ is sufficient, concluding that creep and fatigue life was not adversely affected, and even slightly increased in sodium compared to air [59]. However, there is a gap in the literature for higher temperatures (up to $800^{\circ} \mathrm{C}$ ), which is of keen interest for the development of solar receivers and advanced thermal energy storage technologies. In particular, how well do nickel-based superalloys such as H230 or $740 \mathrm{H}$ resist sodium corrosion? Evidence from limited studies suggest nickel alloys may have sufficient resistance in the planned application, but direct testing is warranted. To fill this gap, the ASTRI Advanced Materials Group undertook a comprehensive literature review to determine what information is currently available and identify knowledge gaps. The team has developed a research strategy to address the identified gaps regarding the compatibility of structural materials with liquid sodium at temperatures between $550^{\circ} \mathrm{C}$ and $800^{\circ} \mathrm{C}$. The draft review can be accessed via Table 32, Folder 13-Sodium Subsystem, ASTRI Sodium Receiver Materials Issues.

\subsubsection{Testing Alloy Compatibility With Sodium}

An experimental program is ongoing to address the material compatibility information gaps for these (and other) materials in liquid sodium at the Gen3 operating temperatures. To allow characterisation of these material/liquid sodium interactions, QUT has implemented a new capsule (static) testing ability as of September 2020. This is in addition to a new flow loop being commissioned at ANU. The capsule contains four smaller crucibles each with sodium and a material of interest (so four exposure tests are conducted in a single capsule-with the view to having multiple capsules in the future). Additionally, a small thermosiphon (dynamic) system is underdevelopment. This dynamic system will permit study of the elemental de-alloying and 
condensation from alloys in liquid sodium in the hot leg and cold leg, respectively. Figure 44, below, shows the static capsule system currently in use and the planned thermosiphon dynamic system.
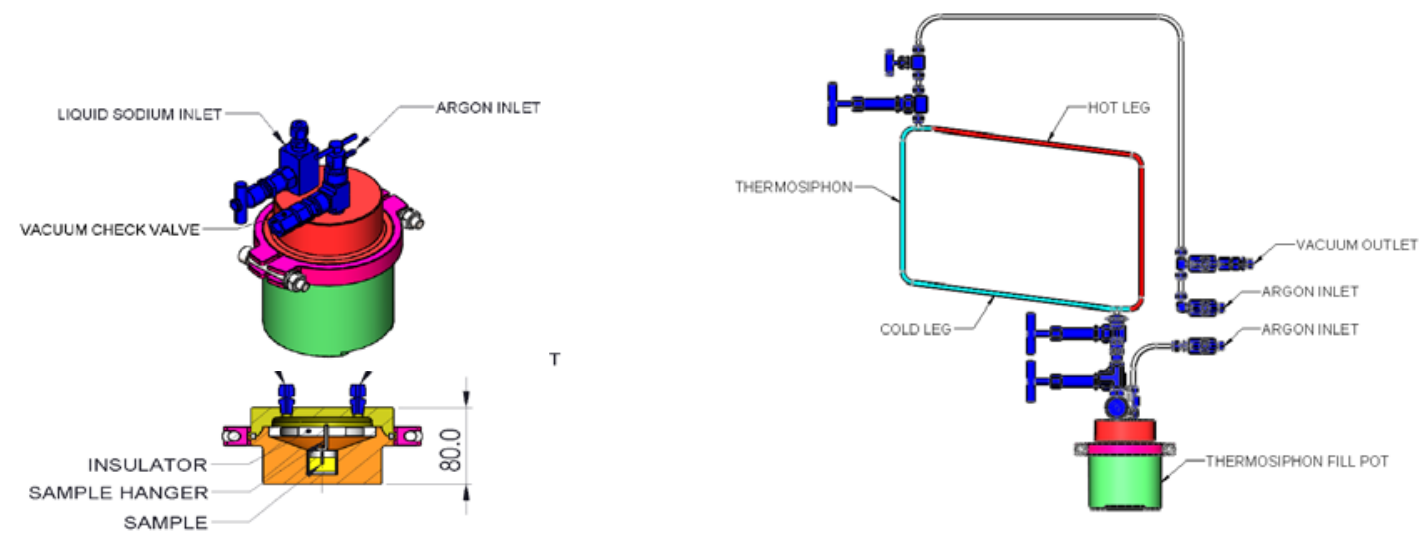

Figure 44. Schematics of static-capsule (left) and dynamic-thermosiphon (right) sodium exposure experiments at QUT

Images courtesy of QUT

All health and safety protocols to use the sodium have been finalised and testing commenced in September 2020. The first melt in the static system was to validate procedures and determine what crucible materials of construction should be used to contain the sodium/alloy samples. Alumina crucibles were selected, and a second test campaign immediately started with $3 \times 740 \mathrm{H}$ samples and $1 \mathrm{x} \mathrm{SiC}$ sample held at $750^{\circ} \mathrm{C}$. After completing 300 hours, however, it was determined that three crucibles had cracked and released their sodium. Only one crucible was intact (with the $\mathrm{SiC}$ ). An analysis of the cracked crucibles led to the conclusion it was due to the re-use of crucibles and only new crucibles will be used moving forward. The tests were restarted and samples removed after 500-h for examination. Unfortunately the sodium levels had dropped due to vaporization and the results were inconclusive. At the time of submission, the test protocols were being revised and hence no additional data are available. The ASTRI team will continue refinement of their procedures and resume the experiments in 2021. Lack of validation of nickel-alloy performance in $750^{\circ} \mathrm{C}$ sodium leaves this element as a project risk that must be addressed prior to pilot-scale testing.

\subsection{Sodium Receiver}

\subsubsection{Commercial Sodium Receiver}

For the commercial scale design, a conservative approach is adopted which draws on the existing knowledge about cylindrical receivers used in commercial systems based on nitrate salts and adapts it to the requirement of a sodium-cooled receiver.

Receiver and field capacity. Per the DOE requirements, the target system output is $100 \mathrm{MW}_{\mathrm{e}}$. Systems analysis of 1, 2, 3 and 4 independent tower/power-cycle systems indicated that significant system efficiency improvement could be obtained by switching from a single 100$\mathrm{MW}_{\mathrm{e}}$ tower to two independent $50-\mathrm{MW}_{\mathrm{e}}$ towers. The receiver and field design assumptions were refined, including: 
- Sizing the receiver for optimized annual performance as opposed to design point, leading to the selection of larger receiver diameters to compensate for spillage losses from lateral astigmatism.

- Inclusion of a field oversizing factor which leads to significant improvement in plant capacity factor and thus annual energy yield. The oversized field is able to compensate for lower DNI due to seasonal and/or weather-based variations.

The receiver and field presented in the following sections are based on the following set of assumptions:

1. A power block net output of $55.5 \mathrm{MW}_{\mathrm{e}}$ (accounting for $\sim 10 \%$ parasitic losses at design point for the whole plant) with design point net efficiency of $48 \%$ (see $\S 3.1$ for more detail on power block efficiency assumptions).

2. A solar multiple, defined as the ratio of the receiver thermal output to the power-block thermal input, of 3.0.

3. An assumed design point receiver efficiency, defined as the ratio of the receiver net heat gain to the incident radiative energy of $90 \%$, estimated from previous parametric evaluations. Note this value is only used for initial sizing and is recalculated from the optical and thermal model for performance evaluation.

4. A field oversizing factor of 1.15 ( $15 \%$ increased field design point output), obtained from parametric evaluations.

The resulting nominal receiver output capacity is rounded-up to $350 \mathrm{MW}_{\text {th }}$ (from $347 \mathrm{MW}_{\text {th }}$ ) while the oversized field nominal output capacity is rounded up to $445 \mathrm{MW}_{\text {th }}$. In the rest of this section, design point refers to Equinox Solar Noon at Daggett in California, with an ambient temperature of $300 \mathrm{~K}\left(\sim 27^{\circ} \mathrm{C}\right)$, a ground wind speed of $5 \mathrm{~m} / \mathrm{s}$ a DNI of $980 \mathrm{~W} / \mathrm{m}^{2}$ and a circumsolar ratio of $2 \%$.

Field and receiver dimensions determination. It is impossible to efficiently design a heliostat field and a receiver independently as their performance is intrinsically linked, notably through spillage losses. The field design and receiver diameter are determined simultaneously using the fast cone-optics code SolarPILOT from NREL [60]. First, a parametric study evaluates field designs for a range or receiver diameters. The objective of this step is to determine a receiver diameter just large enough to capture most of the incident radiation from a heliostat field with design power of $385 \mathrm{MW}_{\text {th }}$, without consideration of the field over-sizing. No simulation of receiver thermal performance is made at this point and the receiver height is oversized to avoid its influence on the results. The selected diameter is the smallest one that leads to a spillage below $0.5 \%$ of the configuration with minimum spillage simulated. This factor of $0.5 \%$ was deemed suitable from independent work on receiver and field co-optimization for minimum LCOE for ASTRI at ANU.

The heliostats used are square, have a $7.07 \mathrm{~m}$ side length $\left(50 \mathrm{~m}^{2}\right.$ area $)$ and are assumed to have an effective reflectance of $87.5 \%$ which includes the intrinsic reflectance $(95 \%)$, the mirror cover ratio (i.e., the fraction of the heliostat structure covered in mirror, set to $97 \%$ ) and an average soiling factor $(95 \%)$. The increasing awareness of the importance of heliostat of field optical accuracy has led to the development of several recent concepts (Heliomax from Heliogen, 
Stellio from sbp, the Tewer heliostat concept) with similar facet sizes and high optical accuracy (below the $1.5 \mathrm{mrad}$ value assumed in this work).

The heliostat overall optical error is simulated using a single Gaussian error applied to the local normal of the mirror in ray-tracing simulations. This error covers both non-ideal shape and micro-surface deformations, and tracking error. For calm conditions assumed here with wind speed below $10 \mathrm{~m} / \mathrm{s}$, the optical error is $1.5 \mathrm{mrad}$. When the wind speed goes above $10 \mathrm{~m} / \mathrm{s}$ the optical error increases to $2 \mathrm{mrad}$. Finally, if wind speeds exceed $15 \mathrm{~m} / \mathrm{s}$, the field is parked into stow position. In the simulation work, the heliostats have an assumed ideal curvature at the slant range. The main design variables specific to the heliostat field are summarized in Table 12.

Table 12. Heliostat field specific parameters

\begin{tabular}{|l|l|}
\hline Parameter & Value \\
\hline Heliostat dimensions & $7.07 \mathrm{~m} \times 7.07 \mathrm{~m}\left(50 \mathrm{~m}^{2}\right)$ \\
\hline Actuation type & Azimuth-elevation drives \\
\hline Mirror reflectance & $95 \%$ \\
\hline Mirror cover ratio & $97 \%$ \\
\hline Average soiling level & $95 \%$ \\
\hline $\begin{array}{l}\text { Optical error in calm conditions } \\
\text { (wind speed below } \mathbf{1 0} \mathbf{~ m / s} \text { ) }\end{array}$ & $1.5 \mathrm{mrad}$ (surface normal conical error) \\
\hline $\begin{array}{l}\text { Optical error in windy conditions } \\
\text { (wind speed over } \mathbf{1 0} \mathbf{~ m / s )}\end{array}$ & $2 \mathrm{mrad}$ (surface normal conical error) \\
\hline Wind speed operational threshold & $15 \mathrm{~m} / \mathrm{s}$ \\
\hline
\end{tabular}

The receiver diameter is fixed and the field design algorithm of SolarPILOT run again to obtain the right oversized field with a design capacity of $445 \mathrm{MW}_{\text {th }}$ this time, and with a range of aspect ratios. Sensitivity analyses shows that an aspect ratio (height over diameter) between 1 and 1.1 is suitable and leads to designs that are efficient and able to manage peak fluxes below flux limits as will be shown in the final design. These aspect ratios are smaller than commercial nitrate salt receivers for two main reasons:

- Higher temperatures increase losses and tend to favor lower receiver heights from a thermal efficiency point of view.

- The specific flow-path constraints imposed by the thermophysical properties of liquid sodium have an influence on the minimum diameter that can be used, which in this work pushed the receiver diameter slightly above the values that would typically be adopted from an optical efficiency consideration only.

The receiver diameter obtained with this method is $14 \mathrm{~m}$ and the height is set at $14.5 \mathrm{~m}$. Figure 45 shows the intermediate nominal field design at $385 \mathrm{MW}_{\text {th }}$ and the final oversized field design

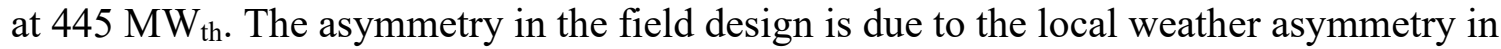
Daggett, California where the field is located. The total heliostat count is 14,461 . 


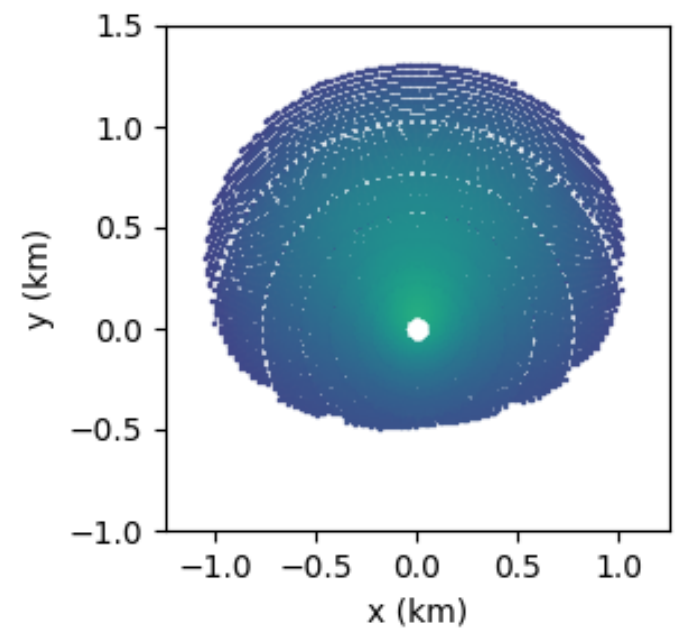

(a)

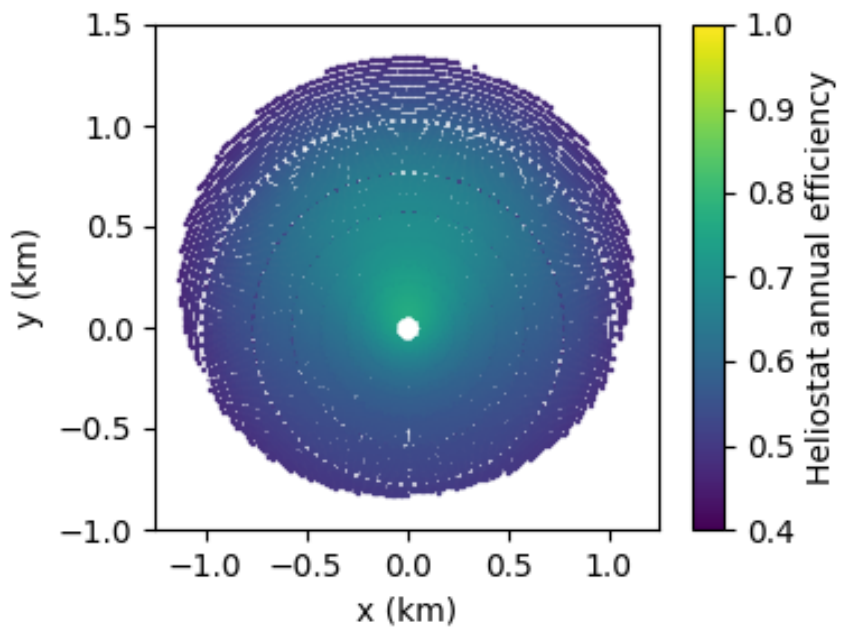

(b)

Figure 45. (a) nominal field obtained along with the receiver diameter of $14 \mathrm{~m}$ and oversized height $(20 \mathrm{~m})$ and $(\mathrm{b})$ the oversized field used for the final system with receiver dimensions of 14-m diameter and 14.5-m height.

Receiver design. The receiver design follows the same paradigm as current commercial nitrate salt designs: parallel thin-walled pipes are arranged in planar banks between two headers and the banks are arranged to form pseudo-cylindrical arrangements. The heat transfer fluid flows through the receiver following a designed set of "flow-paths" that are sensitive to a range of variables and, in our case, dictated by the velocity limits of the sodium heat transfer fluid (HTF) in the pipes. This limit is itself dictated by corrosion and erosion considerations. In this work, we originally based our estimate of this maximum velocity at $2.44 \mathrm{~m} / \mathrm{s}$ in accordance with the data available in Foust [61] and revised this value to $3.0 \mathrm{~m} / \mathrm{s}$ after discussion with the materials compatibility research team in ASTRI, and with David Wait from Nooter/Eriksen, based on his own experience with testing sodium receivers at Sandia in the early 1980s. This value, which is probably still conservative, is assumed as the limit for the flow of liquid sodium in the receiver pipes at nominal conditions.

Flow-path design. The flow-path design needs to strike a good trade-off between heat transfer efficiency, obtained when the liquid sodium flows at velocities closest to the peak limit, and design simplicity, to minimize complexity and capital cost of the system. In the proposed system this is obtained by:

1. Identifying all the possible flow-path configurations for the selected receiver diameter and capacity with the number of banks varied from 8 to 24 using a purposed made simplified heat-transfer model.

2. Selecting the minimum number of flow-paths (minimum independent flow circuits, valves, pumps, receiver crossings, etc.)

3. Selecting the number of banks that lead to the maximum velocity below the limit for this minimum number of flow-paths.

The resulting design for the configuration presented is 12 banks and 4 parallel flow paths. Each flow-path is composed of three pipe banks in series, two banks on the North side of the receiver and one on the South side. As for commercial cylindrical receivers, the flow-paths are introduced 
on the north side to match the colder regions of the receiver with the most intense concentrated flux and cross the north-south axis to even-out the energy output of each flow-path as the sun position varies during daily operations. The flow-path arrangement is illustrated in Figure 46.

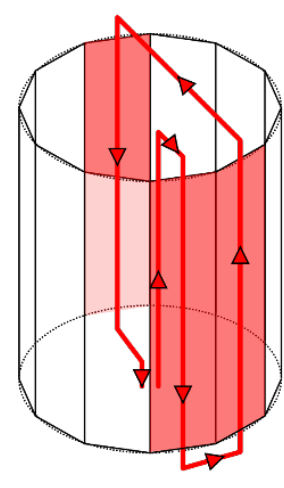

Flow-path 0

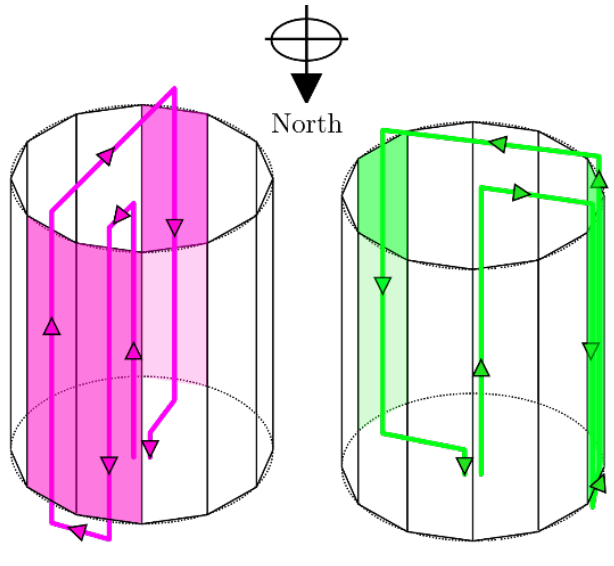

Flow-path 1
Flow-path 2

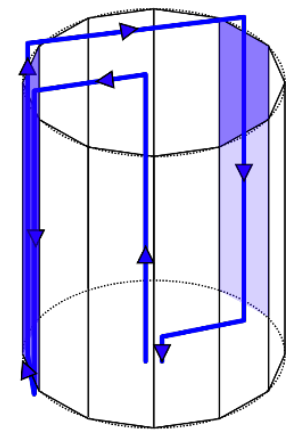

Flow-path 3

Figure 46. Receiver flow-path arrangement

The choice is made to introduce the flow at the top of the receiver during operations because it enables the last bank of the flow-path to flow downwards. The receiver will operate close to atmospheric pressure and, in event that the receiver loses flow (e.g., pump failure) and the field lose communications, the flow of sodium in this critical region of the flow-path (hightemperatures) flows with gravity to cool the receiver pipe walls when expelled from the inlet vessel.

The pipes are coated with a high-absorptivity coating with $98 \%$ solar weighted absorptance and 91\% emittance. Although higher than the commonly used Pyromark 2500 absorber paint, such values are consistent with recent developments in absorber coatings, including by NFT (Tokyo, Japan), in collaboration with ANU [62] and by NanoSD (San Diego, CA).

Pipe banks. In the proposed design, the pipe banks are all identically built of $60.3 \mathrm{~mm}$ outer diameter pipes with $1.2 \mathrm{~mm}$ wall thickness made of the nickel superalloy, Alloy $740 \mathrm{H}$. The choice of these dimensions is based on technical and economic considerations. While the costing models used in this project do not possess the level of details necessary to include such factors, economics favor the use of larger pipe diameters because it significantly reduces the number of individual welds, simplifies Quality Assurance procedures (non-destructive testing) and assembly operations.

Small diameter pipes lead to increased heat transfer rates at the inner wall of the pipes which leads to improved efficiency. Similarly, thinner walls are favorable from a heat-transfer perspective because they reduce the conductive barrier within the pipe wall and therefore lower the temperature of the outer wall of the pipe, leading to further efficiency improvements. The pipe diameter selected in this work is relatively large compared with current industry standards and is feasible thanks to the good heat-transfer properties of liquid sodium. Manufacturing advice from John Cockerill guided the choice of a $1.2 \mathrm{~mm}$ wall thickness. A pipe spacing of 1 $\mathrm{mm}$ is assumed in the proposed design to allow for assembly and welding access. The full receiver pipe banks design is summarized in Figure 47. 


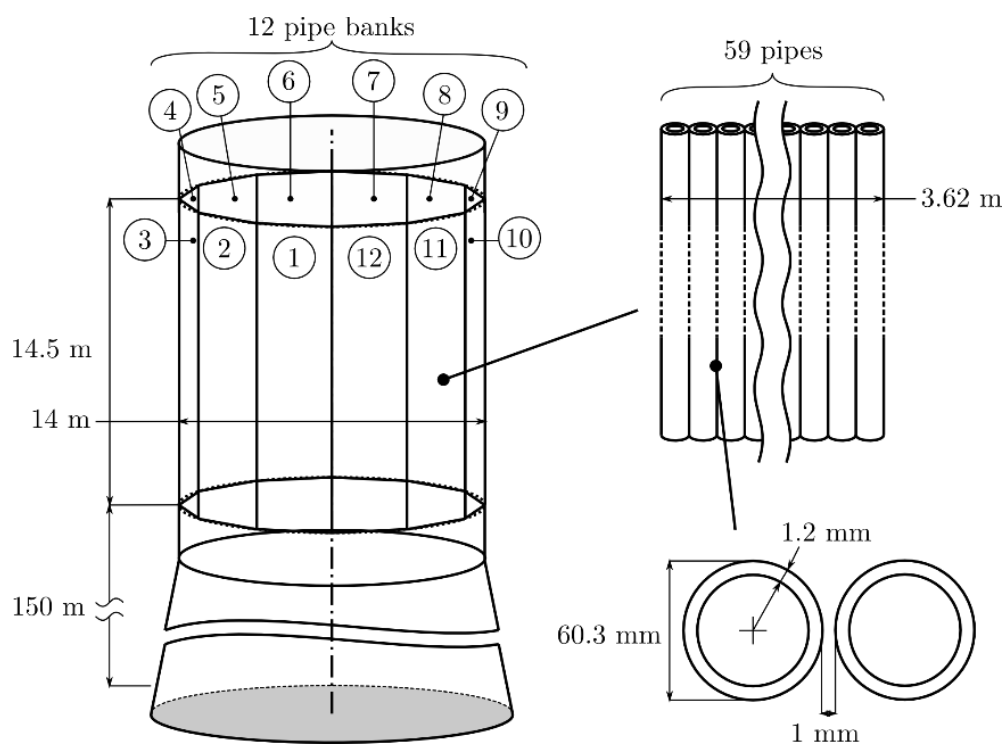

Figure 47. Receiver configuration summary

Table 13. Summary of key receiver parameters for the commercial-scale design

\begin{tabular}{|l|l|}
\hline Parameter & Value \\
\hline Receiver pipe banks active height & $14.5 \mathrm{~m}$ \\
\hline Receiver diameter & $14 \mathrm{~m}$ \\
\hline Receiver pipe banks width & $3.62 \mathrm{~m}$ \\
\hline Number of pipe banks & 12 \\
\hline Number of pipes per bank & 59 \\
\hline Number of flow-paths & 4 \\
\hline Pipe external diameter & $60.3 \mathrm{~mm}$ \\
\hline Pipe wall thickness & $1.2 \mathrm{~mm}$ \\
\hline Pipe spacing & $1 \mathrm{~mm}$ \\
\hline Pipe alloy & $\mathrm{Inconel} \mathrm{740H}$ \\
\hline Receiver pipe coating solar weighted absorptance & $98 \%$ \\
\hline Receiver pipe coating thermal wavelengths emittance & $91 \%$ \\
\hline
\end{tabular}

Receiver operations simulation. The receiver performance is evaluated using a combination of detailed ray-tracing with the Solstice software from the French CNRS PROMES ${ }^{10}$ and codes developed at ANU to solve the energy, mass and momentum balance [63]. These codes have been verified against other widely adopted tools both within this project and independently by ASTRI [65]. The sodium thermophysical properties are obtained from literature data [66]. Some key assumptions in this modeling work should be noted:

\footnotetext{
${ }^{10}$ Solstice PROMES: https://www.labex-solstice.fr/solstice-software/.
} 
- The external convective heat-transfer coefficient, used to evaluate the receiver convective loss, is using the Siebers \& Kraabel method despite being above the validated range of this correlation [67]. So far, there is no other approach to model convective loss as: 1) there is no experimental dataset to calibrate models with, 2) CFD simulations of the external convective loss from large scale cylindrical receivers requires the use of DNS approaches which are extremely computationally intensive and virtually infeasible at the scale required. To evaluate the wind speed at the height of the receiver, the $10 \mathrm{~m}$ mast measurement available in TMY files is extrapolated using an atmospheric boundary layer exponent lay with a factor of 0.16 , suitable for clear open land [68]. Typically, a 10meter-high measured wind speed of $5 \mathrm{~m} / \mathrm{s}$ leads to a wind speed of the order of $7.5 \mathrm{~m}$ at the height of the tower.

- Conduction losses are typically negligible as the heat is lost in the volume of the receiver and the back sides of the pipe banks are well insulated and are neglected [69].

- The pipe banks are discretized using a 1D approach which is equivalent to assuming even distribution of flow and temperature within adjacent pipes in a bank. This assumption greatly accelerates simulation times and lead to very small discrepancies compared with the individual pipe simulation approach when the full receiver efficiency is considered. In addition, this assumption is typically very close to the reality for external cylindrical receivers.

- The pipe banks are optically modeled as flat surfaces with absorptance and emittance equivalent to the "real" geometry by means of effective absorptance and emittance. For convective loss, the full pipe geometry is considered.

- The internal heat transfer coefficient is modeled using the Skupinski correlation. Here again, the available correlations in the literature were surveyed and this specific correlation was found to lead to the best match to reported experimental data for liquid sodium in the temperature range evaluated [70].

The receiver is operated below the allowable flux limits imposed by creep and fatigue allowances to ensure a suitable lifetime. Flux limits established through inelastic thermomechanical analysis are integrated into a heliostat field aiming strategy that adjusts every individual heliostat aimpoint on the receiver surface and iteratively solves the receiver model until a satisfactory aiming is found (see $\S 4.8 .4$ for more on how flux limits are established). The specific aiming strategy used is MDBA (Modified Deviation-Based Aiming) which ANU has recently developed and presented at the SolarPACES 2020 conference [71]. For each simulation, the selection of heliostats in the field is made to ensure that the receiver nominal thermal output can be reached if there is enough solar resource, and the mass flow of the receiver is adjusted so that the receiver delivers $740^{\circ} \mathrm{C}$ liquid sodium output.

Commercial system simulation results. Design point plots are shown in Figure 48 to illustrate the receiver operations. The fraction of net heat flux to available flux in green stays below unity at all positions, the flow velocity respects the $3 \mathrm{~m} / \mathrm{s}$ constraint, and the pressure drops are below 0.5 bar. At design and in the off-design cases studied (not shown). 

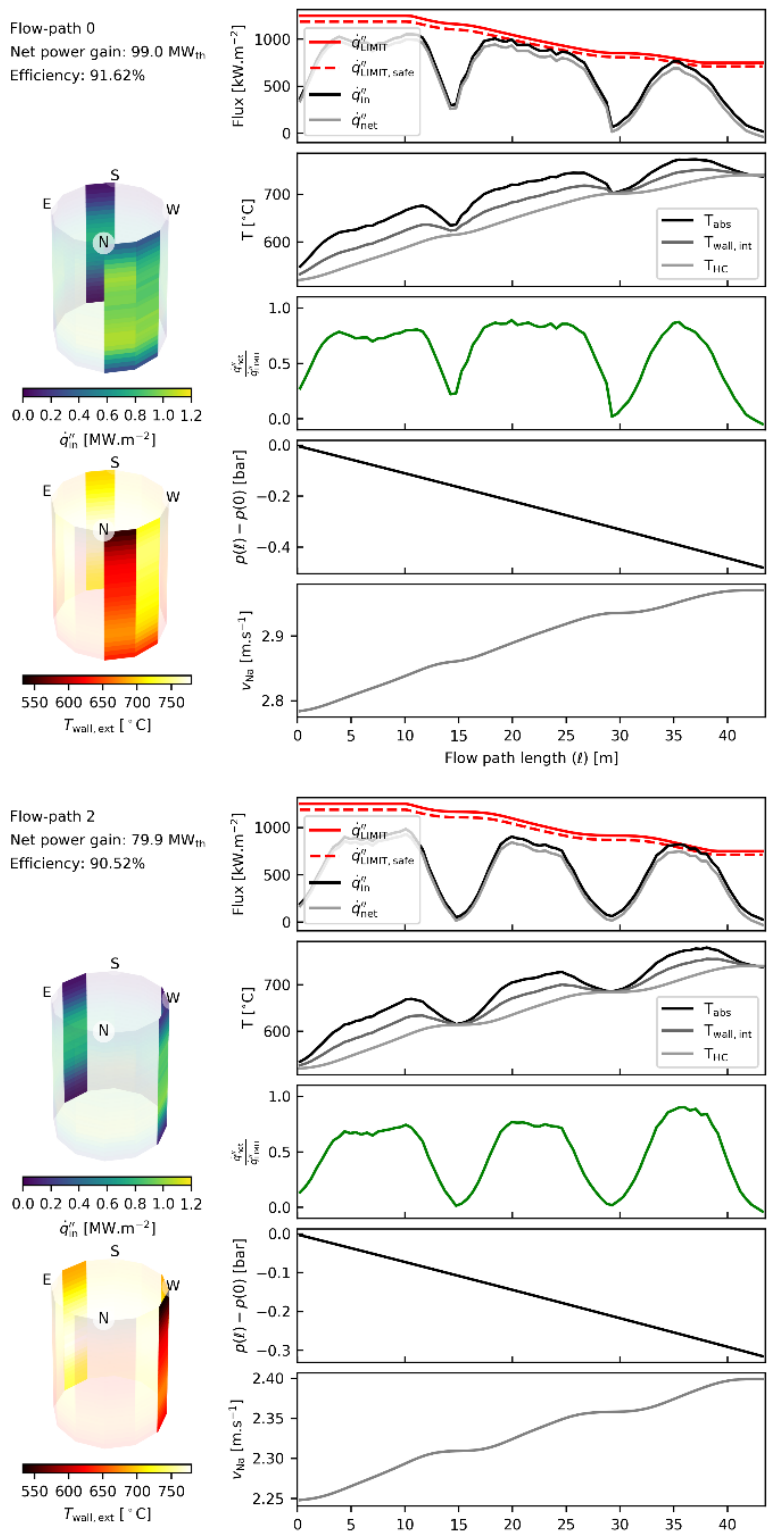

Flow-path 1 Net power gain: $95.1 \mathrm{MW}_{\mathrm{t}}$

Efficiency: $91.32 \%$
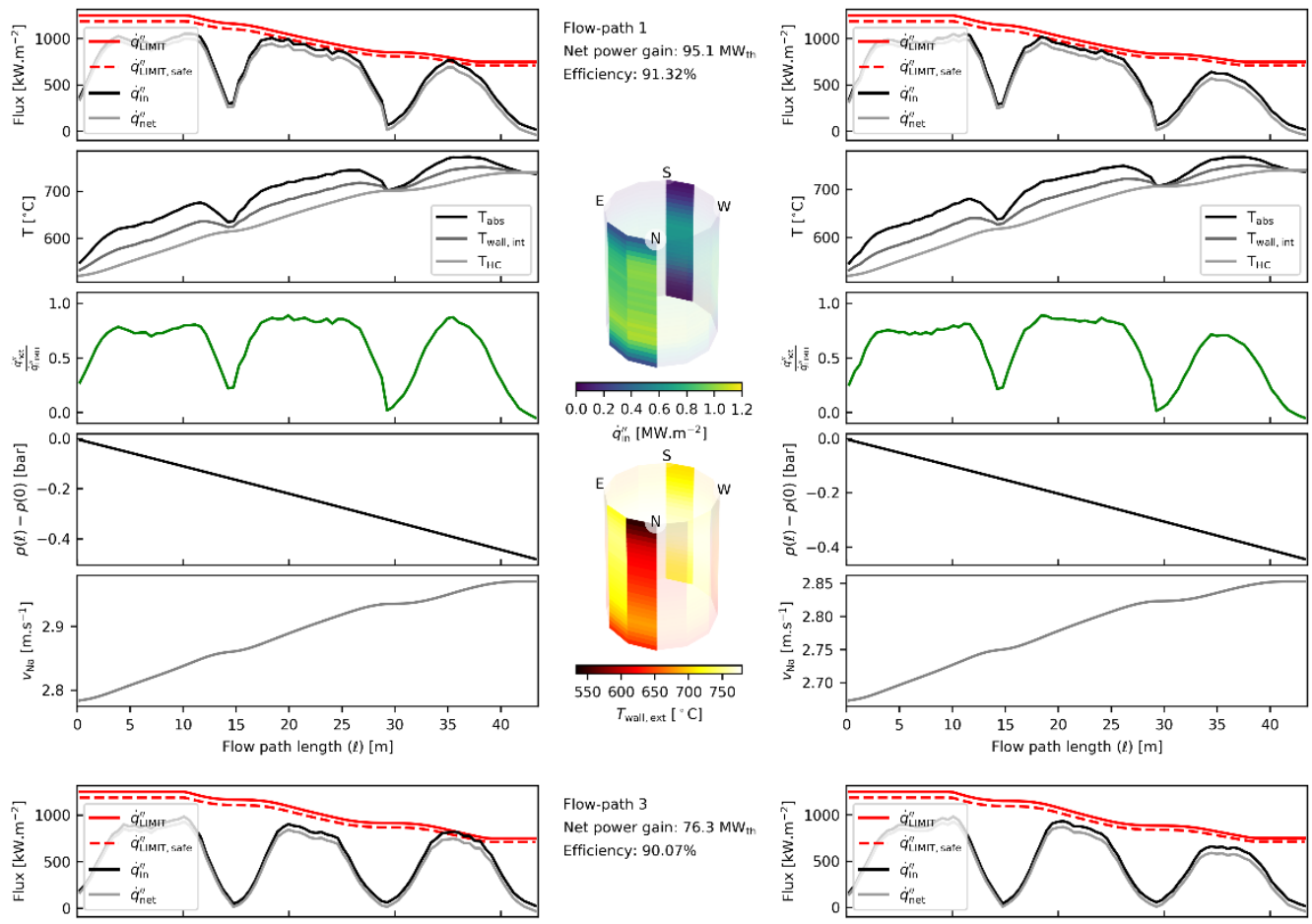

Flow-path 3
Net power gain: $76.3 \mathrm{MW}_{\text {th }}$
Efficiency: $90.07 \%$
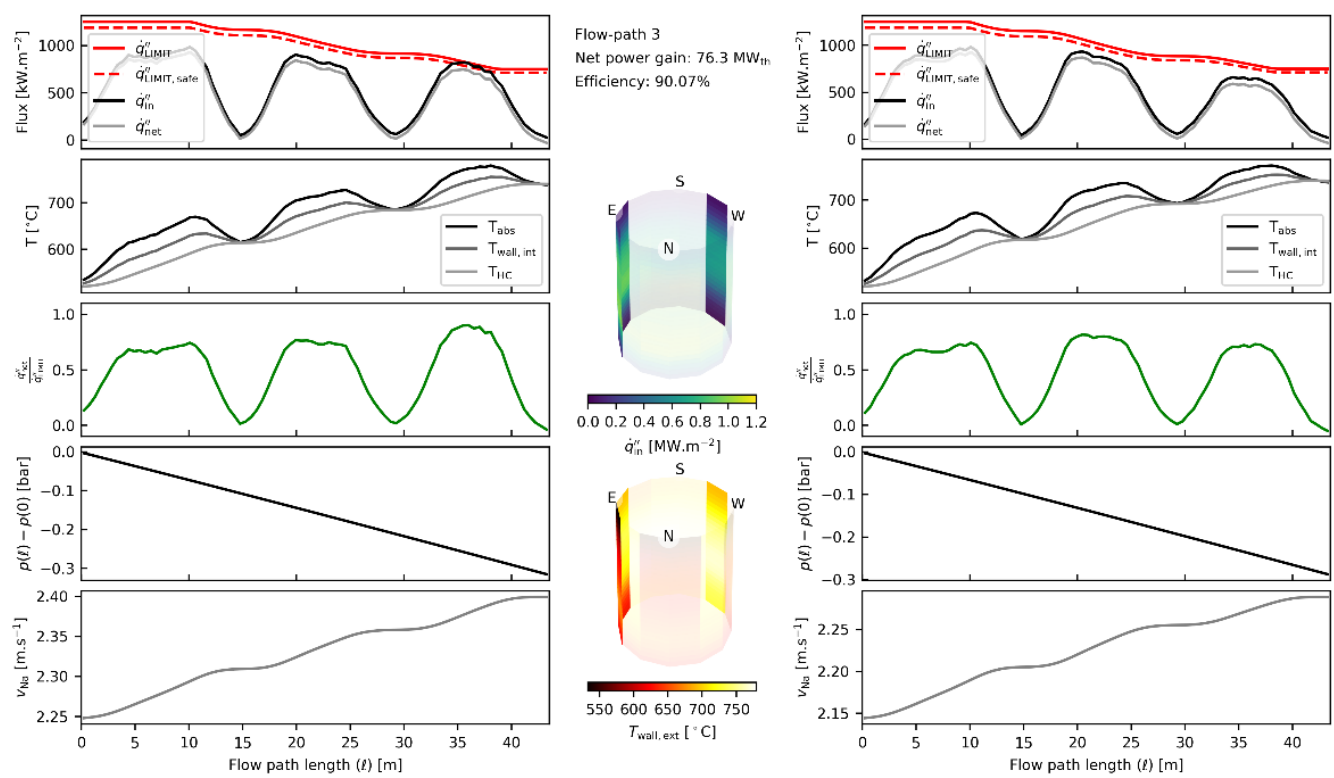

Figure 48. Design point receiver performance per flow-path

In Table 14, key results for a set of representative sun positions are given to illustrate again receiver and field operations. Field utilization is the ratio of the number of heliostats used to the total number of heliostats in the field. The field efficiency, intercept efficiency, receiver and intercept efficiency and overall efficiency all consider the used field and not the total oversized field. 
Table 14. Field and receiver performance at key sun positions

\begin{tabular}{|c|c|c|c|c|c|c|c|c|c|c|}
\hline & \multicolumn{3}{|c|}{ Summer } & \multicolumn{4}{|c|}{ Equinox } & \multicolumn{3}{|l|}{ Winter } \\
\hline & Noon & $\begin{array}{l}\text { Noon } \\
+2 \mathrm{~h}\end{array}$ & $\begin{array}{l}\text { Noon } \\
+6\end{array}$ & Noon & $\begin{array}{l}\text { Noon } \\
+2 \mathrm{~h}\end{array}$ & $\begin{array}{l}\text { Noon } \\
+4 \mathrm{~h}\end{array}$ & $\begin{array}{l}\text { Noon } \\
+5 \mathrm{~h}\end{array}$ & Noon & $\begin{array}{l}\text { Noon } \\
+2 \mathrm{~h}\end{array}$ & $\begin{array}{l}\text { Noon } \\
+4 \mathrm{~h}\end{array}$ \\
\hline DNI (W/m2) & 950 & 930 & 520 & 980 & 950 & 805 & 590 & 930 & 875 & 510 \\
\hline Field utilization & 0.882 & 0.926 & 1.000 & 0.877 & 0.937 & 1.000 & 1.000 & 1.000 & 1.000 & 1.000 \\
\hline Field efficiency & 0.647 & 0.632 & 0.416 & 0.639 & 0.618 & 0.539 & 0.420 & 0.590 & 0.562 & 0.369 \\
\hline Intercept efficiency & 0.978 & 0.972 & 0.962 & 0.968 & 0.955 & 0.961 & 0.957 & 0.952 & 0.957 & 0.950 \\
\hline Solar absorption efficiency & 0.987 & 0.987 & 0.987 & 0.987 & 0.987 & 0.987 & 0.987 & 0.987 & 0.987 & 0.987 \\
\hline Thermal efficiency & 0.923 & 0.924 & 0.830 & 0.921 & 0.922 & 0.906 & 0.846 & 0.920 & 0.913 & 0.792 \\
\hline Receiver efficiency & 0.912 & 0.912 & 0.819 & 0.909 & 0.910 & 0.895 & 0.835 & 0.908 & 0.901 & 0.782 \\
\hline Receiver and intercept efficiency & 0.891 & 0.886 & 0.788 & 0.881 & 0.869 & 0.860 & 0.799 & 0.865 & 0.862 & 0.743 \\
\hline Overall efficiency & 0.577 & 0.560 & 0.328 & 0.563 & 0.537 & 0.463 & 0.335 & 0.511 & 0.484 & 0.274 \\
\hline Spillage loss (MW $\mathbf{t h}_{\text {th }}$ & 8.78 & 10.93 & 6.17 & 12.58 & 17.96 & 12.48 & 7.97 & 19.26 & 15.70 & 7.09 \\
\hline $\begin{array}{l}\text { Solar power through aperture } \\
\left(\mathbf{M W}_{\text {th }}\right)\end{array}$ & 384.0 & 384.1 & 154.2 & 385.1 & 383.8 & 307.8 & 176.2 & 383.0 & 346.6 & 133.7 \\
\hline Solar reflection loss $\left(\mathrm{MW}_{\mathrm{th}}\right)$ & 4.92 & 4.93 & 1.98 & 4.94 & 4.92 & 3.95 & 2.26 & 4.91 & 4.44 & 1.71 \\
\hline Emission loss ( $\mathrm{MW}_{\text {th }}$ ) & 25.4 & 25.4 & 22.5 & 26.3 & 26.1 & 25.0 & 23.5 & 26.5 & 26.1 & 24.0 \\
\hline Convection loss ( $\mathrm{MW}_{\mathrm{th}}$ ) & 3.57 & 3.56 & 3.34 & 3.64 & 3.62 & 3.53 & 3.41 & 3.66 & 3.62 & 3.46 \\
\hline $\begin{array}{l}\text { Net thermal power to the HTF } \\
\left(\mathrm{MW}_{\text {th }}\right)\end{array}$ & 350.0 & 350.2 & 126.3 & 350.2 & 349.2 & 275.4 & 147.1 & 347.9 & 312.4 & 104.5 \\
\hline Peak absorbed flux (kW) & 1062 & 1087 & 583 & 1040 & 1067 & 1013 & 670 & 1047 & 1019 & 514 \\
\hline Peak tube wall temperature (K) & 1052 & 1052 & 1035 & 1053 & 1051 & 1053 & 1039 & 1049 & 1055 & 10328 \\
\hline Peak fraction of allowable flux & 0.94 & 0.95 & 0.51 & 0.91 & 0.90 & 0.90 & 0.62 & 0.94 & 0.93 & 0.48 \\
\hline Max HTF velocity $(\mathrm{m} / \mathrm{s})$ & 2.75 & 2.96 & 1.14 & 2.97 & 2.91 & 2.44 & 1.35 & 2.90 & 2.67 & 0.93 \\
\hline Receiver pressure drop (MPa) & 0.041 & 0.048 & 0.007 & 0.048 & 0.046 & 0.032 & 0.010 & 0.046 & 0.039 & 0.005 \\
\hline
\end{tabular}

\subsubsection{Pilot-Scale Sodium Receiver}

The pilot-scale receiver is a flat "billboard" type designed to be representative of a commercialscale unit. The receiver consists of two (east and west) flow paths with independently controlled mass flow rates to ensure the targeted sodium outlet temperature of $740^{\circ} \mathrm{C}$ is achieved. Computer renderings of the pilot-scale receiver casing and tubing are presented in Figure 49 and flow path parameters are summarized in Table 15. Each flow path consists of three panels of heat transfer tubes, with 11 tubes and two headers in each panel. Each flow path has a serpentine layout with the inlet at the top of the inner-most panel and the outlet at the bottom of the outer-most panel. The heat transfer tubes are seamless $740 \mathrm{H}$, with an outer diameter of $25.4 \mathrm{~mm}$, thickness of $1.65 \mathrm{~mm}$ and irradiated length of $1.77 \mathrm{~m}$. The overall width of the billboard is also $1.77 \mathrm{~m}$, as it was found that a 1:1 aspect ratio allows for maximum interception of the incident concentrated solar radiation beam.

Key criteria considered when determining the receiver design include: (i) safety, reliability and structural integrity (e.g., adherence to allowable flux limits determined by mechanical stress 
analyses), (ii) similarity with the proposed commercial receiver design (e.g., external-type receiver, $740 \mathrm{H}$ tubes, sodium heat transfer coefficient of approximately $2 \times 10^{4} \mathrm{~W} / \mathrm{m}^{2} / \mathrm{K}$ ); (iii) performance (e.g., ability to deliver the $1-\mathrm{MW}_{\text {th }}$ capacity throughout the year with reasonable combined interception and receiver efficiency); and (iv) cost (e.g., minimizing complexity and size).

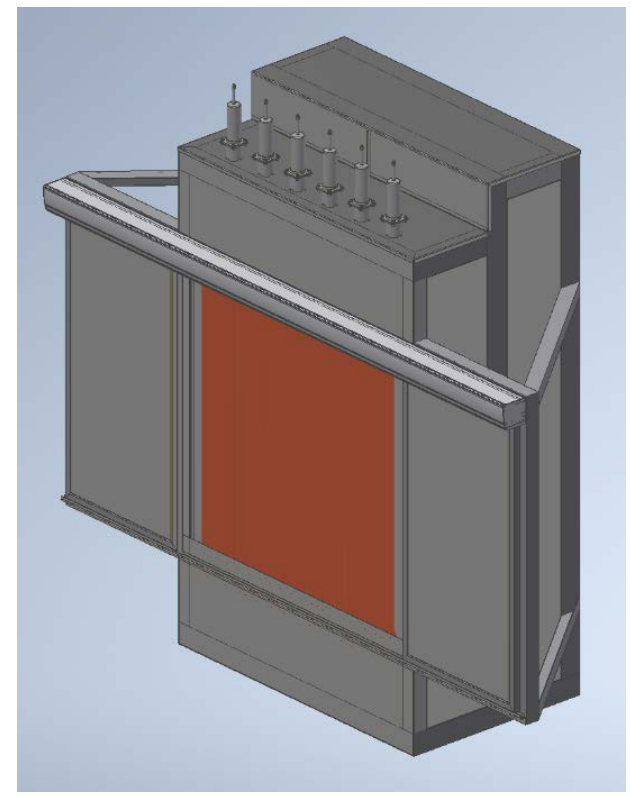

(a) Front view of casing and tubing assembly

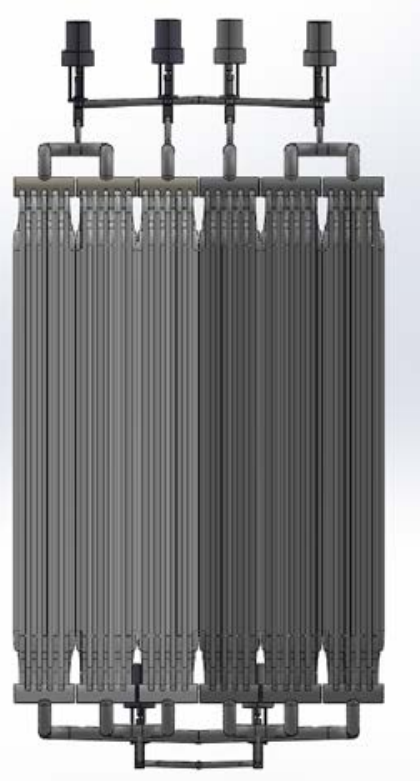

(c) Front view of tubing assembly

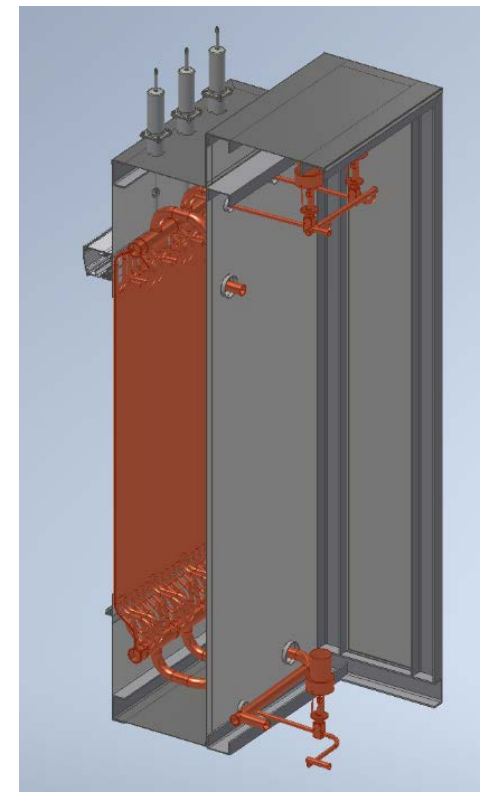

(b) Rear cross section view of casing and tubing assembly

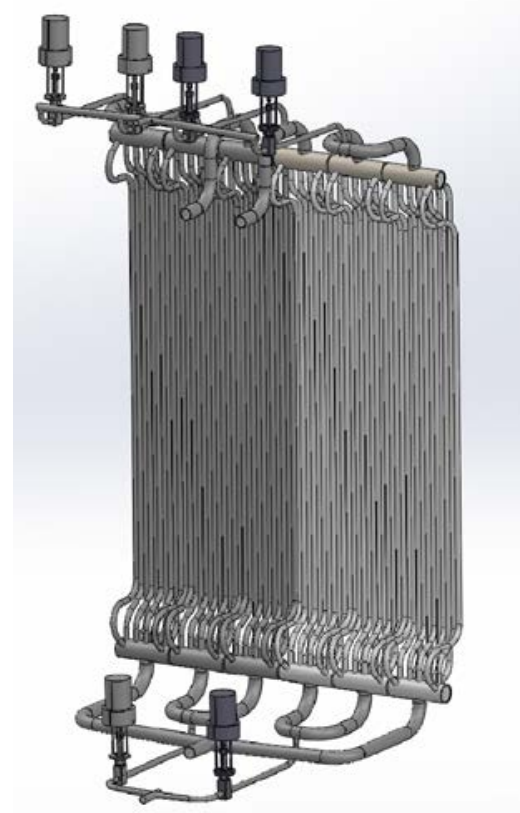

(d) Rear view of tubing assembly

Figure 49. 3D renderings of the $1 \mathrm{MW}_{\text {th }}$ pilot sodium receiver design. See also Folder 13-Sodium Subsystem, via Table 32 
Table 15. Summary of flow path parameters for the 1-MW $\mathrm{MW}_{\text {th }}$ pilot sodium receiver design

\begin{tabular}{|l|l|}
\hline Parameter & Value \\
\hline Design thermal capacity & $1 \mathrm{MW}$ th \\
\hline Design sodium inlet temperature & $520^{\circ} \mathrm{C}$ \\
\hline Design sodium outlet temperature & $740^{\circ} \mathrm{C}$ \\
\hline Design total sodium mass flow rate & $3.7 \mathrm{~kg} / \mathrm{s}$ \\
\hline Flow paths & 2 \\
\hline Flow path inlet location & Top of inner-most panel \\
\hline Flow path outlet location & Bottom of outer-most panel \\
\hline Panels per flow path & 3 \\
\hline Tubes per panel & 11 \\
\hline Irradiated length per tube (height of billboard) & $1.77 \mathrm{~m}$ \\
\hline Tube wall-to-wall spacing (within panels) & $1.2 \mathrm{~mm}$ \\
\hline $\begin{array}{l}\text { Tube wall-to-wall spacing (between adjacent } \\
\text { panels) }\end{array}$ & $4.0 \mathrm{~mm}$ \\
\hline Tube OD & $25.4 \mathrm{~mm}$ \\
\hline Tube thickness & $1.65 \mathrm{~mm}$ \\
\hline Tube material & Alloy $740 \mathrm{H}$ (seamless) \\
\hline Tube coating & High performance solar-selective coating \\
\hline Overall irradiated width of billboard & $1.77 \mathrm{~m}$ \\
\hline & \\
\hline
\end{tabular}

Mechanical design. The mechanical design of the 1-MW $\mathrm{W}_{\text {th }}$ pilot-scale receiver draws on experience gained during the design of the ASTRI $700-\mathrm{kW}_{\text {th }}$ prototype sodium cavity receiver. The two designs are quite similar, featuring vertical tube panels, individually hung panels with spring hangers, pneumatic filling and draining valves, and a similar enclosure design, albeit with different geometries to achieve the billboard and cavity shapes. The mechanical layout of the 1$\mathrm{MW}_{\text {th }}$ receiver is described in the receiver P\&ID (see ref. document A72-D3 Rev 01). The design specifications and requirements for the receiver are documented in the Receiver Functional Specification, document 3435, see Table 32, Folder 13-Sodium Subsystem.

Panel and piping design. The panel tubes consist of straight sections of tubing (exposed to solar flux) and bent 'branch' sections butt welded on both ends of the straight tubes. The bent branches are separated from the straight tube sections since the $740 \mathrm{H}$ material requires a solution anneal heat treatment following cold bending operations. Thus, to avoid potential distortion of the tubes during the high temperature solution annealing process, the relatively short branch sections are separated from the straight tube sections. Also, the butt weld between the straight tube and the bent branches is positioned to be outside of the region exposed to solar flux. The ends of the branches are welded to the header pipes at the top and bottom of each panel. The header pipe ends are closed with welded flat plate end caps. 
It is noted that in the interest of saving material and fabrication costs, stubs between the bent branches and the headers have been omitted from the panel design. Analysis completed for the $700-\mathrm{kW}_{\text {th }}$ ASTRI prototype receiver indicated that stubs were not needed from the perspective of mechanical strength or from the perspective of thermal shock loading during transient conditions. The stress analysis results for the $1-\mathrm{MW}_{\text {th }}$ receiver indicates that stubs are also not required in this design from a mechanical strength perspective, however, it is noted that the thermal shock loading analysis has not yet to be undertaken for the 1-MW $\mathrm{MW}_{\text {th }}$ receiver. If the analysis shows stubs are required, these could be readily included in the design.

Panel and piping supports. The receiver panels are hung individually from spring hangers mounted on the enclosure roof. Guide tubes are welded to the interconnect piping at the top and bottom of each panel so that the panels are permitted to translate vertically but are fixed for lateral translations. The Lisega spring hangers have been sized for the mass of the panels full of sodium and to permit the necessary thermal expansion of the panels. The inlet and outlet piping are supported by welded pipe shoes.

Panel and piping materials. A summary of the panel and piping materials is provided in Table 16. Special Metals have provided a quotation for the above materials, with a lead time of 20 weeks offered on the tubing and piping. The price per kilogram offered is very reasonable (range of $\$ 92-110 / \mathrm{kg}$ ), however, the minimum order quantity is $750 \mathrm{~kg}$ for each size which is significantly larger than the quantity required for the pilot system. Special Metals are very interested in being involved with this project and have offered to review the MOQ's. Follow up is also required on a quotation for the plate material.

Table 16. Pilot sodium receiver panel and piping materials (WT = wall thickness)

\begin{tabular}{|l|l|l|l|l|}
\hline Item & $\begin{array}{l}\text { OD } \\
(\mathrm{mm})\end{array}$ & $\begin{array}{l}\text { Nominal } \\
\text { WT }(\mathrm{mm})\end{array}$ & Material & Standard \\
\hline Tubes and branches & 25.4 & 1.65 & N07740 seamless tube & ASTM B983 \\
\hline Headers & 88.9 & 7.62 & N07740 seamless pipe & ASTM B983 \\
\hline $\begin{array}{l}\text { Inlet piping \& interconnect } \\
\text { pipe between headers }\end{array}$ & 60.33 & 2.769 & N07740 seamless pipe & ASTM B983 \\
\hline Outlet piping & 60.33 & 2.769 & N07740 seamless pipe & ASTM B983 \\
\hline Outlet pipe header & 60.33 & 2.769 & N07740 seamless pipe & ASTM B983 \\
\hline $\begin{array}{l}\text { Drainage and filling piping } \\
\text { (panel side of valves) }\end{array}$ & 25.4 & 1.65 & N07740 seamless tube & ASTM B983 \\
\hline $\begin{array}{l}\text { Drainage and filling piping } \\
\text { (sodium loop side of valve) }\end{array}$ & 25.4 & 1.65 & $316 \mathrm{H}$ Seamless Tube & ASTM A213/A213M \\
\hline Filling pipe header & 33.4 & 3.378 & $316 \mathrm{H}$ Seamless Pipe & ASTM A312/A312M \\
\hline Drainpipe header & 33.4 & 3.378 & $316 \mathrm{H}$ Seamless Pipe & ASTM A312/A312M \\
\hline Header end caps & - & 10 & N07740 plate & ASTM B872 \\
\hline
\end{tabular}

Panel and piping stress analysis. FE Consultants were engaged to carry out stress analysis on the receiver panel and piping to ASME BPVC Section VIII Div1/Div2. The input assumptions for the stress analysis are documented in "FE Model Input Data.xlsx, dated 20/11/20". The 
temperature distribution applied to the panel tubes was output from the heat transfer modeling work. The results indicate that the receiver design is suitable for the target design life $(10,000$ hours of on-sun operation). The stress analysis work is documented in the Gen3L Sodium Receiver Report, FE-201119-01-R-01. These reports can be accessed via Table 32, Folder 13Sodium Subsystem.

Receiver surface coating. The pilot sodium receiver tubing is to be coated with a highperformance coating. The present design calls for use of the NanoSD coating developed under DOE funding, but the final selection is to be negotiated with the pilot receiver panel manufacturer, noting some of the coating options are proprietary.

Insulation. The space between the receiver tubing and the enclosure back wall is insulated with Superwool Plus blanket, $128 \mathrm{~kg} / \mathrm{m}^{3}$, with a nominal thickness of $400 \mathrm{~mm}$. Similarly, the headers and other piping and tubing are insulated with Superwool.

Instrumentation. The receiver instrumentation is summarized in the receiver P\&ID (ref. document A72-D3 Rev 01, see Table 32, Folder 13-Sodium Subsystem). There are a total of 50 thermocouples in the receiver, including 26 thermocouples attached to the rear of the panel tubing. The thermocouples are secured to the tubing using a 'welded-cap' method, where small caps made from $740 \mathrm{H}$ pipe are welded to the tubing to clamp the thermocouples in place. The thermocouples are type K, high temperature fiberglass flat twin with SS braid, tcaus.com.au stock number C78.

Electrical heating / heat tracing. All piping, headers and valves are to be heat traced with a high temperature heat tracing product, HORST HSQ-900. This product is a flexible heating cable with high temperature $\left(900^{\circ} \mathrm{C}\right)$ resistance. Sizing and layout of the heat tracing for the pilot receiver is yet to be carried out.

Electric heating mats are attached to the inside of the enclosure door which can be used for heating the straight tube sections of the receiver when the doors are closed. This capacity may be used in freeze recovery, to help maintain receiver temperatures during standby operation, or potentially for pre-heating the receiver tubing prior to start-up operations. The heating mats are a HORST product, HMSG-450 size 6, order number 036006, which is a flexible mat made of glass fiber fabric with a nominal temperature of $450^{\circ} \mathrm{C}$. Each heating mat has a rating of $2 \mathrm{~kW}$ and is equipped with a NiCr-Ni temperature sensor for temperature regulation. Three mats are attached to both enclosure doors, giving a total heating capacity of $12 \mathrm{~kW}$.

Based on steady state loss calculations for the receiver, and assuming the receiver is maintained at $300^{\circ} \mathrm{C}$, an ambient temperature of $0^{\circ} \mathrm{C}$, and assuming $30 \%$ of the hot air leaks out of the enclosure door, a heating capacity of $8.2 \mathrm{~kW}$ would be required. Thus, the selected heating capacity of $12 \mathrm{~kW}$ is considered to be conservative.

Sodium Valves. Swagelok bellows seal valves are employed for both the draining and filling / vent valves. The valves are off-the-shelf products, part number SS-12UAW-TW-HT-8O, pneumatically operated, with a 316 stainless steel body, 1" tube butt-weld connections, and a maximum service temperature limit of $650^{\circ} \mathrm{C}$. The valves feature a secondary containment to prevent leaks if the primary seal fails. 
The filling / vent valves (located at the top of the receiver) as well as the drain valves (located at the bottom of the receiver) are opened during the sodium filling sequence to ensure the panels, headers and interconnect piping are completely full of sodium, and are then closed. The drain valves are opened during the sodium draining sequence, and sodium in the receiver drains by gravity back to the sodium loop, noting that piping in the receiver is designed with a 1.5-degree slope.

As summarized in Table 16, the tubing on the sodium loop side of the valves is $316 \mathrm{H}$ material, while the tubing on the panel side of the valves is $740 \mathrm{H}$. Thus, there is a dissimilar weld location directly adjacent to each valve, noting that a short $50-\mathrm{mm}$ section of $316 \mathrm{H}$ material is welded to the panel side of the valve so that the dissimilar weld is not directly adjacent to the valve body.

'Cold legs' are incorporated in the tubing on the panel side of the valves (by removing sections of insulation), so that the temperature at each of the dissimilar weld locations is less than $520^{\circ} \mathrm{C}$, which is below the creep range for both materials, and reduces the differential thermal expansion induced stresses across the weld due to different coefficient of thermal expansion values. The cold legs also ensure that the valve temperatures are below the maximum service limit of the valves.

Enclosure and aperture door design. The receiver enclosure consists of 316 stainless steel sheet metal and standard section structural members. The enclosure is seam welded in order to contain sodium in the event of a sodium leak. The enclosure design features removable rear wall sections and a removable roof access cover to facilitate equipment and insulation installation and maintenance access.

Two horizontally sliding doors driven by a Kone electric door operator slide across the aperture of the receiver to help contain sodium and smoke in the event of a sodium leak. This feature is included in the design to address safety requirements at the Sandia site. Due to the receiver location in the tower, there is a risk of smoke entering the tower and, as such, it was decided that an aperture door on the receiver was an appropriate risk mitigation measure for this pilot plant. When the aperture doors are in the open position, these also act as shields for the surrounding equipment from solar field flux spillage. Due to the relatively high levels of solar flux in the spillage regions, it is intended that ceramic fiber board, RSLE-57, will also be secured on regions of the aperture doors and regions on the enclosure above and below the receiver aperture.

Fabrication. Fabrication of the receiver panels and piping involves standard pressure vessel manufacturing techniques, including cold bending, heat treatment, machining and pressure welding. It is noted that the $740 \mathrm{H}$ material employed in the receiver panels and piping requires post bending heat treatment (PBHT), in the form of a solution anneal of the entire part, for parts with a strain rate $>5 \%$ [72]. Since the strain rates in the pilot receiver design exceed this limit, PBHT is required for all $740 \mathrm{H}$ material parts that are cold worked. $740 \mathrm{H}$ material also requires post weld heat treatment (PWHT) in accordance with specific procedures provided by the manufacturer [72]. The PWHT can be performed locally or to an assembly of parts (such as the receiver panels). Special Metals have carried out successful trials of dissimilar welding between $740 \mathrm{H}$ and $316 \mathrm{H}^{11}$. No issues were encountered with fabricating these welds, noting that the post-weld heat treatment conditions were adjusted within the range allowed by ASME Code Case 2702 to accommodate the ferritic materials.

\footnotetext{
${ }^{11}$ https://asmedigitalcollection.asme.org/PT/proceedings /ETAM2018/40764/V001T01A005/230444
} 
For quality assurance and sodium safety, non-destructive testing (NDT) of all panel and piping welds is required in addition to hydrostatic pressure testing, as noted on the fabrication drawings. In addition to the NDT requirements of the ASME codes, the pilot receiver is to have the following NDT as a minimum: (i) $100 \%$ RT of pipe butt welds and (ii) $100 \%$ DPI external + $100 \%$ visual internal \& external of other welds. Refer to the receiver fabrication drawings for further details on the pilot receiver design and fabrication methods (see Table 32).

\subsubsection{Pilot-Scale Performance Modeling}

An optics (Monte Carlo ray tracing) and heat transfer (steady state mesh-based flux balance) model for the NSTTF heliostat field and 1-MW th pilot sodium receiver has been built using CSIRO's Heliosim software [73], see Figure 50.

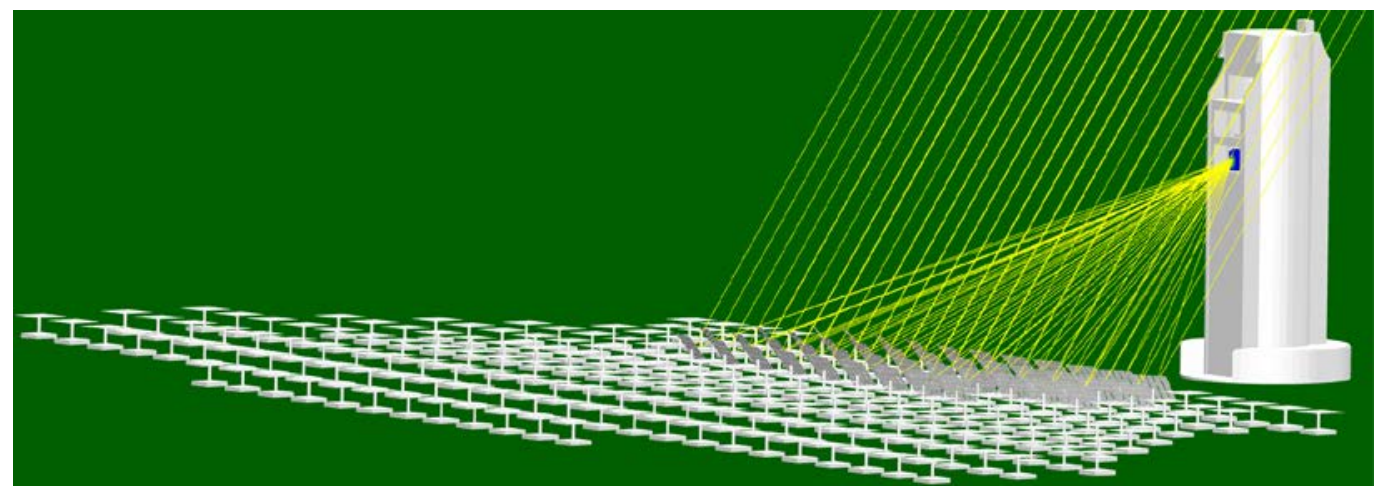

Figure 50. 3D renderings from the Heliosim software GUI of the NSTTF heliostat field and 1MWth pilot sodium receiver model

NSTTF heliostat field model. The heliostat field optics are simulated using the Monte Carlo ray tracing model implemented in Heliosim, which has been validated against other models including Tonatiuh and SolTrace [65]. The layout for the NSTTF heliostats is presented in Figure 51 . The indicated block of 84 heliostats ( 7 rows $\times 12$ columns) was found via the simulations performed in the present work to be sufficient for ensuring a thermal power output of $1 \mathrm{MW}_{\text {th }}$ throughout the year for \pm 3 hours from solar noon, assuming historical average DNIs for days with cloudless skies.

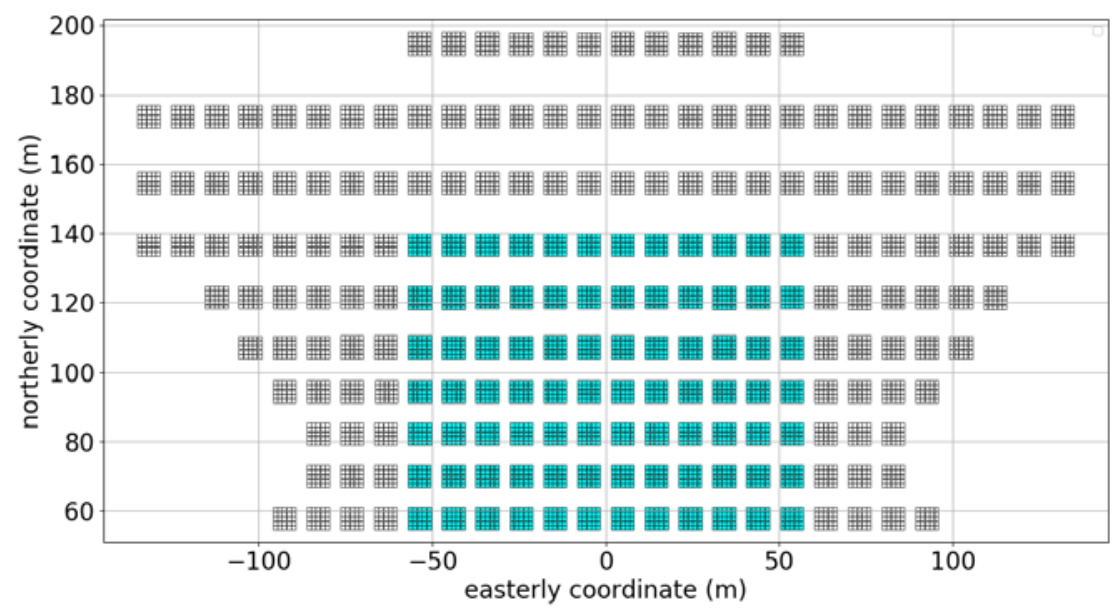

Figure 51. Block of 84 heliostats from the NSTTF estimated to be required for annual operation of the pilot sodium receiver to ensure $1 \mathrm{MW}_{\text {th }}$ output 
Key parameters for the NSTTF heliostat field model implemented in Heliosim are summarized in Table 17. Due to current limitations of the Heliosim software, two simplifications were made to the heliostat representation: (1) uniform spacing assumed between facets, and (2) on-axis canting in the vertical axis. The actual NSTTF heliostats have non-uniform spacing, and off-axis canting in the vertical axis. Whilst the assumption of uniform facet spacing is unlikely to lead to significant error, the neglect of off-axis canting in the vertical axis may lead to slight errors in field performance for particular times of the year (e.g., in summer when the solar elevation angle is high). Other possible sources of error in the model are the assumed values for facet solar reflectance, total beam error and sun shape, which have been estimated based on experience and previous characterization experiments performed by Sandia. A dedicated heliostat field characterization experiment was performed in December 2020 to validate these parameters. A comparison of the Heliosim optical model with the experimental measurements is ongoing, and the current status is presented in the proceeding section.

Table 17. Key parameters for the NSTTF heliostat field model implemented in Heliosim. Parameters that are known to differ from the actual facility are shown in blue italics.

\begin{tabular}{|l|l|}
\hline Parameter & Value \\
\hline Total heliostat count & 218 \\
\hline $\begin{array}{l}\text { Estimated heliostat count required for } \\
\text { annual operation of pilot receiver }\end{array}$ & 84 \\
\hline Heliostat actuation & Azimuth-elevation \\
\hline Heliostat aperture size (width $\mathbf{x}$ height) & $6.81 \times 6.35 \mathrm{~m}$ \\
\hline Heliostat facets (width $\mathbf{\times}$ height) & $5 \times 5$, uniform spacing \\
\hline Facet size (width $\mathbf{x}$ height) & $1.22 \times 1.22 \mathrm{~m}$ \\
\hline Facet focal point $(\mathbf{x}, \mathbf{y}, \mathbf{z})$ & $(0,8,54.56 \mathrm{~m})$ \\
\hline $\begin{array}{l}\text { Proposed location for centroid of pilot } \\
\text { sodium receiver aperture }(\mathbf{x}, \mathbf{y}, \mathbf{z})\end{array}$ & $(-1.5,9.0,38.5 \mathrm{~m})$ \\
\hline Facet horizontal canting & On-axis \\
\hline Facet vertical canting & On-axis \\
\hline Facet solar reflectance & 0.92 \\
\hline Facet slope error & 1.2 mrad \\
\hline Heliostat tracking error & 0.5 mrad \\
\hline Total beam error & 1.3 mrad \\
\hline Aim point distribution(s) & 4 (rectangular) \\
\hline Sun shape & Limb darkened \\
\hline Atmospheric attenuation & 23 km visibility \\
\hline Additional shading objects & Tower from CAD model \\
\hline
\end{tabular}

NSTTF heliostat field characterization experiment. An experiment was run by Sandia to characterize the performance of the NSTTF heliostat field when targeting the proposed 1-MW pilot sodium receiver design. A radiometer and eight thermocouples were installed in a $1.77 \times$ 
$1.77 \mathrm{~m}$ board fabricated from RSLE. The board was mounted at the 220 level of the NSTTF tower where the pilot receiver is proposed to be installed. During the experiments, a groundmounted beam characterization system recorded the backscatter of radiation from the board. Using the radiometer data, the camera image intensities were calibrated to $\mathrm{W} / \mathrm{m}^{2}$ of incident irradiance.

Table 19 shows an initial selection of "shots" that were run on the $4^{\text {th }}$ of December 2020 with a single aim point (4-point aiming was also characterized). Solar noon on this day was at 11:58. Comparison of the measured and simulated irradiance maps for an afternoon case is presented in Figure 52. While reasonable agreement between the measured and simulated incident power (i.e., integrated irradiance over the board), peak irradiance exhibits significant discrepancy especially for the morning shots (e.g., $-35.7 \%$ error for the 11:52 shot). There are a number of factors that could contribute to this discrepancy, including:

- The neglect of off-axis canting in the vertical axis for the simulated heliostat facets

- The assumed sun shape (limb darkened), facet slope error (1.3 mrad) and facet solar reflectance (0.92) used in the simulations

- Uncertainties in the calibration of the experimental measurements

These will be investigated as part of ongoing work to develop a more accurate model of the NSTTF heliostat field in Heliosim.

Table 18. Summary of NSTTF heliostat field characterization experiment rebuilding with Heliosim for selected cases

\begin{tabular}{|l|l|l|l|l|l|l|l|l|}
\hline Time & $\begin{array}{l}\text { DNI } \\
\left(\mathrm{W} / \mathrm{m}^{2}\right)\end{array}$ & $\begin{array}{l}\text { Utilized } \\
\text { heliostats }\end{array}$ & $\begin{array}{l}\text { Measured } \\
\text { peak } \\
\text { irradiance } \\
\left(\mathrm{kW} / \mathrm{m}^{2}\right)\end{array}$ & $\begin{array}{l}\text { Simulated } \\
\text { peak } \\
\text { irradiance } \\
\left(\mathrm{kW} / \mathrm{m}^{2}\right)\end{array}$ & $\begin{array}{l}\text { Simulated } \\
\text { peak } \\
\text { irradiance } \\
\text { error }(\%)\end{array}$ & $\begin{array}{l}\text { Measured } \\
\text { incident } \\
\text { power } \\
(\mathrm{kW})\end{array}$ & $\begin{array}{l}\text { Simulated } \\
\text { incident } \\
\text { power } \\
(\mathrm{kW})\end{array}$ & $\begin{array}{l}\text { Simulated } \\
\text { incident } \\
\text { power } \\
\text { error }(\%)\end{array}$ \\
\hline $\mathbf{1 0 : 3 5}$ & 939 & 38 & 815 & 606 & -25.6 & 792 & 761 & -3.9 \\
\hline $\mathbf{1 0 : 4 9}$ & 944 & 40 & 962 & 667 & -30.6 & 904 & 826 & -8.7 \\
\hline $\mathbf{1 1 : 4 7}$ & 961 & 28 & 713 & 478 & -32.9 & 652 & 656 & 0.5 \\
\hline $\mathbf{1 1 : 5 2}$ & 957 & 32 & 843 & 542 & -35.7 & 782 & 729 & -6.8 \\
\hline $\mathbf{1 1 : 5 6}$ & 957 & 36 & 968 & 623 & -35.6 & 883 & 815 & -7.6 \\
\hline $\mathbf{1 4 : 2 1}$ & 870 & 38 & 683 & 636 & -6.8 & 680 & 770 & 13.3 \\
\hline $\mathbf{1 4 : 2 5}$ & 864 & 44 & 819 & 738 & -9.9 & 784 & 871 & 11.2 \\
\hline $\mathbf{1 4 : 3 3}$ & 848 & 50 & 816 & 815 & -0.2 & 935 & 969 & 3.7 \\
\hline
\end{tabular}



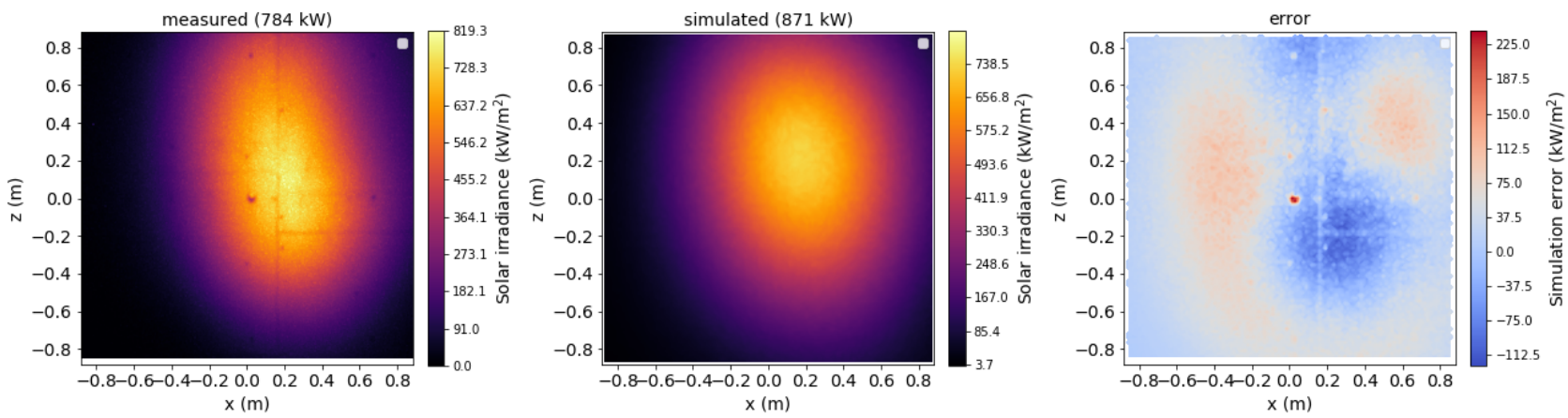

Figure 52. Comparisons of measured and simulated irradiance maps for 14:25 shot from the NSTTF solar field characterization experiment rebuilding with Heliosim

Sodium receiver model. Similar to the approach applied for simulation of the ASTRI 700-kW $\mathrm{kW}_{\text {th }}$ prototype sodium cavity receiver [74], two levels of modeling complexity were considered for the 1-MW th pilot sodium receiver: (i) Representation of tube banks using a planar surface (simple model), and (ii) Representation of individual tubes using actual cylindrical geometry (detailed model). The simple model approximates the tube banks as flat surfaces that pass through the tube centerlines, while the detailed model retains the actual geometry of each cylindrical tube, with the gap between tubes and the backing insulation included. In the present work, the simple model was used to determine heliostat aiming strategies and receiver performance for a number of representative points throughout the year, while the detailed model was applied to the Equinox design point condition to validate the simple model and for computing temperature boundary conditions for the FEA analyses of the tubing assembly. Visualizations of the simple and detailed computational meshes are shown in Figure 53. 


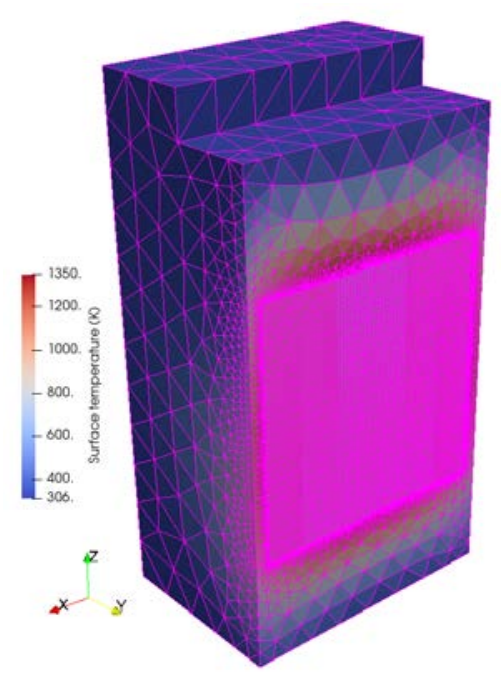

(a) Simple model $(16,452$ mesh facets)

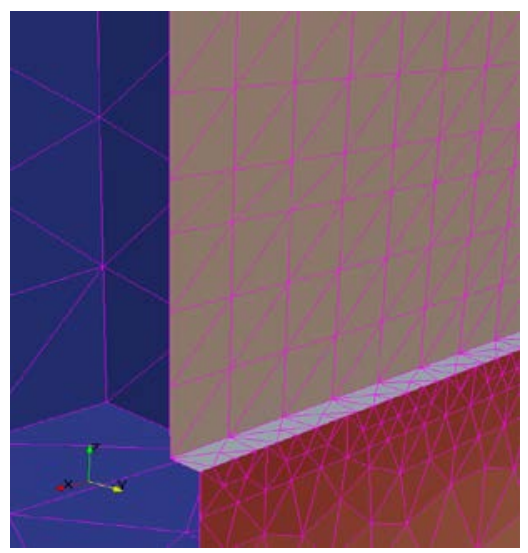

(c) Simple model with clipping applied in YZ symmetry plane - close up of planar surface representing the pipes

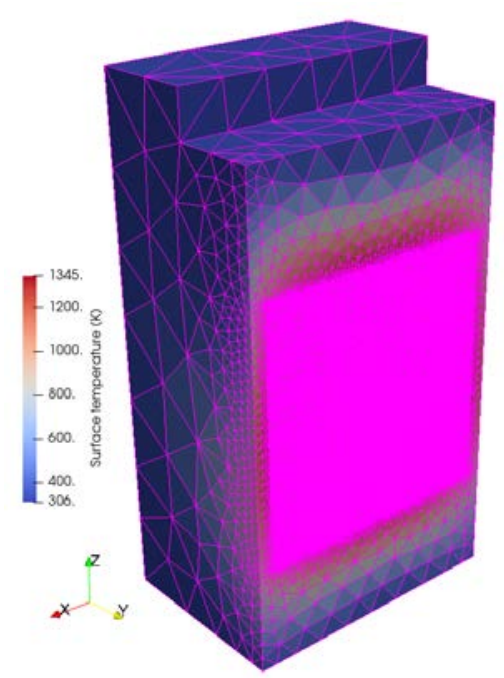

(b) Detailed model (55,012 mesh facets)

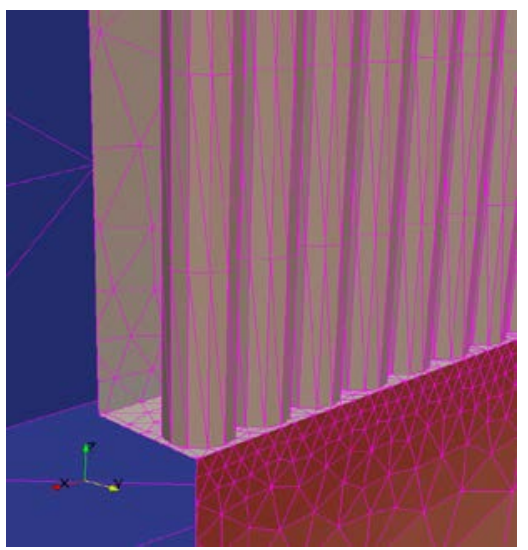

(c) Detailed model with clipping applied in YZ symmetry plane - close up of pipes

Figure 53. Visualizations of the simple and detailed computational meshes for the 1-MW $\mathrm{MW}_{\text {th }}$ pilot sodium receiver

Due to the significantly lower mesh resolution, the simple model has lower computational requirements than the detailed model. For the equinox design point, the simple model was found to reproduce key results from the detailed model such as thermal power output and peak fraction of allowable flux to within $0.4 \%$ and can therefore be used with confidence for the other points considered.

A summary of the heliostat field and receiver performance for the case of 4 distributed aim points is presented in Table 19, the incident solar irradiance maps on the billboard aperture plane are presented in Figure 54, and parameters as a function of flow path position are given in Figure 55. 
Table 19. Summary of ray tracing and heat transfer simulation results for the 1-MW $\mathrm{M}_{\text {th }}$ pilot sodium receiver using four distributed aim points and the simple receiver model

\begin{tabular}{|c|c|c|c|c|c|c|}
\hline Date & Spring & Equinox & Summ & Solstice & Wintel & Solstice \\
\hline Hours relative to solar noon & 0 & +3 & 0 & +3 & 0 & +3 \\
\hline DNI (W/m2) & 1055 & 1000 & 1020 & 980 & 960 & 800 \\
\hline Ambient temperature (K) & 293 & 293 & 305 & 305 & 280 & 280 \\
\hline Wind speed $(\mathrm{m} / \mathrm{s})$ & 6.04 & 6.04 & 6.04 & 6.04 & 6.04 & 6.04 \\
\hline Installed heliostats & 218 & 218 & 218 & 218 & 218 & 218 \\
\hline Utilised heliostats & 44 & 53 & 48 & 60 & 50 & 72 \\
\hline Aim point count & 4 & 4 & 4 & 4 & 4 & 4 \\
\hline Aim points horizontal spread factor & 0.25 & 0.3 & 0 & 0.1 & 0.35 & 0.35 \\
\hline Aim points vertical spread factor & 0.4 & 0.4 & 0.4 & 0.4 & 0.4 & 0.4 \\
\hline Power through aperture (kW) & 1219 & 1200 & 1206 & 1229 & 1201 & 1198 \\
\hline Spillage loss (kW) & 210 & 274 & 217 & 329 & 251 & 312 \\
\hline Receiver solar reflection loss (kW) & 20 & 19 & 19 & 19 & 19 & 19 \\
\hline Receiver thermal radiation loss (kW) & 144 & 144 & 140 & 144 & 142 & 142 \\
\hline Receiver convection loss (kW) & 32 & 32 & 31 & 31 & 32 & 32 \\
\hline Receiver conduction loss (kW) & 4 & 4 & 4 & 4 & 4 & 4 \\
\hline HTF thermal output (kw) & 1018 & 1002 & 1012 & 1031 & 1003 & 1000 \\
\hline Aperture interception efficiency (\%) & 85.3 & 81.3 & 84.8 & 78.8 & 82.7 & 79.3 \\
\hline Receiver efficiency (\%) & 83.6 & 83.4 & 83.9 & 83.9 & 83.5 & 83.5 \\
\hline $\begin{array}{l}\text { Combined interception and receiver } \\
\text { efficiency }(\%)\end{array}$ & 71.3 & 67.9 & 71.1 & 66.1 & 69.1 & 66.2 \\
\hline $\begin{array}{l}\text { East flow path avg mass flow rate per } \\
\text { pipe }(\mathrm{kg} / \mathrm{s})\end{array}$ & 0.168 & 0.167 & 0.166 & 0.175 & 0.164 & 0.164 \\
\hline $\begin{array}{l}\text { West flow path avg mass flow rate per } \\
\text { pipe }(\mathrm{kg} / \mathrm{s})\end{array}$ & 0.167 & 0.163 & 0.167 & 0.164 & 0.165 & 0.165 \\
\hline $\begin{array}{l}\text { East flow path max. fraction of allowable } \\
\text { net flux from } 100,000 \mathrm{hr} \text { elastic analysis (-) * }\end{array}$ & 1.02 & 0.94 & 0.99 & 1.02 & 0.95 & 0.94 \\
\hline $\begin{array}{l}\text { West flow path max. fraction of allowable } \\
\text { net flux from } 100,000 \text { hr elastic analysis (-) }\end{array}$ & 0.97 & 1.00 & 1.00 & 1.02 & 0.97 & 0.97 \\
\hline $\begin{array}{l}\text { East flow path max. fraction of allowable net } \\
\text { flux from } 10,000 \mathrm{hr} \text { inelastic analysis }(-)^{*}\end{array}$ & 0.57 & 0.54 & 0.53 & 0.58 & 0.53 & 0.54 \\
\hline $\begin{array}{l}\text { West flow path max. fraction of allowable } \\
\text { net flux from } 10,000 \mathrm{hr} \text { inelastic analysis (-) }\end{array}$ & 0.54 & 0.57 & 0.53 & 0.58 & 0.52 & 0.53 \\
\hline Max. tube surface temperature $(\mathrm{K})$ & 1047 & 1048 & 1050 & 1045 & 1047 & 1049 \\
\hline Max. insulation surface temperature (K) & 1087 & 1124 & 1016 & 1134 & 1051 & 1081 \\
\hline Max. shield surface temperature (K) & 1450 & 1518 & 1336 & 1499 & 1483 & 1470 \\
\hline Max. average tube wall temperature (K) & 1015 & 1016 & 1012 & 1016 & 1013 & 1015 \\
\hline $\begin{array}{l}\text { Max. average tube temperature wall } \\
\text { disparity }(\mathrm{K})\end{array}$ & 23 & 25 & 25 & 25 & 22 & 24 \\
\hline Max. sodium outlet temperature disparity (K) & 34 & 38 & 39 & 36 & 33 & 36 \\
\hline Max. sodium temperature (K) & 1031 & 1032 & 1031 & 1031 & 1031 & 1032 \\
\hline
\end{tabular}

* based on curves in Figure 62, left. 


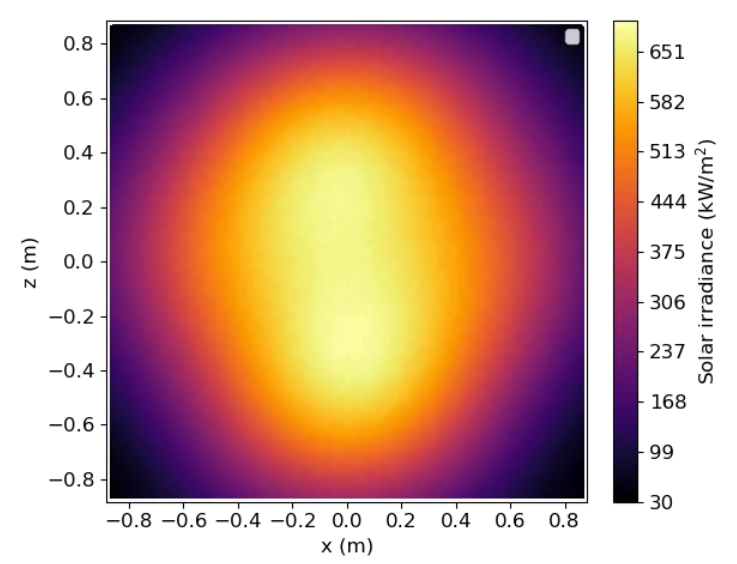

(a) Spring solar noon

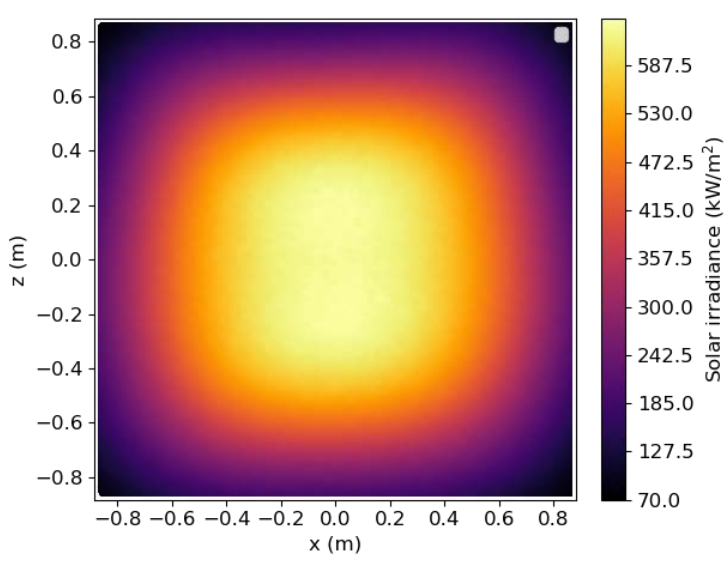

(c) Summer solar noon

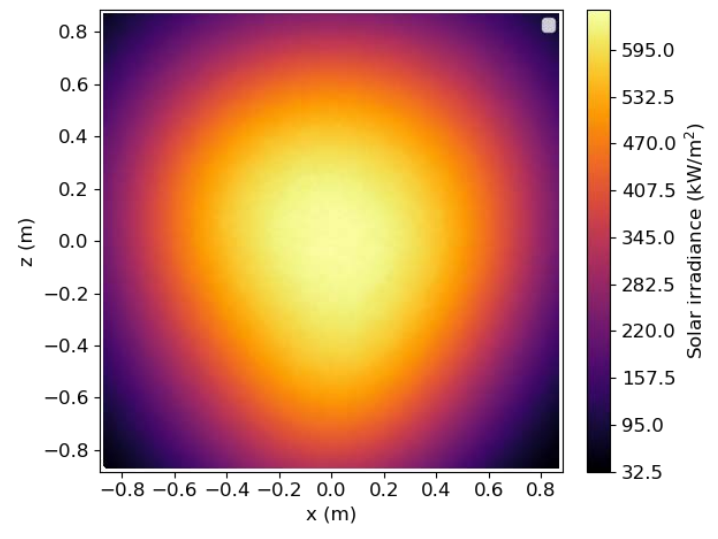

(e) Winter solar noon

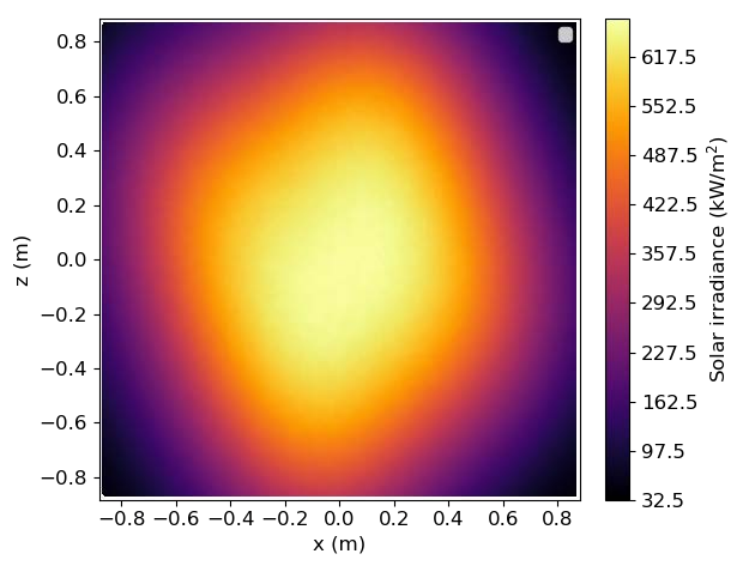

(b) Spring solar noon +3 hours

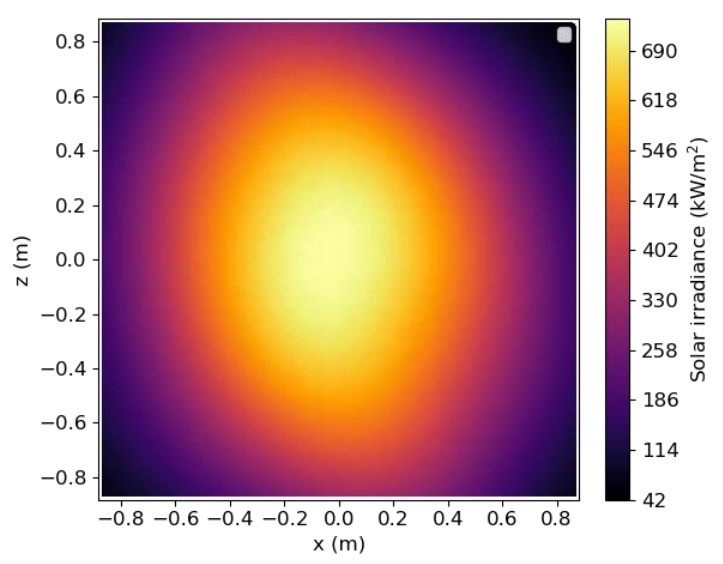

(d) Summer solar noon +3 hours

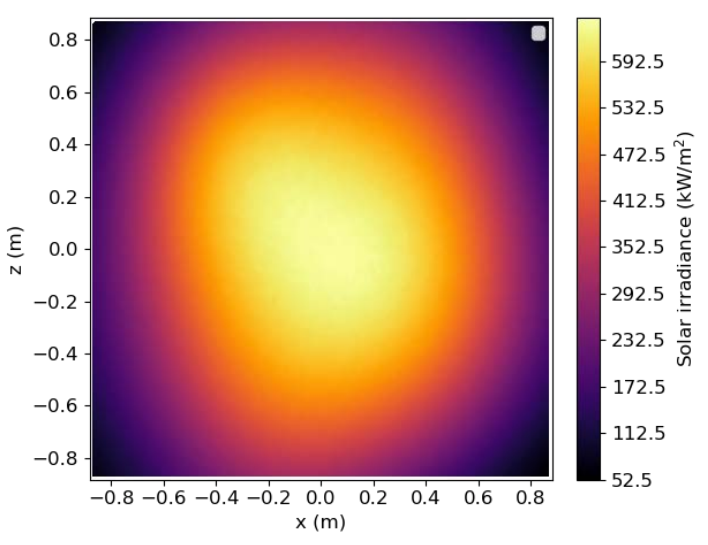

(f) Winter solar noon +3 hours

Figure 54. Incident solar irradiance on the aperture plane $(1.77 \times 1.77 \mathrm{~m})$ of the 1-MWth pilot sodium receiver using 4 distributed aim points and the simple receiver model 

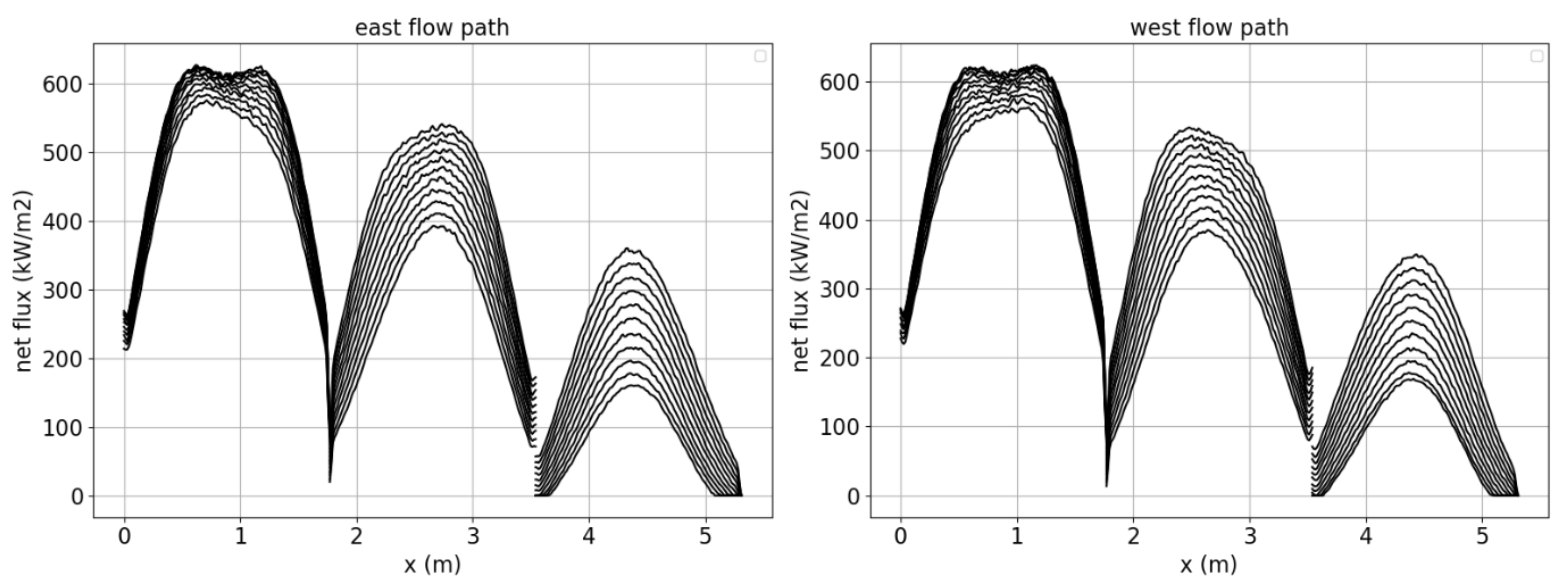

(a) Net flux through tube crown
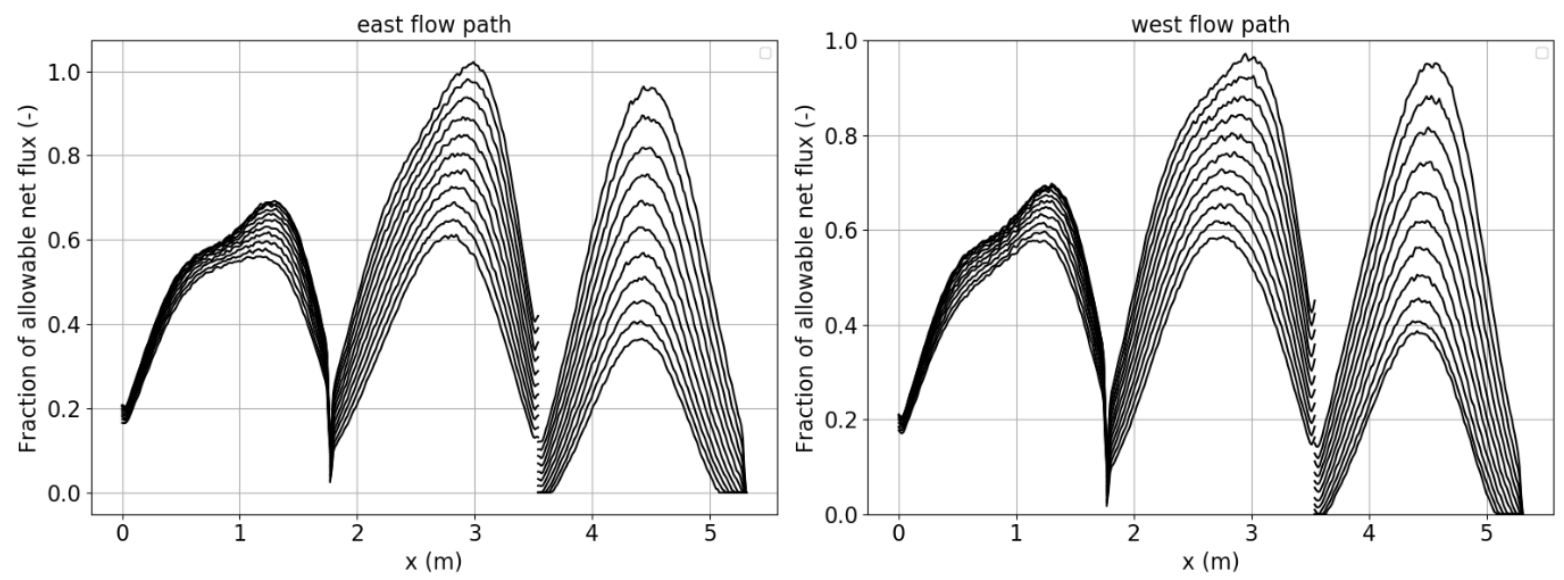

(b) Fraction of allowable net flux from 100,000 hr elastic analysis (see )
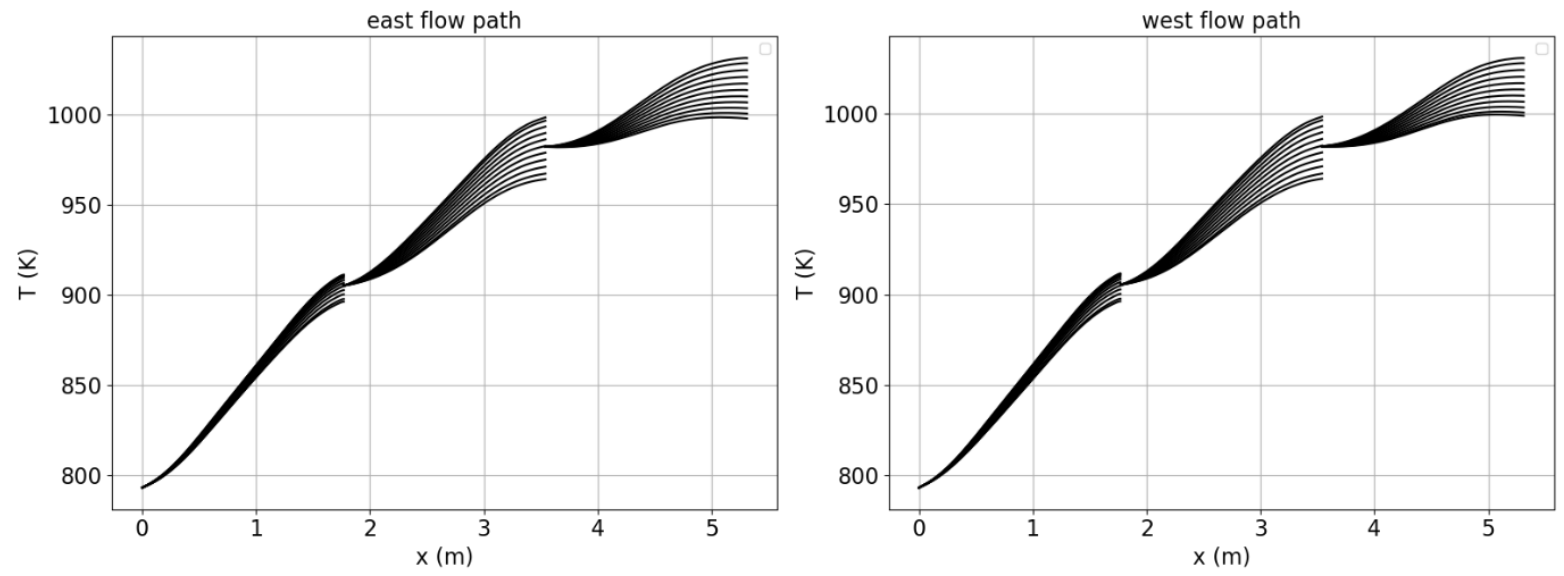

(c) Bulk sodium temperature

Figure 55. Flow path profiles at the spring equinox design point for the 1-MW $\mathrm{H}_{\text {th }}$ pilot sodium receiver using distributed aim points and the simple receiver model. Each line represents the variation along the flow axis of an individual tube. The $x$ coordinate is the accumulated distance from the sodium inlet. 
Receiver heat transfer is simulated by solving the system of nonlinear equations describing a steady state flux balance for each of the facets in the receiver surface mesh. Full details of the heat transfer model for a similar small scale sodium receiver are presented in Potter et al. [74].

Performance predictions were made for both single and distributed aim point strategies. However, presented here are performance results for the preferred operational strategy employing four distributed aim points, which more closely represents the flux distributions expected for the commercial receiver (i.e., a relatively uniform distribution of flux over the tubes, with minimal variation between tubes in a common bank). Nonetheless, it is noted that while the single aim point strategy results in a significantly more concentrated flux distribution, and therefore high variation between tubes in a common bank, it is still deemed a safe operating mode with respect to structural integrity, based on the allowable flux limit from the 10,000-hour inelastic analysis of the $740 \mathrm{H}$ tubing (\$4.8.4). This result suggests that a worse-case scenario (e.g., operator error) of a single aim point being used to deliver 1-MW $\mathrm{MW}_{\text {th }}$ at any point throughout the year should not result in failure of the tube walls.

The key observation from these results is that by using the distributed aim point strategy, the pilot receiver can be operated such that conditions that may compromise the structural integrity of the receiver tubes and headers are minimized. Specifically, the more conservative allowable flux limit from the 100,000-hour elastic analysis ( $\$ 4.8 .4$, described next) can be adhered to, and maximum tube wall temperature disparities in a common bank can be kept below $30 \mathrm{~K}$.

Furthermore, by distributing the flux more uniformly over the tube banks, the receiver efficiency is slightly improved due to reduced exergy loss when differentially heated sodium is mixed in the headers. The trade-off, however, is that aperture interception efficiency is significantly reduced (e.g., from $94.7 \%$ for a single aim point at equinox solar noon, to $85.3 \%$ for distributed aim points). This reduction in aperture interception efficiency is necessary to achieve safe operation of the billboard pilot receiver. As shown in $\S 3.3$, spillage is not an issue for a cylindrical-type commercial-scale sodium receiver where the heliostat field layout and receiver geometry have been designed in a coupled manner.

\subsubsection{Receiver Mechanical Analysis}

An interim report on Materials Selection for the high temperature sodium receiver and loop was provided to DOE in 2019 as part of Milestone 3, outlining the key selection criteria, particularly relating to structural integrity, corrosion, availability and cost. Because of material strength requirements at high temperature, nickel alloys were found to be necessary in the receiver. The strength attributes of Inconel 740H were highlighted (see Figure 18), although Inconel 617 was initially preferred because of the availability of creep-fatigue data and its inclusion in ASME BPVC Section III Division 5 HBB. However, new data became available on Inconel $740 \mathrm{H}$ via a complementary DOE-funded project led by EPRI and Special Metals (DE-EE0008367), including high temperature tensile, creep, fatigue and creep-fatigue testing data, and therefore in early 2020 , Inconel $740 \mathrm{H}$ was confirmed as the material of choice for both the prototype and commercial scale receiver designs.

Structural integrity. Code Case N-47 (now Division 5) in Section III of the ASME B\&PVC was developed to cover the thermally activated creep and relaxation failure modes inherent in elevated temperature service (nuclear up to $593^{\circ} \mathrm{C}$ ) and was used for component design of sodium loops in fast breeder reactors. The high thermal conductivity and low primary-loop 
pressure (e.g., 1.5 MPa) afforded by sodium make designing a sodium receiver for economic certainty a process very much akin to designing fast breeder components. The failure mechanisms in sodium receivers are the same, albeit shifted to a higher operating range (500$750^{\circ} \mathrm{C}$ ). In addition, the minimum shell thickness required by Section VIII (UG-16b) of the ASME B\&PVC is arbitrarily conservative. With detailed analysis it is feasible a wall thickness below the $1.5 \mathrm{~mm}$ minimum required for certification to Section VIII may be justified. Section III (including Division 5) does not currently enforce a minimum shell wall thickness, although wall thickness lower than $1 \mathrm{~mm}$ are probably impractical from a manufacturing perspective.

Guidelines developed by Argonne National Laboratory (ANL) and Idaho National Laboratory (INL) under a DOE-funded project (DE-EE00033872) to determine creep-fatigue behavior and damage accumulation of a candidate material, alloy 740H (UNS N07740), in a CSP receiver [75] provide three lifetime estimation methods:

1. Design by elastic analysis using ASME Section III, Div. 5,

2. Design by elastic analysis using ASME Section III, Div. 5 with reduced margin and simplified creep-fatigue,

3. Design by simple inelastic analysis.

The following section describes how structural integrity assurance according to the guidelines (referred to as ANL-20/03 henceforth) was integrated into the sodium receiver prototype and commercial designs and confirms that a significantly higher (more aggressive) flux density is feasible if inelastic analysis is used to predict receiver tube lifetime. Inelastic analysis is considered the most accurate and least conservative standard for high-temp creep-fatigue design [76]. The method described here was used by the team for analysis of both the sodium and the salt receiver options prior to the down selection to sodium at the end of Phase 1.

Method. Elastic and simple inelastic approaches bound the problem with what are essentially "worst case" scenarios of geometric and load dependent variables, requiring from the designer only a transient thermal analysis and small-deformation quasi-static linear-elastic Finite Element Analysis (FEA) of a single Design Cycle. Where primary stress (force from internal tube pressure) is low and secondary stress (strain from thermal gradients $\approx \alpha \Delta T$, where $\alpha$ is coefficient of thermal expansion) dominates, creep strain incurred while the receiver is on-sun will relax stress. If relaxation of strain-controlled stress is not reset from plasticity during transients of startup, operation and shutdown (as required by ANL-20/03 for Alloy $740 \mathrm{H}$ on account of its superior yield strength), a global relaxation response of structure will be reached following enough repetition of a given Design Cycle. Inelastic modeling requires significantly more computation time to repeat the Design Cycle enough to reach a steady-state stress-strain hysteresis response of structure.

During the initial stages of this project, the ASME B\&PVC Section VIII Div. 2 was used to predict maximum allowable flux incident on tubes using linear-elastic analysis. The so-called Elastic Ratcheting Analysis Method assumes that the thermal strain range as dictated by the flux incident on the tube "shakes down" from plasticity in the first few cycles and creep relaxation thereafter. The method is also referred to as the "twice yield" method in that it can allow thermal strain ranges up to two times the yield stress at temperature if they are infrequent enough. As stipulated by the Elastic Ratchet Analysis Method, when the allowable stress $S_{\mathrm{m}}$ incorporating 
time-dependent creep out to 100,000 hours is used to bound thermal strain range, instead of yield stress, a naive estimate of "indefinite" tube life is attained. While ignoring damage from fatigue, this method is conservative as it assumes that creep rupture is still bound by an un-relaxed and constant "forward-creep". The Elastic Ratchet Analysis Method is valuable in that it allows first estimates to be made quickly.

Original FEA models considered a 3D tube illuminated along its length with some Gaussian-like distribution, with the concentrated light assumed to be collimated and therefore described by a cosine distribution about the illuminated tube side circumference. The 3D tube ends were allowed to expand axially by a constant force-annulling strain but not rotate. ${ }^{12}$ To calculate single Design Cycle thermoelastic stress (Figure 56) for a $10.5 \mathrm{~m}$ long tube with outer diameter (OD) $60 \mathrm{~mm}$ requires a few minutes on a PC with 4 cores. To perform 100 repetitions of the Design Cycle using the inelastic constitutive model described by ANL-20/03 Part 2 requires three days on a typical lab computer. In an attempt to find computational savings, a 2D generalized plane strain (GPS) model was located on same tube where the combination of elevated temperature and incident flux combine to give it the shortest lifetime to rupture. The two models provide very near agreement in the prediction of stress relaxation at this location out to 100 diurnal cycles. The 2D-GPS model requires around 24 hours to simulate 1825 diurnal cycles (5 years) on a single core personal computer.
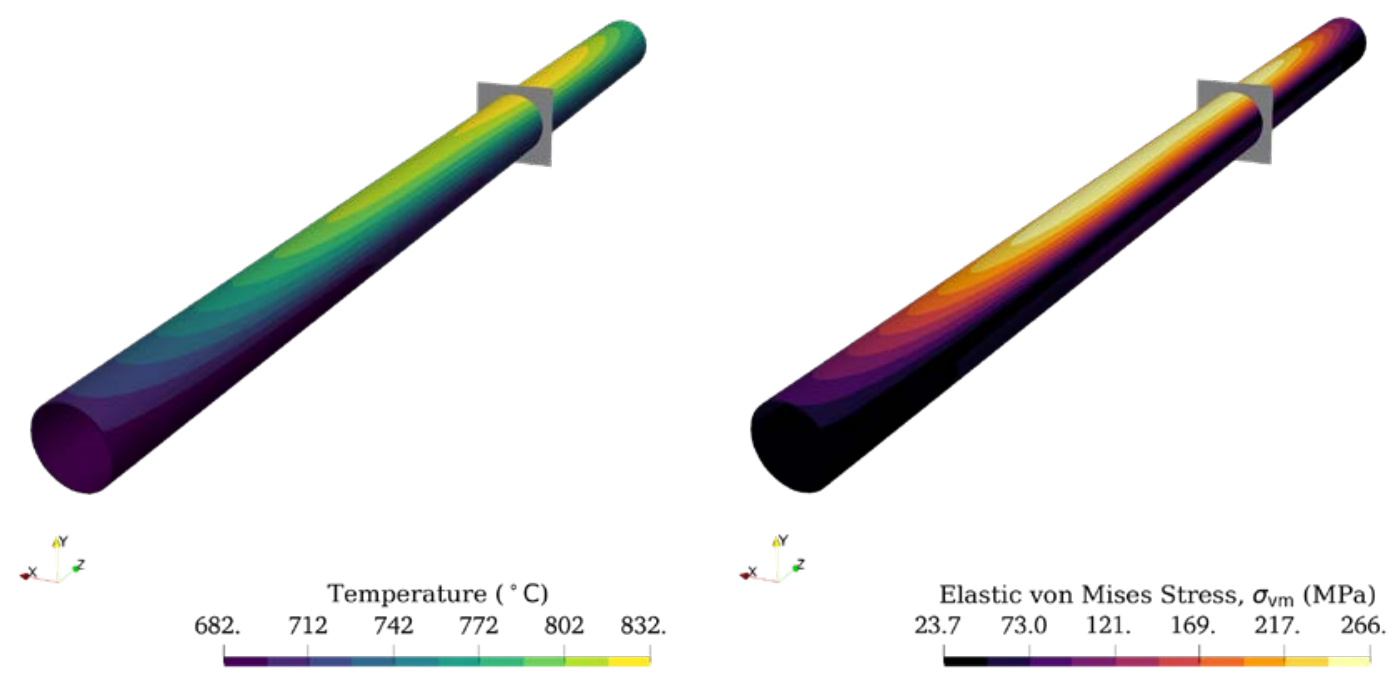

Figure 56. Temperature (left) and equivalent thermoelastic stress (right) of $10.5 \mathrm{~m}$ long (z coordinate scaled by 0.1$) 60-\mathrm{mm}$ OD and $1.2-\mathrm{mm}$ wall $740 \mathrm{H}$ tube with peak flux density $1-\mathrm{MW} / \mathrm{m}^{2}$, sodium mass flow $7 \mathrm{~kg} / \mathrm{s}$ (bulk fluid velocity $3.4 \mathrm{~m} / \mathrm{s}$ ) and bulk fluid temperature of 682 to $740^{\circ} \mathrm{C}-$ plane indicates location of 2D-GPS model

Verification of the Inelastic Finite Element Analysis method. Given the complex nature of coupling a transient thermal analysis (transfer of externally applied flux to internal forced convection of a bulk fluid) with a quasi-static structural solution (internal pressure and thermal induced strain) utilizing an inelastic constitutive model, significant effort was spent ensuring that no mistakes were made in model construction. A case study based on the Bree cylinder [77], [78]

12 This condition ignores the impact of tube attachment to header via bends (which introduce spring coefficients), and tubes in the same panel receiving different levels of flux in concert. 
was implemented in two leading open-source FEA tools, the MOOSE framework maintained by ANL and INL [79], and code_aster maintained by Electricité de France (EDF) [80], and relaxation profiles were compared against time-integration of uniaxial power-law creep, with good agreement as illustrated in Figure 57. Once it was clear that the constitutive model from ANL-20/03 Part 2 was properly implemented, 2D-GPS sodium receiver tube models were created in both codes and results again compared to ensure that spatial and time-integration error was kept to a minimum while reasonable FEA time-stepping and mesh discretization could be used.
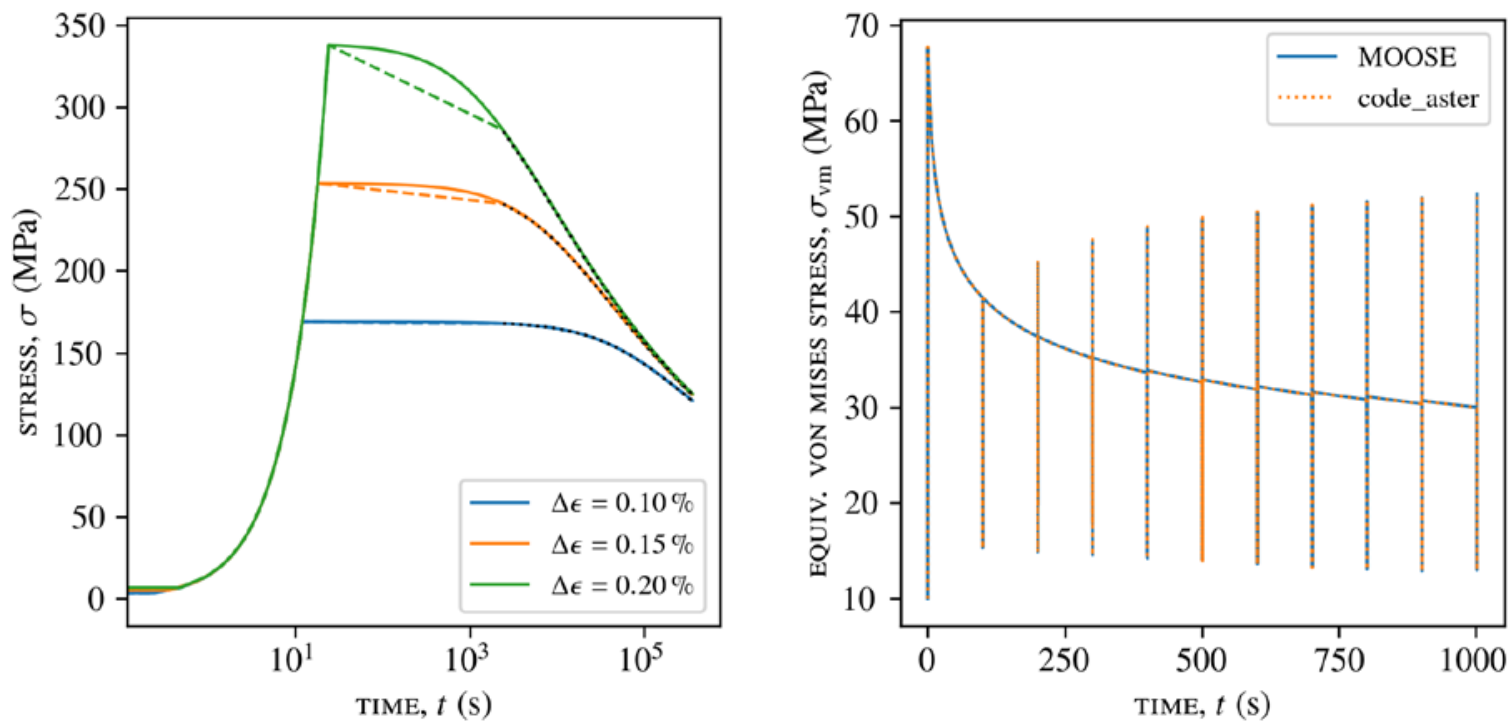

Figure 57. Uniaxial $\mathrm{A} 740 \mathrm{H}$ creep at $800^{\circ} \mathrm{C}$ in (left) showing a "hot tensile" ramp of strain at a strain rate of 8.33e-5 s-1 up to peak values and subsequent hold with relaxation over 100 hours (solid lines using logarithmic time-step, dashed lines FEA time-step, and black dotted lines timeintegration of power-law equivalent), and a comparison of element-averaged equivalent von Mises stress from 10 cycles of a Bree cylinder (with fictive material parameters and Bree coordinates $X=0.1, Y=1.5$ ) in (right) with 100 second hold times.

Maximum allowable flux. Inelastic 2D-GPS simulations were run for 1825 diurnal cycles (five years). Creep and fatigue damage fractions were calculated according to the "ASME approach" of linear damage summation with a creep-fatigue envelope. For this the damage module from Messner and Barua [81] was used with the minor modification that the damage accumulated in the first five years of (simulated) operation could be directly integrated, and the final diurnal cycle response then used to determine how many more cycles could be added before the creep-fatigue damage envelope was reached. It was ensured that at least a further 30 years of cycles might be extrapolated from the final cycle response before the creep-fatigue damage envelope was reached.

Design Cycles used in these simulations were chosen to reflect the expected diurnal operation of the prototype or commercial system. For the prototype receiver, where intermittent on-sun operation might be interspersed with periods of off-sun standby, and where temperature in the receiver is planned to be maintained at that of the inlet $\left(500^{\circ} \mathrm{C}\right)$, a ten-hour Design Cycle with four off-sun events, each lasting roughly one hour, was implemented. Repeated over the specified lifetime of five years results in a total on-sun operation of a little over 1e4 hours with five full thermal strain range fatigue cycles per day. For the commercial A-SCR the same ten-hour cycle was used without off-sun events, assuming more continuous operation in relatively cloud-free location. 
To simplify the incorporation of flux limits derived from structural integrity considerations into coupled optical-thermohydraulic models used for receiver design, maximum allowable flux values were calculated for a range of values of sodium fluid temperature and mass flow (bulk fluid velocity). Thus, it was not necessary for the thermohydraulic models to resolve the circumferentially varying temperature profile of the tube, yielding a significant saving in calculation while providing a satisfactory balance of energy arriving at, absorbed and re-emitted by the tube at any given location. For both the commercial and pilot-scale receivers, the maximum allowable flux was calculated and compared (Figure 58) using both the conservative ASME B\&PVC Section VIII Div. 2 Elastic Ratchet Analysis Method (solid line), and then the aggressive ANL-20/03 Method C (dashed lines with markers identifying the combination of bulk sodium temperature and flux simulated). The information contained in Figure 58 was then provided in table format for integration into coupled optical-thermohydraulic modeling by other team members.
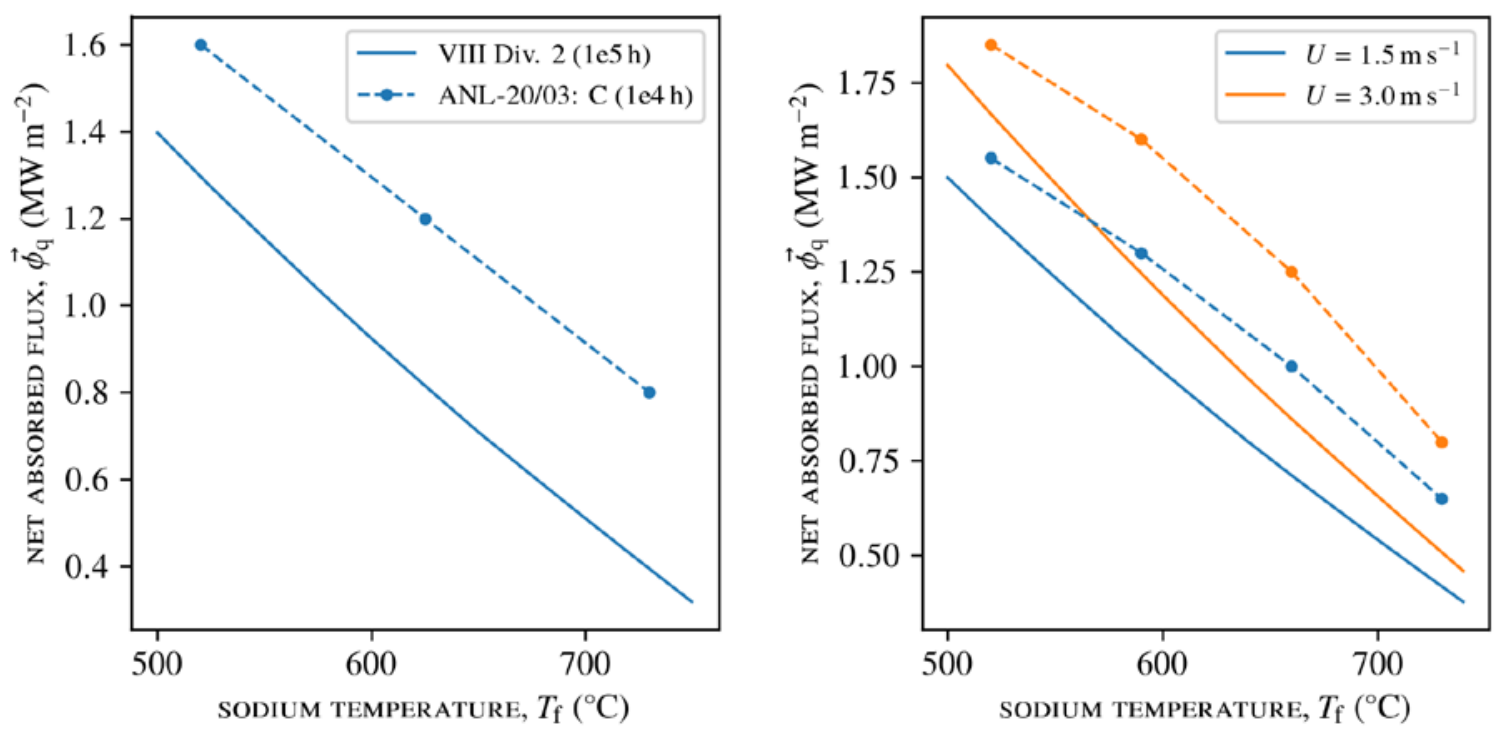

Figure 58. Maximum allowable flux determined by ASME B\&PVC Section VIII Elastic Ratchet Analysis Method (solid lines) and ANL-20/03 Method C (dashed) for (left) the 1-MWth Sandia prototype using $25.4 \mathrm{~mm}$ OD and $1.65 \mathrm{~mm}$ wall and (right) the commercial-scale sodium receiver using $60 \mathrm{~mm}$ OD and $1.2 \mathrm{~mm}$ wall $\mathrm{A} 740 \mathrm{H}$ tubing, also comparing two different fluid velocities.

Comparing the values between the elastic and inelastic methods in Figure 58b, the higher flux allowed using the inelastic method is more pronounced at the hot end of the receiver. For the $3 \mathrm{~m} \mathrm{~s}^{-1}$ case, flux at the hot end of the receiver increases from $500 \mathrm{~kW} \mathrm{~m}^{-2}$ to $800 \mathrm{~kW} \mathrm{~m}^{-2}$ whereas moving towards the cold end of the receiver predictions agree more. The reason for this is that the Elastic Ratchet Analysis Method ignores fatigue. At the cold end of the receiver failure is limited by creepfatigue interaction, and as sodium temperature climbs above $600^{\circ} \mathrm{C}$ maximum allowable flux is limited by creep-rupture alone. It follows that an increase in fatigue cycles considered over the lifetime of plant will limit flux at the cold end of the receiver but not the hot end. ${ }^{13}$ For the range of

13 For example, if one were to assume five full on/off-sun events per day instead of just one, the time taken to reach failure at the cold end of the commercial receiver is roughly one third (e.g., 15 years instead of 35), whereas at the hot end lifetime would only be shortened by a year. 
sodium temperatures considered $\left(520-730^{\circ} \mathrm{C}\right)$ here inelastic analysis allows for a smaller receiver design with better performance and lower cost.

The decision was made to design the $1-\mathrm{MW}_{\text {th }}$ prototype receiver based on the maximum flux values determined by the Elastic Ratchet Analysis Method for an indefinite creep life $(100,000$ hours), which, comparing the curves in Figure 58(a) is a conservative approach, and permits fluxes of a similar magnitude (slightly lower) than the commercial scale design. Testing at higher fluxes will also be possible, and lifetime estimates can be adjusted depending on the testing cycle history.

\subsection{Sodium Heat Transfer Loop}

A small-volume sodium heat transfer loop transfers energy from the receiver to the sodium / salt heat exchanger. For the pilot scale, the receiver and heat exchanger are both located at the 220 level of the Sandia NSTTF ${ }^{14}$. The complete sodium loop comprises the following key components:

\section{Commercial \& pilot}

- Sodium receiver,

- Sodium/salt heat exchanger,

- Sodium pumps,

- Inlet (surge) tank,

- Sump tank,

- Cold trap,

- Instrumentation and control system, and

- Argon system.

\section{Additional in the pilot only}

- Sliding door on the receiver, fitted with auxiliary heating,

- Enclosure for entire loop including fire suppression trays, and

- Scrubber system for emergency emission control.

The layout of the commercial-scale system includes a ground-mounted sodium/salt heat exchanger. For the pilot plant with a concrete tower, it was decided to locate all sodium equipment at the receiver level of the NSTTF tower. This way it can be entirely housed in an enclosure, connected to a scrubber system which will remove smoke in the event of any leak and fire. The riser/downcomer carries salt between the 220 level and the base on the tower. The sodium loop and balance of plant have been laid out within the 220 level of the NSTTF solar tower as shown in the 3D rendering in Figure 59. The main safety response in the event of any incident is allow gravity drain back of sodium back to the sump tank. This necessitates the receiver being located relatively high up in the test bay. As a consequence, there is presently interference with a crane located above the receiver (Figure 60), which will need to be removed during initial construction.

14 Note, at Sandia the "220 level" is actually only $170 \mathrm{ft}$ above ground level, with the additional $50 \mathrm{ft}$ is below ground. The focal height of the receiver is at 54.56m (refer to Table 17), or $179 \mathrm{ft}$. 


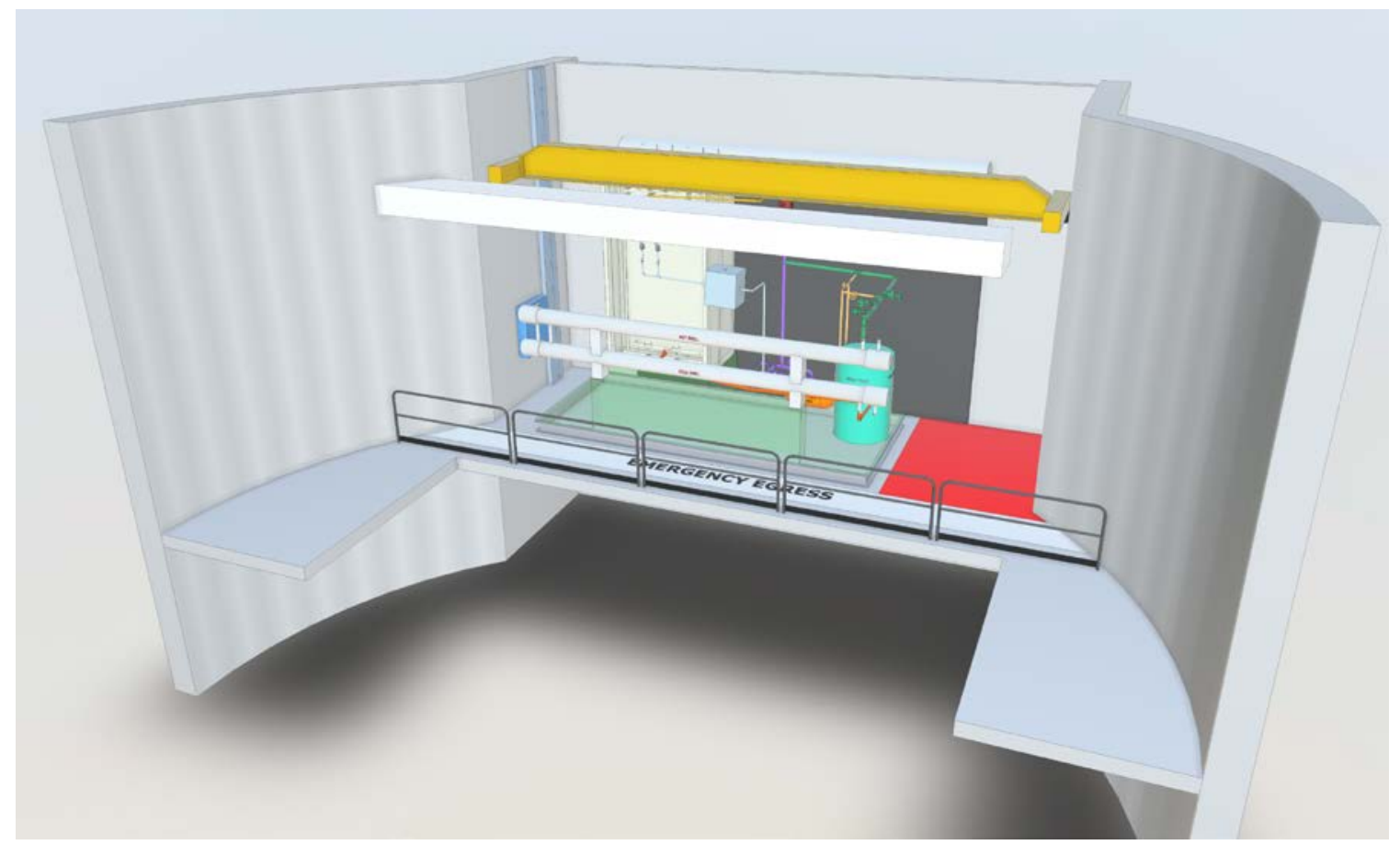

Figure 59. Sodium Loop at the 220 level of the Sandia tower. View from inside the tower: back of receiver housing is at left, also depicted in Figure $\mathbf{6 0}$

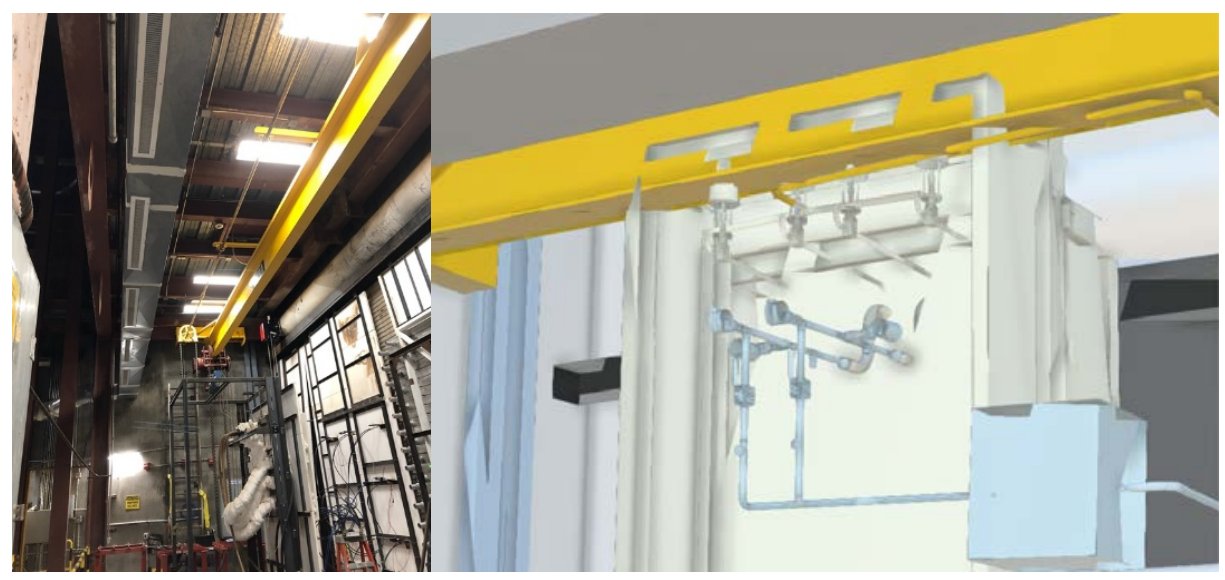

Figure 60. Interference of sodium receiver housing and existing crane, which will be removed during initial site construction. (Left) site photo; (Right) 3D render of proposed sodium-receiver housing overlaying with the crane

\subsubsection{Sodium Pump}

Commercial scale. Development of suitable pumps for sodium service has been predominately driven by Gen IV nuclear reactor (Liquid Metal Fast Reactor, or LMFR) programs worldwide. Sodium pumps can be broken into two technology types: mechanical and electromagnetic (EM).

The high electrical conductance of liquid metals makes possible the use of electromagnetic pumps in which the hydrodynamic head is produced by electromagnetic force. Electromagnetic pumps are inherently reliable due to their simplicity - they have no moving parts and do not require seals. The main shortcoming of these pumps is their low efficiency. A large number of 
electromagnetic pumps have been constructed, predominantly in small sizes although some at commercial scale. Large capacity DC conduction pumps manufactured by General Electric have operated at $650^{\circ} \mathrm{C}, 8.5$ bar pressure head at $22 \%$ efficiency [82]. Potentially two or more of these pumps could be used in series in a solar tower. Higher efficiencies (43\%) have been demonstrated in linear induction pumps, but not at the temperature required.

Mechanical pumps designed for use with liquid metals are available in a wide range of capacities, and efficiencies to $77 \%$. The majority of these pumps are centrifugal type, "freesurface" pumps, which means that they are mounted with the shaft vertical to avoid sealing directly against sodium (i.e., the same type of pumps used in existing molten salt tanks for CSP). The Sodium-NaK handbook [82] lists around 20 examples of such pumps operating above the necessary $520^{\circ} \mathrm{C}$, including in large commercial LMFR plants such as Rhapsodie (France) and BN-350 (Russia) at similar flow rates to those required for a commercial-scale solar tower. Our current commercial configuration calls for $2 \times 50 \mathrm{MW}_{\mathrm{e}}$ towers with the pump specifications as listed in Table 20, and Figure 61 gives an indication of where such a pump sits in relation to previously demonstrated nuclear-based pumps. While the capacity appears readily achievable, the pumping head is higher than required in typical nuclear applications, which are mostly below $120 \mathrm{~m}$. Nonetheless, additional pressure head for this type of pump can be achieved with addition of more pumping stages, as has been demonstrated in the CSP industry for molten salt. In summary, there appear to be no technical barriers for obtaining suitable mechanical pumps at the temperatures and pressures required for the Gen3 Liquids Pathway commercial concept.

Table 20. Pump specifications for the commercial and pilot-scale sodium pumps

\begin{tabular}{|l|l|l|}
\hline Item & Commercial & Pilot \\
\hline Operating temperature & $520^{\circ} \mathrm{C}$ & $520^{\circ} \mathrm{C}$ \\
\hline Operating pressure & $200 \mathrm{kPAg}$ & $200 \mathrm{kPAg}$ \\
\hline Required Head & $1,430 \mathrm{kPa}$ & $100 \mathrm{kPa}$ \\
\hline Capacity (mass) & $1,132 \mathrm{~kg} / \mathrm{s}$ & $3.64 \mathrm{~kg} / \mathrm{s}$ \\
\hline Capacity (volume) & $82 \mathrm{~m} 3 / \mathrm{min}$ & $0.26 \mathrm{~m} 3 / \mathrm{min}$ \\
\hline
\end{tabular}




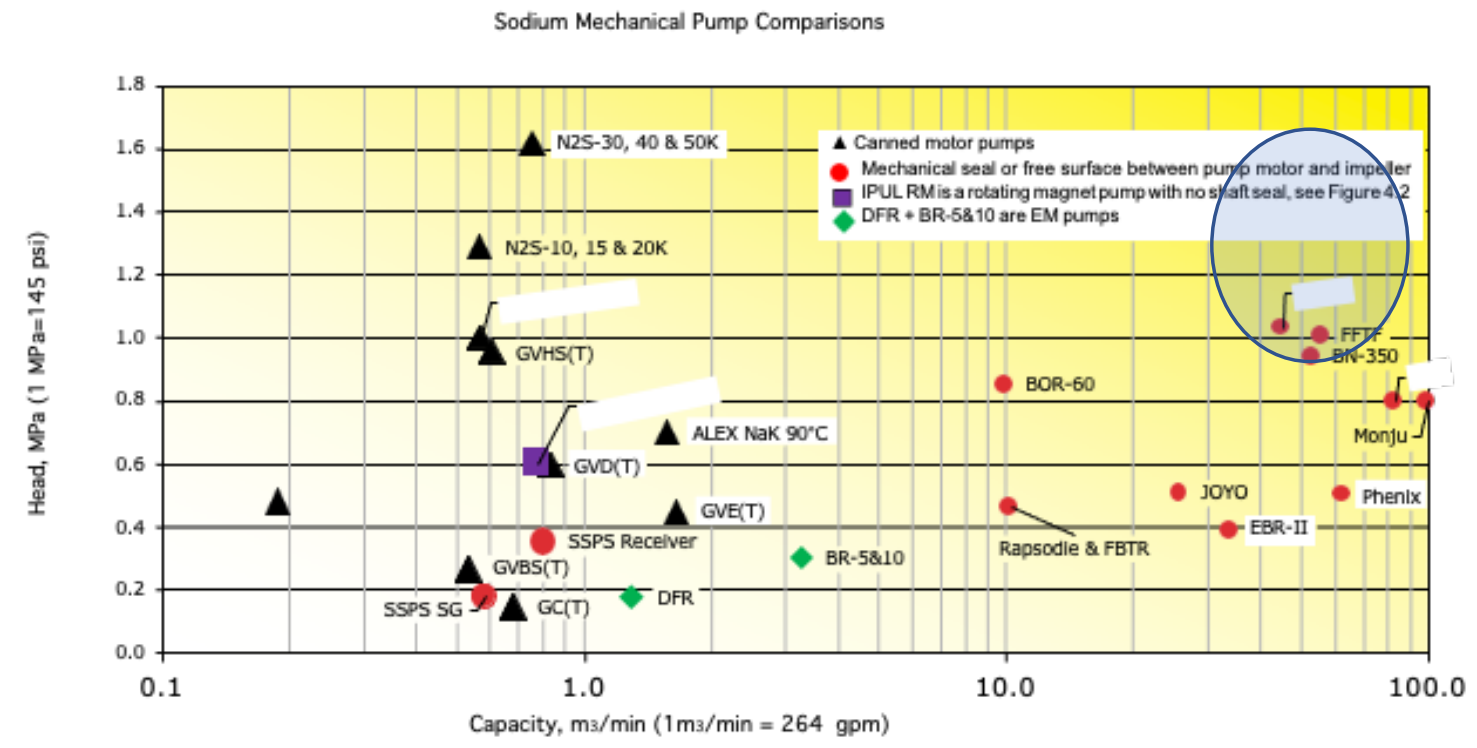

Figure 61. Operating points for various sodium pumps, with the circle highlighting typical operating region for a CSP plant

Pilot scale. As mentioned above, electromagnetic pumps are safe and simple to operate, and thus ideal for pilot-scale demonstration. Indeed, in the nuclear industry EM pumps are most commonly deployed in pilot scale facilities. The operational simplicity, combined with the knowledge that there is a clear, low-risk pathway for obtaining a mechanical pump suitable for the temperatures and pressures required at commercial-scale, led to the decision to specify EM pumps for the pilot-scale plant. Advantages include lower risk of sodium leaks, in that EM pumps are characterized by the absence of moving parts eliminating the need for seals and bearings that are found in mechanical pumps. Other advantages for the pilot facility include simpler maintenance and repairs, and improved reliability. The pilot-scale pump specification is shown above in Table 20. Key variation from the commercial system is that because the pilot scale loop is entirely housed on the 220' level of the Sandia tower, there is a much lower pressure head compared to the commercial system, where the pump is located at ground level and hence requires capacity to overcome the tower height.

Several EM-pump options have been identified, with typical characteristics of operating temperatures up to $600^{\circ} \mathrm{C}$, max flowrates of $140 \mathrm{~m}^{3} / \mathrm{h}$, head of up to $500 \mathrm{kPa}$, operating pressures of $1500 \mathrm{kPa}(\mathrm{g})$ and N.P.S.H. (bars abs.): $100 \mathrm{kPa}$. Hence it is clear that that there are suitable market available units. Several commercial suppliers have been identified, such as CMI Novacast and Creative Engineers. On a similar note, the sodium flow meter will also be electromagnetic technology with suppliers the same as for the pump.

\subsubsection{Sodium Purification System}

Similar to molten salt, controlling impurities in liquid sodium is critical. Oxygen in particular must be maintained at less than a few parts per million (ppm). To achieve this, large scale (e.g., nuclear) sodium facilities employ cold trapping, which is a technique whereby impurities are removed by precipitation utilizing the difference in solubility of impurities in sodium at different temperatures [83]. A cold trap operates by cooling a small fraction of the flow in the main piping system to crystallize and collect oxygen-bearing precipitates on a stainless-steel wire mesh. The 
practical lower limit of oxide concentration that can be achieved by cold trapping has not been clearly established, but is considered to be in the range 2-5 ppm [84].

The design processes for sizing the cold trap requires knowledge of the expected amount of oxygen that will be present in the sodium over its lifetime. Sources of oxygen include oxides on the internal surfaces of the piping and equipment, oxygen in the initial sodium charge, oxygen impurities in the cover gas and oxygen introduced from any maintenance operations. Once the expected quantity of oxide to be removed over the lifetime of the cold trap is known, then sizing of filter material, residence times, economizer and coolers can be completed. The design specification for the pilot-system cold trap for this application is shown in Table 21. Design and procurement of a cold trap at commercial scale is a straightforward exercise.

Table 21. Cold trap design specification for the pilot plant

\begin{tabular}{|l|l|l|}
\hline Parameter & Unit & Value \\
\hline Target outlet oxygen level in Na & $\mathrm{ppm}$ & $\sim 5$ \\
\hline Na mass in System & $\mathrm{kg}$ & 400 \\
\hline Lifetime of System & years & 5 \\
\hline Na-wetted surface area of System & $\mathrm{m}^{2}$ & 50 \\
\hline Anticipated System oxygen in-leakage & $\mathrm{ppm}_{\mathrm{yr}}$ & 3 \\
\hline Na inlet temperature & ${ }^{\circ} \mathrm{C}$ & 520 \\
\hline Outer wire mesh grade (course) & $\mathrm{SWG}^{*}$ & 30 \\
\hline Inner wire mesh grade (Fine) & $\mathrm{SWG}^{*}$ & 36 \\
\hline Cold trap vessel fabrication code & $\mathrm{ASME} \mathrm{B31.1}^{\prime}$ & \\
\hline${ }^{*}$ British Standard Wire Gauge & \multicolumn{2}{|l}{} \\
\hline
\end{tabular}

\subsubsection{Commercial Sodium Valves}

Valves in sodium flow systems are used for isolation, flow control and anti-flow reversal. Valve configurations available for sodium are fairly standard including gate valves, globe valves, ball valves, check valves, butterfly valves and more. Required conditions for both the pilot and commercial plant are within an operating range previously demonstrated in nuclear programs. Correspondence with valve manufacturer, Velan, confirms availability of a wide range of sizes (from DN8-DN700) and valve types.

\subsubsection{Sodium-to-Salt HX}

Commercial. A shell-and-tube heat exchanger has been selected for the commercial scale design. Guidelines for the design of such heat exchangers are well documented in the Tubular Exchanger Manufacturers Association (TEMA) standards. The use of these standards guaranties a simple and robust design over a wide range of operational temperatures and pressures. The selected configuration has the chloride salt on the shell side, and liquid sodium in the tubes, and a counter-flow design with one shell pass and one tube pass. Tubes are arranged in a triangular layout. Key dimensions of the design are given in Table 22. The optimal design is a long, slender design, and in practice this would be split into 2 or more separate units in series (as has been done for the pilot plant design). 
Table 22. Key parameters for the sodium-salt heat exchanger in the commercial plant

\begin{tabular}{|l|l|l|}
\hline Parameter & Unit & Value \\
\hline Shell diameter & $\mathrm{m}$ & 1.78 \\
\hline Shell length (cumulative) & $\mathrm{m}$ & 21.3 \\
\hline Number of tubes & & 4930 \\
\hline Tube diameter & $\mathrm{mm}$ & 19.05 \\
\hline Tube thickness & $\mathrm{mm}$ & 0.9 \\
\hline Tube length & $\mathrm{m}$ & 21.3 \\
\hline Heat transfer area (per unit) & $\mathrm{m}^{2}$ & 6,278 \\
\hline
\end{tabular}

The design specifications described above were included in the heat exchanger model. The model uses the LMTD method to determine the required thermal conductance at design, ensuring a minimum approach temperature difference of $20^{\circ} \mathrm{C}$ between the hot and cold fluids. The tubeside Nusselt number is calculated using the correlation from Cheng and Tak [85] as recommended by [86]. The shell-side heat transfer coefficient is estimated using the BellDelaware method [87], which estimates the shell-side heat transfer coefficient by calculating the ideal heat transfer coefficient and applying correction factors due to baffle cut and spacing, leakage due to shell-to-baffle clearance, and bundle bypass flow. The ideal heat transfer coefficient is found assuming complete crossflow between the fluid in the shell-side and tube bundle. The details of the heat exchanger model are available in [25].

The heat exchanger model was implemented using the Modelica language and is available as part of the SolarTherm library on GitHub. This model is integrated into the system-level model of the commercial CSP plant.

Pilot Scale. A heat exchanger design has been developed for the pilot by Allied Heat Transfer (see Folder 13-Sodium Subsystem, Sodium-Salt HEX, Table 32). It is a counter-flow heat exchanger consisting of two units in series (Figure 62). Initially a single unit was designed, but it was found that increasing the heat transfer area to meet the low heat transfer coefficient resulted in growth in the shell diameter and tube numbers, which pushed up cost. Splitting the heat exchanger in two units results in more slimline shells and enables lower cost materials to be utilized in the lower temperature shell. The tubes will Inconel 740H, and the shell SS316 for the colder shell and a nickel superalloy in the hotter shell. The thermal design optimizes the pressure drop of both sides of the heat exchanger, resulting in a predicted salt side pressure drop of $48 \mathrm{kPa}$, well below the allowance of $200 \mathrm{kPa}$. Some key parameters of the design are listed in Table 23. 


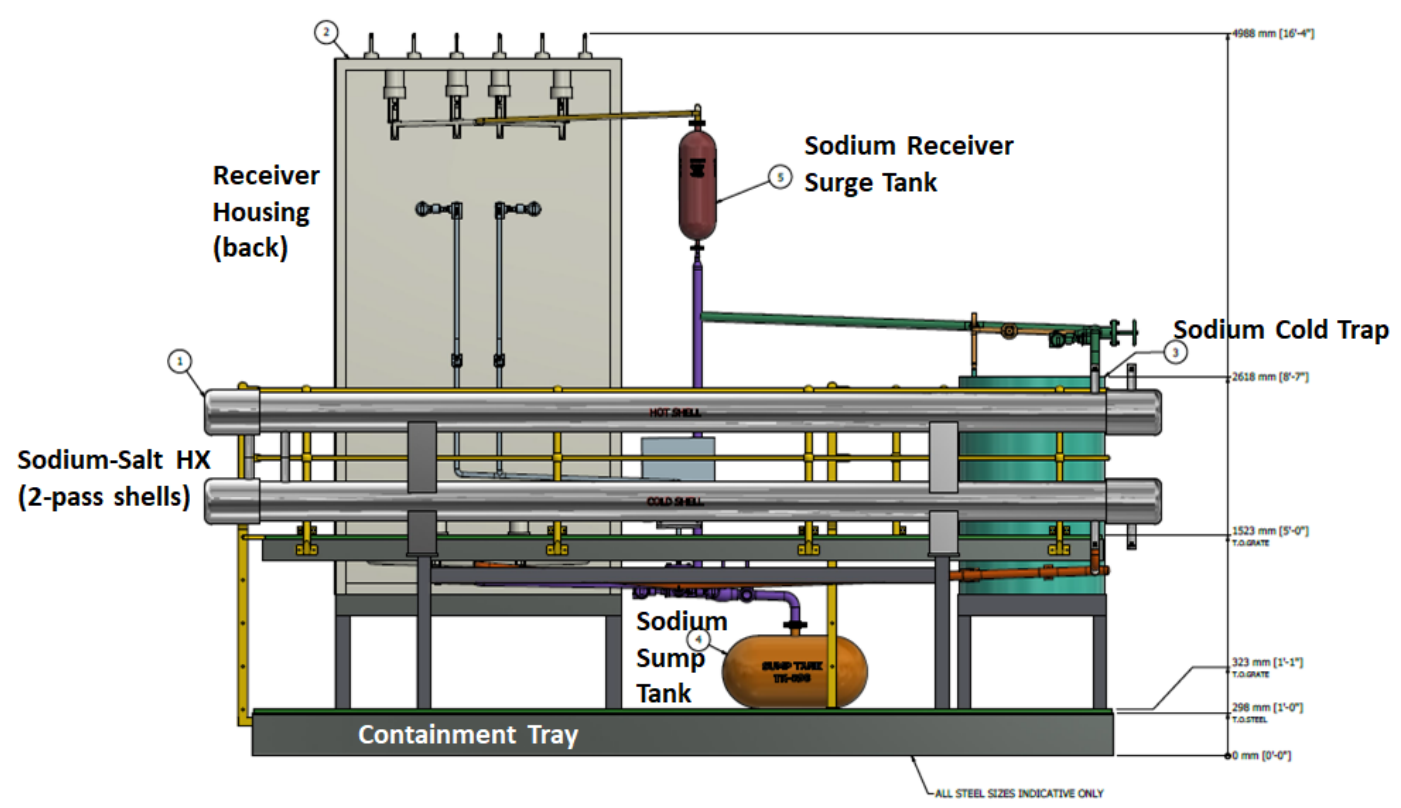

Figure 62. Sodium/salt heat exchanger arrangement

Table 23. Key parameters for the sodium-salt heat exchanger in the pilot plant

\begin{tabular}{|l|l|l|}
\hline Parameter & Unit & Value \\
\hline Number units & & 2 \\
\hline Shell diameter & $\mathrm{mm}$ & 264.6 \\
\hline Shell length & $\mathrm{mm}$ & 6000 \\
\hline Number of tubes & & 55 \\
\hline Tube diameter & $\mathrm{mm}$ & 25.4 \\
\hline Tube thickness & $\mathrm{mm}$ & 1.651 \\
\hline Tube length & $\mathrm{mm}$ & 6000 \\
\hline Heat transfer area (per unit) & $\mathrm{m}^{2}$ & 26.289 \\
\hline
\end{tabular}

\subsubsection{Sodium Riser and Downcomer (Commercial System)}

The sodium riser and downcomer designs for the commercial scale configuration are estimated using a detailed heat-transfer model for thermal insulation using heat loss coefficients from ASTM C 680.89 coupled with ASME B31.3 design guidelines $(\mathrm{K}<0.003$ rule) for thermal expansion loop design and AS 1210 design guidelines for pipe thickness determination. The expansion loops were assumed to have dimension of $3 \mathrm{~m}$ perpendicular to the pipe run and an aspect ratio of 2 (leading to $1.5 \mathrm{~m}$ in the direction of the pipe run). The maximum acceptable surface temperature of the insulated pipes is $65^{\circ} \mathrm{C}$. The design pressure of $14.3 \mathrm{bar}$ is established by adding 1 bar of allowable pressure drop to the hydrostatic pressure head from the top of the receiver to the bottom of the tower $(164.5 \mathrm{~m})$ to account for receiver pipe banks pressure drops $(<0.5$ bar) and all other flow disturbance coming from elbows and bends in the expansion loops, valves, headers, etc. 
Riser material is stainless steel 316 and the downcomer material is alloy $740 \mathrm{H} .$. Minimum diameter for each component are estimated based on the receiver mass flow, thermophysical properties of liquid sodium and a peak velocity of $4.57 \mathrm{~m} / \mathrm{s}$ as per [61]. The pipe insulation follows the design adopted in an Abengoa study [18] with a first layer of ceramic fiber blanket covering the pipe bare wall and heat trace transitioning into an outer shell of calcium silicate, itself wrapped in stainless steel sheeting. The resulting designs are presented in Table 24.

Table 24. Riser and downcomer design summary

\begin{tabular}{|c|c|c|}
\hline & Riser & Downcomer \\
\hline Tower height & \multicolumn{2}{|l|}{$150 \mathrm{~m}$} \\
\hline Minimum pipe outer diameter & $624.4 \mathrm{~mm}$ & $652.7 \mathrm{~mm}$ \\
\hline Minimum pipe wall thickness & $3.87 \mathrm{~mm}$ & $7.82 \mathrm{~mm}$ \\
\hline Ceramic fiber blanket thickness & $25 \mathrm{~mm}$ & $25 \mathrm{~mm}$ \\
\hline Calcium silicate thickness & $125.8 \mathrm{~mm}$ & $246.0 \mathrm{~mm}$ \\
\hline Total length & $214.0 \mathrm{~m}$ & $217.5 \mathrm{~m}$ \\
\hline Ratio of total length to run & 1.43 & 1.45 \\
\hline Number of expansion loops & 11 & 12 \\
\hline Heat loss & $70.7 \mathrm{~kW}$ & $91.0 \mathrm{~kW}$ \\
\hline Temperature drop & $0.02^{\circ} \mathrm{C}$ & $0.03^{\circ} \mathrm{C}$ \\
\hline
\end{tabular}




\section{Risk Registry}

At the beginning of the project the Liquid Pathway team established a Risk Registry and sought input from key project contributors regarding the expected areas of risk associated with the overall design. The proposed system was subdivided into components or subsystems and assigned a responsible party to solicit feedback and categorize the risk as shown in Table 25 . The purpose of the risk registry was to identify and rank potential risk to the overall project goal of demonstrating a system capable of achieving the DOE Gen3 goal for low-cost CSP.

Table 25. Risk Registry component categories and responsible parties

\begin{tabular}{|l|l|l|}
\hline Component / Subsystem & Owner & Supporting Roles (review/scoring) \\
\hline Chloride Salt Chemistry & Y. Zhao & ICL \\
\hline Salt Tanks & C. Turchi & S. Gage, Job Industrial, JT Thorpe \\
\hline Ullage Gas System & C. Turchi & B\&P \\
\hline Salt Chemistry Control & L. Irwin & Y. Zhao \\
\hline Salt Pumps & C. Turchi & D. Barth, Hayward Tyler \\
\hline Salt Melter & C. Turchi & ICL, Hatch \\
\hline Primary Heat Exchanger (salt-to-sCO ${ }_{2}$ ) & M. Carlson & VPE \\
\hline Thermal Transport System & K. Armijo & B\&P \\
\hline Salt Receiver & J. Martinek & DLR, Nooter/Eriksen \\
\hline Sodium Receiver System & J. Coventry & ANU, CSIRO, Sandia \\
\hline Heat Rejection System (sCO ${ }_{2}$ loop) & M. Carlson & B\&P \\
\hline Facility Infrastructure & K. Armijo & B\&P \\
\hline Sodium-compatible thermal energy storage & J. Coventry & QUT, Sandia \\
\hline
\end{tabular}

The team created a master spreadsheet to identify and track risk associated with each of the components listed in Table 25. The risk tally helped guide the research agenda by focusing resources on the most significant risks to project success. The initial assessment included input from 20 different people representing 14 different organizations. This preliminary assessment identified over 600 risk elements, averaging about 50 per component. The initial scoring was reviewed throughout Phase 1 to track progress and re-assess the research agenda. As the project progressed through Phase 1, new participants engaged in the process and revisions were made. By the end of Phase 1 (project Q6) the major risk areas had been coalesced into the top risks per component/subsystem. The progression of risk for these top risk areas can be reviewed by the colored tabular scores presented in Table 26, where red rates a higher risk and green is a lower risk. The full Phase 1 Risk Registry can be found via Folder 15-Safety and Permitting Docs, see Table 32.

Risk reductions were seen in salt chemistry and handling, as the wider research in chloride salts gained understanding of the salt's properties and characteristics. Also reducing was risk associated with salt melting as the expertise of team member Hatch was integrated into the project. Advances made by the salt pump vendors, funded under other DOE awards, led to greater confidence and reduced risk in this component technology. 
Some increasing risks were associated with knowledge gained during the research project. For example, early estimates indicated that salt vapor pressure would be negligible and not affect system performance. However, data gained during the project indicated that the salt vapor pressure was significant enough to cause salt precipitation and possible freezing within the system headspace and ullage gas system, thereby constituting an unforeseen risk. Salt vapor remains a significant risk contributor. At the end of Phase 1 the greatest perceived project risks included:

- Salt vapor challenges to the gaseous regions in valves, tanks, and sensors,

- Pressure and flow meter reliability,

- Salt valve performance,

- The integrity of the expansion joints and mortar joints in the salt tank liner,

- The structural durability of the diffusion-bonded PHX,

- Durability of a salt receiver, and

- Overall system fire protection and controls.

Several areas noted as high risk at the end of Phase 1 were reduced in Phase 2. Down selection of the sodium receiver eliminated the risks associated with the salt receiver design. Advances made in the etching and bonding of Ni-alloy reduced risk in the PHX and the ullage gas system was simplified to an open-pipe vent to the scrubber, which removing the need for pressure controls on the tank. Including these changes, 76 "top risk" areas experienced reduction, 16 were perceived as unchanged, and 23 were either newly discovered or saw increases during Phases 1 and 2 . This amounts to a reduction of $66 \%$ of the identified top risks. 
Table 26. Risk progression through the project's first six quarters that constituted budget Phase 1

\begin{tabular}{|c|c|c|c|c|c|c|c|c|c|c|c|}
\hline $\begin{array}{c}\text { Component and } \\
\text { Owner }\end{array}$ & $\begin{array}{c}\text { Risk/Aspect } \\
\text { (Collapse: Failure Mode) }\end{array}$ & $\begin{array}{c}\text { Project } \\
\text { Start }\end{array}$ & Q4 & Q5 & Q6 & $\begin{array}{c}\text { Component and } \\
\text { Owner }\end{array}$ & $\begin{array}{c}\text { Risk/Aspect } \\
\text { (Collapse: Failure Mode) }\end{array}$ & $\begin{array}{c}\text { Project } \\
\text { Start }\end{array}$ & Q4 & Q5 & Q6 \\
\hline Salt & Freeze/melt temperature & 5.0 & 2.5 & 2.5 & 2.5 & Primary HX & HX body & 5.0 & 5.0 & $4.0^{\circ}$ & 3.0 \\
\hline \multirow[t]{10}{*}{ Y. Zhoa } & Getter solubility & 5.0 & $4.0^{\circ}$ & $3.0^{7}$ & 3.0 & M. Carlson & Structural & 5.0 & 5.0 & 5.0 & 5.0 \\
\hline & Particle count & 5.0 & 3.5 & 2.0 & 3.0 & & Headers/manifolds & 4.2 & 4.2 & 4.2 & 4.2 \\
\hline & Heat capacity & 4.5 & 2.5 & 2.5 & 2.5 & & Inspection ports & 4.2 & 4.2 & 3.5 & 3.5 \\
\hline & Handling & 3.8 & $3.0^{\circ}$ & 3.0 & 2.5 & & Cost & 3.8 & 3.8 & 4.0 & 3.0 \\
\hline & Freeze/melt temperature & 3.8 & 2.5 & 2.5 & 2.5 & & Connections to piping & 2.8 & 2.8 & $2.0^{\circ}$ & 2.0 \\
\hline & Thermal conductivity & 3.1 & 2.0 & 2.0 & 2.0 & & Schedule & 2.3 & 2.3 & 2.3 & 3.0 \\
\hline & Basicity (magnesium hydroxide/magr & 3.0 & 3.0 & $2.5^{5}$ & 2.5 & & Insulation & 2.2 & 2.2 & 2.2 & 2.0 \\
\hline & Density & 2.5 & 1.5 & 1.5 & 1.5 & & $T$, P sensors & 1.6 & 1.6 & 1.6 & 1.6 \\
\hline & Cost & 1.9 & 1.9 & 1.9 & 1.9 & & Particles in the salt & 3.0 & $3.0^{\circ}$ & 2.0 & 1.7 \\
\hline & Vapor pressure & & $3.0^{\top}$ & $3.0^{2}$ & 3.0 & Thermal Transport & P sensors & 5.0 & 5.0 & 5.0 & 5.0 \\
\hline Salt Chemistry & Salt Thermodynamic Potential (Corro & 5.0 & 3.0 & 2.8 & 2.5 & K. Armijo & Flowmeters & 5.0 & $5.0^{7}$ & 4.5 & 4.5 \\
\hline \multirow[t]{7}{*}{ Y. Zhoa } & Salt Particulates Form & 3.6 & 4.0 & 2.5 & 3.0 & & Salt Valves & 4.4 & 4.6 & 4.5 & 4.7 \\
\hline & Exhaust scrubber & 3.1 & 3.0 & $3.0^{\circ}$ & 3.0 & & Salt Piping & 4.0 & 3.0 & 3.0 & 3.0 \\
\hline & Sensors and controls & 3.1 & 3.0 & $2.8^{7}$ & 2.5 & & Corrosion sensors & 3.8 & 3.5 & 3.4 & 3.3 \\
\hline & Heater Freeze Recovery & 3.1 & 3.0 & 3.0 & 3.0 & & Joints/Welds & 3.5 & 4.0 & 4.0 & 4.0 \\
\hline & Gas conditioning/handling & 2.7 & 2.0 & $3.0^{\top}$ & 3.0 & & Galvanic corrosion/protection & 3.0 & $4.0^{\circ}$ & 4.0 & 4.0 \\
\hline & Sensors and controls & 2.3 & 2.0 & 2.8 & 2.5 & & Heat Trace & 2.0 & 1.0 & 1.0 & 1.0 \\
\hline & Corrosion control implementation & 5.0 & 5.0 & $3.0^{7}$ & 3.0 & & Insulation & 1.3 & 1.0 & 1.0 & 1.0 \\
\hline Salt Tanks & Freeze protection heater & 5.0 & $3.0^{\circ}$ & $2.5^{\circ}$ & 2.5 & & \multicolumn{2}{|c|}{ System Integration with subcomponents } & $3.0^{\circ}$ & 3.0 & 3.3 \\
\hline \multirow{11}{*}{ C. Turchi } & Sensors (leakage, level) & 5.0 & $2.0^{\top}$ & 2.0 & 2.0 & Salt Receiver & Panels/tubes & 5.0 & 5.0 & 5.0 & 4.5 \\
\hline & Isolation Valves & 4.8 & - & - & - & J. Martinek & Headers & 5.0 & $4.5^{\circ}$ & 3.0 & 1.0 \\
\hline & Internal insulation & 3.2 & 5.0 & & & & Valves & 5.0 & 5.0 & $4.0^{7}$ & 4.0 \\
\hline & Containment alloy & 3.2 & 2.0 & 2.0 & 2.0 & & Bypass line & 3.6 & $2.7^{7}$ & 2.7 & 2.7 \\
\hline & Foundation & 3.2 & $3.0^{\circ}$ & 3.0 & 3.0 & & $T$, P sensors & 3.6 & 3.6 & 3.6 & 3.6 \\
\hline & External insulation & 0.8 & - & - & - & & Downcomer & 3.6 & $2.5^{\mathrm{V}}$ & 2.5 & 2.5 \\
\hline & Hot face integrity against salt penetra & 3.2 & $5.0^{\circ}$ & 4.0 & 4.0 & & Buffer tanks & 3.1 & 3.1 & 3.1 & 3.1 \\
\hline & Hot face liner cost & 3.2 & $4.0^{\circ}$ & $2.5^{5}$ & $1.5^{\top}$ & & Riser & 2.7 & $2.0^{\circ}$ & 2.0 & 2.0 \\
\hline & Roof Modules & 3.2 & $5.0^{\circ}$ & $4.0^{\circ}$ & $3.5^{5}$ & & Preheater & 2.2 & 2.2 & 2.2 & 2.2 \\
\hline & Mortar Joints & 3.2 & $5.0^{7}$ & $5.0^{\top}$ & $4.5^{\prime}$ & & Insulation & 2.0 & 2.0 & 2.0 & 2.0 \\
\hline & Expansion Joints & 3.2 & $5.0^{\top}$ & $5.0^{7}$ & $5.0^{\top}$ & Sodium Receiver & Headers & 5.0 & 4.0 & $3.0^{2}$ & 3.0 \\
\hline Ullage Gas & Gas conditioning/handling & 5.0 & 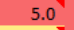 & 5.0 & 5.0 & J. Coventry & Valves & 3.2 & 3.2 & $3.2^{2}$ & 3.2 \\
\hline \multirow[t]{6}{*}{ C. Turchi, D. Dorsey } & Exhaust scrubber (for acid gases) & 3.2 & 4.0 & 5.0 & $4.5^{\curlyvee}$ & & Panels/tubes & 3.0 & $2.5^{7}$ & $2.5^{7}$ & 2.5 \\
\hline & Sensors and controls & 3.2 & $5.0^{\gamma}$ & $5.0^{7}$ & $5.0^{\prime}$ & & Pump & 3.0 & 3.0 & $3.0^{7}$ & 3.0 \\
\hline & Gas & 3.0 & 1.0 & $4.0^{\top}$ & $4.5^{7}$ & & $T$, P sensors & 2.0 & $2.0^{7}$ & 2.0 & 2.0 \\
\hline & Pump/blower & 2.0 & 1.0 & 1.0 & 1.0 & & Safety and Acceptance & 2.0 & 2.0 & 2.0 & 2.0 \\
\hline & Valves & 0.8 & 3.0 & 5.0 & 5.0 & & Buffer tanks & 1.5 & 1.5 & 1.5 & 1.5 \\
\hline & Salt vapor pressure & & $5.0^{\circ}$ & 5.0 & 4.5 & & Bypass line & 1.5 & 1.5 & $1.5^{5}$ & 1.5 \\
\hline Salt Pumps & Shaft & 5.0 & 3.0 & $2.0^{\circ}$ & 2.0 & & Calibration panel (flux) & 1.2 & 1.2 & 1.2 & 1.2 \\
\hline \multirow{9}{*}{ D. Barth } & Tank sparger system & 5.0 & $1.5^{\mathrm{N}}$ & 1.5 & 1.5 & & Insulation & 0.9 & 0.9 & 0.9 & 0.9 \\
\hline & Motor & 3.8 & 1.5 & 1.5 & 1.5 & & \multicolumn{2}{|l|}{ Material compatibility w sodium } & & & 3.0 \\
\hline & Radial Bearings/ & 3.8 & $3.0^{7}$ & $2.0^{7}$ & 2.0 & Sodium-to-Salt HEX & Sensors (leakage, level) & 5.0 & 1.0 & 1.0 & 1.0 \\
\hline & Main mounting plate seals & 3.8 & 2.0 & $2.0^{\circ}$ & 2.0 & J. Coventry & Internal insulation & 3.3 & 1.0 & 1.0 & 1.0 \\
\hline & Bearings/seals & 3.8 & $2.0^{\circ}$ & $2.0^{\circ}$ & 2.0 & & Thermal storage media & 3.1 & 1.0 & 1.0 & 1.0 \\
\hline & Flow & 3.8 & 1.5 & $1.5^{\vee}$ & 1.5 & & Isolation Valves & 3.1 & 1.0 & 1.0 & 1.0 \\
\hline & Valve heat tracing & 3.8 & 3.0 & $3.0^{\circ}$ & 3.0 & & Storage heat exchanger $(\mathrm{HX})$ & 2.2 & 2.2 & $2.0^{\circ}$ & 2.0 \\
\hline & Insulation & 3.8 & 2.0 & $1.5^{\top}$ & 1.5 & & External insulation & 1.9 & 1.0 & 1.0 & 1.0 \\
\hline & Insolubles in melted salt & 3.8 & $3.0^{\top}$ & $2.0^{\top}$ & 2.0 & & Containment alloy & 1.9 & $1.9^{7}$ & $1.9^{2}$ & 1.9 \\
\hline Salt Melter & Sensors and controls & 5.0 & $4.0^{\circ}$ & 4.0 & 3.5 & & Operations & 1.6 & $1.6^{2}$ & $1.6^{7}$ & $1.6^{2}$ \\
\hline R. Effenberger & Valves & 2.5 & $2.0^{7}$ & 2.0 & 1.0 & & Freeze protection heater & 1.6 & 1.0 & 1.0 & 1.0 \\
\hline \multirow[t]{9}{*}{ C. Turchi } & Molten-salt transfer system & 2.5 & $3.0^{\circ}$ & 3.0 & $2.5^{\top}$ & & Foundation & 0.9 & 0.9 & 0.9 & 0.9 \\
\hline & Salt-purification system & 2.5 & $3.0^{\circ}$ & 3.0 & $2.5^{\top}$ & & Storage $\mathrm{HX}$ thermal ramp rate & & 3.0 & $2.5^{4}$ & 2.5 \\
\hline & Heat source & 0.5 & $0.5^{\top}$ & 0.5 & 0.5 & Infrastructure & Fire Protection Systems & 5.0 & 4.5 & 4.0 & 4.2 \\
\hline & Dry-salt transfer system & 0.5 & 2.0 & 2.0 & $2.5^{\top}$ & K. Armijo & Control Systems & 5.0 & 5.0 & 4.7 & 4.7 \\
\hline & Gas conditioning/handling & 0.1 & 2.0 & 2.0 & 2.0 & & Dump pit/tank & 3.3 & 3.5 & 3.5 & 3.5 \\
\hline & Exhaust scrubber & 0.1 & $2.0^{\top}$ & $2.0^{\top}$ & $2.0^{\top}$ & & Tower & 2.5 & 2.2 & 2.2 & 2.2 \\
\hline & System designer/provider & 4.0 & $3.0^{\top}$ & 1.0 & $1.0^{\top}$ & & Lifts / Hoists & 2.5 & 2.3 & 2.2 & 2.2 \\
\hline & & & & & & & Solar Field & 1.7 & 1.5 & 1.5 & 1.5 \\
\hline & & & & & & & Power Supply & 1.7 & 1.7 & 1.7 & 1.9 \\
\hline
\end{tabular}

\subsection{Transition to FMEA Tracking}

During Phase 1, Sandia initiated a process to categorize the potential failure modes associated with the proposed pilot-scale system. This Failure Modes \& Effects Analysis (FMEA) is a standard protocol for experiments undertaken at the laboratory. At the outset of Phase 2 the Risk Registry from Phase 1 was transferred into the FMEA spreadsheet format used by Sandia. During the project, five FMEA review meetings engaged subject-matter experts from the prior risk assessments as well as Sandia management and Environment, Safety, and Health personnel. The current FMEA spreadsheet lists and rates over 400 risk elements for the proposed project. 
This spreadsheet is included in the proposal package as the Phase 2 Risk Registry in Folder 15Safety and Permitting Docs (See Table 32). Excerpts are provided within the text below.

\subsection{Pilot-Scale Demonstration Primary Risks}

During Phase 2, effort was placed on understanding the risk from salt vapors. The project revamped the ullage gas handling system and significantly reduced the number of valves in the overall system. The receiver down-selection meetings at the end of Phase 1 led to selection of a sodium receiver, which eliminated risk associated with the salt receiver design and operation, and focused attention on risks associated with the sodium loop and receiver design, which deal primarily with the potential for leaks and fire hazard.

Salt tanks. Integrity of the salt tanks depends upon the ability or the floor, wall, and roof insulation to resist penetration by the salt or salt vapors. Both tanks use the same liner design, so the analysis focuses on the hot salt talk for risk assessment.

The hot face brick has exhibited excellent resistance to salt penetration and there is little concern regarding the effectiveness of the hot face brick. However, the mortar joints and expansion joints remain an element of concern. Experimental measurement of the brick/mortar composite and associated design work in Phase 2 led to better understanding of the thermomechanical stress in the tank and allowed the team to significantly reduce the number expansion joints in the tank design. However, leakage through an expansion or mortar joint could allow salt to reach the underlying insulating fire brick. In this event, salt would wet the fire brick resulting in increased heat loss through the tank wall and possible overheating of the steel shell. The resulting heat bloom would be easy to identify on the surface of the tank but correcting the leakage would be difficult. The best means to address this risk is to employ a liner that retains its insulating performance when wetted by the salt; however, no suitable material was found during the project's work.

\begin{tabular}{|c|c|c|c|c|c|}
\hline $\begin{array}{c}\text { System/component } \\
\text { process }\end{array}$ & Potential Failure Mode & Potential Causes & Consequence & $\begin{array}{c}\text { Risk Priority: } \\
\text { (Cumulative) } \\
\begin{array}{c}\text { [1-30] } \\
\end{array}\end{array}$ & Engineered Controls \\
\hline Cold/Hot Tanks & Roof Insulation Failure & $\begin{array}{l}\text { Salt vapor condensation or } \\
\text { solidification in the insulation }\end{array}$ & $\begin{array}{l}\text { Loss of insulating ability causing localized } \\
\text { hot soots. Additional weight on roof. }\end{array}$ & 16 & \\
\hline Cold/Hot Tanks & $\begin{array}{l}\text { Wetting of insulation material } \\
\text { (Floor) }\end{array}$ & $\begin{array}{l}\text { Crack in the mortar seal, brick or } \\
\text { expansion ioints. }\end{array}$ & $\begin{array}{l}\text { weakend mechanical strength } \\
\text { (subsidancel. }\end{array}$ & 14 & $\begin{array}{l}\text { Monitor of heat loss thru } \\
\text { foundation }\end{array}$ \\
\hline Cold/Hot Tanks & Cracking of the liner & $\begin{array}{l}\text { Improper thermal heat up or } \\
\text { thermal cvcling }\end{array}$ & $\begin{array}{l}\text { Schedule delay for having to repair and } \\
\text { orevare the tank }\end{array}$ & 14 & \\
\hline
\end{tabular}

Salt vapor. As indicated by the FMEA, many major system risks are associated with the vapor pressure of the salt. Condensing or freezing salt vapors threaten the bellows and operation of the salt valves and necessitate complex balancing of the ullage gas pressure and temperature at the valves. Salt vapor deposition in the ullage gas lines or sensor ports could lead to plugging and errant operation of the system controls. Salt vapor deposition within the tanks' roof insulation is a potential threat to the insulating ability of the ceramic fiber blankets and could lead to excessive heat loss and/or weight gain that impacts roof integrity. The pilot scale system will quantify the magnitude of these risks and test the ability of the system to address the potential threat.

\begin{tabular}{|c|c|c|c|c|c|}
\hline $\begin{array}{c}\text { System/component } \\
\text { process }\end{array}$ & Potential Failure Mode & Potential Causes & Consequence & $\begin{array}{c}\text { Risk Priority: } \\
\text { (Cumulative) } \\
{[1-30]}\end{array}$ & Engineered Controls \\
\hline Ullage Gas System & plugging of ullage gas system by salt & Salt vapor scaling & Overpressurization or potential vacuum & 19 & \\
\hline Ullage Gas System & salt ingress into ullage gas system & Improper salt chemistry & $\begin{array}{l}\text { Component deterioration and control } \\
\text { failure }\end{array}$ & 18 & Mg contacting on cold salt \\
\hline Ullage Gas System & Air ingress & $\begin{array}{l}\text { Bad seal or undetected rupture disk } \\
\text { failure }\end{array}$ & $\mathrm{HCl}$ development & 17 & $\begin{array}{l}\text { Rupture disk equipped with } \\
\text { burst indicator to alarm. IR }\end{array}$ \\
\hline Ullage Gas System & valve leakages & packing leakages & $\begin{array}{l}\text { Valve stem will freeze up from salt vapors } \\
\text { or liauid salt. }\end{array}$ & 17 & $\begin{array}{l}\text { Motor amperage monitored } \\
\text { and logged for scaled }\end{array}$ \\
\hline
\end{tabular}


Salt corrosion control. The melting protocols have produced a chloride salt with low corrosion potential in lab testing [27], and melting of $200 \mathrm{~kg}$ of salt at the FASTR test loop at Oak Ridge National Lab was successful. The risk remains that intrusion of air or moisture into the pilotscale system will initiate corrosion. The pilot-scale unit includes $\mathrm{Mg}$ metal exposed to cold salt via the cold-tank recirculation line to mitigate the impact of any moisture or oxygen that enters the system. The effectiveness of this approach remains unproven and will be an objective of the pilot-scale testing. The $\mathrm{Mg}$ is held in an inline basket strainer and is followed by $\mathrm{C} 276$ mesh filters to capture $\mathrm{MgO}$ particulate that may be formed in the process. Salt chemistry will be monitored by the inclusion of electrochemical sensors in the cold-salt and hot-salt recirculation lines at the two tanks. These sensors will provide a warning if the salt chemistry varies outside the desired redox range and will also monitor for species that are indicative of corrosion, e.g., $\mathrm{MgOHCl}$. Under extreme conditions, $\mathrm{Mg}$ can be added directly to the salt hot tank to reset the salt redox conditions to a non-corrosive start. However, addition on $\mathrm{Mg}$ in the hot side must be made with caution because the beneficial effect of reduced corrosion potential is offset by the possible evolution of hydrogen gas from the melt.

Salt valves. The molten salt valves planned for the chloride-salt system are patterned after valves used in nitrate salts at temperatures from $300^{\circ} \mathrm{C}$ to about $560^{\circ} \mathrm{C}$. Materials of construction for chlorides at up to $720^{\circ} \mathrm{C}$ have been vetted in laboratory testing. The Flowserve StarPac globe valve design incorporates temperature and pressure sensors to facilitate system control as well as ullage gas ports to protect the valves from salt vapors. These valves can provide flow control or isolation. Yet the valves have not been tested in flowing chloride salt conditions. Testing planned at FASTR was delayed by COVID-19 and not able to be completed by the end of the Phase 2 period. Thus, despite extensive design expertise in molten-salt applications, significant risk remains with the performance of the valves under representative conditions in molten chloride salt. The area of greatest concern is salt vapor permeation into the stem packing and bonnet leading to possible valve seizing or bonnet damage. While the pilot-system is designed to test and derisk salt valves, the team recommends preliminary testing in a smaller system that can provide representative conditions at lower cost, such as FASTR or perhaps in the ongoing DOEfunded valve design project at Sandia (see project report in Folder 12-Project Reports, Salt Valves, Adv Molten-Salt Valve Project, Table 32).

\begin{tabular}{|c|c|c|c|c|c|}
\hline $\begin{array}{l}\text { System/component } \\
\text { process }\end{array}$ & Potential Failure Mode & Potential Causes & Consequence & $\begin{array}{c}\text { Risk Priority: } \\
\text { (Cumulative) } \\
\begin{array}{c}\text { [1-30] } \\
\end{array}\end{array}$ & Engineered Controls \\
\hline Salt Valves - $2^{\prime \prime}$ & $\begin{array}{l}\text { Loss of control of } \mathrm{N} 2 \text { barrier over salt } \\
\text { or bellows oressurization }\end{array}$ & $\begin{array}{l}\text { System failure, (e.g. loss of } \\
\text { oressure sensors due to oressure }\end{array}$ & System Shutdown (Immediate Shutdown) & 23 & $\begin{array}{l}\text { Pressure/flow N2 ullage gas } \\
\text { sensors would vary from }\end{array}$ \\
\hline Salt Valves - $2^{\prime \prime}$ & Valve Bonnet Packing Failure & $\begin{array}{l}\text { Wear from being stroked or } \\
\text { oxidation due to temv. }\end{array}$ & N2 gas loss & 18 & $\begin{array}{l}\text { Flow pr pressure sensor } \\
\text { measurements, indicating a }\end{array}$ \\
\hline Salt Valves - 2" - ALL FCVs & External Valve Leakage & Bonnet leakage & Salt Dispersion \& loss of inventory & 13 & $\begin{array}{l}\text { Monitor heat tracing for } \\
\text { failures, visual inspections }\end{array}$ \\
\hline
\end{tabular}

Flanges. As much as possible, the salt and sodium piping networks are fully welded systems. However, certain locations, such as valves, pumps, heat exchangers, and particle filters greatly benefit from flanged fittings to facilitate installation, maintenance, and possible material of construction changes. Grayloc, RTJ, and similar valves have been used for molten salt and liquid metal applications in past testing and are planned in the pilot-unit but have not been tested in flowing chloride salt. Similar to the case described for valves, the team recommends preliminary testing in a system that can provide representative conditions at lower cost, such as FASTR or perhaps in the DOE-funded valve design project at Sandia. 
Sodium safety and acceptance. Safety is central to the successful use of sodium in the Liquid Pathway. Sodium is a flammable metal which reacts violently with water and chlorinated hydrocarbons. Significantly, sodium thermodynamic reaction with the ternary chloride salt would lead to formation of $\mathrm{Mg}$ metal - a corrosion inhibitor - and $\mathrm{NaCl}$. Sodium is not used in $\mathrm{sCO}_{2}$ (nor obviously water/steam) heat exchangers in the Gen3 design.

At the temperatures of interest for CSP, most spillages of liquid sodium can be expected to result in fires. Sodium will react violently with the conventional fire extinguishing material, i.e., water, so training is essential in sodium-fire response. Sodium fires produce a dense white smoke which contains highly alkaline materials, sodium monoxide $(\mathrm{NaO})$ and sodium hydroxide $(\mathrm{NaOH})$, which can cause irritation and rapid tissue destruction through chemical and thermal burns. If a sodium fire contacts a concrete surface, chemical reactions can occur and the heat may vaporize moisture in the concrete, causing the surface to spall.

\begin{tabular}{|c|c|c|c|c|c|}
\hline $\begin{array}{c}\text { System/component } \\
\text { process }\end{array}$ & Potential Failure Mode & Potential Causes & Consequence & 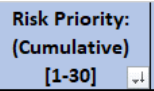 & Engineered Controls \\
\hline Sodium System & $\begin{array}{l}\text { Loss of sodium containment in the } \\
\text { receiver }\end{array}$ & Receiver leak & $\begin{array}{l}\text { Potential spallation of sodium on the } \\
\text { structure concerete }\end{array}$ & 19 & $\begin{array}{l}\text { Adding external surface } \\
\text { cladding to the outside }\end{array}$ \\
\hline Sodium System & Valve Failure & \begin{tabular}{|l|} 
Improper sodium purity that can \\
cause sodium oxide formation, that
\end{tabular} & sodium leakage. & 17 & $\begin{array}{l}\text { Maintain proper } 02 \\
\text { monitoring and sodium }\end{array}$ \\
\hline Sodium System & $\begin{array}{l}\text { Cross-Contamination Salt into the } \\
\text { SodiumLine }\end{array}$ & $\begin{array}{l}\text { Rupture of the HEX (due to welds, } \\
\text { thermal expansion of mats. creed }\end{array}$ & $\begin{array}{l}\text { Sodium reduces salt and changes salt } \\
\text { combosition (change in Me composition) }\end{array}$ & 17 & \\
\hline
\end{tabular}

Several specific measures are implemented for design safety in the proposed CSP plant. In common with past loops at Sandia [88] and Plataforma Solar [89], both the commercial and pilot scale systems are designed to allow gravity drain back to a sodium sump. A system of this type is typical for most sodium loops (including for non-solar applications, in nuclear plants and laboratories e.g., KIT, ANL, ANU), even if the loop is designed to normally remain filled. Although fire response protocols would be formally determined in Hazard Analysis, the safest response is typically to allow drainage of the sodium to the sump tank and wait to let any sodium that has escaped containment burn out. This requires detection (e.g., by visual means, smoke sensors, conductivity sensors) and response. It is unlikely that firefighters would enter the tower or the vicinity near the base of the tower until after the incident. Additionally, Sandia conducted a number of sodium burn tests near the proposed pilot-system construction site and demonstrated sodium safe-handling protocols that can be used to prevent fires [90]. Such training is key to familiarizing local fire fighting teams with the unique features of sodium.

Special care must be used in the design and construction of the facility to prevent in leakage of water from rain, snow, groundwater, or from adjacent areas or structures. At Sandia, a roller door can be fully shut-in front of the receiver and the sodium equipment itself is fully contained in a sealed enclosure with a fire suppressing containment tray.

Loss of containment from the outside of the receiver is also a possibility. While the response would be the same - drainback and wait — there are other potential hazards. Further work is required to determine if quantities of sodium likely to escape in the event of tube rupture would extinguish and neutralize before falling to the ground. This will likely depend on both the tower height and ambient conditions. Protection of the upper parts of a concrete tower may be prudent, as splashing of sodium near the top onto the tower seems probable in the event of a leak. 
Finally, it is noted that as part of this project, an in-depth report on "Sodium safety and Protocols for CSP" was prepared and issued as part of Milestone T-1.6.3 (see Table 32, Folder 12-Project Reports, Liquid Pathway Milestone Reports).

Sodium compatibility with $740 \mathrm{H}$. In systems operating at less than $650^{\circ} \mathrm{C}$, stainless steel is universally recommended for sodium containment because iron alloys are cheaper and less susceptible to element leaching than Ni alloys. However, the thermo-mechanical strength required in the Gen3 application necessitates Ni alloys such as $\mathrm{H} 230$ or $740 \mathrm{H}$. As described in $\S 4.7 .1$, there is sparse data on $\mathrm{Ni}$ alloys in sodium at temperatures greater than $700^{\circ} \mathrm{C}$. The few references indicate $\mathrm{Ni}$ is prone to leaching, but the level may be acceptable [45], [48], [49]. The project's attempt to validate this assumption in Phase 2 was unsuccessful due to issues with the experimental apparatus. This work is ongoing within the ASTRI program, but currently remains a point of risk.

\subsection{Risk Registry for Progression to Commercial Scale}

Evaluation Criterion \#5 calls for the creation of a new Risk Registry that addresses the challenges associated with issues related to the scaling up of the 1-MW test facility to a future 100-MW facility. In his overview of technology adoption for the DOE's CSP Workshop on Next Generation Receivers, David Wait presented the graphic shown in Figure 63. Risk related to commercial adoption can be mapped to the four categories described by Dr. Wait: Operability, Scalability, Market Adoption, and Cost.
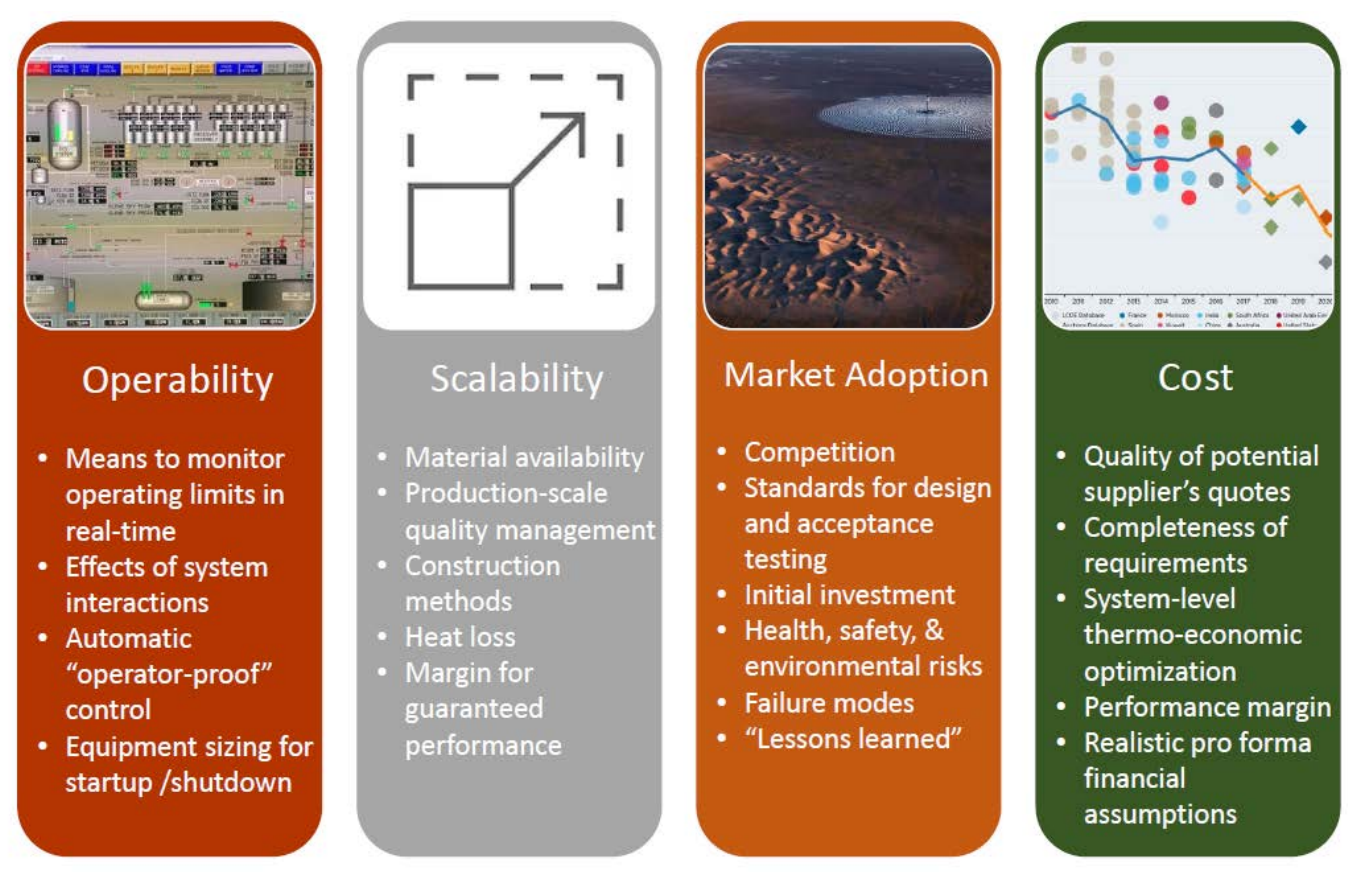

Figure 63. Considerations for technology development [91]

Operability. Operability refers to the means of tracking and controlling system performance and ensuring that performance seen in early demonstration will translate to commercial effectiveness. The planned demonstration utilizes components and systems that represent those that will be employed at commercial scale. The globe valves and salt pumps of the $1-\mathrm{MW}_{\text {th }}$ test utilize the same design approach and materials likely to be used at commercial scale. The sodium receiver 
was selected to be a flat panel design that mimics the larger receiver panels of a commercial system. The salt tank liner uses the same materials proposed for the commercial scale.

A key element of the demonstration will be the interaction of the different components and subsystems. Understanding the interoperability of the three fluid loops is essential in the design and acceptance of the liquid pathway approach. A majority of the test time will be dedicated to system startup, transient operations, and shutdown in order to demonstrate the ability to control the different fluids and their thermal response. The ability to validate system models is one of the items on the commercialization risk registry. Fortunately, the liquid pathway has an extensive database and experience related to liquid-HTF systems analysis and modeling that can be relied upon to guide model development.

Scalability. Risk associated with technology scalability involves materials and methods being available for the system design. The liquid pathway benefits from proven design approaches related to pumps, piping, heat exchangers, and solar receivers. Construction methods for liquidbased CSP systems are documented and can be relied upon to guide the proposed Gen3 technology. This includes information on molten salt technologies as well as available data for the design and operation of sodium-based thermal systems coming from the nuclear industry.

The selected scale of a 50-MWe system aids the transition from demonstration to commercial scale. The system size is selected to allow for salt tanks that do not exceed the dimensions of current nitrate-salt tanks. The Gen3 program requires deployment of an $\mathrm{sCO}_{2}$ power cycle that is currently in development. The smaller $50-\mathrm{MW}_{\mathrm{e}}$ capacity selected here will reduce the timeline for development of a commercial $\mathrm{sCO}_{2}$ power cycle that matches with this plant capacity.

Market Adoption. One of the major challenges of the Gen3 program is to develop advanced technology that is sufficiently familiar to existing technology developers to allow for acceptance and market adoption. All current commercial CSP plants utilize liquid HTFs for thermal energy capture and conversion. This provides an existing ecosystem of technology providers and system developers that will be familiar with the technologies and design methodology inherent in the proposed Gen3 Liquid Pathway approach. Many of the design standards and industry practices such as documented in the CSP Best Practices Study [9] are applicable to the proposed Liquid Pathway technology.

The greatest challenges associated with this pathway will be understanding the nuances of working with a chloride molten salt and the unique aspects of a liquid-metal sodium receiver. Fortunately, there are established protocols and knowledge available from the magnesium industry, other molten salt handling guidelines, and the historic use of sodium as a thermal transfer fluid. The market activity of Vast Solar is particularly relevant to this pathway. Vast Solar, the Innovation Award Winner at SolarPACES 2019, is pursuing the first commercial sodium-receiver CSP plant at a site near Mount Isa, Australia (Figure 64). Success in this endeavor will garner attention and experience with sodium handling and receiver operations at a CSP plant. As important, this first project will demonstrate acceptance of the investor community in a CSP plant of 50-MW scale working with sodium.

During Phase 2, the Liquid Pathway team brought onboard three new TAC members with sodium handling experience to help guide the team. Moving into Phase 3 demonstration, the 
team will make greater use of these resources, reaching out to experts at Creative Engineers, CEA France, and Vast Solar to make sure the demonstration facility has the best possible opportunity to showcase the advantages of this fluid in CSP operations. Much like the Solar Two report spurred interest and confidence in the Gen2 molten salt tower technology, a successful Gen3 demonstration - combined with a successful deployment of a 50-MW e sodium-CSP plant by Vast Solar-will accelerate the timeline for commercial introduction of the Gen3 technology.

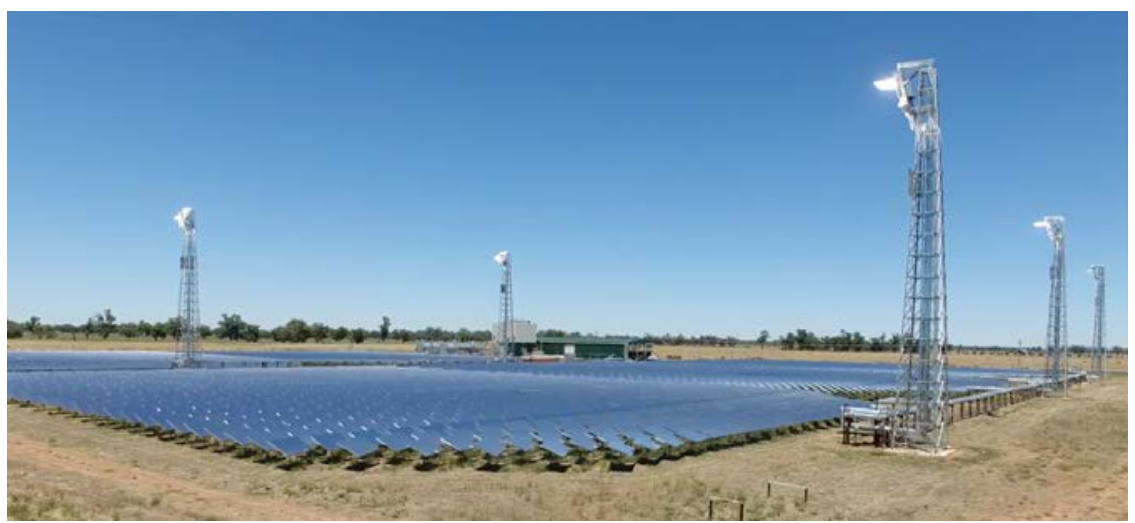

Figure 64. Vast Solar's 5-MW Jemalong pilot plant has derisked sodium handling in preparation for their proposed Mt. Isa project

Cost. Attractive cost projections and confidence in the methodology by which those costs are obtained, are essential for any new technology to gain a foothold in a competitive market. Here the Liquid Pathway can borrow from the existing Gen2 modeling for much of its performance estimates. SAM and SolarTherm models have been vetted against data from existing plants that use very similar receiver and thermal storage designs. The Liquid Pathway heat exchangers and thermal transport systems are based on known unit designs, taken to higher operating temperatures. As noted in $\S 3.3$, the projections for the Liquid Pathway design meet the CSP Gen3 program targets for LCOE. The durability of the Gen3 components and subsystems present the greatest uncertainty and risk to these cost estimates. Only through operating time and experience can this risk be retired, which necessitates the proposed pilot-scale plant development and test.

In summary, the risk categories associated with transition from the $1-\mathrm{MW}_{\text {th }}$ pilot-scale to a commercial plant are outlined in Table 27. The current FMEA will remain a living document if the Liquid Pathway is selected for demonstration. During any Phase 3, the FMEA will be reviewed and updated to document and address specific project risks, including materials availability and construction delays. 
Table 27. Primary risks in the transition from 1-MW th to commercial scale

\begin{tabular}{|c|c|}
\hline Risk Category & Mitigating Factors \\
\hline $\begin{array}{l}\text { Control of the three } \\
\text { HTFs in a transient, } \\
\text { high-temperature } \\
\text { system }\end{array}$ & $\begin{array}{l}\text { - Charging and Discharging systems are decoupled } \\
\text { - Modeling of liquid heat transfer systems is well advanced and } \\
\text { component designs differ little from existing state-of-the-art }\end{array}$ \\
\hline $\begin{array}{l}\text { Relevance of the 1- } \\
\text { MWth Scale to } \\
\text { commercial design }\end{array}$ & $\begin{array}{l}\text { - Pilot system's flat-panel receiver conceptually similar to current molten } \\
\text { salt receivers } \\
\text { - Vetting of design models at pilot scale will lend credibility to commercial } \\
\text { performance estimates } \\
\text { - Overall system design similar to current molten-salt power towers }\end{array}$ \\
\hline $\begin{array}{l}\text { Market acceptance of a } \\
\text { new technology }\end{array}$ & $\begin{array}{l}\text { - Expertise in current nitrate salts relevant to the Gen3 design } \\
\text { - Design and practice guidelines exist for liquid-sodium systems } \\
\text { - } 50-\mathrm{MW}_{\mathrm{e}} \text { Sodium/salt CSP project in development by Vast Solar } \\
\text { - Smaller, } 50-\mathrm{MW}_{\mathrm{e}} \text { commercial scale selected to match with current salt } \\
\text { tank dimensions and quicker development of the } \mathrm{SCO}_{2} \text { power cycle }\end{array}$ \\
\hline Equipment durability & $\begin{array}{l}\text { - Materials selection guided by laboratory testing } \\
\text { - Coatings available to enhance corrosion resistance, although the small } \\
\text { piping size limits utility for pilot-scale system. Coupon tests will compare } \\
\text { coated and uncoated materials. }\end{array}$ \\
\hline Cost & $\begin{array}{l}\text { - Performance and cost models can leverage methodology and data from } \\
\text { Gen2 CSP technology and past sodium systems }\end{array}$ \\
\hline
\end{tabular}




\section{Phase 3 System Design, Project Management, Construction, and Operations}

\subsection{Integrated System Design}

The 1-MW th pilot scale system is proposed to be built at Sandia's National Solar Thermal Test Facility (NSTTF). Computer renderings of the system are provided below in Figure 65 and Figure 66, followed by a drawing of the salt tanks (Figure 68) and a system schematic for the Long-Term Hold operating mode (Figure 69). Additional drawings and graphics with higher resolution can be found in Folder 04-Drawings, see Table 32.

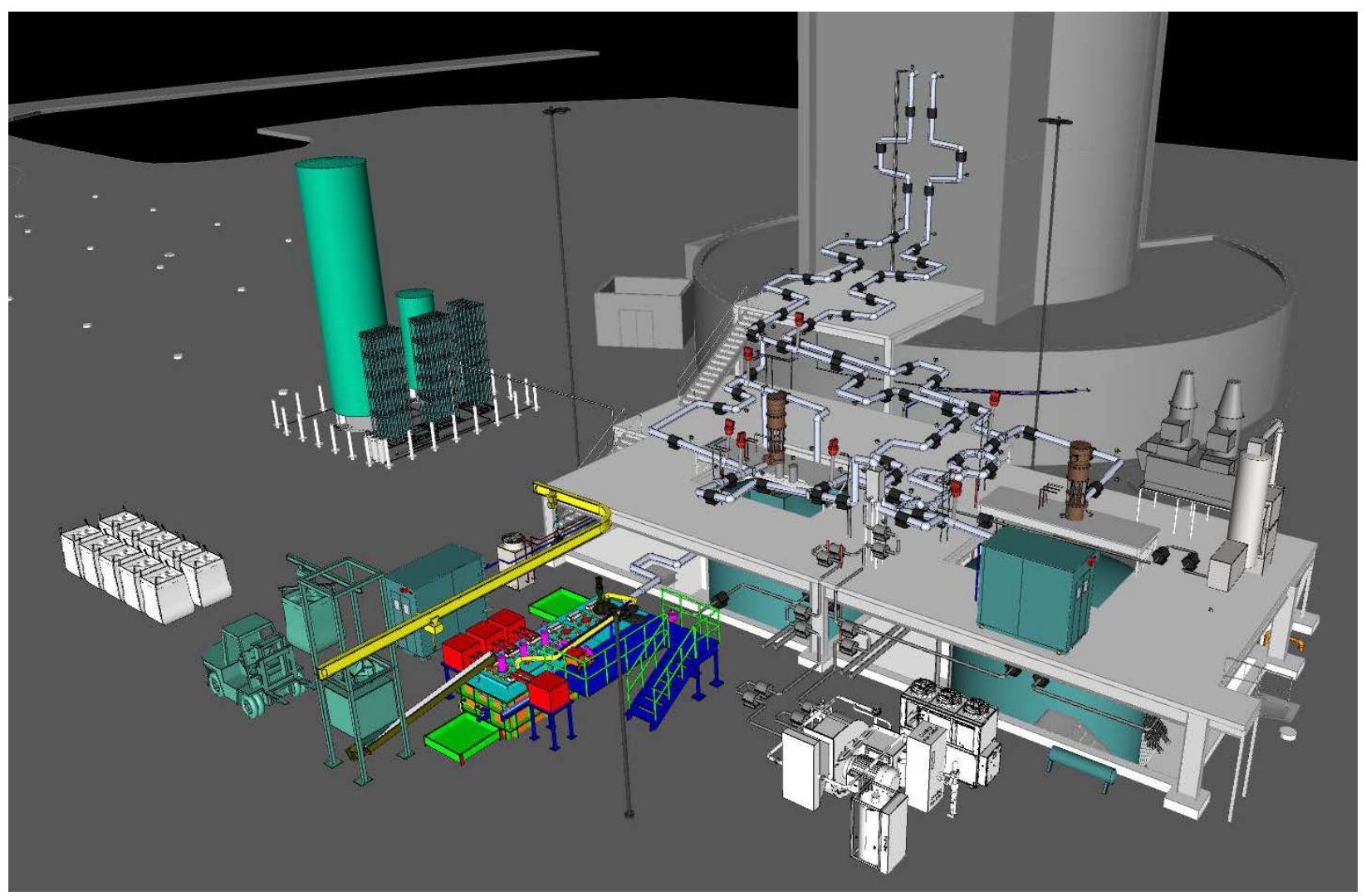

Figure 65. Rendering of the pilot-scale system components at the base of the NSTTF tower. See Table 32 for additional System Layout Drawings. 


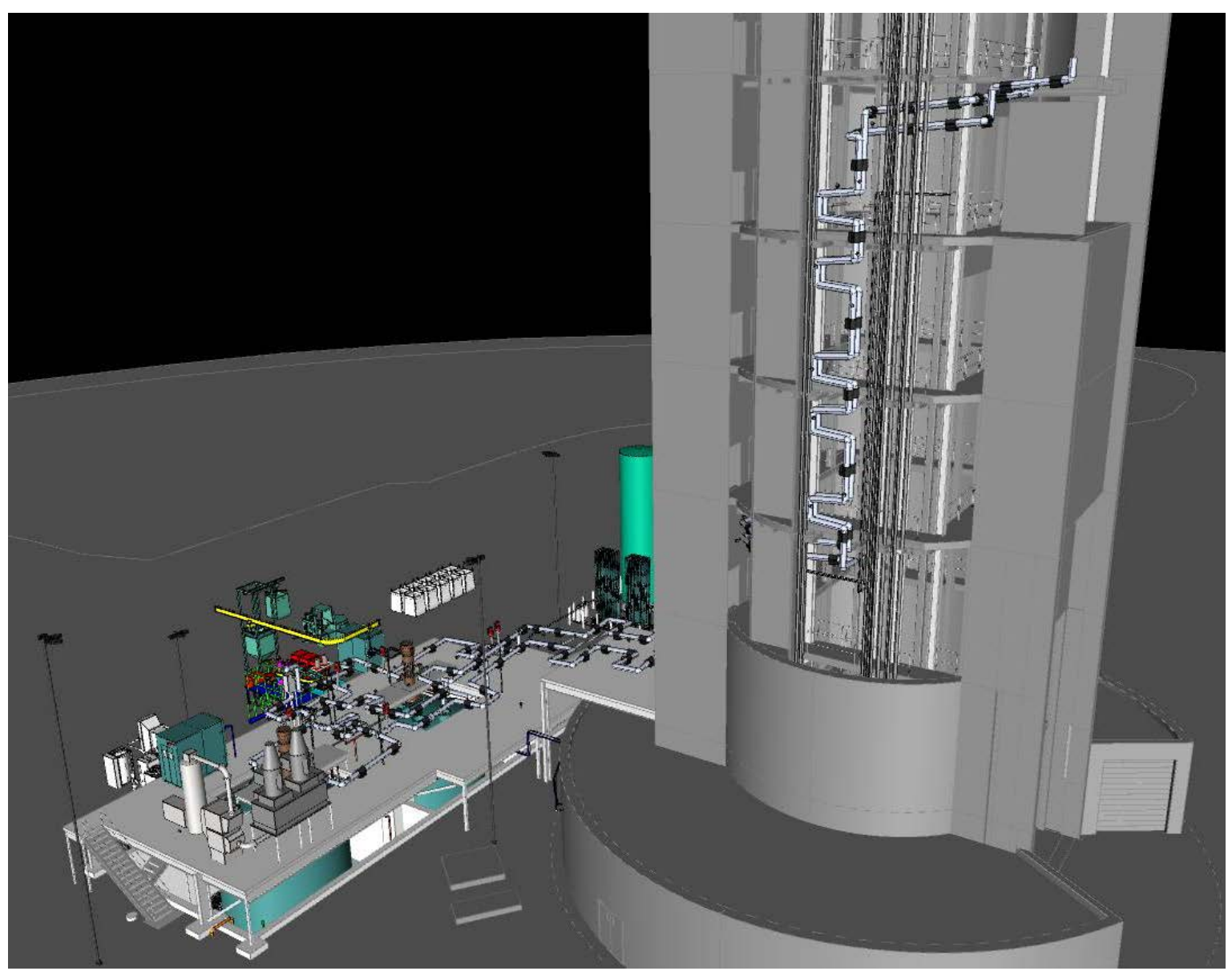

Figure 66. Rendering of the pilot-scale system at NSTTF showing a cut-away view of the salt piping in the tower. See Table 32 for additional System Layout Drawings.

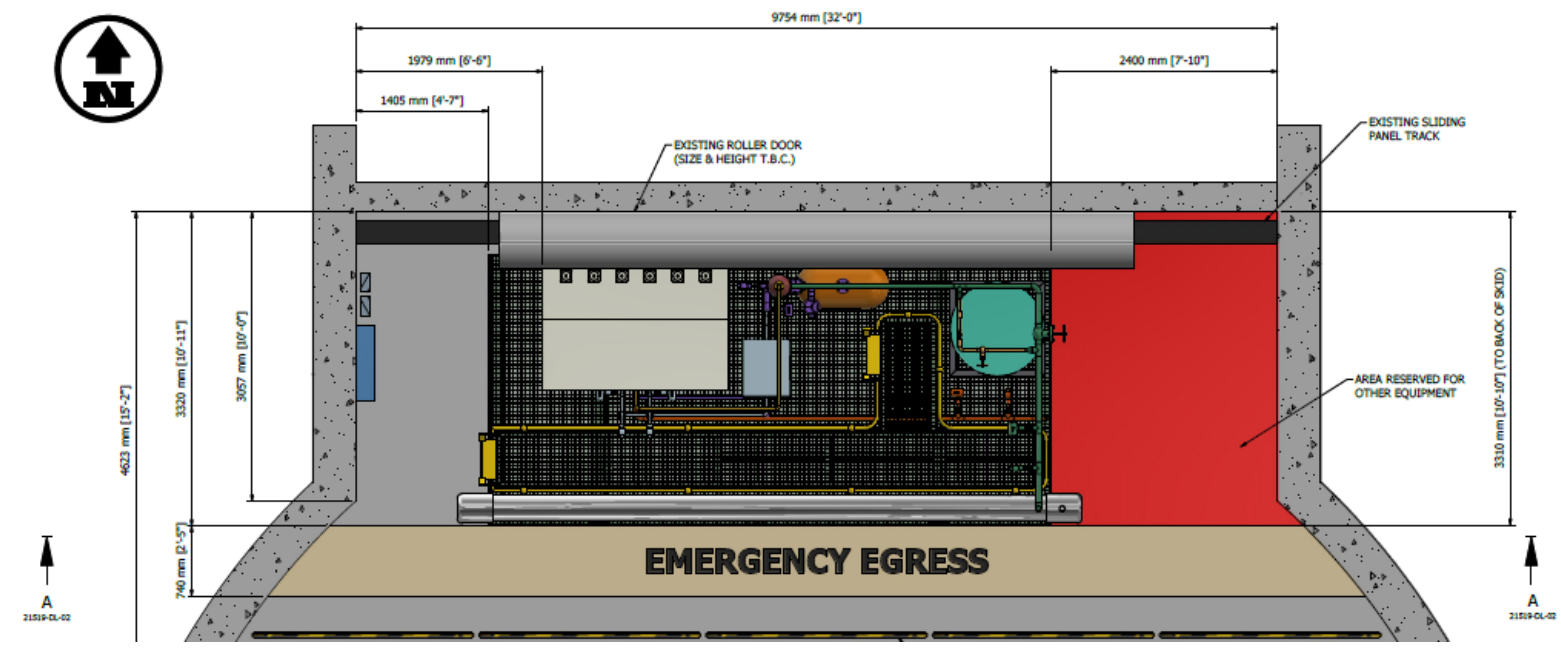

Figure 67. Plan view of the sodium loop at the 220 level in the tower. The receiver sits in the box at upper left and the sodium/salt HEX runs along the lower edge of the containment tray (dark hatched area). The entire loop will be enclosed in a steel-sheeted chamber. 


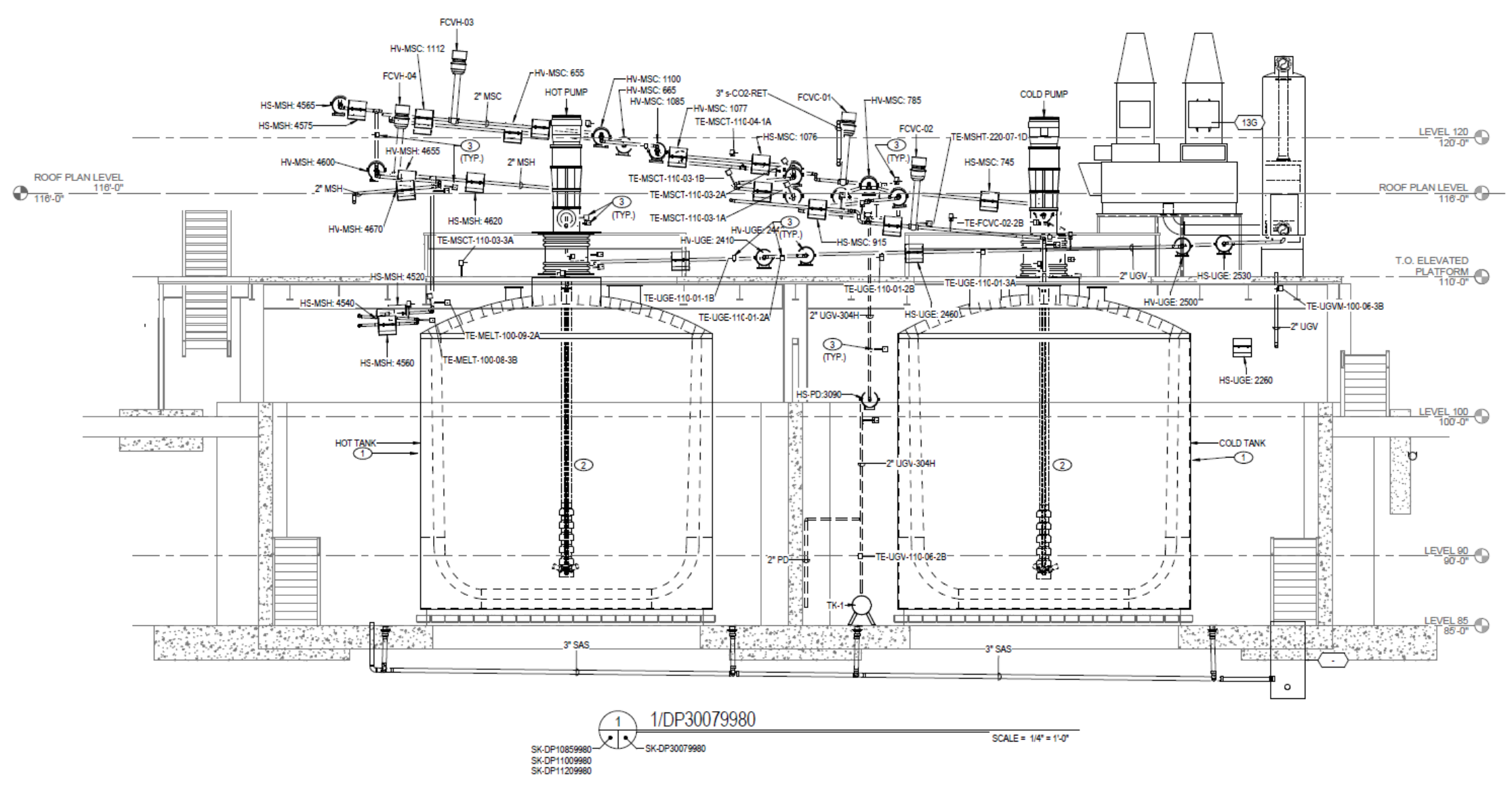

Figure 68. Detail of the salt tanks, showing piping expansion loops and heat trace. Scrubber is at upper right. See Table 32, Folder 04Drawings, for higher resolution and additional System Layout Drawings. 


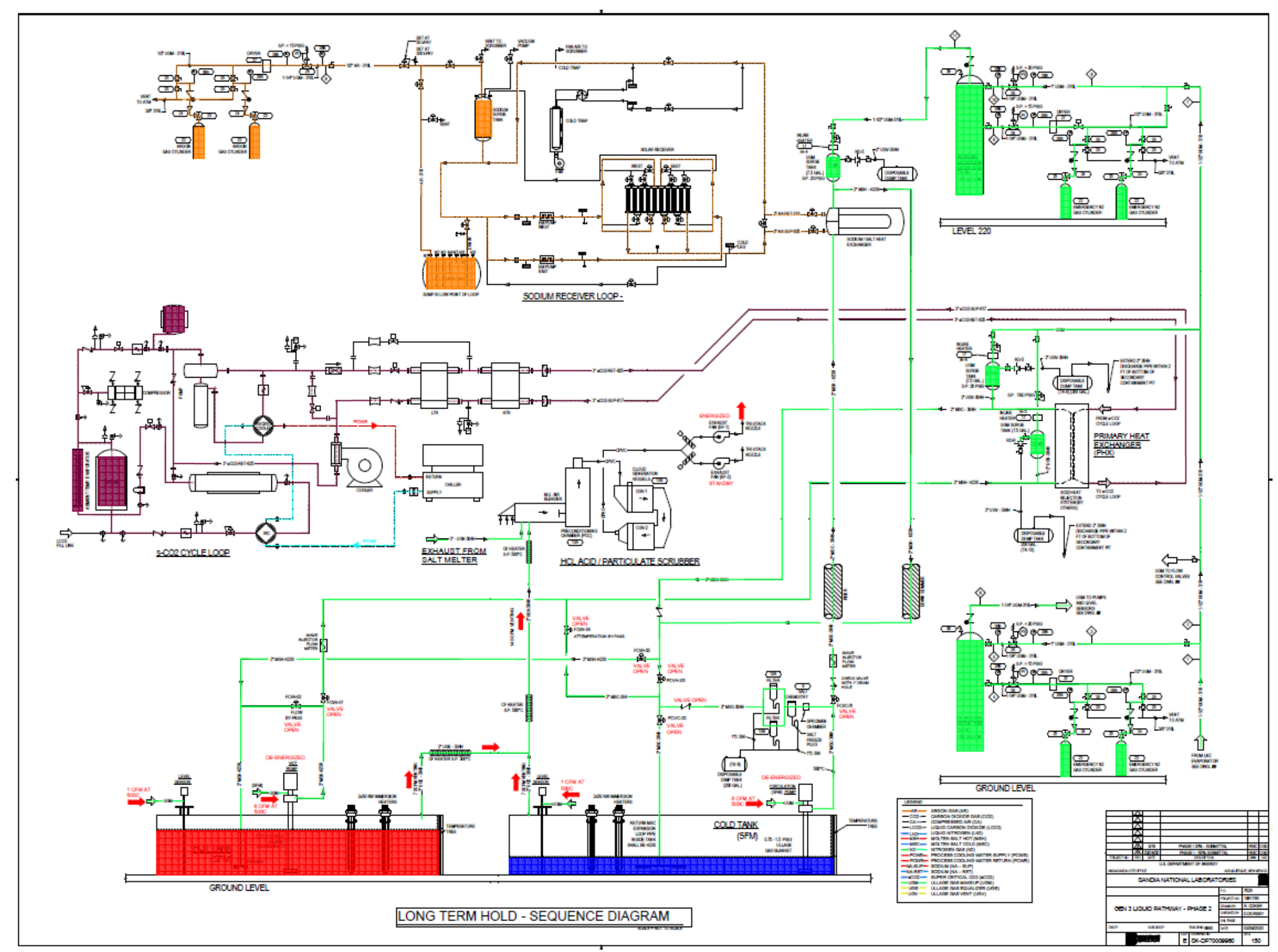

Figure 69. Process flow diagram for the Long Term Hold operational mode 


\subsection{Phase 3 Schedule and Test Plan}

The Liquid Pathway plans the operational objectives associated with the receiver and the balance of system (BOS) testing to fit within the allotted 3-year Phase 3 timeline, Table 28.

Table 28. Expected timeline for Phase 3 contracting, procurement, construction, and testing

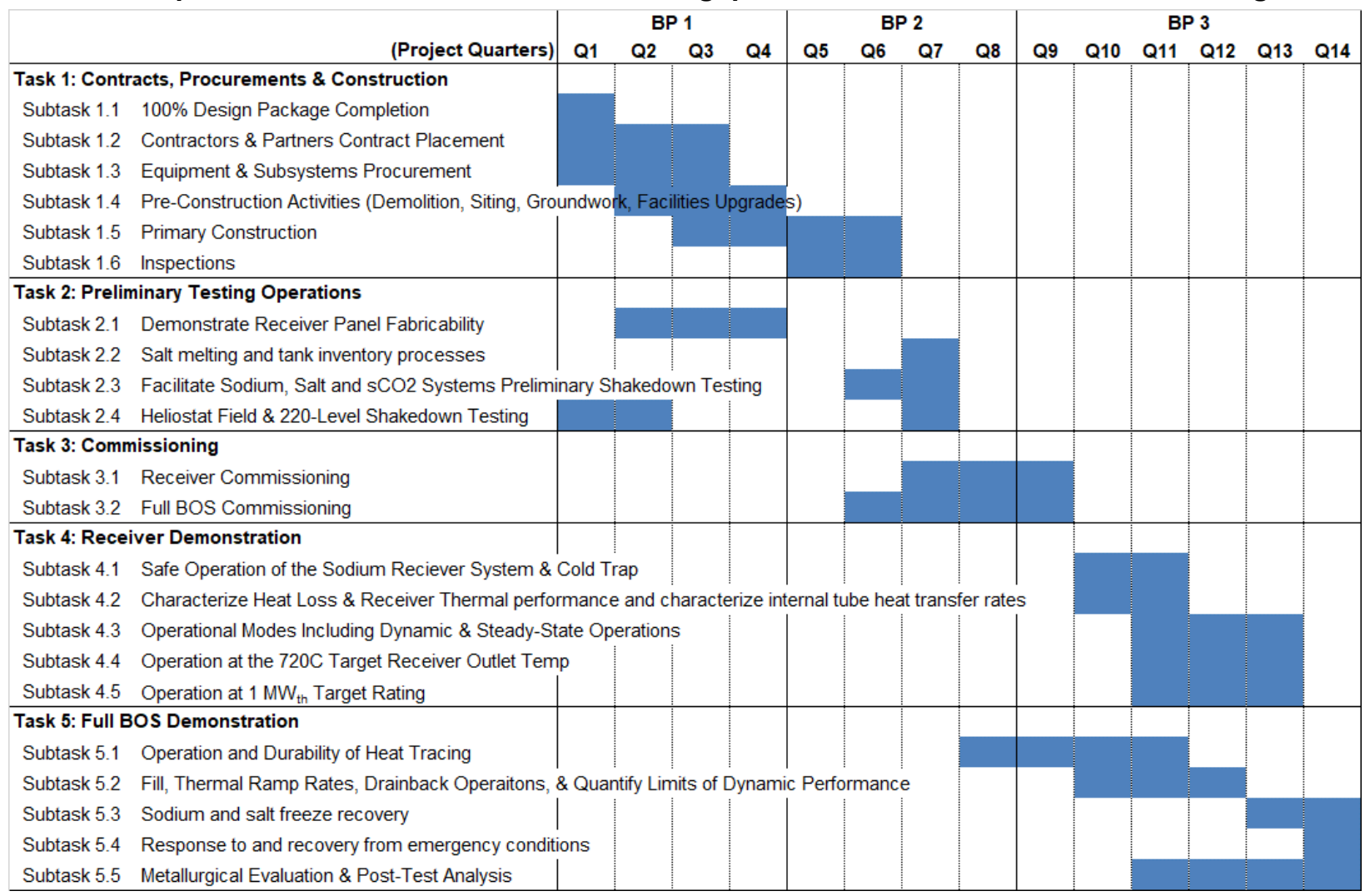

\subsubsection{Task 1: Contracts, Procurements \& Construction}

Should the Liquid Pathway be selected for continuation, final 100\% design package documents will be completed, pending any final change-orders. In parallel, any $100 \%$ completed subsystem components will have purchase orders submitted. Contracts will be placed with project partners and contractors following the submission of the 100\% design package to the Sandia Facilities. Pre-construction activities are expected to immediately follow contract placement with a lead construction entity to being siting, demolition, groundwork and facilities upgrades. This will be completed closely with Sandia Facilities personnel. Final construction will include close collaboration between Sandia, the lead construction contractor and partnering subcontractors (e.g., Hatch, ASTRI, JT Thorpe/Job Industrial, etc.). Prior to commission, all systems will have thorough inspections completed, which will include those for electrical safety, ES\&H/IH ullage gas and scrubber systems, thermal transport/weldment inspections and civil inspections.

\subsubsection{Task 2: Preliminary Testing Operations}

Subtask 2.1: Demonstrate receiver panel fabricability. Fabrication of the 1-MW th pilot-scale receiver system will provide a detailed assessment of the workability of the materials, ease of manufacturing for the selected alloys and tube dimensions, and fabrication cost. The basic header-panel design of the $1-\mathrm{MW}_{\text {th }}$ receiver is analogous to that of the individual panels planned 
for a commercial-scale receiver, with similar material, fabrication, and welding requirements. Weldments, thermal-mechanical stress and pressure safety will also be considered from the standpoint of both nominal operations and contingency failure modes.

Subtask 2.2: Salt melting and tank inventory processes. Preparation of the salt melter at the Sandia NSTTF site will initially consist of salt totes staging/processing and initial melter separate effects shake-down testing to ensure nominal operation of the ullage gas system, pumps, valves and electrical systems. Sensor and scrubber checks will also be conducted. The actual salt melting process will be conducted over approximately 3 weeks to inventory approximately 35,000 gallons of purified salt initially into the hot tank. Close attention will be paid to the purity of the salt (with head space measurement of trace amounts of humidity, HCL and $\mathrm{H}_{2}$ ) via salt purification sensors at various stages of the melting process. Operations for breaking each tote into a hopper for inventory and facilitation of the salt melting process is expected to occur continuously $24 / 7$ until the salt is completely inventoried. This work will take place over threeshifts of two technologists, with oversight from at least one engineer from Sandia and Hatch throughout the duration of the operation.

Subtask 2.3: Facilitate sodium, salt and $\mathrm{sCO}_{2}$ systems preliminary shake-down testing. Prior to commissioning the project team will need to complete their piping and electrical inspections as well as comprehensive functionality reviews of the initial controls and data acquisition (DAQ) sensor signals for the entire pilot system. This work will evaluate valve, pump and heater actuation within the control's algorithms. To support a successful commissioning process, this work will also be performed to finalize pre, nominal and post-test checklists as well as hand-off processes administrative controls and O\&M operations.

Subtask 2.4: Heliostat field \& 220-level shakedown testing. The NSTTF heliostat field, comprising 218 heliostats, will be inspected for any O\&M issues prior to commissioning and testing. Here, encoders, wiring, gearboxes and DAQ hardware will be inspected and repaired in the event of any reliability issues. Configuration event files will be developed for each of all operational modes and emergency scenarios between the heliostat field with the calibration panel and sodium receiver. This will also include the ability to facilitate multiple aim-point flux and spread strategies. Here, redundant by-pass controls will be developed to facilitate SCRAM contingency processes pertaining to the Gen 3 test campaign. Although built during Phase 2 of the Gen3 project, at the 220' level, the calibration panel will be inspected and tested to ensure proper flow cooling, controls and operation of the Kendall radiometer up to $100 \mathrm{~W} / \mathrm{cm}^{2}$ to provide margin beyond the $80 \mathrm{~W} / \mathrm{cm}^{2}$ testing flux target. To ensure accuracy during testing, beam photometrics will be adapted for the calibration panel and sodium receiver to characterize beam peak flux distribution and level. This work may also include the addition of high-speed flux gauges on the periphery of the sodium receiver to provide additional flux target mapping during on-sun receiver testing.

\subsubsection{Task 3: Commissioning}

Subtask 3.1: Receiver Commissioning. The commissioning process will begin with sodium receiver loop since this system will provide the primary working fluid and heat source to the molten salts and subsequent $\mathrm{sCO}_{2}$ media. The broad objective of this subtask will be to demonstrate satisfactory operation of a sodium-cooled receiver panel over a wide range of power levels, transient conditions, and emergency situations. Prior to on-sun testing receiver 
commissioning will include activity-level work to gain familiarity with the controls, instrumentation, and unique features of the sodium receiver, sodium-salt heat exchanger, and sodium loop under fully controllable conditions.

Subtask 3.2: Full BOS Commissioning. To facilitate commissioning of the pilot system commissioning documents included in the $90 \%$ design package will be employed that include 60 Pre-Functional Test documents and 10 Functional Performance Test documents. These commissioning documents will be updated during Phase 3 when construction contractor submittals are reviewed and approved for construction. These documents provide the preliminary outline for the Commissioning process. The following is our preliminary responsibility work chart, Table 29, for the commissioning communications process. This document will be updated as the project develops during Phase 3.

Table 29. Commissioning team communication diagram

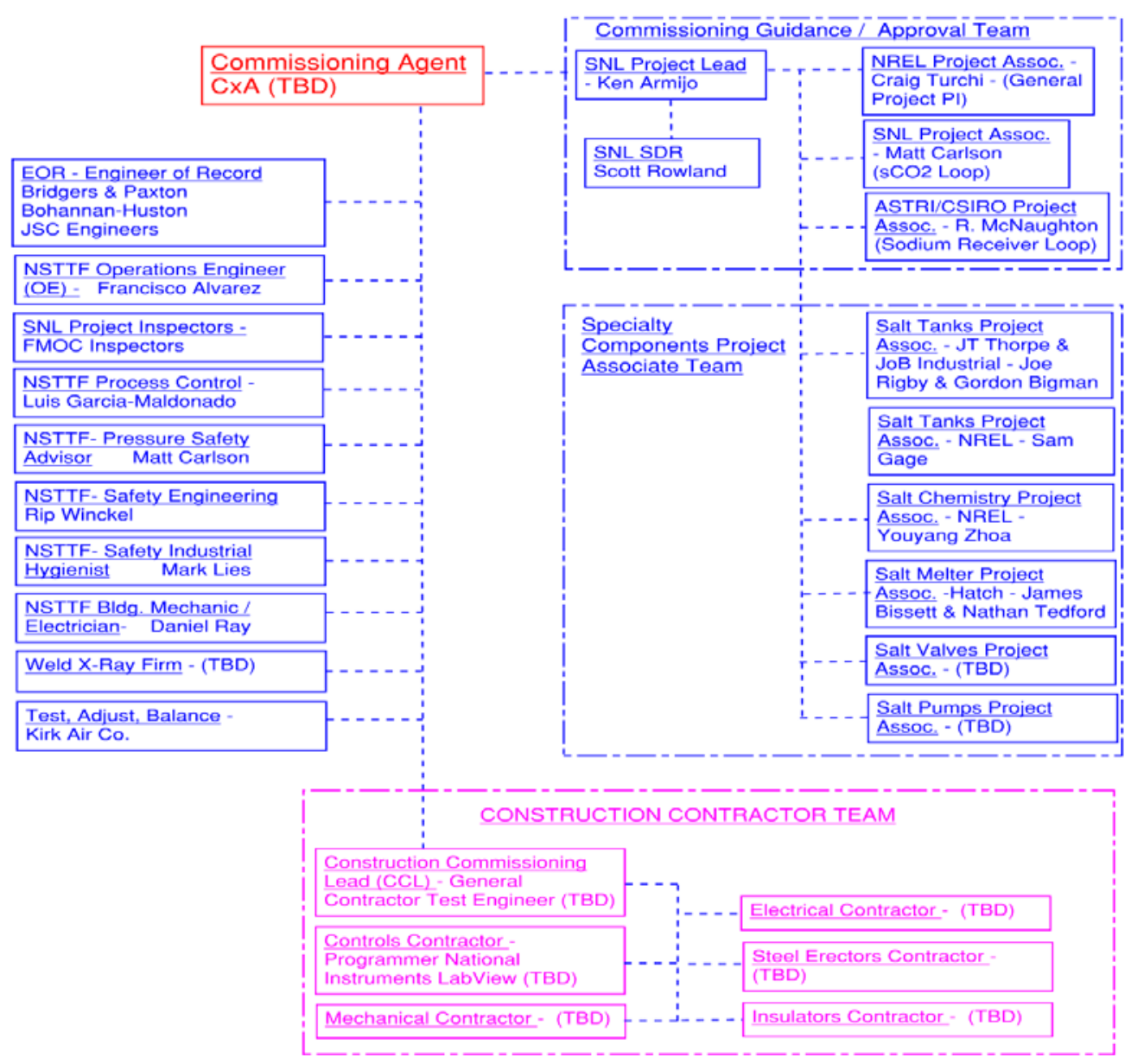

For the molten salt and $\mathrm{sCO}_{2}$ systems, initial flow testing will be performed by measuring a pressure drop vs flow rate through each side without significant heat transfer. Here, this activitylevel work will consist of heat input from the tank and piping heaters, not on-sun input. The hot flow test will be done by bringing the heat exchanger up to $500^{\circ} \mathrm{C}$, the near lower-bound of the system envelope. For the molten salt system, additional heat input will be provided via the recirculation by-pass loops for both hot and cold pumps. Here, commissioning work will include 
pump and valve actuation under flowing salt conditions. For the salt valves, the team will validate the $\mathrm{C}_{\mathrm{v}}$ profiles for the flow control valves as well as the ability to open/close both salt and ullage gas shut-off ball valves. Control valve operation will also be evaluated based on flow measurements. The pumps will also be cycled within their nominal operational envelope between 1,800 and 2,200 RPM to test controllability as well as the operational conditions of the variable frequency drives. The ability to drain-back the system will also be evaluated at this low temperature condition. Additionally, both sodium-salt HEX as well as the PHX will be evaluated at this $500^{\circ} \mathrm{C}$ target temperature to evaluate thermal-fluid conditions as well as component thermal gradients and leak-resistance. The $500^{\circ} \mathrm{C}$ target temperature was chosen since it will be above known salt vapor plating temperatures as high as approximately $480^{\circ} \mathrm{C}$, as well as being below potential sensor error limitations.

For the $\mathrm{sCO}_{2}$ system, evaluation will be performed for flow temperature and pressure conditions with no or minimal $\mathrm{sCO}_{2}$. This evaluation will evaluate heating/cooling and control systems, including cycling of the compressor and valves. Once this work is completed a series of performance tests will be performed. These tests will look at steady-state performance for different heat transfer duties and transient performance for startup, shutdown, and load/demand changes where transient conditions can be experienced from one duty to another. Overall, the $\mathrm{sCO}_{2}$ commissioning plan tasks the team will facilitate will be:

- Inventory management campaign

○ Verify filling capability

○ Verify trim and main venting

○ Verify inventory recovery

- Cold low flow test campaign

○ Verify instrumentation

- Verify component flow resistance

- Verify flow control stability

- Heated flow test campaign

- Verify operation at temperature.

In addition to the table above, cold flow testing will be performed by measuring a pressure drop versus flow rate through each side without significant heat transfer. The hot flow test will be done by bringing the heat exchanger up to full temperature and pressure conditions with no or minimal $\mathrm{sCO}_{2}$. Once that is all completed a series of performance test will be performed. These tests will look at steady-state performance for different heat transfer duties and transient performance for startup, shutdown, and load/demand changes where we experience a transient from one duty to another.

\subsubsection{Task 4: Receiver Demonstration}

The objectives of the pilot-scale testing are to derisk the commercially relevant technology. Hence, the specific performance metrics of the pilot-scale system, e.g., receiver efficiency, thermal storage efficiency, are less relevant than the ability to demonstrate reliability of the 
system operations, system components, and system models. The team has identified multiple operational objectives associated with the receiver. A detailed Technical Work Document will be developed and approved during the early stages of Phase 3.

Subtask 4.1: Safe Operation of the Sodium Receiver \& Cold Trap. While sodium provides superior heat transfer capabilities in the receiver, the safety and reactivity concerns surrounding sodium can have significant implications on perception and acceptance of the technology.

Demonstration of safe operation throughout the test campaign, including implementation and demonstration of leak detection systems, will showcase successful management of these risks. Receiver design and operation will follow all identified risk mitigation measures, and emergency procedures will be developed and demonstrated under simulated conditions. This subtask will be performed throughout the testing campaign providing pre/post and in-situ on-sun test characterization of the receiver tubes, headers, valves and insulation boards to evaluate heating profiles and potential issues related to sodium flow, containment and controllability.

Maintaining sodium purity levels under high temperature operation is critical to avoid excessive corrosion, premature material degradation, and component failures. The proposed approach is to utilize a cold trap during nighttime or standby conditions. Demonstration of the operation of the cold trap, coupled with during- and/or post-test metallurgical evaluation, will provide confidence that sodium purity can be maintained at acceptable levels.

Subtask 4.2: Characterize Heat Loss \& Receiver Thermal Performance and Characterize Internal Tube Heat Transfer Rates. Throughout the test campaign receiver thermal performance will be characterized via a combination of (i) optical property measurements during receiver commissioning, (ii) infrared thermography, (iii) direct mounted flux gauges, (iv) a flux calibration panel adjacent to the receiver, and (v) thermocouple measurements at the receiver tube back walls, headers, header interfaces, tube support structure, panel support structure, and heat shields. Characterization of optical and thermal loss in the pilot-scale system under both steady state and dynamic conditions will facilitate validation of predictive performance models under a range of incident flux, mass flow, and ambient temperature conditions. Validated pilotscale performance models will provide confidence in commercial-scale performance projections.

Comparison of model-predicted temperature conditions against measured values, and calculation of the corresponding internal tube heat transfer coefficients under a variety of flow and temperature conditions will verify heat transfer correlations used in the design and performance predictions of both pilot-scale and commercial-scale receiver systems. Selected mass flow rates will replicate dimensionless flow conditions (e.g., Reynolds number) relevant to the commercialscale design, while maintaining pilot-scale receiver operation within survivability constraints determined from component thermal and structural modeling.

Subtask 4.3: Operational Modes Including Dynamic \& Steady-State Operations. Suitable operation and control of the sodium receiver and sodium-salt heat exchanger system will be demonstrated under all modes of operation expected in a commercial-scale system to derisk the ability of the loop to respond to and survive expected conditions. Operational modes listed in Table 30 encompass dynamic startup, shutdown, cloud transient, and emergency recovery conditions as well as those typical of normal steady state operations under high DNI conditions. For the sodium receiver loop, the team has identified 11 operational modes that will be evaluated 
to validate receiver operation. These operational modes include both transient and steady-state activities where outlet temperatures are expected to be as high as $740^{\circ} \mathrm{C}$. High-temperature operation above $500^{\circ} \mathrm{C}$ will likely require molten salt flow within the sodium/salt HEX to avoid thermal-mechanical stress and weldment issues.

Table 30. Overview of receiver operational modes. See 04 - Drawings via Table 32 for more detail.

\begin{tabular}{|l|l|l|}
\hline Mode & Operation & Brief Description \\
\hline Receiver preheat & Transient & $\begin{array}{l}\text { Preheating of empty receiver accomplished with low levels of } \\
\text { solar flux. Preheating of sodium-salt heat exchanger (HX) } \\
\text { accomplished with a combination of electrical heat tracing, } \\
\text { salt circulation, and sodium circulation. }\end{array}$ \\
\hline Fill operation & Transient & Flood-fill receiver panels with sodium \\
\hline $\begin{array}{l}\text { Attemperation start- } \\
\text { up ramp }\end{array}$ & Transient & $\begin{array}{l}\text { Circulate sodium through receiver and sodium-salt HX while } \\
\text { ramping-up flux concentration }\end{array}$ \\
\hline Charging & Steady state & $\begin{array}{l}\text { Normal daily receiver operation under high-DNI conditions. } \\
\text { Mass flow control to maintain 740 } \\
\text { temperature from the receiver and 720 } \\
\text { temperature from the sodium-salt } \mathrm{HX}\end{array}$ \\
\hline PHX attempet
\end{tabular}

Receiver Preheat: The sodium loop (Figure 70) is maintained with a cover gas of argon during operation and standby. Once the transport system, including the receiver, is gradually heated at a rate between $5-10^{\circ} \mathrm{C} / \mathrm{min}$, which is the limit for the salt-wetted piping sections, including the salt-side of the sodium/salt HEX. Initial heating will be performed beyond the sodium melting temperature of approximately $98^{\circ} \mathrm{C}$, until all piping reaches a steady temperature of $500^{\circ} \mathrm{C}$. During the heating of the piping, the sump tank will also undergo via its respective heating system to achieve a steady $500^{\circ} \mathrm{C}$ also. Heating beyond this point is undertaken with solar flux. Since the receiver doesn't have heat trace, heating for this subsystem will come from beamed energy from the heliostat field or heating mats on the inner side of the receiver cover door. For this operation a multiple aim-point strategy will be facilitated to spread the heat uniformly across the receiver panels, with a thermal ramp from $5-30 \mathrm{~W} / \mathrm{cm}^{2}$ in increments of $5 \mathrm{~W} / \mathrm{cm}^{2}$, over a time period determined during receiver commissioning. 


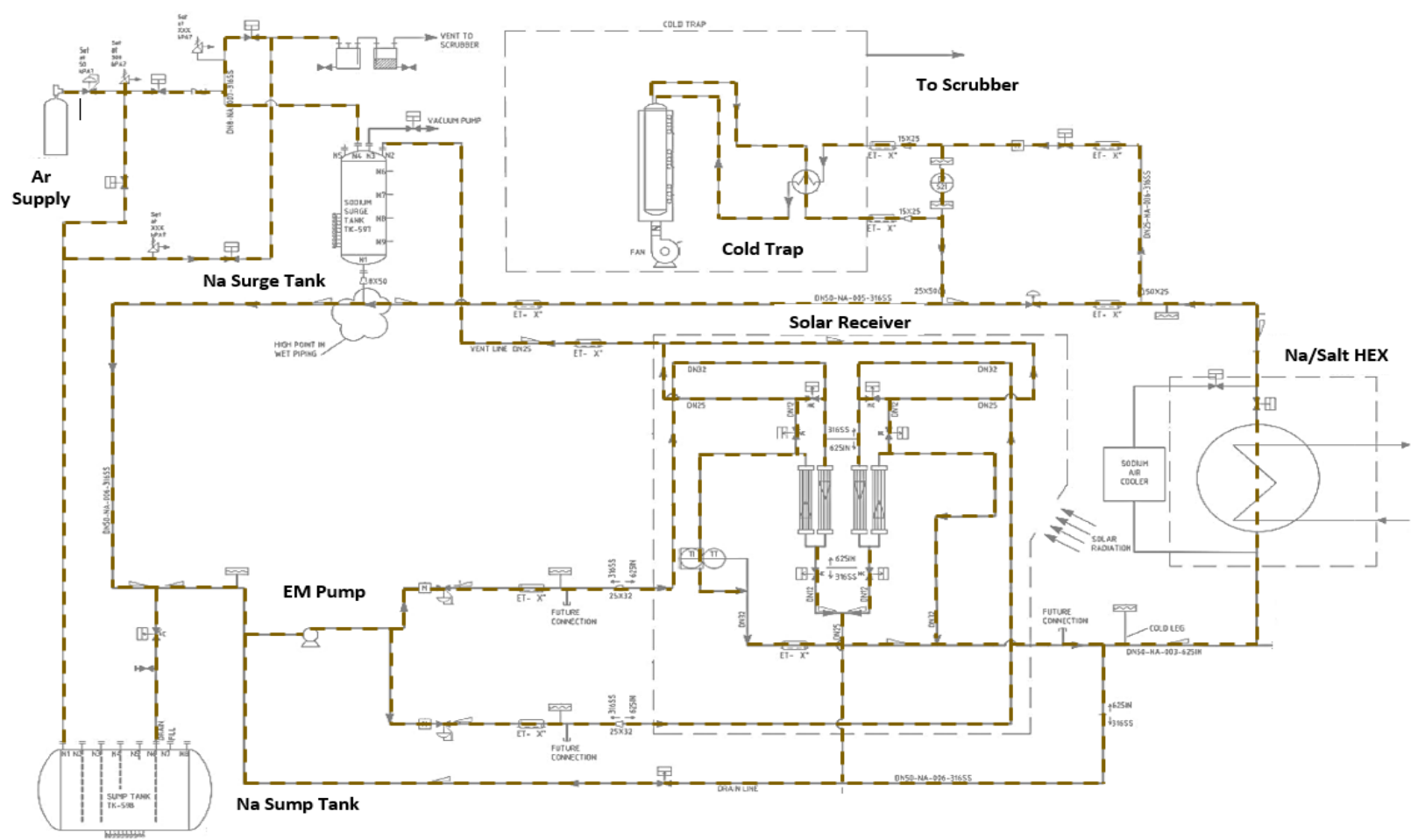

Figure 70. Sodium Receiver Preheat operational mode diagram showing system filled with argon

Fill Operation: Once the entire receiver thermal transport system, including the receiver panels have reached a steady $500^{\circ} \mathrm{C}$ temperature, a shut-off valve on the top of the sump tank will be opened releasing $500^{\circ} \mathrm{C}$ sodium into the receiver system as shown in Figure 71. This sodium will be cycled through the system via a single electromagnetic (EM) pump. During this time heliostats will continue to provide heat input on the receiver, where temperatures and IR thermography will continuously be used to evaluate thermal distributions. This process will continue until both receiver and sodium/salt HEX subsystems reach a steady temperature of around $550^{\circ} \mathrm{C}$. 


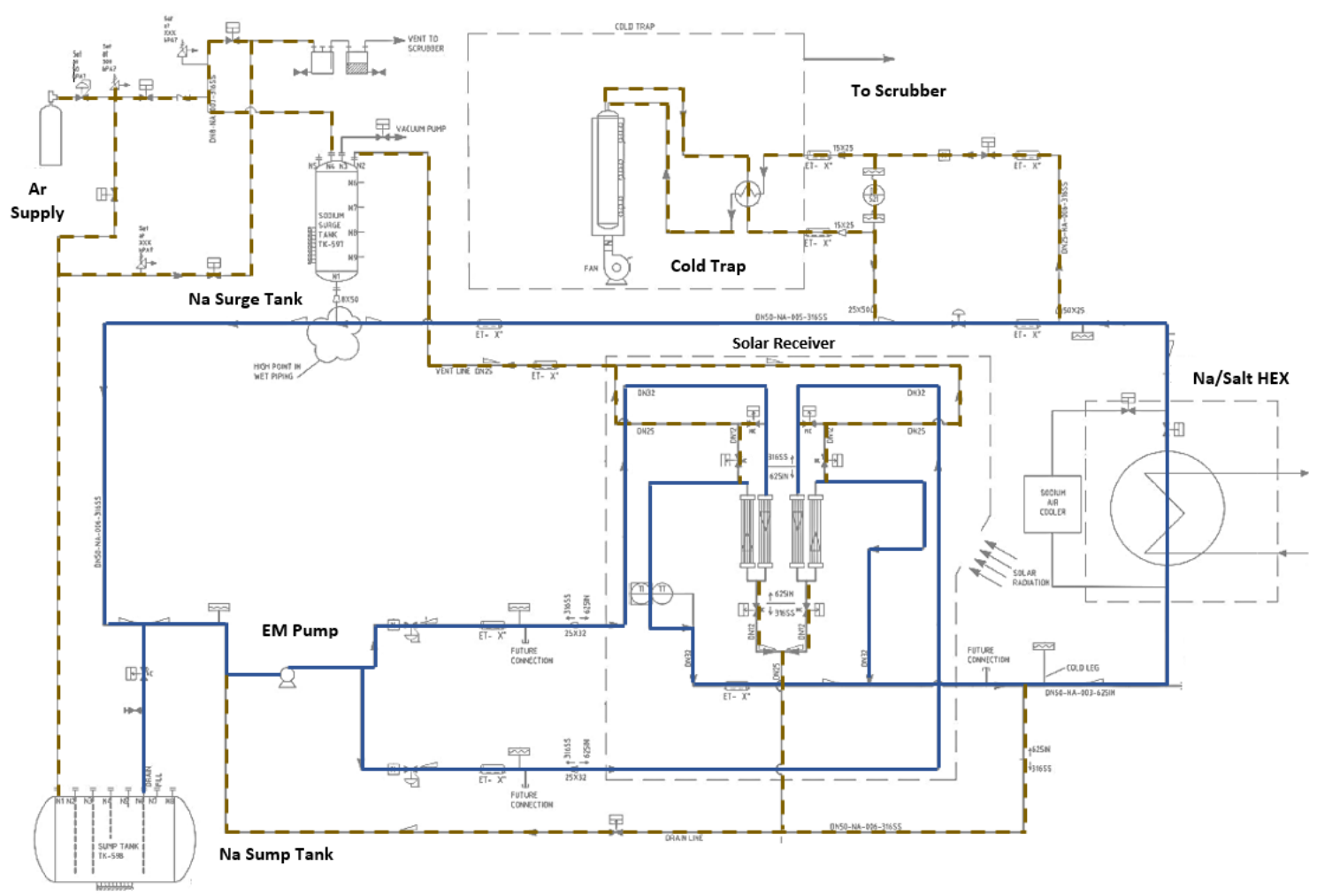

Figure 71. Sodium Receiver Fill operational mode diagram showing sodium circulation via the EM pump

The receiver and sodium-salt heat exchanger system provides the means of filling the hot storage tank to enable operation and evaluation of downstream components. To satisfy this objective, the receiver and heat exchanger will be operated at high enough mass flow rates and thermal power to fill the hot tank within the desired daily timeframe. In the event that outlet temperatures at this flow rate cannot meet the target conditions, auxiliary heat will be provided using ceramic fiber heaters, such that salt is delivered to the hot tank at the target $720^{\circ} \mathrm{C}$ outlet temperature.

Attemperation Start-Up Ramp: Further heat input will continue via the heliostat field in increments of 5-10 W/ $\mathrm{cm}^{2}$ until the total incident flux (as measured on the calibration panel and receiver-advancement high-speed flux gauges) reaches $60 \mathrm{~W} / \mathrm{cm}^{2}$. This operational mode can be seen in Figure 72 which is expected to be facilitated at a rate of approximately $10-12^{\circ} \mathrm{C}$ until target flux and receiver power levels are achieved. During this process cold salt recirculation will begin as described next.

Once the sodium recirculation conditions are established, the cold salt piping (filled with nitrogen cover gas and preheated to $500^{\circ} \mathrm{C}$ heat trace) will be filled with circulating cold salt. The salt system will fill the riser and downcomer pipes simultaneously using a crossover valve at the base of the tower. Once the pipes are filled with salt, flow will be initiated up the riser, through the sodium-to-salt HEX and down the downcomer as shown in Figure 73. Cold salt in the downcomer will return to the cold salt tank during this stage. 


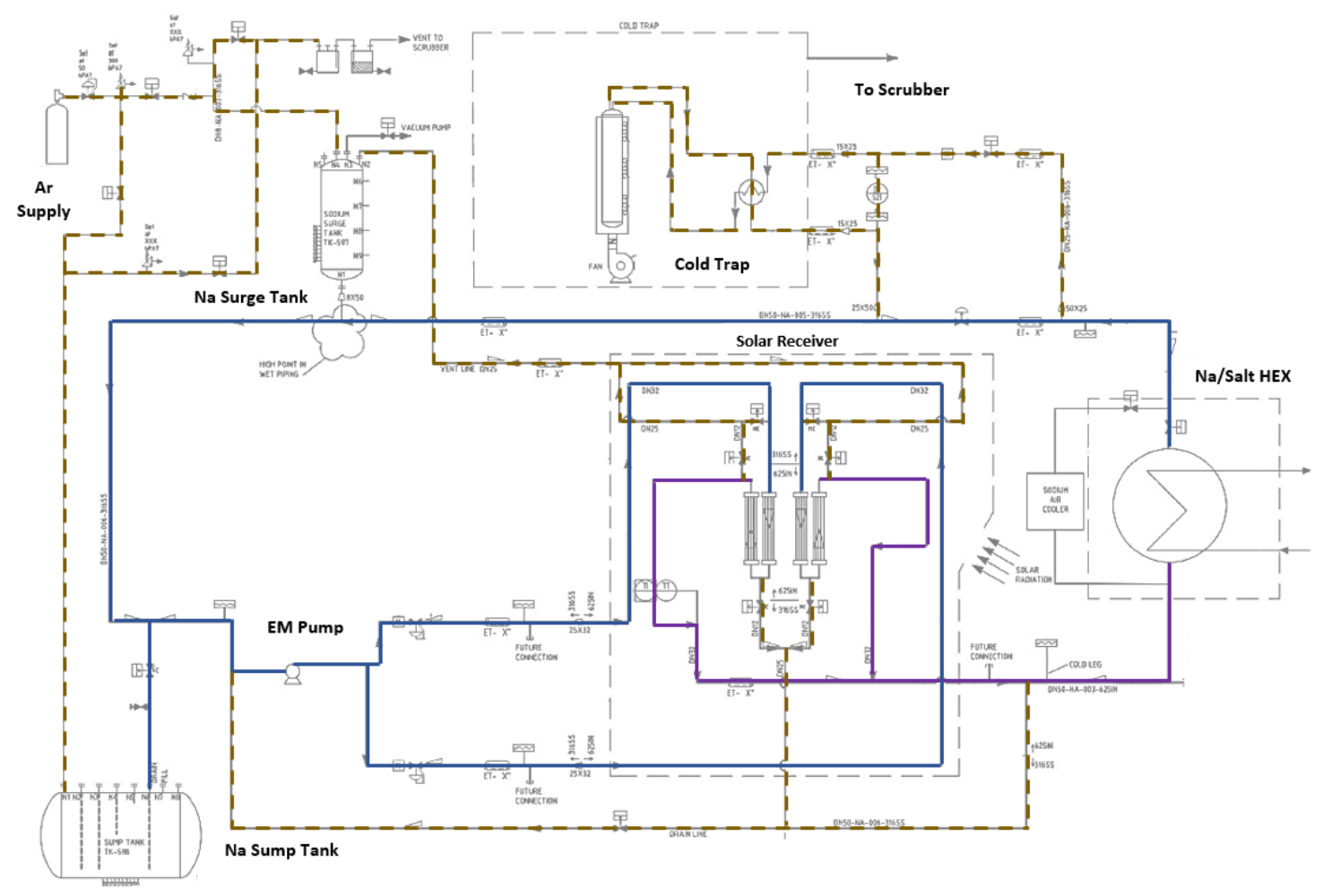

Figure 72. Sodium/Salt HEX Attemperation operational mode diagram

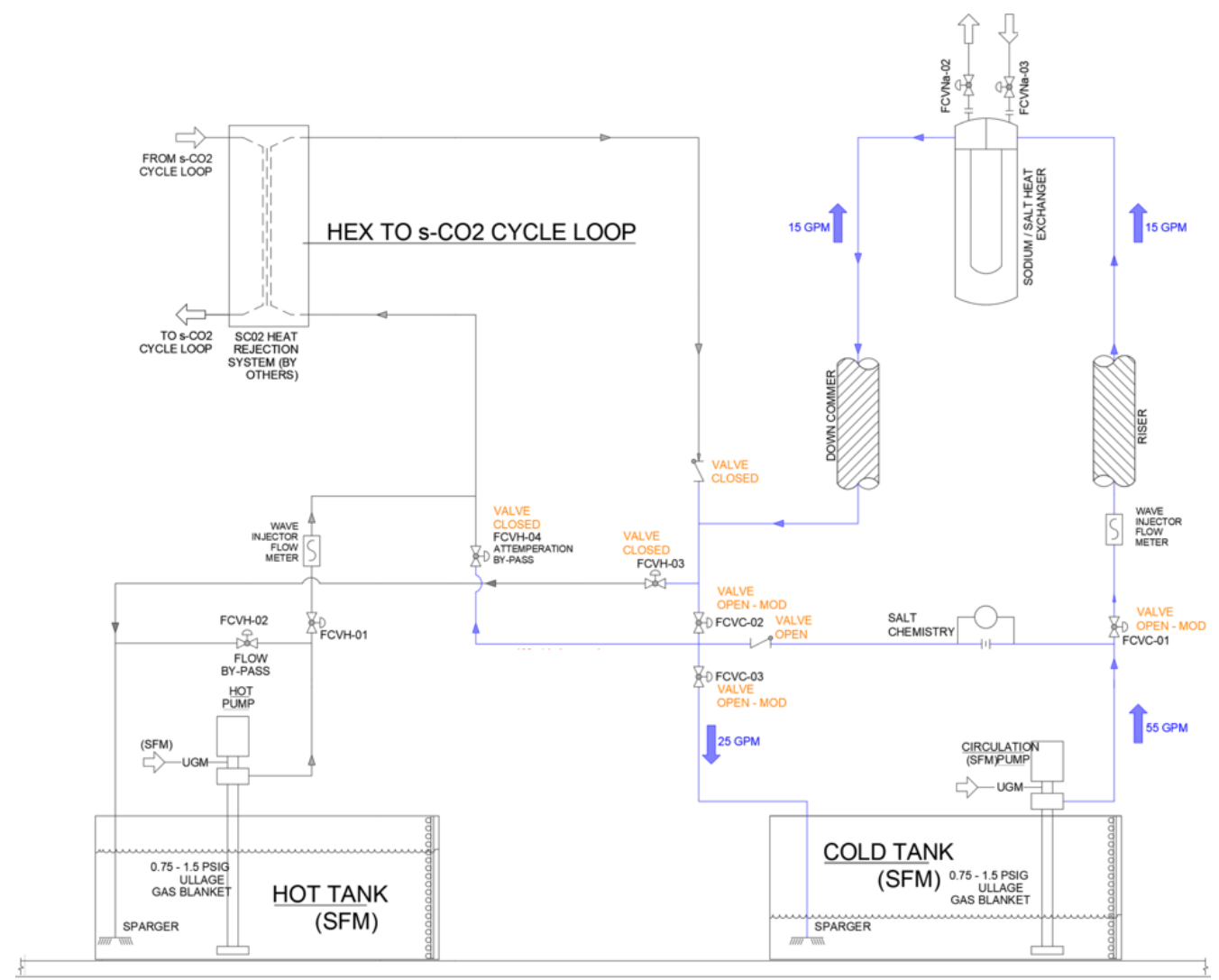

Figure 73. Molten salt flow to the preheated sodium/salt HEX is established. Cold salt returns to the cold salt tank. 
Charging: During the attemperation mode the sodium outlet temperature will be increased until the target outlet temperature of $740^{\circ} \mathrm{C}$ is reached. As the salt heats up, a temperature of approximately $650^{\circ} \mathrm{C}$ will trigger the diversion of the downcomer salt to the hot salt tank. At this point the system will be operated in a steady operational mode, which is expected to occur over a 4-6 hour period (+/- 3 hrs. from solar noon), which is based on the annual average period that a relatively steady flux can be put on to the NSTTF solar tower for any given heliostat configuration.

To achieve the receiver outlet temperature target under varying DNI conditions will require responsive operations to adjust temperatures, pressures and flow characteristics, in addition to heliostat flux. Within the tower BOS system, successful performance realization will require the team to facilitate fill and heating ramp profiles to bring the media temperatures to target levels while avoiding thermal shock conditions or large transient or spatial thermal gradients that could adversely affect the thermal transport system.

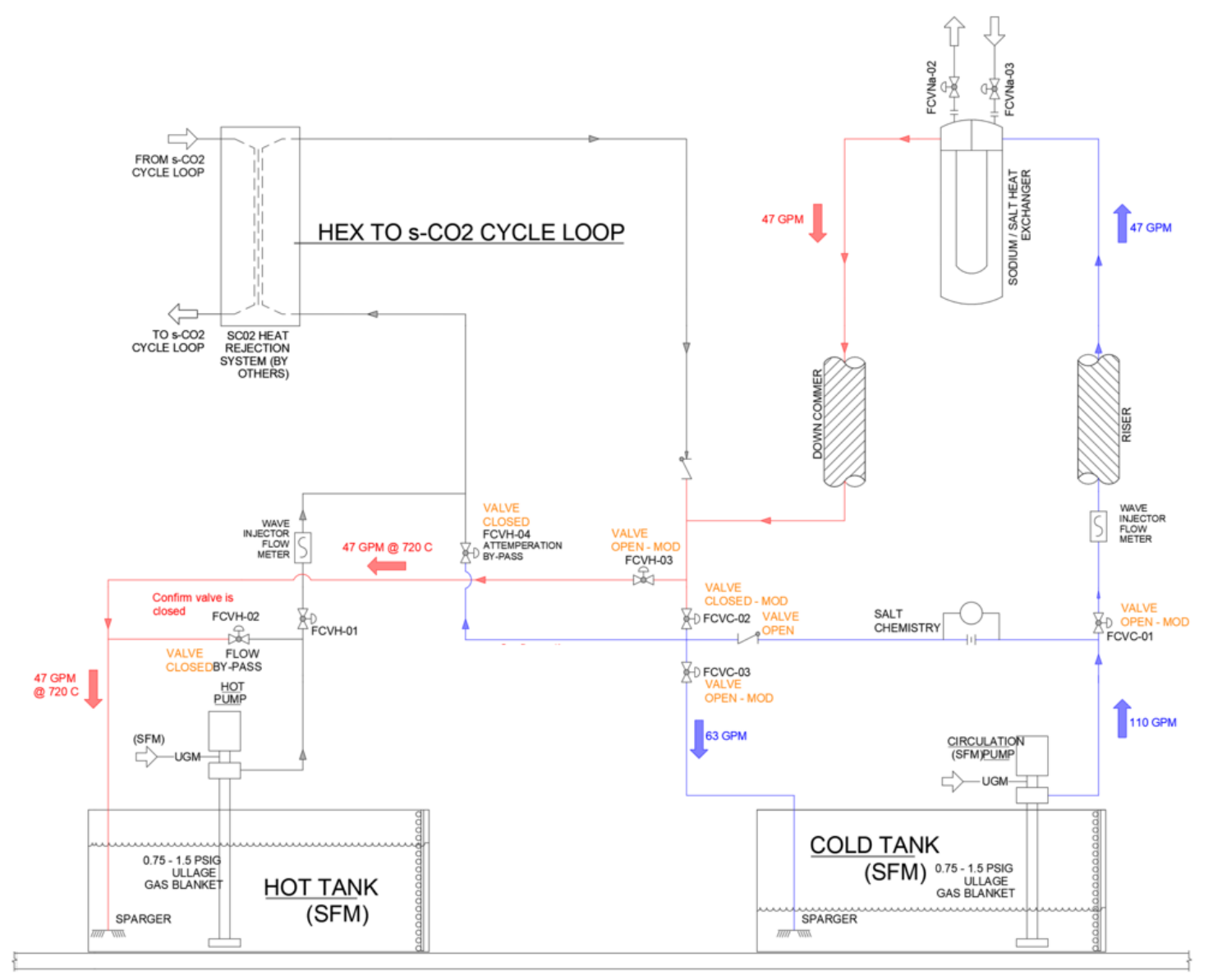

Figure 74. Molten-salt storage Charging operational mode diagram

Steady state operations that will be performed during the test campaign will primarily consist of charging and discharging processes. Each operational mode will be executed on separate days. For the charging operation, as shown in Figure $74,500^{\circ} \mathrm{C}$ cold salt will flow the sodium/salt $\mathrm{HEX}$ at a flow rate of $47 \mathrm{GPM}$, and return to the hot tank at $720^{\circ} \mathrm{C}$. During all salt pumping, a fraction of the salt recirculates immediately to the tank. This design promotes mixing in the tanks and allows for salt chemistry control and filtering on the cold salt loop. Furthermore, recirculation allows for testing a larger salt pump. 
During charging, the receiver, sodium/salt HEX and piping systems may experience dynamic conditions due to charging solar conditions. Rapid temperature changes in receiver outlet temperature arising from cloud transients will expose the sodium-salt heat exchanger to similarly rapid transient events. Responsiveness, controllability, and survivability under dynamic conditions are thus paramount to successful system performance. Sodium's good thermophysical properties mean that thermal transients will be rapidly conveyed to the sodium/salt HEX. Developing an understanding of ramping limits during startup and shutdown, developing control strategies during transient events, demonstrating the ability to control receiver outlet temperature, and demonstrating survivability of the receiver, piping, valves, and sodium-salt heat exchanger when exposed to characteristic solar ramp rates will derisk functionality of these key components under dynamic conditions. Testing is initially planned with simulated cloud events to provide a more controlled environment while gaining knowledge on the responsiveness of the system. Further testing will be performed during these dynamic conditions to evaluate overall system performance and operability.

PHX Attemperation and Discharging. During discharge operations the sodium loop is not in use and hot salt flows to the PHX. Prior to discharging hot salt through the PHX, a PHX attemperation mode is employed to avoid thermally shocking the PHX. This attemperation mode entails blending hot and cold salt to moderate the temperature sent to the PHX, Figure 75.

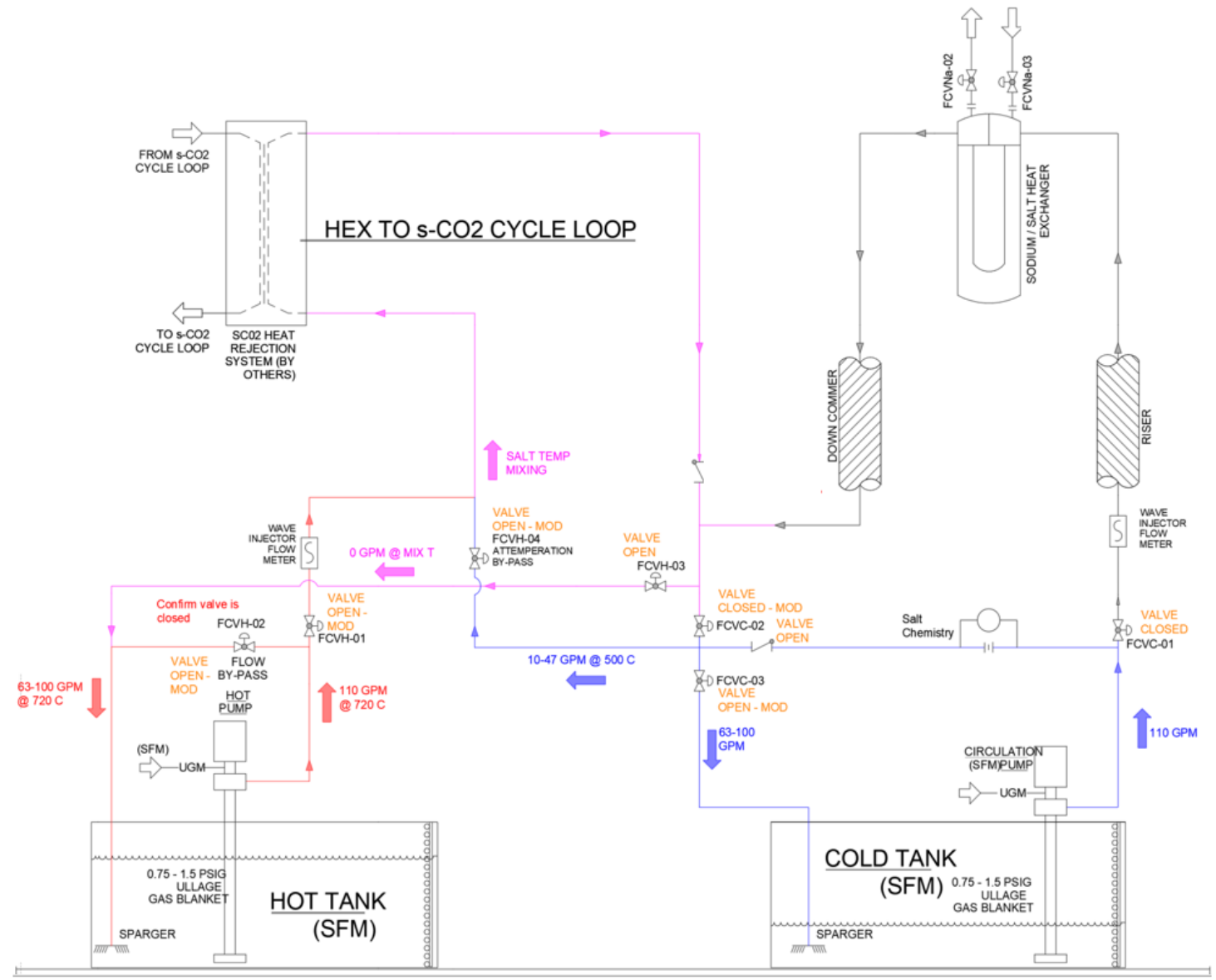

Figure 75. Molten salt PHX Attemperation operational mode diagram 
Once the hot tank/PHX thermal transport system and PHX reach a temperature of $720^{\circ} \mathrm{C}$, cold salt flow is returned to full recirculation at the cold tank and discharging operations continue at steady state, Figure 76. The PHX is designed for 1-MW th duty. During discharging, PHX outlet salt will pass to the cold tank at a rate of 47 GPM and a designed temperature of $500^{\circ} \mathrm{C}$.

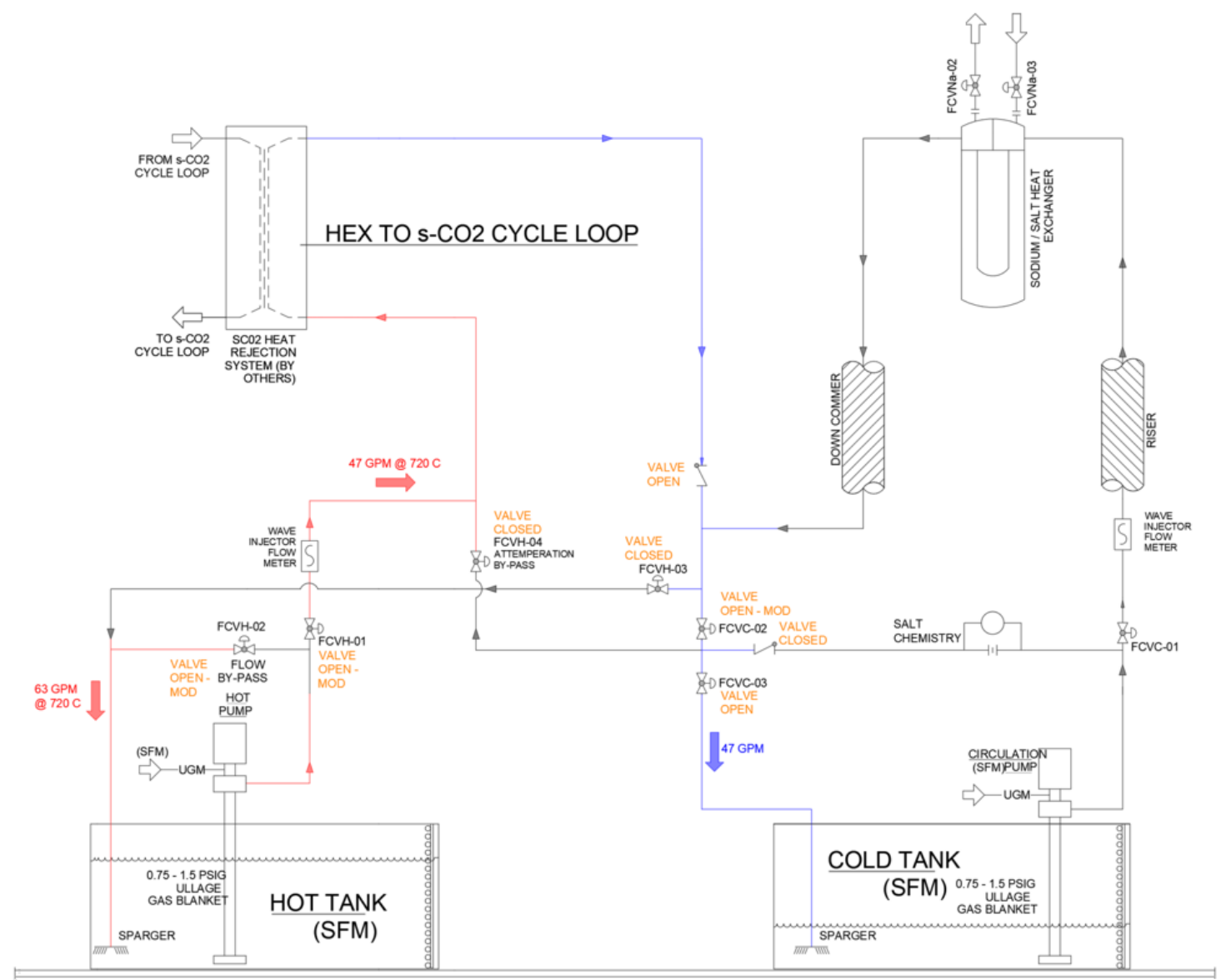

Figure 76. Molten salt Discharging operational mode diagram

Broad Operational Tests: For steady operations, broad test objectives for the sodium receiver system will be performed to demonstrate satisfactory operation of a sodium-cooled receiver panel over a wide range of power levels. Specific test goals that support these objectives are:

- Demonstrate near-steady control during insolation changes

- Control several panels in parallel

- Demonstrate panel dimensional stability

- Achieve representative lateral power distribution

- Demonstrate acceptable panel thermal losses

- Achieve a maximum number of diurnal thermal cycles

- Demonstrate satisfactory diurnal startup and shutdown

- Demonstrate satisfactory nocturnal thermal control.

\subsubsection{Task 5: Full BOS Demonstration}

Subtask 5.1: Operation \& durability of heat tracing. Thermal transport heat tracing is critical to avoid freezing and to recover from freeze events. Demonstration of appropriate heat tracing 
applications and durability of the heat tracing at high temperature conditions will provide confidence in the applicability for commercial-scale systems. The system is employing heat tape on the piping for cost reasons, but this approach is not believed to be viable for commercial plants, where the team recommends the use of ceramic fiber $(\mathrm{CF})$ heaters (see "Heat-trace options report, Milestone ST-1.3.2.1). CF heaters will also be employed in the pilot system only around valves and other irregular geometry locations. This task tracks the performance and reliability of these systems using TCs and IR thermography.

\section{Subtask 5.2: Fill, thermal ramp rates, drain-back operations \& quantify limits of steady} and dynamic performance. To achieve the project temperature targets above $700^{\circ} \mathrm{C}$ under varying solar conditions will require responsive operations to adjust temperatures, pressures and flow characteristics, in addition to heliostat flux. Within the tower BOS system, successful performance realization will require the team to facilitate fill and heating ramp profiles to bring the three fluid temperatures to target levels without facilitating thermal shock conditions or large transient or spatial thermal gradients that could adversely affect components within the thermal transport system. For the molten salt system, automation of heating controls will be important considering the large amount of thermal transport piping, fittings and valves. This operation will be coupled with the fill and steady operations of the sodium receiver within Task 4.

Subtask 5.3: Sodium and salt freeze recovery. The system involves two fluids (sodium and chloride salt) subject to freezing risks at different temperatures. While procedures have been developed for recovering from freeze events in nitrate salt and sodium systems, freeze events and freeze recovery with chloride salts and sodium-salt heat exchangers are not well understood. Salt's poor thermal conductivity, high freezing temperature, and large volume change on melting, all relative to sodium, indicate that salt freezing and freeze recovery will be the more challenging condition. Additionally, there are still a number of literature unknowns related to salt vapor plating and impacts of chloride salt volumetric expansion on piping and weldment stress. Developing thermal management strategies and procedures and quantifying allowable rates for recovering from freeze events at the pilot scale will prove that recovery from adverse freeze events is possible. Barring accidental freezing, these tests will carefully facilitate salt freeze/thaw events in a number of strategic locations within the system toward the end of the test regime.

Subtask 5.4: Response to and recovery from emergency conditions. In addition to salt and sodium freeze events, the team will perform other strategic emergency event operations to carefully drain-back the system during a simulated leak from various locations in and around the receiver and two heat exchangers. Emergency recovery from valve, heaters, pump heliostat failures are also expected to take place to build confidence for operational risk mitigation and recovery. Here, power outage or surge scenarios will be considered based on FMEA guidance during Phases $1 \& 2$ to assess subsystem/component heat loss and heating redundancies.

Subtask 5.5: Metallurgical evaluation. Corrosion and compatibility of nickel alloys with sodium at the hot-side temperature conditions are of concern for long-term survivability of the system. Incorporation of coupon sets and sacrificial loops in the hot-side and cold-side piping networks that can be removed, examined, and subjected to destructive testing at designated stages during the test campaign will permit metallurgical analysis of damage over time. This information can provide early warning of potential failures and can be used to verify material degradation models. 
Upon completion of test campaign, tube samples from each receiver straight-tube and tube-header, as well as other BOS thermal-transport interface sections will be subjected to metallurgical evaluation to assess alloy suitability and susceptibility to damage from erosion, corrosion, erosioncorrosion, fatigue, creep, creep-fatigue, species migration, stress corrosion cracking, etc. Post-test destructive testing will be used in conjunction with laboratory-scale testing to validate material degradation models and gain confidence in the ability to predict damage and degradation, and thereby to design components to a specified commercial-scale service life.

\subsection{Phase 3 Estimated Cost}

The pilot-system cost estimate was performed by B\&P in accordance with Sandia's Facilities Management and Operations Center (FMOC) Form \#FRM-017 Construction Estimating Workbook. Sandia FMOC owns and maintains this Excel-based spreadsheet. The project labor rates per trade are defined by Davis-Bacon Act and apply to all federal contractors and subcontractors that must pay their laborers and mechanics employed under the contract no less than the locally prevailing wages and fringe benefits. The minimum wages and benefits for Sandia are based on Union wages that are updated yearly by Sandia FMOC under separate tab in the spreadsheet. The CSI (Construction Specification Industry) column automatically activates the correct wage under the specific CSI number. The CSI system is written for general building construction; therefore, its applicability to power plant construction is difficult; hence the use sometimes of system titles which someone from the commercial power industry would question. Under our contract B\&P must follow Sandia FMOC estimate procedures.

Quantities used in the estimate are based on REVIT ${ }^{\mathrm{TM}}$ 3D computer generated drawing takeoffs used in the spreadsheet. The price of material and equipment is based on quotes from suppliers or manufacturers that our estimators have obtained. The time to install the material or equipment is based on Saylor Current Construction Costs 2019 that is an industry standard construction cost-estimating handbook. The various columns within the spreadsheet apply markups the contractor and sub-contractors will apply to a typical project at Sandia. Sandia FMOC is responsible for the multipliers - most critically the Sandia Facilities overhead rate - that vary with specific site conditions and project difficulty. It can be noted here that one of the other Topic 1 projects, the Particle Pathway, is located at Sandia and subject to the same process.

Site condition scaling factors inserted into the spreadsheet by our estimators are based on feedback from the various discipline lead engineers. The scaling factors address labor adjustments (current bidding climate), site conditions, work hours, crew density, working height, number of floors, job duration, accessibility, specialty tools and equipment required, Kirkland Air Force Base access (on which Sandia sits), remote site distance, property protection area, site access training, and on-going site testing. Some equipment—often project-specific items such as the PHX or salt pumps — are assumed Sandia Furnished Equipment or Material (SFE or SFM) due to the duration of deliverability. A separate column near the end of each line contains a column for such pricing, usually obtained from the project partner estimate. The final column in the spreadsheet has the final burden cost for each line. The FMOC spreadsheet is a controlled document and not supplied in the proposal package; the detailed cost estimate has been summarized in Table 31. The Total Project Cost of \$57.2 million significantly exceeds the \$25 million federal funding target set by the DOE program. The expected range for the pilot system cost is $\$ 52$ to $\$ 68$ million. This estimate is approximately double the $\$ 31.2$ million funding target set by the DOE program (federal share of $\$ 25$ million plus $20 \%$ minimum cost share). 
Table 31. Estimated costs for Phase 3 under the Liquid Pathway project. See also, Folder 02Calculations, Cost Calculations, Phase 3 Pilot System.

\begin{tabular}{|c|c|c|c|c|}
\hline \multicolumn{5}{|c|}{ MAJOR EQUIPMENT COST SUMMARY - 90\% SUBMITTAL } \\
\hline \multicolumn{5}{|c|}{ REV. DATE: 01/05/2021 } \\
\hline $\begin{array}{c}\text { CSI } \\
\text { Division }\end{array}$ & System Description & Sub-System Description [Source] & Burdened Costs & $\begin{array}{l}\text { Project } \\
\text { Quote }\end{array}$ \\
\hline $0100 \quad 00$ & General Conditions & & $\$ 5,051,832$ & $x$ \\
\hline 020000 & Debris Disposal \& Fees & & $\$ 5,620$ & \\
\hline $0300 \quad 00$ & Concrete & & $\$ 366,207$ & \\
\hline $05 \quad 00 \quad 00$ & Metals & & $\$ 537,090$ & $x$ \\
\hline 130000 & Special Construction & Elect Control Panel Hot Box & $\$ 103,967$ & $x$ \\
\hline 220505 & Demolition & Demo Pipes, tanks & $\$ 83,629$ & $x$ \\
\hline 220719 & Piping Heat Tape, CF Heaters & Includes Thermocouples & $\$ 653,913$ & $\mathrm{X}$ \\
\hline 220719 & Piping Insulation & & $\$ 749,576$ & $\mathrm{X}$ \\
\hline 221113 & Water Distribution System & Water, sanitary, Outdoor Eyewash & $\$ 300,650$ & $x$ \\
\hline 221113 & $\mathrm{HCl}$ Acid Scrubber/ Exh Fans & Water Treatment & $\$ 441,806$ & $\mathrm{X}$ \\
\hline 221123 & Molten Salt Pumps & Hot \& Cold Salt Pumps [Sulzer] & $\$ 926,345$ & $\mathrm{x}$ \\
\hline 221219 & Hot \& Cold Salt Tanks & Includes Foundation Heat Rejection [Job Ind.] & $\$ 2,130,265$ & $\mathrm{X}$ \\
\hline 221219 & Hot \& Cold Tank Lining & [JT Thorpe] & $\$ 1,013,844$ & $\mathrm{X}$ \\
\hline 221219 & Hot \& Cold Tank Preheat/Purge & [TEAM] & $\$ 143,263$ & $\mathrm{X}$ \\
\hline 232113 & Tank Imersion Heaters & & $\$ 103,335$ & $\mathrm{x}$ \\
\hline 221219 & Salt Melter \& Material & [Hatch] & $\$ 3,990,495$ & $\mathrm{x}$ \\
\hline 221219 & Primary Heat Exchanger & {$[\mathrm{VPE}]$} & $\$ 815,975$ & $x$ \\
\hline 221219 & Sodium Loop \& Scrubber & Piping to Roof Scrubber Included [ASTRI, CSIRO] & $\$ 2,561,750$ & $\mathrm{X}$ \\
\hline 221316 & Storm Water Drainage & & $\$ 37,391$ & $x$ \\
\hline 221519 & Compressed Air System & Compressor \& Piping & $\$ 68,563$ & $\mathrm{x}$ \\
\hline 221519 & Surge Tanks \& Dump Tanks & [Mesa Equipment] & $\$ 425,162$ & \\
\hline 226313 & Ullage Gas Piping System & LN2 Equipment Leased by SNL & $\$ 491,683$ & $\mathrm{x}$ \\
\hline 232113 & Salt Piping & & $\$ 714,974$ & $x$ \\
\hline 232113 & Ullage Gas Equalizer/Vent Pipe & & $\$ 422,541$ & $x$ \\
\hline 232113 & Misc. Piping Components & Check Valves, Filters, Filter baskets, O-Rings & $\$ 512,946$ & $\mathrm{x}$ \\
\hline 233113 & Hot Box A/C Unit & Ductwork, grilles, insulation included & $\$ 52,511$ & $x$ \\
\hline 253400 & Hot/Cold Salt Control Valves & 2 FCVC \& 5 FCVH Flow Control [Flowserve] & $\$ 2,377,888$ & $\mathrm{x}$ \\
\hline 253400 & Salt Flowmeters & [Krohne] & $\$ 167,835$ & $x$ \\
\hline 253400 & PLC Cabinets, Component, Software, & & $\$ 2,380,129$ & $x$ \\
\hline 253400 & \begin{tabular}{|l|l|} 
Heat Tape Controls & \\
\end{tabular} & & $\$ 524,000$ & $x$ \\
\hline 253400 & \multicolumn{2}{|c|}{ FCV CF Heater and Gas Barrier Control System Interface } & $\$ 614,923$ & $\mathrm{x}$ \\
\hline 253400 & \begin{tabular}{|l|l} 
Misc. Instrumentation & \\
\end{tabular} & & $\$ 1,664,845$ & \\
\hline 260505 & Electrical Demo & & $\$ 104,054$ & \\
\hline 260513 & Medium Voltage Cable & & $\$ 138,753$ & $\mathrm{x}$ \\
\hline 260519 & Low Voltage Conduit \& Cable & & $\$ 902,055$ & $\mathrm{x}$ \\
\hline 260526 & Grounding \& Bonding & & $\$ 47,187$ & $\mathrm{x}$ \\
\hline 260537 & Raceways \& Boxes & & $\$ 197,019$ & $\mathrm{x}$ \\
\hline 260553 & Wiring Connections & & $\$ 21,075$ & $x$ \\
\hline 261000 & Medium Voltage Transformer & & $\$ 155,317$ & $x$ \\
\hline 262200 & Low Voltage Distribution & & $\$ 545,109$ & $x$ \\
\hline 263000 & Electrical Power Storage & & $\$ 120,708$ & $x$ \\
\hline 265000 & Lighting \& Sensors & & $\$ 152,432$ & $x$ \\
\hline 310000 & Earthwork & & $\$ 53,521$ & $\mathrm{x}$ \\
\hline 320000 & Exterior Improvements & subgrade, basecourse, paving, bollards & $\$ 157,140$ & $\mathrm{x}$ \\
\hline \multirow[t]{19}{*}{$\begin{array}{llll}41 & 00 & 00\end{array}$} & Material Handling & Crane Rental & $\$ 512,862$ & $x$ \\
\hline & & & $\$ 33,542,185$ & \\
\hline & & Bond Cost at $2 \%$ & $\$ 670,844$ & \\
\hline & & Escalation Costs at $7.53 \%$ & $\$ 2,577,318$ & \\
\hline & & Sub Total (SFE + Constr Contracts) & $\$ 36,790,347$ & \\
\hline & Sub Total Estimate Range Low & $\$ 31,271,794$ & & \\
\hline & \multirow{2}{*}{\multicolumn{2}{|c|}{$\begin{array}{rr}\$ 4 /, 82 /, 450 \\
\text { Anticipated ECC Based on SNL Procedure FIN100.4.7 }\end{array}$}} & & \\
\hline & & & $\$ 36,790,347$ & \\
\hline & \multicolumn{2}{|c|}{ SNL Facilities/Procurement/Corp. Load Costs } & $\$ 13,034,812$ & \\
\hline & SNL Sandia Furnished Equipment (SFE) & \begin{tabular}{|r|}
$\$ 10,200,000$ \\
\end{tabular} & & \\
\hline & Construction Contracts Estimate & $\$ 26,590,347$ & & \\
\hline & \multirow{5}{*}{$\begin{array}{c}\text { Phase } 3 \text { Non-Construction Costs for } \\
\text { SNL NSTTF and NREL }\end{array}$} & SNL FMOC TOTAL PROJECT COST (TPC) & $\$ 49,825,158$ & \\
\hline & & Programmatic Commissioning Costs & $\$ 797,710$ & \\
\hline & & SNL Labor Operating Costs - Based on FTE & $\$ 3,770,860$ & \\
\hline & & SNL Phase 3 Materials/Utilities Operating & $\$ 1,329,517$ & \\
\hline & & NREL Phase 3 Costs (incls ASTRI support) & $\$ 1,511,930$ & \\
\hline & & TOTAL PROJECT COSTS & $\$ 57,200,000$ & \\
\hline & & SNL FMOC TPC (Low) + Non-Constr & $\$ 51,700,000$ & \\
\hline & & SNL FMOC TPC (Pessimitic) + Non-Constr & $\$ 68,300,000$ & \\
\hline
\end{tabular}




\section{Appendix: Document Reference Table}

Supporting documents for the Liquid Pathway proposal are referenced in Table 32 below. Throughout the report this table is referenced to provide the reader with additional information on specific topics.

Table 32. Reference table for $90 \%$ Design Package documents

\begin{tabular}{|c|c|c|c|c|}
\hline $\begin{array}{l}\text { Main Folder } \\
\text { Title }\end{array}$ & Sub-Folder Title & Document or Sub-Folders Title & $\begin{array}{l}\text { Page } \\
\text { Count }\end{array}$ & $\begin{array}{l}\text { Revision } \\
\text { Date }\end{array}$ \\
\hline \multirow{15}{*}{$\begin{array}{l}01 \text { Basis of } \\
\text { Design }\end{array}$} & $\begin{array}{l}\text { Design Analysis - } \\
\text { Phase } 2\end{array}$ & & 30 & $12 / 15 / 20$ \\
\hline & & Codes \& Standards & & \\
\hline & & Integrated Safety Management System & & \\
\hline & & Pipe Code Analysis & & \\
\hline & & Existing Systems & & \\
\hline & & Civil & & \\
\hline & & Structural & & \\
\hline & & Mechanical & & \\
\hline & & Electrical & & \\
\hline & & Modifications & & \\
\hline & & General & & \\
\hline & & Civil & & \\
\hline & & Structural & & \\
\hline & & Mechanical & & \\
\hline & & Electrical & & \\
\hline \multirow{5}{*}{$\begin{array}{l}02 \\
\text { Calculations }\end{array}$} & $\begin{array}{l}\text { Structural } \\
\text { Calculations }\end{array}$ & & 339 & $12 / 20$ \\
\hline & $\begin{array}{l}\text { Piping Stress } \\
\text { Analysis }\end{array}$ & & 204 & $12 / 09 / 20$ \\
\hline & $\begin{array}{l}\text { Mechanical } \\
\text { Calculations }\end{array}$ & & 572 & $12 / 15 / 20$ \\
\hline & $\begin{array}{l}\text { Electrical } \\
\text { Calculations }\end{array}$ & & 2 & $12 / 15 / 20$ \\
\hline & Cost Calculations & Various supporting spreadsheets & & \\
\hline \multirow{6}{*}{$\begin{array}{l}03 \\
\text { Specifications }\end{array}$} & Div. 01 - General & 01065 ESH for Construction Contracts & 55 & $10 / 14 / 19$ \\
\hline & & $\begin{array}{l}\text { 01065A Attachment A Rescue of Personnel in } \\
\text { Confined Spaces }\end{array}$ & 3 & $4 / 18 / 16$ \\
\hline & & 01065S ESH of Service Contracts & 26 & $4 / 18 / 16$ \\
\hline & & $\begin{array}{l}01453 \text { Construction Inspection Report } \\
\text { Requirements }\end{array}$ & 5 & $4 / 18 / 16$ \\
\hline & & 01505 Construction Waste Management & 12 & $12 / 17 / 19$ \\
\hline & & 01505A SWCRC Guidance Document & 4 & $4 / 18 / 16$ \\
\hline
\end{tabular}




\begin{tabular}{|c|c|c|c|c|}
\hline $\begin{array}{l}\text { Main Folder } \\
\text { Title }\end{array}$ & Sub-Folder Title & Document or Sub-Folders Title & $\begin{array}{l}\text { Page } \\
\text { Count }\end{array}$ & $\begin{array}{l}\text { Revision } \\
\text { Date } \\
\end{array}$ \\
\hline & & 01505B Waste Management Plan Template & 3 & $4 / 18 / 16$ \\
\hline & & $\begin{array}{l}01701 \text { Subgrade Utilities As-built } \\
\text { Requirements }\end{array}$ & 8 & $5 / 31 / 16$ \\
\hline & & 013216 Contractor's Project Schedule & 13 & $2 / 15 / 20$ \\
\hline & & 013300 Submittal Procedures & 13 & $2 / 01 / 17$ \\
\hline & & 015726 Dust Control & 5 & $7 / 25 / 19$ \\
\hline & & 017719 Contract Closeout & 7 & $11 / 20 / 19$ \\
\hline & & 01810S Commissioning & 16 & $12 / 15 / 20$ \\
\hline & & Preliminary Prefunctional Tests & 180 & $11 / 02 / 20$ \\
\hline & & Preliminary Functional Performance Testing & 47 & $9 / 21 / 20$ \\
\hline & Div. 03 -Concrete & & & \\
\hline & & 033000S Cast in Place Concrete & 30 & $3 / 05 / 18$ \\
\hline & & 312000 Earthwork & 21 & $2 / 19 / 18$ \\
\hline & & 316329S Drilled Concrete Piers & 4 & $10 / 28 / 20$ \\
\hline & & $\begin{array}{l}321123.10 \text { Aggregate Base Courses for } \\
\text { Under Pavements }\end{array}$ & 11 & 2/19/18 \\
\hline & & 321216.01 Paving Asphalt Binder & 9 & 2/19/18 \\
\hline & & 321216.02 Asphalt Concrete Material & 21 & 2/19/18 \\
\hline & & 321216.03 Asphalt Concrete Installation & 17 & 2/19/18 \\
\hline & Div. 05- Metals & & & \\
\hline & & 051200 Structural Steel Framing & 15 & $8 / 07 / 17$ \\
\hline & & 053100 Steel Decking & 9 & $3 / 27 / 17$ \\
\hline & & 054000 Cold Formed Metal Framing & 10 & $5 / 01 / 19$ \\
\hline & & 055000 Metal Fabrications & 17 & $5 / 02 / 19$ \\
\hline & Div. 09 - Finishes & & & \\
\hline & & 099000 Painting & 20 & $8 / 15 / 17$ \\
\hline & Div. 22 - Plumbing & & & \\
\hline & & 220719 Plumbing Piping Insulation & 34 & 2/08/19 \\
\hline & & $\begin{array}{l}221513 \text { General Service Compressed Air } \\
\text { Piping }\end{array}$ & 18 & $3 / 22 / 19$ \\
\hline & & $\begin{array}{l}221519 \text { General Service Packaged Air } \\
\text { Compressors and Receivers }\end{array}$ & 14 & 2/19/18 \\
\hline & & 223000 Plumbing & 21 & $12 / 10 / 19$ \\
\hline & & 226313 Gas Piping for Laboratory Facilities & 11 & $8 / 22 / 19$ \\
\hline & $\begin{array}{l}\text { Div. } 23 \text { - Process } \\
\text { Piping Systems }\end{array}$ & & & \\
\hline
\end{tabular}




\begin{tabular}{|c|c|c|c|c|}
\hline $\begin{array}{l}\text { Main Folder } \\
\text { Title }\end{array}$ & Sub-Folder Title & Document or Sub-Folders Title & $\begin{array}{l}\text { Page } \\
\text { Count }\end{array}$ & $\begin{array}{l}\text { Revision } \\
\text { Date }\end{array}$ \\
\hline & & $\begin{array}{l}230050 \text { Basic Mechanical Materials and } \\
\text { Methods }\end{array}$ & 17 & $1 / 03 / 19$ \\
\hline & & $\begin{array}{l}\text { 230533S - Piping, Equipment and Gas } \\
\text { Heating Systems - Special Specification }\end{array}$ & 14 & $12 / 15 / 20$ \\
\hline & & 230548 Vibration and Limit Control & 8 & $4 / 18 / 16$ \\
\hline & & 230593 Test, Adjust and Balance for HVAC & 36 & $12 / 13 / 17$ \\
\hline & & $\begin{array}{l}230594 \text { System Component Checkout and } \\
\text { Balance }\end{array}$ & 5 & $4 / 18 / 16$ \\
\hline & & 230595 Mechanical Systems Demonstrations & 4 & $4 / 18 / 16$ \\
\hline & & $\begin{array}{l}230719 \text { Piping Insulation - Special } \\
\text { Specification }\end{array}$ & 46 & $12 / 15 / 20$ \\
\hline & & 232113 Hydronic Piping & 29 & $3 / 22 / 19$ \\
\hline & & $\begin{array}{l}232124 \text { Molten Salt Pumps - Special } \\
\text { Specification }\end{array}$ & 30 & $12 / 15 / 20$ \\
\hline & & $\begin{array}{l}\text { 232125S Molten Salt Piping Systems - } \\
\text { Special Specification }\end{array}$ & 22 & $12 / 15 / 20$ \\
\hline & & $\begin{array}{l}232500 \text { Chemical Treatment for Hydronic } \\
\text { Systems }\end{array}$ & 10 & $10 / 19 / 18$ \\
\hline & & 233113 Metal Ducts & 26 & $2 / 19 / 20$ \\
\hline & & 233300 Air Duct Accessories & 23 & $6 / 08 / 20$ \\
\hline & $\begin{array}{l}\text { Div. } 25- \\
\text { Instrumentation \& } \\
\text { Controls }\end{array}$ & & & \\
\hline & & $\begin{array}{l}\text { 257001S Process Equipment Control System } \\
\text { - Special Specification }\end{array}$ & 46 & $12 / 15 / 20$ \\
\hline & & $\begin{array}{l}\text { 250523S - Molten Salt Valves - Special } \\
\text { Specification }\end{array}$ & 8 & $12 / 15 / 20$ \\
\hline & Div. 26 - Electrical & & & \\
\hline & & $\begin{array}{l}260475 \text { Primary Systems Safety } \\
\text { Requirements }\end{array}$ & 11 & $4 / 18 / 16$ \\
\hline & & 260513 Medium Voltage Cables & 29 & $6 / 11 / 19$ \\
\hline & & $\begin{array}{l}260519 \text { Low Voltage Electrical Power } \\
\text { Conductors and Cables }\end{array}$ & 10 & $3 / 22 / 18$ \\
\hline & & $\begin{array}{l}260526 \text { Grounding and Bonding for Electrical } \\
\text { Systems }\end{array}$ & 9 & $3 / 22 / 18$ \\
\hline & & $\begin{array}{l}260529 \text { Hangers and Supports for Electrical } \\
\text { Systems }\end{array}$ & 7 & $3 / 21 / 18$ \\
\hline & & $\begin{array}{l}260533 \text { Raceways and Boxes for Electrical } \\
\text { Systems }\end{array}$ & 14 & $3 / 15 / 18$ \\
\hline & & $\begin{array}{l}260543 \text { Underground Ducts and Raceways } \\
\text { for Electrical Systems }\end{array}$ & 18 & $5 / 08 / 18$ \\
\hline & & $\begin{array}{l}260574 \text { Overcurrent Protective Device Arc- } \\
\text { Flash Study }\end{array}$ & 4 & $4 / 22 / 16$ \\
\hline
\end{tabular}




\begin{tabular}{|c|c|c|c|c|}
\hline $\begin{array}{l}\text { Main Folder } \\
\text { Title }\end{array}$ & Sub-Folder Title & Document or Sub-Folders Title & $\begin{array}{l}\text { Page } \\
\text { Count }\end{array}$ & $\begin{array}{l}\text { Revision } \\
\text { Date }\end{array}$ \\
\hline & & 260620 Schedule for LV Electrical Distribution & 7 & $4 / 22 / 16$ \\
\hline & & 261200 Medium Voltage Transformers & 18 & $4 / 18 / 16$ \\
\hline & & 261300 Medium-Voltage Switchgear & 9 & $4 / 18 / 16$ \\
\hline & & 262200 Low-Voltage Transformers & 9 & $4 / 03 / 18$ \\
\hline & & 262412 Switchboards Service Entrance & 11 & $4 / 18 / 16$ \\
\hline & & 262416 Panelboards & 11 & $4 / 18 / 16$ \\
\hline & & 262726 Wiring Devices & 13 & $12 / 11 / 18$ \\
\hline & & $\begin{array}{l}262816 \text { Enclosed Switches and Circuit } \\
\text { Breakers }\end{array}$ & 11 & $9 / 07 / 18$ \\
\hline & & 262913 Enclosed Controllers & 15 & $1 / 08 / 19$ \\
\hline & & 262923 Variable Frequency Motor Controller & 14 & 2/07/19 \\
\hline & & $\begin{array}{l}\text { 263353S - Static Uninterruptible Power } \\
\text { Supply - Special Specification }\end{array}$ & 10 & $5 / 21 / 19$ \\
\hline & & $\begin{array}{l}264313 \text { Surge Protective Devices for Low- } \\
\text { Voltage Electrical Power Circuits }\end{array}$ & 9 & $12 / 19 / 18$ \\
\hline & & 265600 Exterior Lighting & 16 & $11 / 20 / 19$ \\
\hline & & 263600 Transfer Switch & 11 & $1 / 08 / 19$ \\
\hline & Div. 32 - Exterior & & & \\
\hline & & 312000 Earthwork & 21 & 2/19/18 \\
\hline & & $\begin{array}{l}\text { 321123.10 Aggregate Base Courses for } \\
\text { Under Pavements }\end{array}$ & 11 & $2 / 19 / 18$ \\
\hline & & 321216.01 Paving Asphalt Binder & 9 & 2/19/18 \\
\hline & & 321216.02 Asphalt Concrete Material & 21 & $2 / 19 / 18$ \\
\hline & & 321216.03 Asphalt Concrete Installation & 17 & 2/19/18 \\
\hline \multirow{11}{*}{04 Drawings } & & Logic Diagrams 90Perc Submittal & & \\
\hline & 3D Renderings & CAD imagery of pilot-scale system design & & \\
\hline & \multirow{8}{*}{$\begin{array}{l}\text { SNL Gen } 3 \text { Liquid } \\
\text { Pathway } 90 \text { percent } \\
\text { Drawings }\end{array}$} & General Sheets Drawing Sequence 1 - 10 & 10 & $12 / 15 / 20$ \\
\hline & & Civil Drawing Sequence $11-12$ & 2 & $12 / 15 / 20$ \\
\hline & & Structural Drawing Sequence 13 - 27 & 15 & $12 / 15 / 20$ \\
\hline & & Plumbing Drawing Sequence 28 - 31 & 4 & $12 / 15 / 20$ \\
\hline & & Mechanical Drawing Sequence 32 - 49 & 18 & $12 / 15 / 20$ \\
\hline & & Process Piping Drawing Sequence 50 - 119 & 70 & $12 / 15 / 20$ \\
\hline & & $\begin{array}{l}\text { Process Instrumentation Drawing Sequence } \\
120-155\end{array}$ & 36 & $12 / 15 / 20$ \\
\hline & & Electrical Drawing Sequence 156 - 183 & 28 & $12 / 15 / 20$ \\
\hline & $\begin{array}{l}\text { Sodium Receiver } \\
\text { System }\end{array}$ & & & \\
\hline \multirow{2}{*}{$\begin{array}{l}05 \\
\text { Descriptive } \\
\text { Submittal List } \\
\text { (DSL) }\end{array}$} & & & & \\
\hline & $\begin{array}{l}\text { Structural, } \\
\text { Mechanical, } \\
\text { Electrical }\end{array}$ & & 1 & $12 / 15 / 20$ \\
\hline
\end{tabular}




\begin{tabular}{|c|c|c|c|c|}
\hline $\begin{array}{l}\text { Main Folder } \\
\text { Title }\end{array}$ & Sub-Folder Title & Document or Sub-Folders Title & $\begin{array}{l}\text { Page } \\
\text { Count }\end{array}$ & $\begin{array}{l}\text { Revision } \\
\text { Date }\end{array}$ \\
\hline $\begin{array}{l}06 \text { Uniform } \\
\text { Construction } \\
\text { Package }\end{array}$ & $\begin{array}{l}\text { Uniform } \\
\text { Construction } \\
\text { Package (UPC) }\end{array}$ & & 15 & $12 / 15 / 20$ \\
\hline \multirow{2}{*}{$\begin{array}{l}07 \text { Master } \\
\text { Equipment } \\
\text { List }\end{array}$} & $\begin{array}{l}\text { FMOC B9980 } \\
\text { Master Equipment } \\
\text { List (MEL) }\end{array}$ & & 1 & $12 / 15 / 20$ \\
\hline & $\begin{array}{l}\text { Design Submittal } \\
\text { Equipment List }\end{array}$ & & 3 & $12 / 15 / 20$ \\
\hline 09 FandOR & $\begin{array}{l}\text { Functional \& } \\
\text { Operational } \\
\text { Requirements }\end{array}$ & & 30 & $12 / 15 / 20$ \\
\hline $\begin{array}{l}11 \text { Panel } \\
\text { Schedules }\end{array}$ & Electrical & & & $12 / 15 / 20$ \\
\hline \multirow{7}{*}{$\begin{array}{l}12 \text { Project } \\
\text { Reports }\end{array}$} & $\begin{array}{l}\text { Liquid Pathway } \\
\text { Milestone reports }\end{array}$ & & & \\
\hline & $\mathrm{PHX}$ & $\begin{array}{l}\text { PCHE specification sheets and summary } \\
\text { report }\end{array}$ & & \\
\hline & Salt Melter & Hatch contract reports & & \\
\hline & Salt Pumps & Sulzer, Flowserve pump quotes and data & & \\
\hline & Salt Receiver & Nooter-Eriksen report. See also [92] & & \\
\hline & Salt Tanks & Job and JT Thorpe reports & & \\
\hline & Salt Valves & $\begin{array}{l}\text { Gosco ball valve, FASTR globe valve design, } \\
\text { Advanced Molten Salt Valve project reports }\end{array}$ & & \\
\hline $\begin{array}{l}13 \text { Sodium } \\
\text { Subsystem }\end{array}$ & & $\begin{array}{l}\text { Functional Specifications } \\
\text { ASTRI Sodium Materials } \\
\text { Sodium receiver design report and drawings }\end{array}$ & & \\
\hline \multicolumn{5}{|l|}{$\begin{array}{l}14 \mathrm{sCO}_{2} \\
\text { Subsystem }\end{array}$} \\
\hline $\begin{array}{l}15 \text { Safety } \\
\text { and } \\
\text { Permitting } \\
\text { Docs }\end{array}$ & & $\begin{array}{l}\text { Phase } 1 \text { Risk Registry, Phase } 2 \text { Risk Registry } \\
\text { (FMEA), Primary Hazard Screening (PHS), } \\
\text { NEPA, Air Force Form 813, Sodium Safety } \\
\text { Protocols for CSP, Preliminary Pressure } \\
\text { System Data Package, Biological Evaluation, } \\
\text { Historic Cultural Inventory }\end{array}$ & & \\
\hline
\end{tabular}




\section{References}

[1] M. Mehos, C. Turchi, J. Vidal, M. Wagner, and Z. Ma, "Concentrating Solar Power Gen3 Demonstration Roadmap," National Renewable Energy Laboratory, Technical Report NREL/TP5500-67464, 2017.

[2] DOE, "Generation 3 Concentrating Solar Power Systems, Funding Opportunity Announcement (FOA) Number: DE-FOA-0001697.” U.S. Department of Energy, Sep. 11, 2017.

[3] C. S. Turchi, C. Libby, J. Pye, and J. Coventry, "Molten Salt vs. Liquid Sodium Receiver Selection Using the Analytic Hierarchy Process," presented at the SolarPACES 2020, Albuquerque, New Mexico, Oct. 2020.

[4] H. Price, "Dispatchable Solar Power: Adapting CSP to modern grid needs," presented at the SolarPaces 2017, 2017. Accessed: Sep. 27, 2018. [Online]. Available: http://www.solarpaces.org/wp-content/uploads/Hank-Price-Presentation.pdf

[5] H. Tang and J. Hensel, "High Toughness Cermets for Molten Salt Pumps," Powdermet Inc., Final Technical Report DE-FOA0001619. [Online]. Available: https://doi.org/10.2172/1456875

[6] E. Vogli, "Liquid Metals Coatings, Novel Corrosion and Erosion Resistant Amorphous Alloy Coatings," Jul. 2019.

[7] "Markets for Concentrating Solar Power: International Perspectives," EPRI, Palo Alto, CA, 3002019879, 2020.

[8] D. Wait, "Development of $800^{\circ} \mathrm{C}$ Integrated Flow Channel Receiver," Final Technical Report for Award DE-EE0007113, 2018.

[9] M. Mehos et al., "Concentrating Solar Power Best Practices Study," National Renewable Energy Laboratory, NREL/TP-5500-75763, 2020.

[10] T. Neises and C. Turchi, "Supercritical carbon dioxide power cycle design and configuration optimization to minimize levelized cost of energy of molten salt power towers operating at $650{ }^{\circ}$ C, Sol. Energy, vol. 181, pp. 27-36, Mar. 2019, doi:

https://doi.org/10.1016/j.solener.2019.01.078.

[11] N. Weiland and D. Thimsen, "A practical look at assumptions and constraints for steady state modeling of sCO2 Brayton power cycles," presented at the 5th International SymposiumSupercritical CO2 Power Cycles, 2016.

[12] C. S. Turchi, Z. Ma, T. W. Neises, and M. J. Wagner, "Thermodynamic Study of Advanced Supercritical Carbon Dioxide Power Cycles for Concentrating Solar Power Systems," J. Sol. Energy Eng., vol. 135, no. 4, 2013, doi: 10.1115/1.4024030.

[13] J. J. Dyreby, "Modeling the Supercritical Carbon Dioxide Brayton Cycle with Recompression," Ph.D., The University of Wisconsin - Madison, Ann Arbor, 2014. 
[14] S. A. Wright, R. F. Radel, M. E. Vernon, G. E. Rochau, and P. S. Pickard, "Operation and analysis of a supercritical CO2 Brayton cycle," Sandia Rep. SAND2010-0171, pp. 1-101, 2010.

[15] A. T. Louis and T. Neises, "Analysis and Optimization for Off-Design performance of the recompression s-CO2 cycles for high temperature CSP applications," presented at the The 5th International Symposium-Supercritical CO2 Power Cycles, 2016.

[16] M. A. Oliver and R. Webster, "Kriging: a method of interpolation for geographical information systems," Int. J. Geogr. Inf. Syst., vol. 4, no. 3, pp. 313-332, 1990.

[17] C. Murphy, Y. Sun, W. Cole, G. Maclaurin, C. Turchi, and M. Mehos, "The Potential Role of Concentrating Solar Power within the Context of DOE's 2030 Solar Cost Targets," Renew. Energy, p. 137, 2019.

[18] B. Kelly, "Advanced Thermal Storage for Central Receivers with Supercritical Coolants," 08GO18149, Jun. 2010. Accessed: Oct. 10, 2018. [Online]. Available: https://www.osti.gov/servlets/purl/981926

[19] G. Weinrebe, F. von Reeken, M. Wöhrbach, T. Plaz, V. Göcke, and M. Balz, "Towards Holistic Power Tower System Optimization," Energy Procedia, vol. 49, pp. 1573-1581, Jan. 2014, doi: https://doi.org/10.1016/j.egypro.2014.03.166.

[20] A. K. Burghartz, F. v. Reeken, and M. Balz, "Economic evaluation of towers for central receiver systems," in AIP Conference Proceedings, 2018, vol. 2033:090004.

[21] A. K. Burghartz, "Investigation of selected tower construction methods for solar power plants under consideration of the receiver mounting," Technical University of Berlin, 2016.

[22] J. H. Peterseim, S. White, and U. Hellwig, "Novel solar tower structure to lower plant cost and construction risk," in AIP Conference Proceedings, 2016, vol. 1734:070025.

[23] E. J. Lantz, J. O. Roberts, J. Nunemaker, E. Demeo, K. L. Dykes, and G. N. Scott, "Increasing Wind Turbine Tower Heights: Opportunities and Challenges," National Renewable Energy Laboratory, NREL/TP-5000-73629, 2019.

[24] Adrien Farinelle, "Conception and design of a solar receiver working with sodium as heat transfer fluid," Universidad de Zaragoza (project hosted by Cockerill Maintenance \& Ingénierie), 2016.

[25] S. Guccione, "Design and Optimization of a Sodium-Molten Salt Heat Exchanger for Concentrating Solar Power applications," Student thesis, 2020.

[26] P. Humphreys, "Weigh the benefits of on-site nitrogen generation," Plant Engineering. [Online]. Available: https://www.plantengineering.com/articles/weigh-the-benefits-of-on-sitenitrogen-generation/ 
[27] Y. Zhao and J. Vidal, "Potential scalability of a cost-effective purification method for

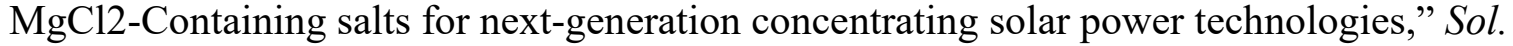
Energy Mater. Sol. Cells, vol. 215, p. 110663, Sep. 2020, doi: 10.1016/j.solmat.2020.110663.

[28] X. Xu and et al., "Experimental Test of Properties of $\mathrm{KCl}-\mathrm{MgCl} 2$ Eutectic Molten Salt for Heat Transfer and Thermal Storage Fluid in Concentrated Solar Power Systems," J. Sol. Energy Eng., 2018.

[29] X. Wang, J. Del Rincon, P. Li, Y. Zhao, and J. Vidal, "Thermophysical properties experimentally tested for $\mathrm{NaCl}-\mathrm{KCl}-\mathrm{MgCl} 2$ eutectic molten salt as a next generation high temperature HTF in CSP systems," J. Solar Energy Engg.

[30] N. Hoyt, "Molten Salt Material Compatibility Research at Argonne National Laboratory," presented at the Molten Salt Reactor Workshop, Oct. 14, 2020.

[31] “ASME B31.1 Power Piping.” American Society of Mechanical Engineers, 2018.

[32] M. Jonemann, "Advanced Thermal Storage System with Novel Molten Salt: December 8, 2011 - April 30, 2013,” 2013, doi: 10.2172/1080117.

[33] G. Shekhovtsov, V. Shchegolev, V. Devyatkin, A. Tatakin, and I. Zabelin, "Magnesium Electrolytic Production Process," in Essential Readings in Magnesium Technology, S. N. Mathaudhu, A. A. Luo, N. R. Neelameggham, E. A. Nyberg, and W. H. Sillekens, Eds. Cham: Springer International Publishing, 2016, pp. 97-100. doi: 10.1007/978-3-319-48099-2_15.

[34] "Volume I - Molten Salt Thermal Energy Storage Subsystem Research Experiment," Sandia National Laboratories, Albuquerque, NM, USA, SAND80-8192, May 1985.

[35] S. Gage, "Technical and Economic Feasibility of Molten Chloride Salt Thermal Energy Storage Systems," presented at the SolarPACES 2020, 2020.

[36] Z. F. Wang, M. J. Chen, Y. Ma, H. Liu, C. H. Han, and X. T. Wang, "Low-temperature molten salt synthesis of forsterite powders with controllable morphology," Int. J. Appl. Ceram. Technol., vol. 14, no. 1, pp. 3-8, 2017, doi: 10.1111/ijac.12574.

[37] "Piping, Stationary Seals, and Gasketing," in Pump Wisdom, John Wiley \& Sons, Ltd, 2011, pp. 35-48. doi: 10.1002/9781118056745.ch4.

[38] W. Ding, A. Bonk, and T. Bauer, "Corrosion behavior of metallic alloys in molten chloride salts for thermal energy storage in concentrated solar power plants: A review," p. 14.

[39] P. Sabharwall and et al., "Molten Salts for High Temperature Reactors: University of Wisconsin Molten Salt Corrosion and Flow Loop Experiments -- Issues Identified and Path Forward," Idaho National Laboratory, INL/EXT-10-18090, Mar. 2010.

[40] J. E. Pacheco, "Final Test and Evaluation Results from the Solar Two Project," Sandia National Laboratories, SAND2002-0120, 2002. 
[41] D. Gill and B. Farley, "Improving a Valve Packing Model to Increase Packing Lifetime in Molten Salt," presented at the ASME International Conference on Energy Sustainability, Minneapolis, MN, USA, 2013. [Online]. Available: http://dx.doi.org/10.1051/jp4:1999314

[42] D. C. Smith, E. E. Rush, C. W. Matthews, J. M. Chavez, and P. A. Bator, "Report on the Test of the Molten-Salt Pump and Valve Loop," Sandia National Laboratories, SAND91-1747, Feb. 1992.

[43] H. Ohshima and S. Kubo, "Sodium-cooled fast reactor," in Handbook of Generation IV Nuclear Reactors, Woodhead Publishing, 2016, pp. 97-118.

[44] R. P. Anantatmula, "Occurrence and prediction of sigma phase in fuel cladding alloys for breeder reactors,” J. Nucl. Mater., vol. 125, no. 2, pp. 170-181, 1984.

[45] T. Suzuki and et al., "Sodium Corrosion Behavior of Austenitic Alloys and Selective Dissolution of Chromium and Nickel," J. Nucl. Mater., vol. 139, pp. 97-105.

[46] S. Shiels, C. Bagnall, A. Keeton, R. Witkowski, and R. P. Anantatmula, "Characterization of the sodium corrosion behavior of commercial austenitic steels," presented at the 2nd Intern. Conf. on Liquid Metal Technology in Energy Production, Apr. 1980.

[47] T. Furukawa, S. Kato, and E. Yoshida, "Compatibility of FBR materials with sodium," J. Nucl. Mater., vol. 392, no. 2, pp. 249-254, 2009.

[48] G. Y. Lai, "Chapter 16: Liquid Metal Corrosion and Embrittlement," in HighTemperature Corrosion and Materials Applications, Materials Park, Ohio, USA: ASM International, pp. 428-435.

[49] H. U. Borgstedt, G. Frees, and H. Jesper, "Versuche zur Natriumkorrosion austenitischer Werkstoffe bei 1000C," Werkst. Korros., vol. 40, pp. 525-531, 1989.

[50] N. P. Bhatt and H. U. Borgstedt, "Corrosion behaviour of structural materials in sodium influenced by formation of ternary oxides," Werkst. Korros., vol. 39, no. 3, pp. 115-123, 1988.

[51] V. Ganesan, V. Ganesan, and H. U. Borgstedt, "Analysis of CREVONA sodium loop material," J. Nucl. Mater., vol. 312, no. 2-3, pp. 174-180, 2003.

[52] T. Gnanasekaran, R. K. Dayal, and B. Raj, "Liquid metal corrosion in nuclear reactor and accelerator driven systems," in Nuclear Corrosion Science and Engineering, Woodhead Publishing, 2012, pp. 301-328.

[53] J. Pacio and T. Wetzel, "Assessment of liquid metal technology status and research paths for their use as efficient heat transfer fluids in solar central receiver systems," Sol. Energy, vol. 93, pp. 11-22, 2013.

[54] M. Romedenne, F. Rouillard, D. Hamon, B. Malard, and D. Monceau, "Carburization of austenitic and ferritic stainless steels in liquid sodium: Comparison between experimental observations and simulations," Corros. Sci., vol. 159, 2019. 
[55] S. P. Awasthi and H. U. Borgstedt, "An assessment of solubility of some transition metals (Fe, Ni, Mn and Cr) in liquid sodium," J. Nucl. Mater., vol. 116, no. 1, pp. 103-111, 1983.

[56] A. V. Karpov, M. K. Kononyuk, L. I. Mamaev, and Y. L. Kulikov, "Compatibility of structural materials with sodium according to data from the experience gained in 40 years of operation of the BR-5/BR-10 reactor," At. Energy, vol. 91, no. 5, pp. 951-955, 2001.

[57] T. Furukawa and E. Yoshida, "Material performance in sodium," in Comprensive Nuclear Materials, 2012.

[58] S. Hemery, T. Auger, J. L. Courouau, and F. Balbaud-Celerier, "Liquid metal embrittlement of an austenitic stainless steel in liquid sodium," Corros. Sci., vol. 83, pp. 1-5, 2014.

[59] H. U. Borgstedt, "Influence of Liquid Sodium on Mechanical Properties of Steels, Refractory Alloys and Ceramics," in Materials Issues for Generation IV Systems., Springer, 2008.

[60] M. J. Wagner and T. Wendelin, "SolarPILOT: A power tower solar field layout and characterization tool," Sol. Energy, vol. 171, pp. 185-196, 2018, doi:

10.1016/j.solener.2018.06.063.

[61] O. J. Foust, Sodium-NaK Engineering Handbook, Volume 3. New York: Gordon and Breach, 1978.

[62] Kaoru Tsuda, Yasushi Murakami, Juan F. Torres, and Joe Coventry, "Development of high absorption, high durability coatings for solar receivers in CSP plants," AIP Conf. Proc., vol. 2033, no. 1, p. 040039, 2018, doi: 10.1063/1.5067075.

[63] C.-A. Asselineau, "Geometrical Optimisation of Receivers for Concentrating Solar Thermal Systems," Australian National University, 2018.

[64] C.-A. Asselineau, "Geometrical Optimisation of Receivers for Concentrating Solar Thermal Systems," Research School of Engineering, College of Engineering and Computer Science, The Australian National University, 2018.

[65] Y. Wang et al., "Verification of optical modelling of sunshape and surface slope error for concentrating solar power systems," Sol. Energy, vol. 195, pp. 461-474, Jan. 2020, doi:

https://doi.org/10.1016/j.solener.2019.11.035.

[66] J. K. Fink and L. Leibowitz, "Thermodynamic and transport properties of sodium liquid and vapor," Argonne National Lab, ANL/RE-95/2, 1995.

[67] D. L. Siebers and J. S. Kraabel, "Estimating Convective Energy Losses From Solar Central Receivers," Sandia National Laboratories, SAND84-8717, 1984. 
[68] Y. Xu, "Wind Characteristics in Atmospheric Boundary Layer," in Wind Effects on Cable-Supported Bridges, 2013, pp. 25-59.

[69] M. Becker and L. L. Vant-Hull, "Thermal Receivers," in Solar Power Plants:

Fundamentals, Technology, Systems, Economics, C. J. Winter, R. L. Sizmann, and L. L. VantHull, Eds. Berlin, Heidelberg: Springer Berlin Heidelberg, 1991, pp. 163-198.

[70] M. Zheng, J. Zapata, C.-A. Asselineau, J. Coventry, and J. Pye, "Analysis of tubular receivers for concentrating solar tower systems with a range of working fluids, in exergyoptimised flow-path configurations," Sol. Energy, vol. 211, pp. 999-1016, Nov. 2020, doi: https://doi.org/10.1016/j.solener.2020.09.037.

[71] S. Wang, C.-A. Asselineau, J. Pye, and J. Coventry, "An efficient method for aiming heliostat using ray-tracing," presented at the SolarPACES2020, Virtual Conference, 2020.

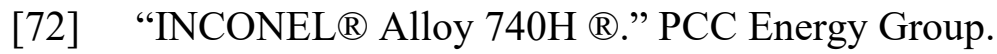

[73] D. Potter and et al., "Heliosim: An integrated model for the optimisation and simulation of central receiver CSP facilities.," in AIP Conference Proceedings, 2018, vol. 2033(1).

[74] D. Potter, J.-S. Kim, and R. K. McNoughton, "Simulation of a demonstration high temperature liquid sodium receiver with Heliosim, in Asia-Pacific Solar Research Conference.," presented at the Asia-Pacific Solar Research Conference, Canberra, 2019.

[75] B. Barua, M. McMurtrey, R. Rupp, and M. Messner, "Design Guidance for High Temperature Concentrating Solar Power Components," Argonne National Laboratory, ANL20/03, 2020.

[76] A. K. Dhalla, Pressure Vessel Research Council. Committee on Elevated Temperature Design, and Welding Research Council, Recommended Practices in Elevated Temperature Design: A Compendium of Breeder Reactor Experiences (1970 - 1987) Volume III. Welding Research Council, 1991.

[77] J. Bree, "Elastic-plastic behaviour of thin tubes subjected to internal pressure and intermittent high-heat fluxes with application to fast-nuclear-reactor fuel elements," J. Strain Anal., vol. 2, no. 3, pp. 226-238, 1967, doi: 10.1243/03093247v023226.

[78] W. J. O’Donnell and J. Porowski, "Upper Bounds for Accumulated Strains Due to Creep Ratcheting,” J. Press. Vessel Technol., vol. 96, no. 3, pp. 150-154, 1974, doi:

10.1115/1.3454160.

[79] C. J. Permann et al., "MOOSE: Enabling massively parallel multiphysics simulation," SoftwareX, vol. 11, p. 100430, Jan. 2020, doi: https://doi.org/10.1016/j.softx.2020.100430.

[80] Electricité de France, "Web site,” 20191989.

[81] M. C. Messner and B. Barua, "A Fast Tool for Receiver Life Estimation and Design," presented at the SolarPACES2020, 2020. 
[82] O. J. Foust, Sodium-NaK Engineering Handbook, Volume 4. New York: Gordon and Breach, 1978.

[83] O. J. Foust, Sodium-NaK Engineering Handbook, Volume 5. New York: Gordon and Breach, 1979.

[84] Michael Rothwell, "Cold trap performance - a general analysis," Oregon State University, 1971.

[85] X. Cheng and N. Tak, "Investigation on turbulent heat transfer to lead-bismuth eutectic flows in circular tubes for nuclear applications," Nucl. Eng. Des., vol. 236, no. 4, pp. 385-393, 2006.

[86] H. Benoit, L. Spreafico, D. Gauthier, and G. Flamant, "Review of heat transfer fluids in tube-receivers used in concentrating solar thermal systems: Properties and heat transfer coefficients," Renew. Sustain. Energy Rev., vol. 55, pp. 298-315, 2016.

[87] K. J. Bell, R. K. Shah, E. C. Subbarao, and R. A. Mashelkar, "Delaware method for shellside design," Heat Transf. Equip. Des. Hemisphere Publ. N. Y., p. 145, 1988.

[88] Rockwell International, "Sodium Solar Receiver Experiment - Final Report," SAND828192, 1983.

[89] IEA, "The IEA/SSPS Solar Thermal Power Plants - Facts and Figures - Volume 1:

Central Receiver System (CRS),” International Energy Agency, 1986.

[90] D. Madden, K. Armijo, and R. V. Winckel, "Permitting for a Gen 3 Pilot-Scale Sodium and Molten Salt System," presented at the SolarPACES, Albuquerque, NM, USA, 2020.

[91] D. Wait, "Impactful R\&D for Technology Adoption," presented at the SETO CSP Virtual Workshop on Next Generation Receivers, Oct. 29, 2020.

[92] J. Martinek, S. Jape, and C. S. Turchi, "Evaluation of external tubular configurations for a high-temperature chloride molten salt solar receiver operating above $700{ }^{\circ} \mathrm{C}$," Sol. Energy, vol. 222, pp. 115-128, Jul. 2021, doi: 10.1016/j.solener.2021.04.054. 


\section{Appendices}

Table 32 in the body of this report provides a guide to the appendices. These appendices were provided in the original report submitted to the U.S. Department of Energy, which included more than 280 separate files. Some modifications and deletions have been made to remove proprietary information for this public final report.

\section{Appendix 1: Basis of Design}

https://www.nrel.gov/docs/fy21osti/79323 appendix1.pdf

Appendix 2: Calculations

https://www.nrel.gov/docs/fy21osti/79323 appendix2.pdf

\section{Appendix 3: Specifications}

https://www.nrel.gov/docs/fy21osti/79323 appendix3.pdf

\section{Appendix 4: Drawings}

https://www.nrel.gov/docs/fy21osti/79323_appendix4.pdf

Appendix 5: Descriptive Submittal List (DSL)

https://www.nrel.gov/docs/fy21osti/79323 appendix5.pdf

Appendix 6: Uniform Construction Package

https://www.nrel.gov/docs/fy21osti/79323 appendix6.pdf

Appendix 7: Master Equipment List

https://www.nrel.gov/docs/fy21osti/79323 appendix7.pdf

\section{Appendix 9: FandOR}

https://www.nrel.gov/docs/fy21osti/79323 appendix9.pdf

\section{Appendix 11: Panel Schedules}

https://www.nrel.gov/docs/fy21osti/79323 appendix11.pdf

\section{Appendix 12: Project Reports}

https://www.nrel.gov/docs/fy21osti/79323 appendix 12.pdf

\section{Appendix 13: Sodium Subsystem}

https://www.nrel.gov/docs/fy21osti/79323 appendix13.pdf

Appendix 14: $\mathrm{sCO}_{2}$ Subsystem

https://www.nrel.gov/docs/fy21osti/79323 appendix 14.pdf

\section{Appendix 15: Safety and Permitting Docs}

https://www.nrel.gov/docs/fy21osti/79323 appendix15.pdf 